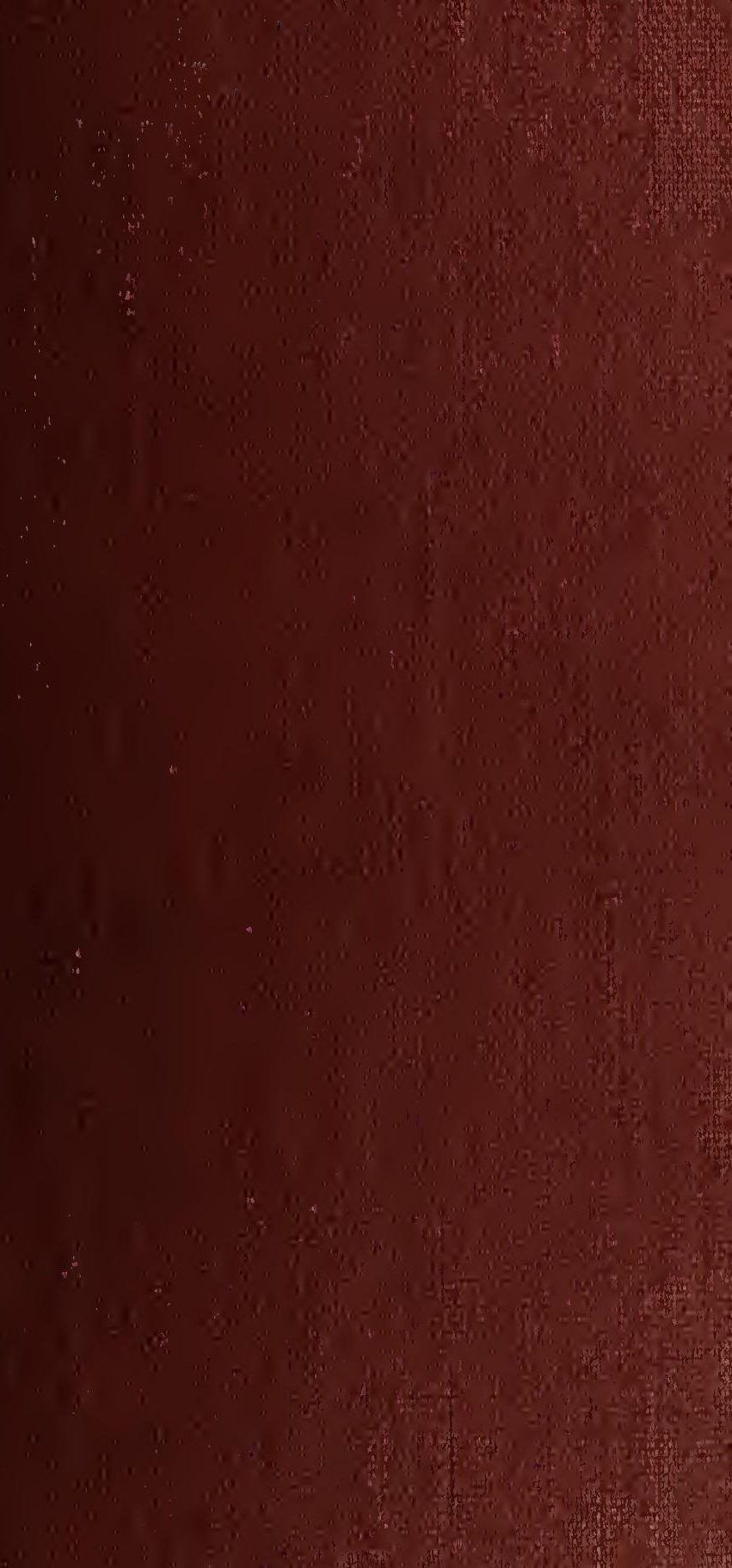


$\operatorname{coseceses} 2, x-2)$

sous

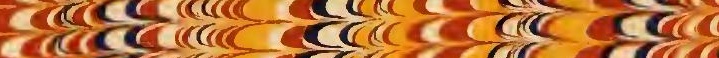

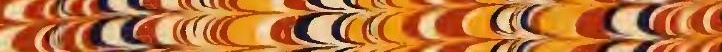

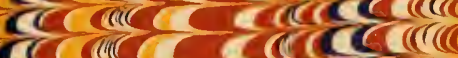

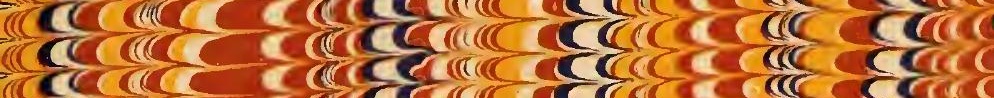
acace

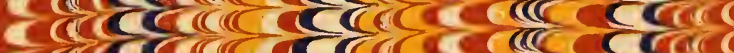

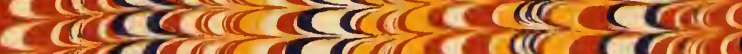

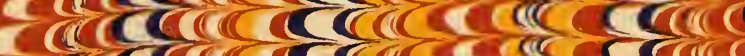
resc बदित

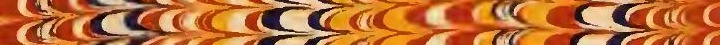

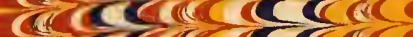
$\operatorname{coc}(\cos$ ब(ce

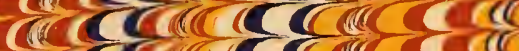
पeder 26 (《) (ब) 10

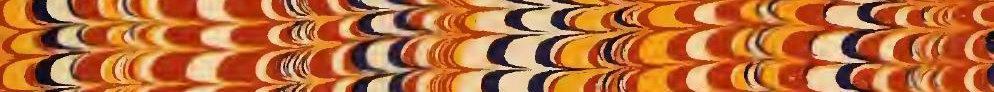
c co@ Cance acare a बac $\cos$ coce cece $\operatorname{crc} 2$. $\operatorname{coc}$

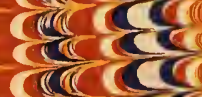
दर्व ये से $-\frac{\cos }{2}$ cद $2 \cos$ caces cace receres icase rece तc ace तc $\operatorname{coc} 20$ $\operatorname{coc} \cos$ सें caces सिखे ति 42 aic cace acke बiecrecr ace curecer

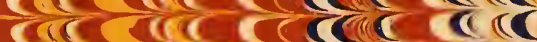

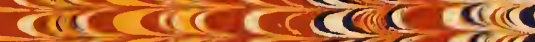

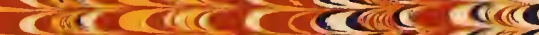

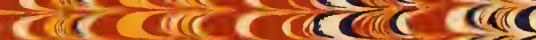

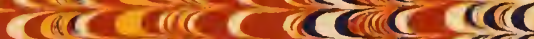
ic

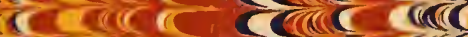
बतe बrices बतec विल

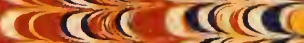
लिखिए rese लcres rime

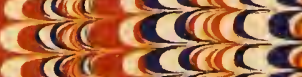
ace cesce

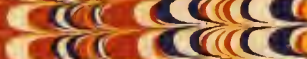
- cen creca - cer acrece a ar derac are $\longrightarrow$ ces

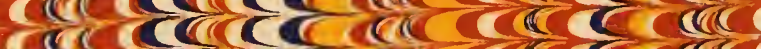

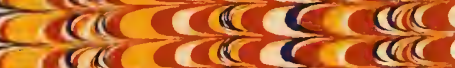

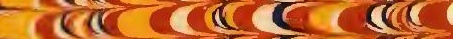

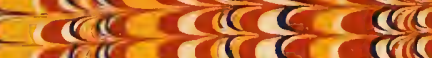

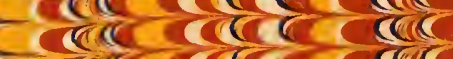

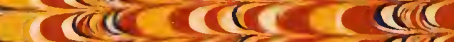

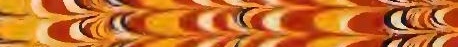
तe cer e ic $(9)$ $\operatorname{coc} c$ (c) ece Ecroc त(c) ब(ब -

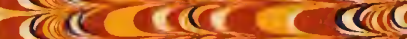

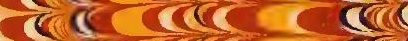
बer ace ce लeखc खा सen rere

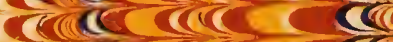
लवखल बता ब

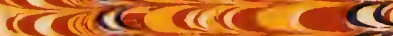
खलिखल खर एवide बत ieracere

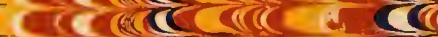

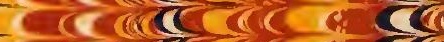
- caracer - ice बतe $\rightarrow$ w 


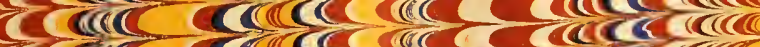

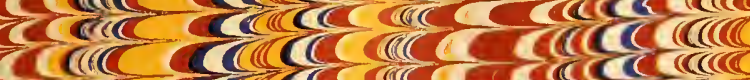

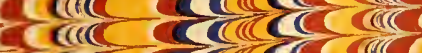
$\Rightarrow c$ cre ( $)$ ( ( करतcacere ac acrosess यद वर्विखि (C) (C)

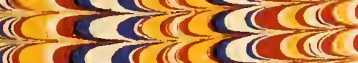
बत्र (I) Cacec (ब) तब (द) icer (c)

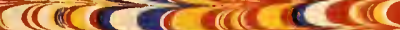

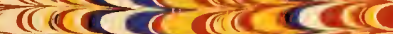
आआ (बतc) तथ त $(\mathbb{C})$ arices ar तerces तC $C(C)$ ¿CR तC $C \mathrm{C}$ बता ति तथ वत्तs तखल खि तब ( $)(C)$

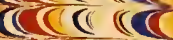
बतित्व ceccus बreced CबCare croces recere तC (बi बCत (rid $\operatorname{sic}(\pi)$ तात्ता तित्र (1) - ब(C) वि लिखि de coscos ccoss corescer

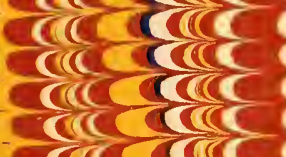
बखि वर्ष खिएव

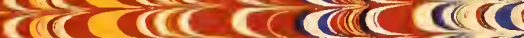

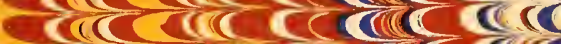

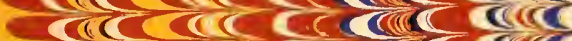

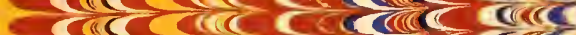

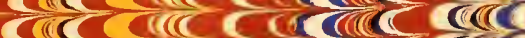

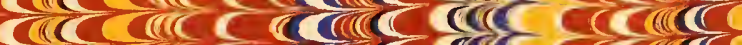
वादे बि

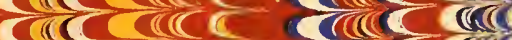

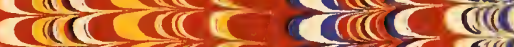

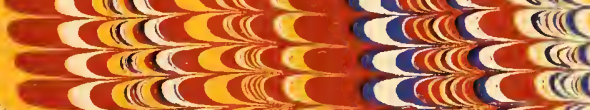
तac C C crecere (r)

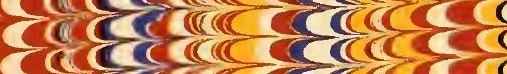
-cosare

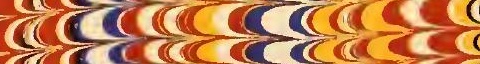

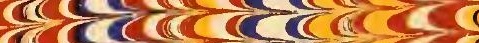

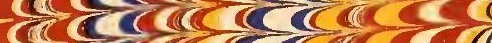
बiscala

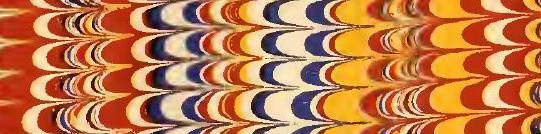

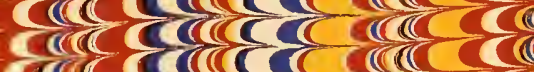

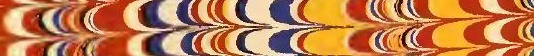

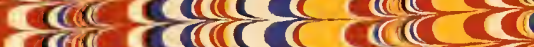

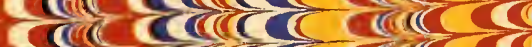
aric race

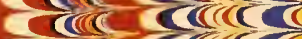
बतब cबar rerce

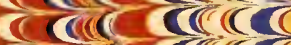

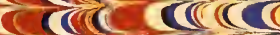
icas dera वत( $)$ त( $)$ ब(ic) बखC बतe बतरत बतes बerc तखा Cब( (C) त्वत( बerece तcorce वeतer

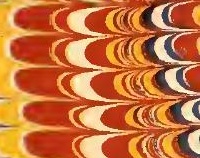
बलिखि खिखि खि rear 





H. Pindell I.

MÉ MOIRES

SUR DIVERS SUJETS

DE L'HISTOIRE NATURELLE

DES INSECTES,

ETC., ETC. 
IMPRIMERIE DE A. BELIN. 


\title{
MÉMOIRES
}

SUR DIVERS SUJETS

DE L'HISTOIRE NATURELLE

DES INSEGTES,

DE GÉOGRAPHIE ANCIENNE

\author{
ET DE CHRONOLOGIE; \\ Par M. L A T REILLE,
}

Membre de l'Institut, Académie royale des Sciences, Associé de diverses Sociétés littéraires de France, des Académies royales de Berlin, de Munich, de Turin, de Naples, d'Upsal; de la Société linnéenne, de la Société wernérienne d'Edimbourg ; de celles des Cinieux de la Nature de Berlin, des Naturalistes de Moscow, de Weteravie, de Pbiladelphie, etc.

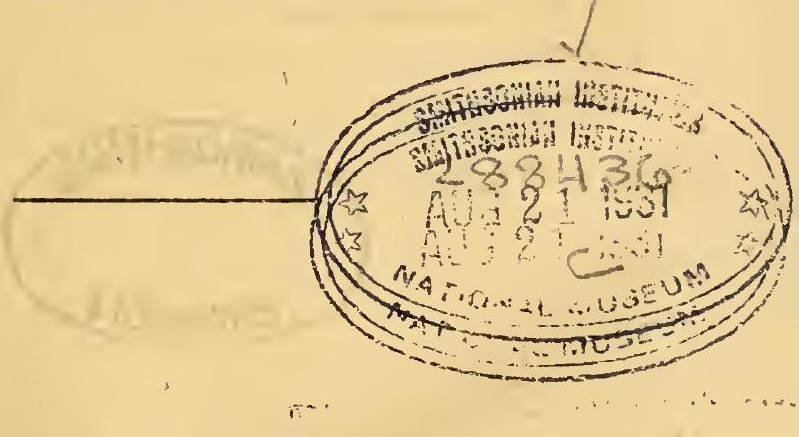

\section{A PARIS,}

Chez DETERVILLE, Libraire, rue Hautefeuille, $\mathrm{n}^{\circ} .8$. I 8 I 9 . 



\section{AVERTISSEMENT.}

LEs. Mémoires dont ce Recueil se compose on tous été publiés, à l'exception de deux. Celui qui a pour objet les Insectes peints ou sculptés sur les monumens antiques de l'Egypte; mon Introduction à la Géographie générale des Animaux de la même classe et mes Considérations relatives à ceux d'entre eux qui vivent en société, font partie de cette belle collection académique (I) par laquelle MM. les Professeurs et Administrateurs du Nuséum d'Histoire Naturelle ne cessent d'illustrer cette branche si intéressante des connoissances humaines. Lc Mémoire où j'expose mon sentiment sur l'origine du Système Métrique des Anciens; celui où j'examine la position géographique des peuples qu'ils désignoient sous le nom de Sères; mes Eclaircissemens sur la Chronologie Egyptienne (2), et une Dissertation concernant l'expédition du Consul Suétone Paulin (3), ont été imprimés séparément, mais on n'en a tiré qu'un petit nombre d'exemplaires, qui ont été distribués à mes amis ạinsi qu'à plusieurs savans. J'ai cru, vu l'impossibilité où l'on est de se procu rerplusicurs de

(1) Imprimée chez M. Belin, hôtel de Cluny, rue des Ma-thurins.

(2) De l'imprimerie de M. Lanoë, ${ } S_{1} 7$.

(3) Chez M. Belin, 1807 . 
ces Mémoires, que le public pourroit accueillir favorablement un Ouvrage où ils seroient réunis, s'ils acquéroient surtout, par des additions ou des changemens nécessaires, un nouvel intérét.

Le premier des deux Mémoires inédits, qui sont joints aux précédens, embrasse les temps primitifs de l'Histoire et présente le parallèle de diverses théogonies. Je ne m'étois d'abord proposé que la discussion du passage de la Genèse, relatif à la situation du jardin d'Eden et que l'examen de ces rapports théogoniques; mais ces recherches en ayant insensiblement amené d'autres, et mon Mémoire étant déjả presque entièrement inprimé, je me suis vu contraint d'en changer le titre et de donner un supplément avec des remarques explicatives ou correctives.

C'est encore ainsi qu'une question fameuse, celle del'Atlantide dePlaton, question bien éloignée originairement de ma pensée, et dont je n'avois parlé que transitoirement et sans aucune idée fixe, s'est rattachée, par suite de ces recherches ultérieures, à mon sujet. J'ai essayé de résoudre cette difficulté dans le second des deux nouveaux Mémoires. Plusieurs des questions soumises à mon examen étant capables d'effrayer le plus profond érudit, je prévois que l'on pourra m'accuser d'une téméraire présomption; mais les personnes qui seroient tentées de me faire ce reproche voudront bien observer que les travaux des savaus de l'expédition d'F,gypte, les relations de divers voyages faits dans l'Inde, 
les progrès de la géographie et de l'histoire naturelle, nous ont procuré des moyens inconnus jusqu'à ce jour, ou de nonvelles lumières sur des problèmes historiques regardés jusqu'ici comme insolubles. Quel que soit le jugement que l'on portera de mes ópinions, j'espère néanmoins qu'on y distinguera l'empreinte de l'amour le plus sincère et le plus impartial pour la vérité, et que l'on verra avec plaisir ceite multitude d'aperçus et de rapprochemens curieux que je présente, et dont plusieurs sont propres à éclaircir des sujets aussi ténébreux. J'ai mis à profit plusieurs traditions orientales qu'on avoit rejetées ou négligées, soit parce que des circonstances fabuleuses les accompagnent, soit parce qu'elles sont couvertes du voile de l'allégoriè. Mais ces traditions, malgré leurs travestissemens, se lient avec des faits avérés, et très-souvent encore avec ceux de la Genèse, livre qui, abstraction faite des opinions religieuses, mérite au moins, comme le plus précieux monument historique de l'antiquité, l'hommage de notre vénération. Puissent les interprètes de ce livre et des autres écrits, dont se compose le code sacré des Chrétiens, l'expliquer et le commenter dans un autre esprit que ceux qui condamnèrent Galilée, Buffon, etc.! Puissent-ils, en amis sincères et éclairés de la Religion, avoir toujours présentes à la mémoire ces réflexions d'un voyageur dans l'Inde, M. Legoux de Flaix.

"Nous serions moins incrédules si, de bonne foi avec nous-mêmes, nous séparions, dams le calme de 
la raison, la partie dogmatique de nos livres et de nos traditions, d'avec la partie qui n'est que philosophique; alors nous respecterions plus la révélation en tout ce qui concerne la morale sur laquelle s'appuient toutes les Religions; alors en dégageant nos livres sacrés de tout ce qui appartient aux sciences physiques, la Religion y gagneroit en même temps que nos connoissances s'accroîtroient, puisqu'aucune barrière' ne les arrêteroit plus dans l'explication des phénomènes de la nature et de l'ouvrage merveilleux de la Providence; alors enfin, les hommes en deviendroient neilleurs, et seroient plus justes et plus recomnoissans envers celui qui les créa, ainsi que toute chose, pour leur bonheur.". 


\section{DU PREMIER AGE}

\section{DU MONDE,}

Et de l'accord des Théogonies phénicienne, chaldéenne et égyptienne, avec la Genèse.

Devx peuples de la plus haute antiquité, les Egyptiens et les Sères, ont été l'objet de mes recherches; l'un, sous le rapport de la chronologie, et l'autre, sous celui de la géographie.

Voulant approfondir, autant qu'il étoit possible, les . difficultés que je m'étois proposé de résoudre, j'ai été conduit à l'examen d'une question bien plus hardie, l'origine des races primitives de l'espèce humaine ou la connoissance des temps les plus reculés de l'histoire. Il semble qu'un sujet si vaste et si compliqué, couvert de ténèbres aussi épaisses, et qui a exercé si long-temps et avec aussi peu de succès la sagacité et la patience de tant d'hommes célèbres, ne puisse fournir aucunes nouvelles lumières. Telle a été aussi dans le principe mon opinion.

J'avois rassemblé d'abord un grand nombre de faits historiques, presque sans l'espérance de pouvoir les coordonner : mais les ayant analysés et comparés avec cet esprit de méthode, qui, dans ces derniers temps, a fait faire aux sciences des progrès si rapides, j’ai cru remarquer que tous ces faits se rattachoient à une tradition principale, celle de la Genèse, livre digne, dans toute 
opinion religieuse quelconque, de nos respects, et qui củ́t trouvé moins de détracteurs, si ceux qui l'ont expliqué ou commenté, plus instruits et plus judicieux, eussent fait'sur le domaine de la lettre quelques concessions à l'allégorie, ainsi qu'à la physique. Il 'm'a paru que cette tradition fondamentale étoit, en outre, la clef de la mythologie. Pour découvrir cette clef, il falloit au préalable bien étudier.les antiquités de l'Egypte et leurs zodiaques principalement, comme étant les sources où les Grecs ont puisé leurs connoissances théogoniques, et qu'ils ont malheureusement corrompues. Ces moyens n'ont pas été jusqu'ici au pouvoir de ceux qui ont essayé de saisir le sens de ces énigmes.

Plusieurs des explications qu'a données à cet égard Dupuis, dans son origine des cultes, sont aussi vraies qu'ingénieuses. Mais il n'a point connu les bases ou les principes généraux de la mythologie, parce qu'il n'a appelé à son secours que les lumières de la physique et de l'astronomie. Les zodiaques égyptiens sont extrêmement simples. Leurs auteurs conçurent le dessein d'établir une relation entre le ciel et la terre. Des noms historiques illustres, ceux de leurs saisons et de quelques objets de leur culte on de leurs usages, furent inscrits dans la voûte azurée. S'il en étoit ainsi, la raison seroit vengée; et la mythologie, purgée de toutes ces erreurs que lui attribuèrent l'intérêt et l'ignorance, rentreroit dans le cercle de l'histoire et dans ceux de la physique et de l'astronomie. Le tableau qui termine ce mémoire présente l'ensemble de tous ces faits que je suis parvenu par bien des tâtonnemens et des combinaisons diverses à rapprocher d'un type unique. Vainement, par exemple, chercheroit-on dans les mythologues une explication satisfaisante de l'emblême 
dont la constellation d'Orion est le sujet : si l'on considère la manière dont elle est représentée sur les zodiaques égyptiens, et si l'on compare les idées que cette image fait naître, avec celles que la Genèse nous apprend du premier homme, je ne crois pas qu'on puisse élever aucun doute sur la certitude de ces rapports. Horus étant dès lors le même qu'Adam, il est à présumer que l'analogie se continue dans la succession des autres demi-dieux; c'est aussi ce que j'ai trouvé en cherchant la vérité de bonne foi et sans influence particulière. Je regrette seulement que d'autres travaux, auxquels je suis obligé de consacrer mon temps, ne me permettent pas de développer ces idées avec toute l'étendue dont elles sont susceptibles.

La géologie et même des traditions nous apprennent que l'Océan avoit primitivement beaucoup plus d'étendue qu'aujourd'hui ; les terres les plus élevées étoient ainsi les seules qui fussent habitables. On voit, par un passage de Justin, relatif aux Scythes de l'Asie, que, pour.expliquer la formation de notre globe, on avoit déjà admis les deux systèmes dominans parmi nos géologues modernes, ou qu'il y avoit déjà des vulcanistes et des neptunistes. Dans l'une ou l'autre de ces hypothèses, les Soythes se croyoient les plus anciens, comme étant originaires des contrées qui s'étoient refroidies les premières; ou qui étoient sorties avant les autres du sein des eaux de la mer. La plupart des savans croient en effet, mais sans aucune donnée positive, ni indication spéciale, que le plateau de l'Asie a été le berceau de l'espècẹ humaine. Privés d'abord des secours qui sont le fruit de l'industrie et du temps, les premiers hommes ont dû fixer leur séjour dans les contrées où la nature pour- 
voyoit elle-même à leurs premiers besoins. Ainsi, le livre de la Genèse, en nous disant que Dieu plaça le premier mortel dans un lieu très-fertile, abondant en toutes sortes de fruits, un jardin en un mot, a-t-il énoncé un fait avoué par la raison, et qui repousse toute allégorie.

Est-il possible, d'après les rensciguemens que nous donne la Genèse sur ec lieu, ou le jardin d'Éden, d'en fixer la position? La question que je propose peut, dans notre siècle, paroître ridicule, soit parce que les uns en rejettent l'objet comme fabuleux, soit parce que les autres pensent qu'elle est trop obseure, et que tous les efforts qu'on a faits pour l'ćclaircir ont été illusoires. Nous venons de voir que les inductions les plus naturelles confirment à cet égard le récit de la Genèse. Je répondrai maintenant aux personnes qui pourroient m'accuser de témérité, que si cette difficulté est restée insolıble, c'est qu'on ne l'a point envisagée sous toutes ses faces, ou dans ses connexions avec les opinions géographiques des anciens, avec l'histoire naturelle et les traditions orientales. Donnons la version littérale du texte hébraïque : "Et l'éternel Dieu avoit planté un jardin en Héden; du côté d'orient ; et un fleuve sortoit d'Héden pour arroser le jardin, et de là se divisoit en quatre chefs. Le nom du premier est Pison; c'est celui qui coule tournoyant par tout le pays d'Havilah, là où il croît de l'or; et l'or de ce pays-là est bon : là aussi se trouve le Bdolah (bdellion), et le Shoham (une pierre précieuse, selon les interprètes). Et' le nom du second fleuve est Guihon (ou Gihon); c'est celui qui coule tournoyant par tout le pays de Cus (l'Éthiopie (I)). Et le nom.

(1) On donna d'abord le nom d'Ethiopiens à tous les peuples 
du troisième fleuve est Hidékel; c'est celui qui va audevant du pays d'Assur; et le quatrième fleuve est $P \dot{c}-$ rath. "Il est fait mention dans Ezéchiel du commierce que faisoient les Tyriens avec les peuples de l'orient; Eden y' est compris, et se trouve le dernier dans cette énumération. Il est encore cité, et toujours le dernier, dans deux autres passages, l'un d'Isaïe et l'autre dú second livre des Rois. Le chapitre i ${ }^{\mathrm{e}}$. de la Genèse nous montre les descendans de Noé, avant leur dispersion, venant de l'orient, et gagnant la plaine de Sinéar ou Schinhar. C'est donc dans les contrées orientales et élevées de l'Asie, le terme des excursions commerciales des 'Tyriens, qu'il faut chercher Eden. Or, l'Hyrcanie, la Sogdiane et la Bactriane des anciens, ou les pays situés entre la mer Caspienne et le Belur-tag sont les seuls auxquels, sous le rapport de la douceur du climat, de la fertilité du sol, des objets de commerce, indiqués plus haut, l'on puisse faire une juste application de ces divers passages. Nous savons de Pline que le meilleur bdellion venoit de la Bactriane; c'est aussi de sa partic orieutale on la plus montagneuse, celle qui est vaisine des sources de l'Indus, que l'on tiroit les émeraudes les plus estimées, les plus beaux rubis, plusieurs autres pierres précieuses, la soie, etc. Il est encore certain que ces contrées produisent beaucoup d'or, et qu'elles furent, avant que la navigation n'eût fait connoître les côtes orientales de l'Afrique, l'Ophir des anciens. La Bactriane offre ainsi toutes les productions qui, selon l'Ecriture, sont propres à la terre d'Havilah. Un fait auquel les commentateurs de la Genèse n'avoient point donné de l'attention, est que les

dont le teint étoit noir ou très-bazané. Les habitans d'une grançe partie de la Perse furẹnt désignés ainsi. 
anciens ont cru long-temps que la mer Caspienne étoit un fleuve, qui versoit ses eaux dans l'Océan glacial. L'expédition des Argonautes et plusieurs passages d'anciens géographes nous en fournissent la preuve.

Cette mer est donc le fleuve qui arrosoit le jardin d'Eden, et l'on pourroit même déduire du texte hébreu qu'il s'agit moins ici d'un fleuve proprement dit que d'un amas considérable d'eaux ou d'un lac. Je concluerai dès lors, que le premier fleuve, ou le Pison, est l'Oxus des anciens, ou le Syhhoûn des modernes; que le second, ou le Guihon, est le Tedzen; que le troisième, ou l'Hidékel, qu'on avoit pris pour le Tigre, quoique l'Ecriture dise simplement qu'il couloit en avant du pays d'Assur, est le Mardus des.anciens, actuellement le Kisil-Ouzein; que le quatrième enfin, ou le Pérath, est le 'Phasis ou l'Araxe, soit pris isolément, soit considéré comme réuni avec l'Euphrate. Si je ne m'abuse point, ces explications sont naturelles et parfaitement coordonnées au texte de la Genèse. Le Màzenderan, partie occidentale de l'ancienne Hyrcanie, me paroît avoir été le premier séjour de l'homme. Cette province nous offre, dans l'ancienne géographie, deux noms de villes très-remarquables, Syringis et Barange (Ptol.). Le premier nous rappelle soit ces antiques souterrains nommés Syringes, soit cettc terre des Syringes (Syriad, Scriadique), oì furent élevés ces monumens lapidaires historiques et astronomiques, désignés par Josèphe sous le nom de colonnes, et qu'il attribue à Seth; ce sont les steles de Manéhon, et qui furent selon lui l'ouvrage du premier Thoth, ou du premier Mercure. La seconde dénomination, celle de Barange de Ptolémée, ville de l'Hyrcanie dont la position semble convenis à celle d'Echref, 


\section{DU MONDE.}

et presque aussi à eelle que d'Anville assigne à Syringis, n'est pas moins singulière par le rapprochement qu'elle nous offre avee ce lieu que Bérose nomme $L a-$ ranchi, et qu'il dit être la patrie d'Otiartes, prédécesseur immédiat de Xixuthrus ou Sisithrus, le dernier roi de Chaldée, anté-diluvien, et qui est évidemment le Noé de la Bible, d'après la eomparaison des faits qui leur sont attribués. Parmi les demi-dieux égyptiens, Thoth ou Tithoes a pour suecesseur Sojus, qui est suivi de Zeus ou Jupiter, le dernier demi-dieu. On peut déduire de ees analogies, tant ordinales que nominales, que l'Otiartes chaldéen est le même que le Thoth égyptien (le second Mercure), et que Xixuthrus et Sojus sont identiques.

Selon Bérose, Cronus apparoît en songe à Xixuthrus, lui prédit l'arrivée d'un grand déluge, qui détuira soụ peu le genre humain, lui donne les mèmes ordres que ceux que, selon la Genèse, Dieu intime à Noé; et lui enjoint en outre de mettre par écrit l'origine et l'histoire de toutes choses, et d'enterrer eet écrit dans la ville de Sippara, ou la eité du Soleil. Or, Ptolémée place une ville ayant un nom presque identique, Siphare, dans l'Arie, ou le Kouhestàn, et dont la position ne paroît guère s'éloigner de eelle de Ferhad, sur la route d'Hérat à Nychâbour et à Mecheled. Après le meurtre d'Abel, Caïn erre çà et là, et se retire à l'orient d'Eden, dans la terre de Nod ou Naïs, et dans laquelle il fonde une habitation, qui reçoit le nom de son fils Hénoeh. L'alliance de leurs desceudans avec ceux des Scth, produisit des hommes d'une taille gigantesque, puissans et très-corrompus. Cä̈, désignoit dans l'ancienne langue des Perses, un géant; et de là l'origine du nom de Cä̆anides, 
donné à la seconde dynastie de leurs rois, qui étoient Scythes ou Géans d'origine. Sur les limites montagneuses de la province de Meḳrân et de celle de Malàn, est un canton appelé Nheda, mais que le géographe de Nubie distingue sous le nom de Nodha, presque semblable à celui de Nod de l'Ecriture. Ces provinces répondent à la Gédrosie de la géographie ancienne, qui a voit Parsis pour métropole. Ptolémée place dans sa partie septentrionale et correspondante au pays de Nheda, les $p a-$ radene, ayant Cuni pour ehef d'habitation. Les Balouches, peuple féroce et sauvage, que l'on dit être une tribu des Afghâns, occupent le pays montagneux situé au nord de celui de Nhẹda, cntre le Kandahâr, le Malàn et le Mekrân ; ils possèdent même la partie occidentale de la côte maritime de cette dernière province, et ceux-ci vivent de poissons crus. Ces Balouches ou ces $\Delta$ fghàns sont les indo-scythes de Ptolémée. Leurs mœurs, la situation des contrées qu'ils habitent, la nature de leur climat, ne semblent-ils pas indiquer qu'ils sont des descendans de Noé.

Dans un fragment d'un livre attribué à Hénoc, les géans, considérés comme le fruit de l'union des égrégores ou des anges-gardiens et des filles des hommes, devinren anthropophages. Dieu ordonna que ces anges prévaricateurs fussent conduits, après avoir été témoins de la destruction de leurs enfans, jusqu'aux extrémités de la terre, et que le mont Hermon, où ils aroient fait le scrment de s'unir aux filles des hommes, seroit toujours couvert de neige. Un passage de Strabon (liv. a) paroît faire allusion à cette singulière fable. Il place à l'extrémité oricntale de l'Asic, près du Caucase, une race d'hommes, les Ileniochi, d'une force extraordinaire, quoique ayant Les 
membres grêles, et ne virant que de brigandage. D'autres anciens géographes peuplent les mêmes lieux de satyres et de faunes. Ptolémée désigne ceux-ci sous la dénomination de Daonae, qui n'est qu'une légère altération de la précédente; il les établit dans une contrée correspondante au royaume d'Ava, et que nous avons appelée Série ou Sérique, au-delì du Gange. Un passage de l'auteur du périple de la mer Erythrée nous apprend que des Scythes étoient venus s'y fixer. Nous savons encore que d'autres Scythes de la mème race, ou des Sères, formèrent de grands établissemens dans la partie de l'Inde en deçà du Gange, et la Mésolie de Ptolémée nous offre un lieu portant aussi le nom de Sippara( 1 ). Dicu condamnạ Caïn, en punition du meurtre d'Abel son frère, à être fugitif et vagabond, et lui imprimá un signe qui devoit le garantir contre ceux qui seroient tentés de lui donner la mort. Ses descendans, errans et farouches comme lui, redoutables par leurs exeursions gucrrières et leurs rapines, distingués eneore par une taille élevée, une constitntion robuste, des habits formés de dépouilles d'animaux, devinrent le fléau de leurs voisins; ils furent comparés à ces animaux dont ils retraçoient les habitudes, et peut-être désignés sous leurs traits, dans une éeriture hiéroglyphique. Ce portrait convient aux Scythes, et on a pu dans le principe les appeler Heniochi, parce qu'ils deseendoient d'Hénoch, fils de Caïn. La constellation du cocher ou du charretier, placée à còlé de Persée (voyez le tableau qui est à la fin du mémoire) avoit reçu le nom d'Heniochus, ce qui nous rappelle la dénomination primitive et les moeurs

(1) Nous trourons encore Sipphara(Ptol.), dans la Mésopotamie. 
de ce peuple. Les anciens Persans le désignèrent sous le nom de $Z$ er ou de Ser, qui veut dire or, expression dérivant peut-être de la précédente, et qu'au surplus nous retrouvons souvent dans la langue primitive des peuples dont le culte religieux étoit celui des Parses ou des Guèbres, et dans lequel le soleil, le feu et l'or étoient les emblèmes de la divinité. Il paroît certain que cette religion a pris naissance dans la partie orientale de la Perse; et comme elle fut primitivement la seule, qu'on la trouve répandue partout, nous pourrions faire valoir encore ce motif en faveur de notre opinion. Elle est conforme à quelques traditions orientales; et ce qui l'appuie encore, c'cst que, selon Alfergani, un canton du Khoraçan, d'une très-longue étendue, porte le nom d'Edeni. La Sogdiane, en outre, a toujours passé pour un paradis terrestre.

Nous voyons, par un passage de l'Edrisi, que de son temps il existoit dans la Sogdiane des montagnes vomissant des flammes et de la fumée. Le chérubin ou cctte épée flamboyante que Dieu, selon la Genèse, plaça à l'entrée du Paradis terrestre, après en avoir chassé le premier homme, n'est peut-être que l'allégorie de l'éruption subite d'un volcan. D'après ce que nous venons de dire, la postérité du premier homme se répandit dans le Khoraçan et les provinces adjacentes de la Perse. Nous ne chercherons point en Arabie cette ville de Nyse, où l'on supposoit que Bacchus ( 1 ), fils de Jupiter et de Semelé, le Dionysius des Grecs, avoit été élevé, mais dans la Margiane, et nous la retrouverons dans

(1) Bacchus peut dériver du mot hébreu Bacar, vache, bocuf; * de becar, délivrer, on a formé le nom de liber. 
Nysa ou Nyscea (1), Nychàbour. Ainsi, le premicr Bacchus, celui qu'on faisoit naître dans l'Inde, et le même que le précédcnt, scra, conme on l'avoit dit, le Noé de la Gcnèse. Cham, son fils, est le second Bacchus, qui transporta probablement le blé du Khoraçan en Egypte. Sa culture s'introduisit ensuite en Mauritanie, et de là passa en Sicilc. Ebn Shoknah rapporte que certains Guèbres nioient le déluge; que d'autres en contestoicnt l'universalité, et croyoient qu'il ne s'étoit étendu quc jusqu'à un certaiu rocher près d'Hulwân, ville de l'Irâk, sur les confins du Kourdistan. Il parô̂troit, par d'autres ténoignages, que les Chinois et les Indiens, quoique ayant cu connoisșance de ce déluge, prétendent qu'il n'a pas atteint leurs pays. Mais sans entrer dans cette discussion, il n'en est pas moins vrai que ces traditions nous ramèneṇt toujours à la partie la plus orientale de la Perse. Le Kouhestàn et le Scdjestân, par la circonscription de lcur bassin, le nombre des rivières qui l'arrosent et qui s'y rendent dans un centre commun, paroissent avoir été les plus exposés à une grande inondation, si l'on admet surtout que le lac Zérêtlı n'existoit pas encorc. Nous verrons ailleurs que lc déluge eut licu daus la saison des pluies.

Toutes les mythologies et toutes les traditions historiques des premiers âges sc rattachent essentiellement, malgré le voile qui les reconvre, à la Genèse. Les uncs, telles que celles des Phéniciens, des Chaldéens, des Egyptiens, des Atlantes, offrent, par lcurs cosmogo-

(2) Ce mot peut venir de Neser, qui en hébreu signifie aigle. Toilà sans doute pourquoi cet oiseau étoit consacré à Jupiter. Nésâé est l'Eilen des Parses et le lieu où Ahrimpn semble balancer le pouvoir d'Ormizd. AIargriane signifie en pehlvi, le pays deș mortels. 
nies et leurs théogonies établics, quoique déguisées, sur les traditions de la Genèse, le caractère d'une antiquité plus grande; les autres, comme celles des Grecs et des Romains, sont empruntées des Phéniciens et des Egyptiens, et ne dépasseut guèrc l'époque de la dispersion da genre humain ou l'existence de Noé.

Les peuples de la côte occidentale de l'Afrique ont des usages qu'ils tiennent évidemment des Egyptiens, on qu'ils y ont portés de leur patrie commune, la Perse orientale. J'ai découvert depuis peu que les Guanches (Mém. sur l'expéd. de Suét. Paulin.) étoient les Sirangae dc Ptolémée, et qu'ils devoient être placés dans le voisinage de Mogador. Il vient de m'être assuré qu'un voyageur anglois avoit effectivement remarqué une grande analogie entre lcs mocurs d'un peuple de cette contrée el ceux des Guanches.

Cette observation importante m'a entraîné dans de nouvelles recherches qui pourront, par leur résultat, jeter quelque rayons de lumière sur l'histoire si obseure des anciens peuples de l'Afrique. Dans l'itinéraire de la côtc maritime de la Gédrosie, du voyage de Néarque, il est fait mention de deux ports, dont l'un est nommé Saranga et l'autrc Portus feminarum; celui-ci est le Alulierum portus de Ptolémée. Une dénomination si singulière semble nous rappeler l'histoire des Amazones d'Afrique, qui firent la guerre aux Gorgones (ou Gorgades, Gorilles), autre nation de femmes gucrrières, qu'Hésiode, le périple d'Hannon, Eudoxe, placent, avec les Hespérides, sur l'Océan occidental ou atlantique, et dans une position peu différente de eelle des Siranga de Ptolémée ou đes Guanches. La même tradition est commune aux autcurs orientaux. Dieu, suirant eus, après aroir ôté le gou- 
vernement du monde aux génies, le donna à Adam et à sa postérité. Ces premières eréatures s'étant rendues indignes de le peupler, furent confinées dans un désert, que les Persans appellent Ginnistàn, le pays des génies (des démons ou des fées), dénomination qui paroît eneore avoir la même source que eelle de Syrangce. Quelques-uns de ces auteurs plaeent aussi ee désert dans la partie occidentale de l'Afrique, où les Gorgones, les Méduses, les Lamies et les Empuses font leur retraite. (Voyez d'Herbelot, Biblioth. orient., art. Badiat al-ginn.)

Si l'on remarque que toutes les contrées où les Sères se sont établis ont pris leur nom, eelui d'Or, on eoncevra aisément que, si cette partie de l'Afrique est devenue une eolonie de ce peuple, on l'aura pareillement considérée comme un lieı fortuné, mais habité par des monstres, des démons, des gorgones, etc., tels que l'on peignoit les déseendans de Caïn. Une partie de ceux qui habitoient la Gédrosie a pu, dans des temps très-aneiens, être forcée d'émigrer; elle aura gagné l'Afrique; et persécutée partout, elle se sera retirée sur la côte occidentale d'Afrique. Le portrait que nous fait Diodore des Amazones paroît être pris de la partie de la mythologie orientale (r), relative à ee qu'on y appelle,

(1) Il est rapporté dans le périple d'Hannon, que eet amiral carthaginois se trouvant dans un grand golfe, ayant à son entrée le. cap nommé Corne du Couchant, fut épouvanté, durant la nuit, par le vacarme que produisoient le son des flútes, le bruit des cymbales et des tambours, mêlés aux cris effroyables des habitans. La relation du voyage de Marc-Paul nous offre une narration analogue. Il dit qu'on entend assez souvent, pendant la nuit, dans le désert de Lop, des concerts de musique produits par les démons, 
en diverses langues, genn ou ginn, div, deuta, peri, etc., ou ce que nous nommons génies, démons, fées, etc. Un de ces démons ou de ces méduses, le plus terrible et le plus cruel, est appelé par les Arabes; Afriet ou Ifriet. Parmi ces traditions, souvent dénaturées, et qui par l'émigration des peuples, se sont successivement propagées d'une contrée à l'autre, il faut soigneusement distinguer les lieux auxquels elles sont propres. Ainsi les Atlantes, descendans de Cham, fai-

et qui pourroient tromper les voyageurs, słils se séparoicnt les uns des autres. C'est par des feux et le bruit, que ees peuplcs éloignoient les bêtes féroces. Telle est l'explication uaturelle de ces faits, qui ont donné lieu au conte populuire du sabbat des sorciers et des assemblées nocturnes des fées. Le nom de sabbat vient d'ailleurs d'un mot hébreu qui signifie repos, et les Egyptiens représentoient celui de la nature et la nuit sous l'emblême de Typhon, ou du mauvais génie. Le désert de Lop fut anciennement le séjour d'une branche des Sères ou de cette nation Scythique, dont les Grorgones faiso ient partie. D'Herbelot cite des faits semblables, à l'artiele Genn ou Ginn, nom sous lequel les Arabes désignent les génies ou les démons. Selon un auteur arabe cité par lui, il régnoit à Mosul, sur le Tigre, l'an ×203 de notre ère, une maladie épidénique qui s'attaehoit à la gorge, et dont tous ceux qui ne consoloient pas une femme de l'espèce dcs ginnes ou des fées, pour la perte qu'elle avoit faite de son fils, étoient attaqués. Laa même maladie eut lieu en Egypte : on la guérissoit en faisant une espèce de bouillie que l'on appliquoit sur la gorge, et que l'on jetoit ensuite dans le $\mathrm{Nil}$, en proféraut quelques paroles de consolation et d'excuse relatives à la mort de l'enfant de cette fée. Le nom de cette fée est Ommankond. Semiazas (livre apocryphe des prophéties dHénoc), chef de ces anges qui eurent eommerce avec les filles des hommes, leur indiqua les vertus médicales des plantes. Les Grecs ont pu transformer ces noms en Amazon, sans inamelles. Mais il se présente une explication plus simple. Les Parses plaçoicnt des Amazones (sans chef) dans l'Armiéuie. Or, nous voyous par Ptolémée que les Syracènes ou les Siranges l'ont habitée. 
soicnt naître leurs dieux dans leur pays, et ce qu'ils disoient d'Uranus et de ses descendans doit se rapporter au temps où ils habitoient l'Asie.

Leur mythologie est formée des derniers dieux de celle de Sanchoniathon, et de quelques allégories astronomiques. Hyperion, qui épousa sa soeur Basilée, ne peut être, d'après la manière dont on raconte la mort de cette déesse, que Noé. L'enlèvement d'Hesperus, fils d'Atlas, auquel le peuple décerna les honneurs divins, et dont elle consacra le nom à la plus brillante des planètes, nous rappelle l'Enoch de l'Ecriture et le second Thoth des Égyptiens. Atlas, père de sept filles, les Atlantides, est un emblême de la constellation du taureau.

Il s'est peut-être glissé dans l'histoire des Amazones de Diodore, quelque confusion au sujet des localités. Tout ce qu'il nous raconte, en effet, du lac Tritonide, du fleuve Triton, qui s'y décharge, de l'ile Hespérie et de la ville de Cercène, paroît bien convenir à cette partie septentrionale de l'Afrique où Ptolémée place le golfe de la petite Syrthe (Syrtis minor), différens lacs formés par le fleuve Triton, et les îles Lotophagites et Cercinna. Si on compare l'état actuel de ce pays avec celui où nous le figure Ptòlémée, on voit que la Méditerranée a empiété dans cette partie, et qu'il a dû s'y opérer des changemens assez considérables. On disoit, suivant Diodore, que le lac Tritonide avoit entièrement disparu par la rupture de tout le terrain qui le séparoit de l'Océan. Cette tradition est peut-être la base de l'histoire de l'Atlantide de Platon. Il est possible que le souvenir de ces événemens ait été, par le changement d'habitation des Gorgones et des Amazones, faussement appliqué à des lieux qui n'en 
furent point le théàtre. Ces traditions peuvent encore se rapporter aux îles Canaries ou à quelque partie de l'Asie.

Les habitans de l'île Hespérie, selon le même historien, ne se nourissoient. que du lait et de la chair de leurs ehèvies et de leurs brebis, dont ils avoient de grands troupeaux. L'usage du blé leur étoit entièrement inconnu. Il paroît aussi que les Guanehes ignoroient l'emploi du fer. Tous ees faits s'expliqueront naturellement, si l'on suppose que ees peuples étoient des descendans des Caïnites ou des Sères; ear ils s'étaient séparés de la société avant la découverte des arts, et avoient eonservé, par la nature des lieux qu'ils habitoient, par l'espèee de proscription à laquelle on les avoit condamnés, l'état sauvage et les mours féroees de leur état primitif. M. Cuvier, par l'examen qu'il a fait des squelettes ou des momies des Guanehes, a reconnu qu'ils avoient les earactères de la race caucasique.

Dans nos reeherehes sur ee peuple, nous n'avous jusqu'iei employé que des auteurs profanes : mais si nous consultons le Pentateuque, toutes ces difficultés s'éelaireiront davantage. Nous y retrouverons les Siranges de Ptolomée ainsi que les causes de leur émigration. Le Deutéronome nous parle d'abord de ee peuple grand et puissant, d'une force et d'une strueture extraordinaires, qu'il nomme Emims, et qui habitoit la contrée de Moab (I). On doit présumer, d'après l'nsage des chars armés de fer que faisoient les Camanéens dans leurs guerres aveeles Hébreux, qu'ils étoient d'origine seythique. La haine que ceux-ei leur portoit éiait excitée par un

(1) Le nom de géant est en arabe giabbar; son plurier giabattoun, giablarin, et giababérah; réplăin, Deuteron. 
Sanatismc religieux, qui avoit commencé dès que les cnfans de Caïn, Beni Cabil, a voient abandonnéle culte de leurs pères, et s'étoient livrés à l'idolàtrie. Cette race et celle de Seth étoient continuellement aux prises l'une avec l'autre. Des Cananéens de diverses tribus échappèrent au massacre général que firent Moïse et Josué de ce peuple; mais il n'est plus fait mention dans la Bible des Gergésiens, ou des Girasènes, ainsi que le portent quelques exemplaires; car il y a plusieurs variantes à cet égard. On avoit déjà soupçonné que ce peuple avoit passé en Afrique, quoiqu'on l'y ait inutilement cherché. On dit neeme qu'on y avoit anciennement découvert un monument où les Cananéens témoignoient qu'ils avoient fui leur patrie pour se dérober aux fureurs de Josué, qu'ils qualifioient de brigand. Ne pouvant revenir vers l'orient, de crainte de trouver encore des ennemis, ni se retirer en Égypte, parce que le passage leur en étoit fermé, et qu'ils y eussent été d'ailleurs très-mal reçus, leur meilleur parti fut de gagner le nord de l'Afrique. La contrée formant aujourd'hui le royaume de Tripoli, celle où se trouve le fleuve Triton de Ptolomée, paroît avoir été leur premier asile. Les Garamantes, peuple de l'Atlas, connu par l'expédition que fit contre eux le consul romain Cornélius Balbus, étoient aussi probablement une colonie asia tique; l'étymologie de leur nom semble l'indiquer.

Mais est-il vrai, ainsi que le rapporte Diodore de Sicile, que les Gorgones ou les Siranges aient trouvé,' dans leur nouvelle retraite, d'autres ennemis aussi cruels que les précédens, les Amazones? Que faut-il penser des exploits aussi glorieux que ceux de Sésostris, de Myrine, souveraine de ces femmes belliqueuses, et qui 
fit un si grand carnage de ces malheureuses Gorgones? Nc seroit-elle pas elle-même un être aussi chimérique que le pcuple avec lequel elle triomphe? Ne seroit-ce pas une fable orientale puisée dans les mêmes sources? C'est ce que je pense, d'après la eomparaison de l'histoirc supposće de eette reine avec eelle d'Huscherk ou Hosehing, le troisième roi persan de la première dynastie, eelle des Peischadadiens, et qui paroît être formée des patriarehes de la Genèse, mais dont l'histoire est accommodée au goût oriental pour le merveilleux. On peut, malgré tous ces contes, reconnoître l'Hénoch de l'Écriture dans Husehenk, nom qui signifie, en langue persane, sage et prudent. Ce souverain reçut cneore de ses peuples le ńom de Pischdàd, qui veut dire dans la même langue le juste ou le libérateur. C'est probablement d'après une de ces vertus sans nombre dont on se plaît à l'orner, que les Grecs auront composé le mot de Myrine. Son histoire romanesque paroît néanmoins offirir, sous l'emblème hiéroglyphique d'un monstre servanı de coursier à ee héros, monstre sorti de l'accouplement d'un erocodile ct de la femelle de l'hippopotame, ne se nourrissant que de serpens et de dragons, les élémens d'une observation astronomique. Cet animal, nommé rakhsche, avoit douze pieds, et avoit été trouvé dans l'île sèche ou nouveau continent. Cette tradition, quoique très -obscure, n'est eependant pas à négliger; elle tend à nous prouver que la partie méridionale de la Perse venoit de sortir du sein des eaux, et que ce monstre cst l'allégorie de la constellation du sagittaire, que l'on trouve sur les plus anciens zodiaques de l'Inde et de l'Égypte. Daus ceux - ci même, la 
ronsteilation du crocodile est peu éloignée de celle dus sagittaire. De ces données, l’on pourra déduire l'époque del'institution de ee premier zodiaque. Husehenk ehargea son général, Harruschir, de subjuguer les Mahisers (Sermahi en persan, téte de poisson), habitans de l'ile de Ramak, située dans la mer d'Oman. Ils ressembloient par la tête, ou plutôt par la manière dont ils la eouvroient, à des moustres marins, et ils se nourrissoient de poisson séché au soleil. Telle est encore la manière de vivre de ces Balouehes qui habitent la côte maritime du Mékrần, ou des Gorgones des anciens. Ptolomée, ce qui est trèsremarquable, les désigne sous leur ancien nom, Rhammce.

Suivant Diodore, Myrine étoit liée d'amitié avee Horus, roi des Égyptiens. Si elle n'est que l'Huschenk des Persans, ou l'Hénoeh de l'Éeriture, Myrine étoit contemporaine d'Adam, qui, dans notre opinion, est le même qu'Horns. La même tradition, mais sous une autre forme, confirme ce rapprochement; Énoch (ou plutôt Énos, descendant de Seth 1 ) fut le premier agsresseur des Caïnites. Il s'ensuit encore que, d'après des passages mal eompris, on a pu donuer à cette partic de la Perse méridionale, qu'on appeloit alors Éthiopic, le nom d'Égypte.

D'autres témoignages constatent la retraite des eaux des mers, ou la diminution de leur étendue primitive. L'un des premiers empereurs de la Chine, Yrao, fut obligé de faire crenser plusieurs canaux pour donner un écoulement aux eaux qui- couvroient unc grande partic du nord de cette contrée. Une partie de la presqu'île de l'Inde, en deçà du Gange, paroît, d'après quelques autres traditions, a voir été long-temps śubmergée. L'ambassadeur Gareias de Silva Figueroa, trouva dans de hautes montagnes des 
environs de Làr, en Perse, une multitude de coquilles marines, les unes adhérentes aux rochers, et les autres entremêlées avec la terre argileusé de la route qu'il suivoit. Ces eireonstances, prouvent que ees coquilles n'étoient point fossiles, et qu'elles y avoient été déposées vers la même époque que la mer avoit abandonné les côtes du Mékrân, situées presque sous le même parallèle que celles du Laristan. En n'évaluant la hauteurs des montagues où Figueroa observa ees coquilles qu'à 200 toises, les eaux de la mer auroient dû s'avancer dans les plaines de l'intéricur des terres jusqu'à près de r 50 licues, ou même un peu plus, la ville de Làr étant éloigुnée d'une quinzaine de lieues de l'océan. 11 résulte de ces faits que le désert de Sewée, à l'ouest de l'Indus, étoit anciennement sous les eaux; qu'il en devoit être de même de toutes les parties basses de notre continent; que la mer Caspienne devoit s'étendre à l'est, et pouvoit communiquer avec l'Océan septentrional, par le inoyen de l'Obi; et que la plupart des volcans aujourd'hui éteints, étoient alors en état de déflagration. Le souvenir s'en étoit conservé, ainsi que semble l'insinuer un passage de Diodore de Sicile (Voyez mon mémoire sur la géographie des insectes). Il est donc manifeste que la plus grande portion de la terre étoit alor's inhabitable.

L'autre partie de la tradition orientale que j'essaie d'approfondir, celle qui est relative à des observations astronomiques, n'est pas moins curieuse. Les zodiaques égyptiens nous donneront des lumières sur un sujet aussi obscur. Huschenk, le héros de eette tradition, étoit nionté, ainsi que nous l'avons dit, sur un monstre qui 
étoit le fruit de l'union d'un crocodile et d'un hippopotame femclle, animal qu'il avoit trouvé dans l'ịle sèche ou nouvcau continent; il avoit eu de la peinc à le dompter, et il lui avoit scrvi de coursier daus ses exploits, particulièrement dans sa gucrre contre les Mahisers, hommes à têtes de poisson, ou plutôt ichthyophages (les gorgones). Le zodiaque du portique du grand templc d'Esné, nous offre entre le scorpion et le sagittaire, mais plus près de celui-ci, d'abord un crocodile ou plutôt un lézard, ensuite un per'sonnage tcnant une verge de scs deux mains, avec la tête coifféc et semblable à celle du crocodile. MM. Jollois et Devilliers prennent cette dernière figure pour celle d'Hercule. Dans le zodiaque du temple au nord de la même ville, nous retrouvons aussi le lézard; mais cntre cette figure et cclle du sagittaire, sont représentés les objets suivans : $1^{\circ}$. un animal assez analogue au cheval, mais avec la tête coillée ct des membres antéricurs liumains; il porte sur son dos un crocodile, et retient, au moyen d'une pelite chaîne, un des pieds de derrière d'un autre animal, mais mutilé; il a en outre entre scs mains ume sorte de hache, avec un corps semblable à nne queuc ou un fil un peu tortueux qui s'y attache. $2^{\circ}$. Hercule. 3o. Vient le sagittaire. La figure du lézard manque dans le zodiaque du grand temple de Dendérah. L'hippopotante, débarrassé du crocodile, retient par une chaine un autre animal, qu'Hercule, avec une têle d'épervier, perce de sa lance. On reconnoît très-bien le crocodile dans la figure correspondante au lézard, sur lc planisphère de Sclialta de Kirchcr. Celui à forme cireulaire de Dendéra ì differe beaucoup, à l'égard de ces allégories, des trois premiers 
zodiaques. Le sagittaire, du zodiaque d'Esné, représente le héros persan, ayant une double tête, déeoehant une flèche, et monté sur son eoursier, dont la queue ressemble à celle du scorpion. Une eouronne, des ailes, un batcau, ont été ensuite ajoutés à eette figure, pour qu'clle devînt l'emblème des vents étésiens. Si les preunières éloiles de la constellation du sagittaire étoient, à l'époque de la première observation, plaeées sous le colure des équinoxes, et près de eclui d'automne, ce fait astronomique dateroit de 3700 ans avant l'ère ehrétienne; et Bailly, d'après un passage de Job, qu'il soupçonne être relatif à l'étoile aldébaran, remonte aussi à la même époquc. La eonstellation du eroeodilc et celle de l'hippopotame, ont été sueeessivement modifiées sur les divers zodiaques, et de manière qu'elles semblent avoic disparu. Une tortue a d'abord remplacé le erocodile. Le corps de eette tortue a été ensuite supprimé ; il n'est plus resté que sa carapace, dont on a fait un luth et enfin une lyre. Le cerbère entortillé autour d'un rameau, qu'Hercule tient d'une main, a succédé à l'hippopotame. La constellation égyptienne du vautour, plaeée près du serpentaire ou d'Apollon, s'est ressentie de la présence de ce dieu, ct a été transformée en un oiseaiu chanteur, le eygne; ear je pense que la figure que MM. Jollois et Devilliers désignent ainsi, se rapporte à la eonstellation de l'aigle; c'est l'emblême de l'inondation du Nil, ainsi que l'iudique la figure d'une oie nageant sur les eaux de ec flerve. Lc vautour a été transformé encore en une harpic.

L'étude des zodiaques égypticns, de celui surtout dus graud temple d'Esné, m'a fourni des olsservations que je 
crois dignes d'intérêt. Ils dérivent d'un zodiaque plus ancien dont on a changé l'ordre des signes. Ainsi, dans l'origine et sous le ciel de la Perse, le signe des gémeaux, représentant l'union de l'homme et de la femme, pouvoit indiquer le renouvellement de l'année, qui auroit eu lieu lorsque cette constellation se levoit le soir. Celle du capricorne étoit voisine du solstice d'hiver, et son coucher héliaque devoit annoncer la saison des pluies. Sur tous les zodiaques égyptiens, la constellation du poisson austral a pour emblème la figure d'un phoque, particularité qui nous donne l'intelligence $d u$ passage de Bérose relatif au demi-dieu Oannès, et qui nous fait entrevoir que les astronomes de ce temps habitoient les bords de la mer Caspienne. Le zodiaque $d u$ grand temple d'Esné nous montre un homme placé debout sur la queue du phoque, et tenant dans une de ses mains trois fleurs portées sur une seule tige. La balance n'étoit pas alors le signe d'un équinoxe, mais celui du point où se touchent les empires des deux génies qui étoient censés gouverner la nature, l'un bon et l'antre mauvais. Dans la figure de la vierge Cérès du même zodiaque, la coiffure allongée et terminée en pointe indique plutôt un bonnet persan que celui d'un Egyptien.

Le signe du lion est représenté par une femme tenant la queuede cet animal. Dans le zodiaque du grand temple de Dendérah, la femme porte une faux, et le lion est sur le dos d'un serpent ou de l'hydre: dans le zodiaque circulaire de la même ville, on voit un oiseau (le corbeau), sur l'extrémité de la queue de ce reptile. Ces allégories me paroissent exprimer le commencement de l'année, et anzoncer qu'il avoit lieu lorsque le soleil se trouvoit 
entre la constellation de la Vierge et celle du lion. Je crois aussi que ces allégories s'appliquent à un érénement mémorable, le déluge de Noé, le demi-dieus Sosus des Égyptiens. Le corbeau, la barque et l'hydre semblent y faire d'autant plus allusion, que ce déluge a eu lieu, selon l'opinion commune des interprètes de la Genèse, le second mois après l'équinoxe d'automne, et précisément le mois qu'indiquoit, à l'époque de la construction des zodiaques de Dendérah (le treizième ou quatorzième siècle avant J. C.), le lever, après le coucher du soleil, de la constellation du lion.

Le céraste, un autre serpent, mais dont le corps forme des ondulations ou une chaîne, et le scarabée sacré, qu'on remarque dans la figure qüi vient immédiatement à la suite de celle du signe du lion, le bouvier d'Isis, placé un peu au-delà, après le signe de la Vierge, nous prouvent qu'on a voulu désigner, $1^{\circ}$. l'inondation du Nil, correspondante à la constellation zodiacale où étoit alors le soleil; $2^{\circ}$. le temps où la terre, lorsque ce fleuve s'est retiré, produit ces reptiles et ce scarabée; $3 \circ$. l'époque des semailles. Il s'ensuit que ces zodiaques représentoient, ainsi que l'avoient déjà bien remarqué MM. Jollois et Devilliers, non l'état du ciel tel qu'il s'offre lorsque le soleil entre dans la constellation du lion ou dans celle de la vierge, mais celui qui a lieu six mois après, et lorsque ces constellations se montrent successivement, après le coucher de cet astre, à l'horizon.

Le signe des mêmes zodiaques, que MM. Jollois et Devilliers rapportent au bouvier d'Isis, me paroît être celui du cocher ou du charretier. La chouette, ou du moins uu oiscnu analogue, et l'écurcuil, qui font partie cle cet cm- 


\section{DU MONDE.}

blême, indiquent que la constellation dont elle étoit l'objet devoit être située près du pôle septentrional. Celle qui paroît aux mêmes savans correspondre au cocher, et que les Égyptiens avoient consacrée au dieu Pạn, sera pour nous la constellation du bouvier. Elle est représentée sous la figure d'un simple berger, accompagué d'un chien, et sans aucun de ces emblêmes de puissance qui caractérisent le dernier demi-dieu (Cham), dont la constellation du cocher fut, à ce qu'il me paroît, l'imagge. 


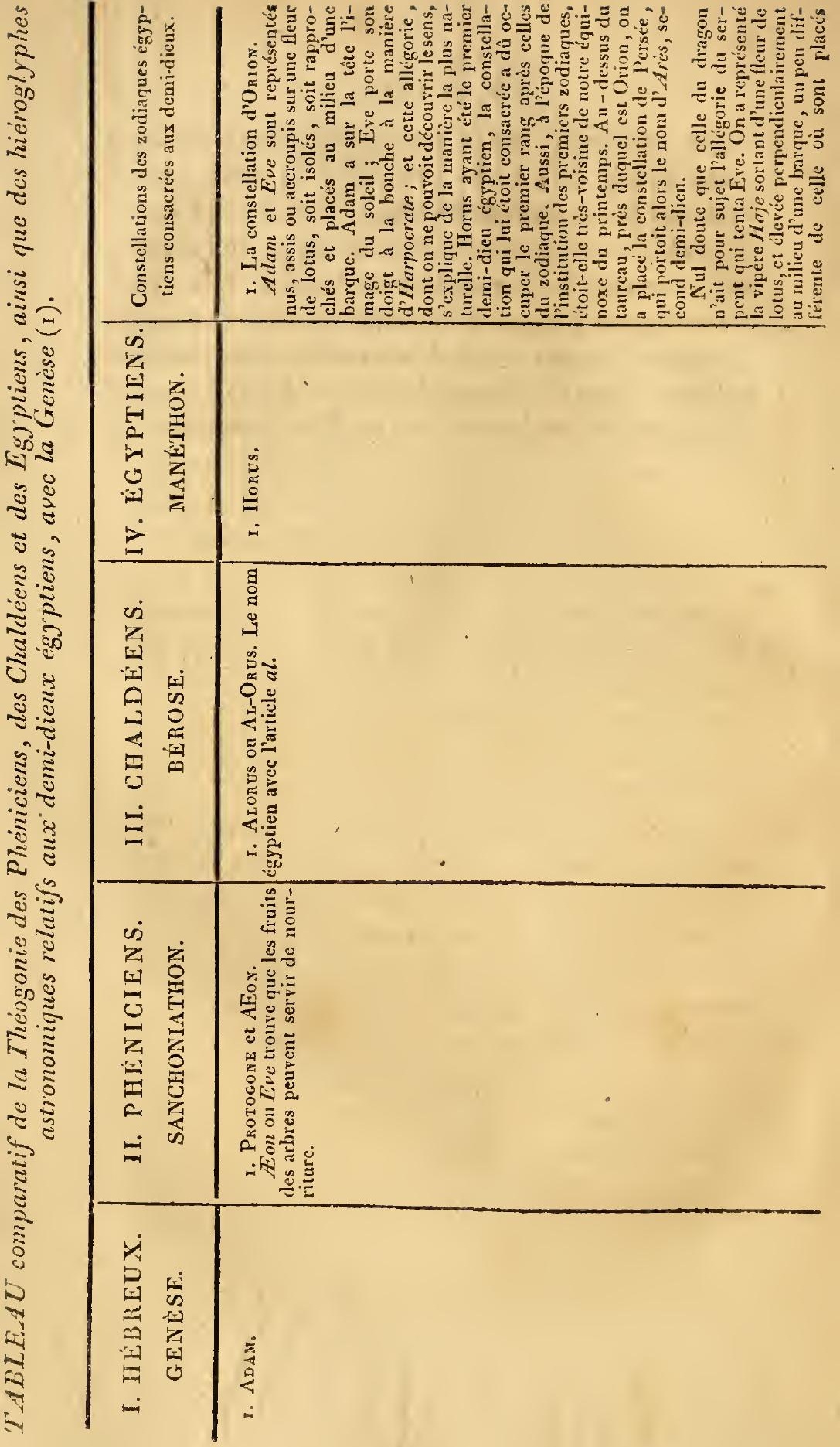




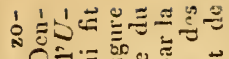

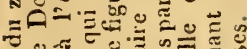

บ

Eบ

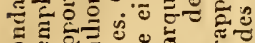

-

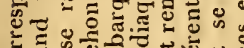

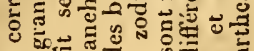

ต्山

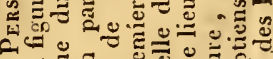

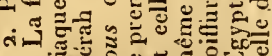

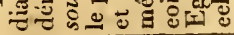

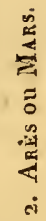

$\Xi$

วี้

这.

要寻

음

돈

की

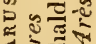

उण

$z$

4i…

च 0

बं

of

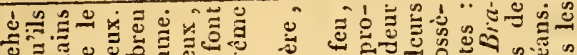
岛

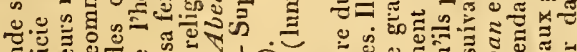

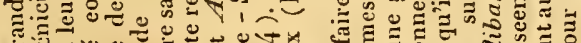
म क्षी

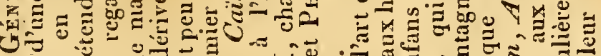
ब कू.

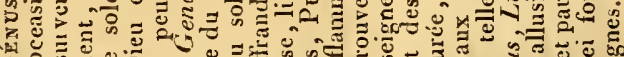

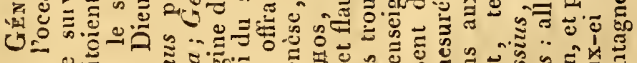

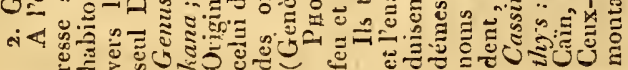

$1 \perp \stackrel{1}{0}$ 車

$\stackrel{0}{0}$

क ०

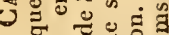

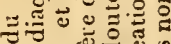

올

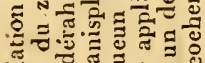

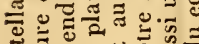

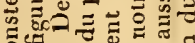

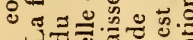
๓๐ $\neg$ 山 .

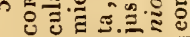

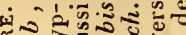

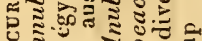

บิ

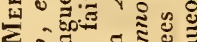

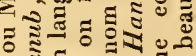

๙

ติ

दु

을.

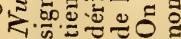

นこ

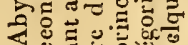

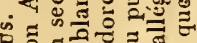
员

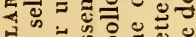
‥ 三

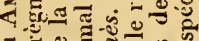

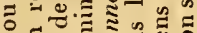

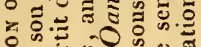

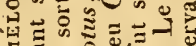

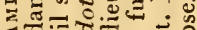

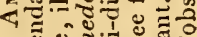
อี ญै ข

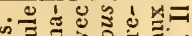
ఉె

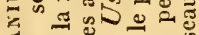
น

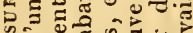
政卷

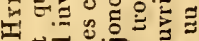

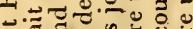
๘ क 造记

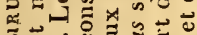
テ

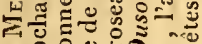
ㅇํㅇ 년 ปั ธี. -

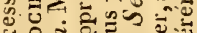

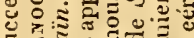

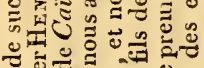
O

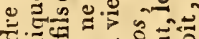
o

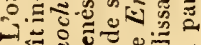

m

웡ํํ

象

$-\frac{0}{0}$

\%

틍 용

$x=2$

플

के ठิ

-

मू

एँ

포

을

ㄴ.

용요

U

ज 웅

잉요

ชี

용

폻

है $₫$.

قิฝ

i)

n

은

I $\equiv$

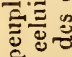

ن. 를

脑

(1)

E 0

ह๐요

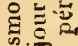

응.․․․

요 엽

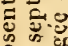

로

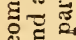

औ

दै

ए०ू

क

둘

둥요

\& 


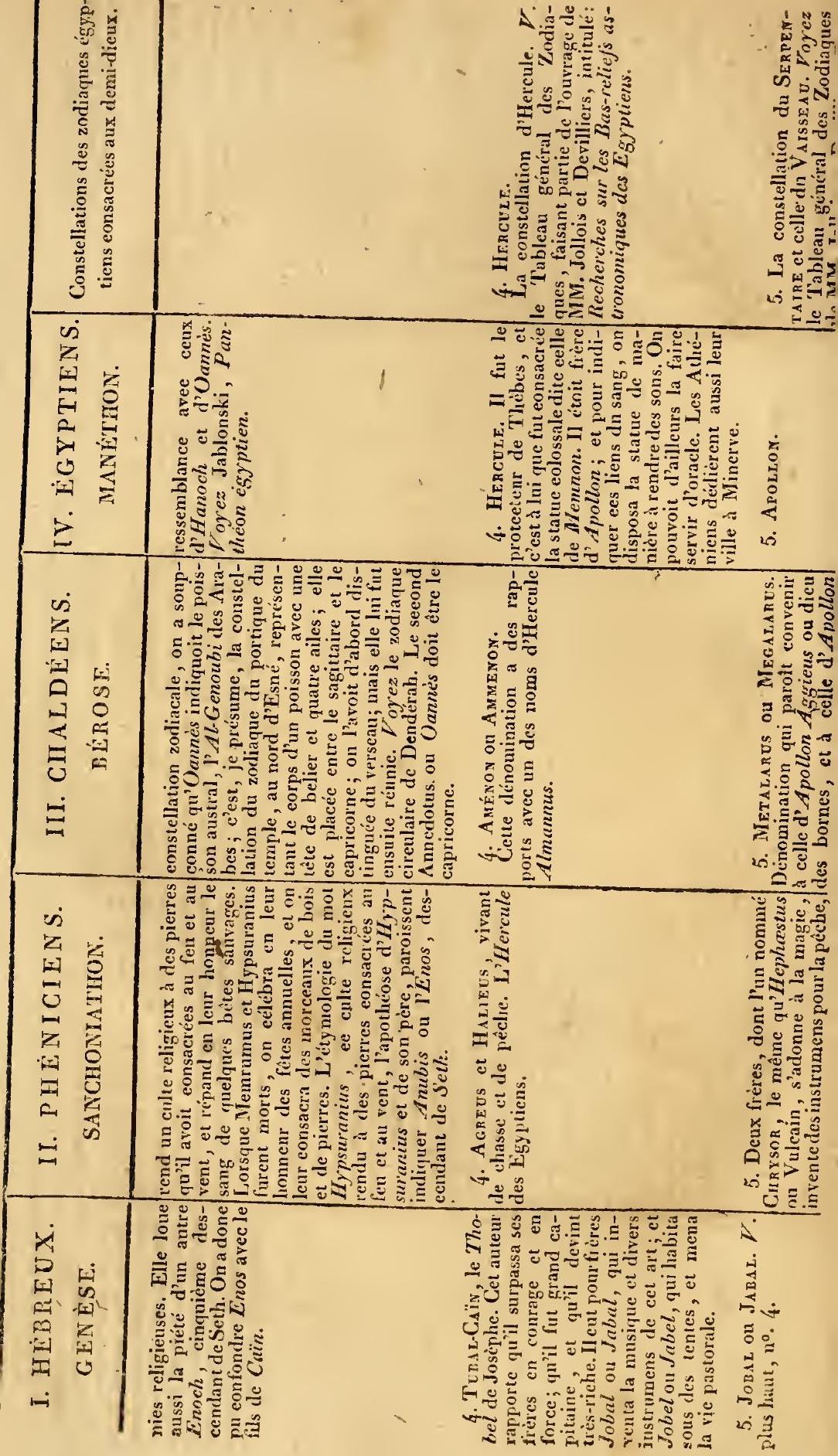




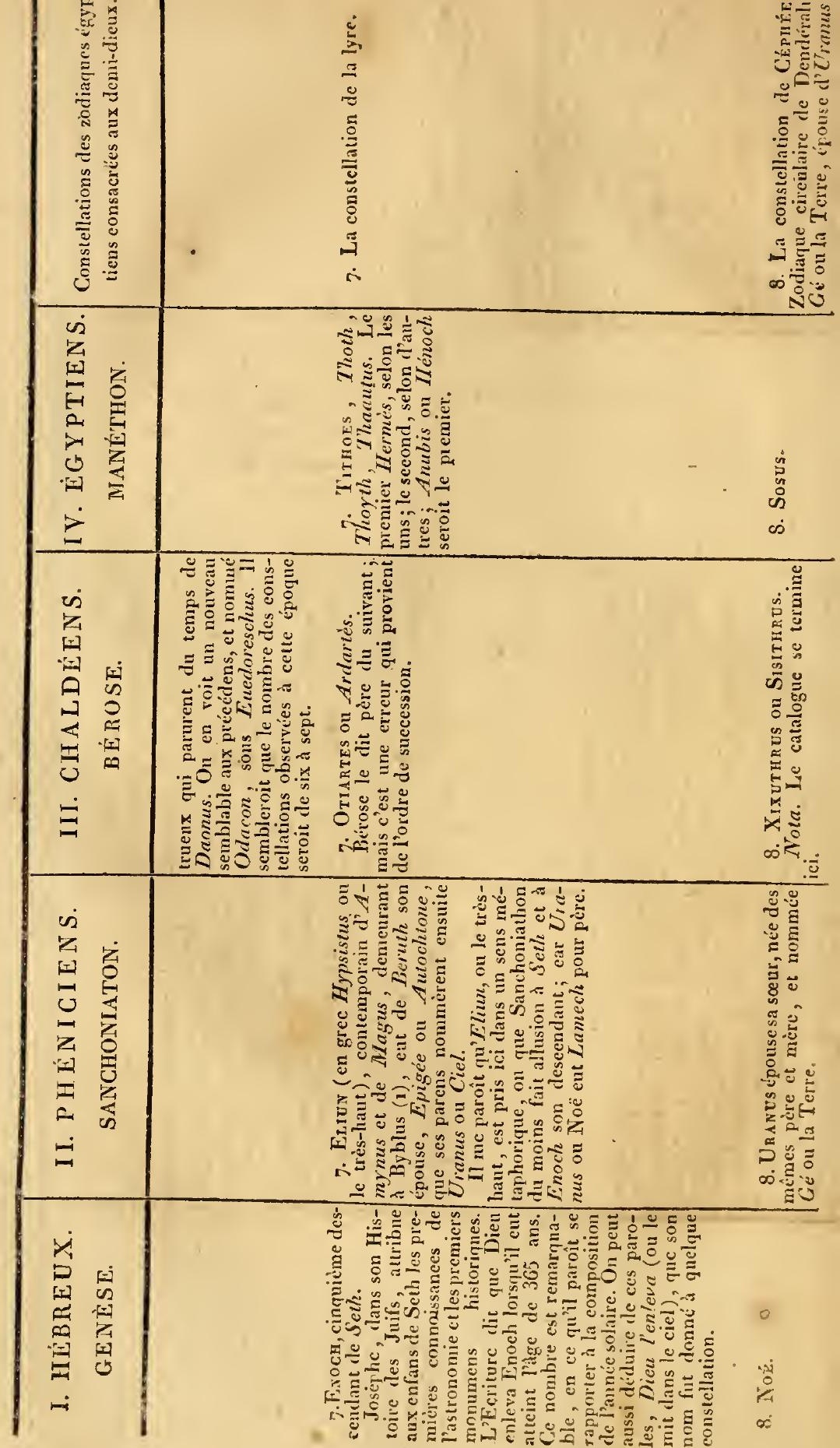




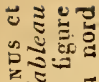

过牙

Ð क के

풍

运

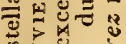

है $=0$

ठ - 대

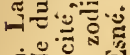

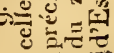

疍

ลี่

E..

U를

तै

령ㅎㅀ

\& 4

th

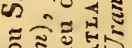

D棌

BD

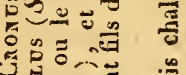

क

这放事

 


\section{ÉCLAIRCISSEMENS ET ADDITIONS.}

LE sujet que je viens de traiter est si vaste, que je n'ai jamais eu la penséc d'en embrasser toute ,l'étendue ; je me suis simplement proposé d'indiquer aux amis de l'histoire une ronte nouvelle, en les invitant à la suivrc par l'exposition de quelques heureux apcrẹus. La révision de ce travail m'a entrainé dans d'autres recherches, ct j'ai recueilli de nouveaux faits qui éclaircissent ou fortifient mon opinion. Ils sont l'objet de ce supplément.

En se détachant de lcur souche commune, pour se transplanter ailleurs, les races primitives dc l'espèce humaine ont porté dans les diverses contrées où elles se sont établics, lcurs traditions, et ont mêmesouvent donné aux montagnes, aux rivières, aux habitations de ces pays, les noms qu'elles avoient imposés, dans leur terrc natale, aux objets analogucs. Les traces de lcur émigration s'étant effacées avcc le temps, on a regardé ces peuples comme autochthoncs. Ils disaient tous, par exemplc, que les dieux étoient nés dans leur pays. En recevant ces traditions sans les approfondir, les historiens grecs et romains ont cru ou nous ont donné lieu de penser qu'elles étoient propres aux contrées qu'labitoient alors ces peuples. C'est ce que nous avons déjà observé relativement aux Atlantes, ou les habitans des régions adjacentes à l'Atlas. Quand on lit dans les dialogues.de Platon, intitulés Timée et Critias, que la fameuse Atlantide étoit unc île située vis-à-vis cette embouchure 
de la Méditerranée, qu'on nommoit anciennement les colonnes d'Hercule, que de cette île on pouvoit passer dans d'autres, de là se rendre sur le continent, et suivre ses côtes jusqu'à celles de la mer appelée le Pont, il est tout naturel de chercher cette Atlantide, plus grande, selon Platon, que la Lybie et l'Asie (l'Asie mineure) ensemble, dans cette partie de l'Océan qui baigne les côtes occidentales de l'Afrique et de l'Europe, et désignée même sous le nom d'Atlantique. Les autres passages du Timée semblent autoriser de plus en plus ure telle direction. Mais on découvre d'abord, dans ce récit, les vestiges d'une antique tradition concernant l'état physique de cette partie du monde, qui, par l'étendue beaucoup plus grande de la mer, étoit divisée en un grand nombre d'iles. Ce souvenir nous reporte à des temps trèsobscurs pour l'histoire, pour ne pas dire jusqu'aux temps fabuleux. Ces Atlantes formoient une grande nation qui avoit injustement envahi toute l'Europe et l'Asie.

Les habitans primitifs de la Grèce, après avoir repoussé les efforts de ces redoutables agresseu's, furent engloutis, ainsi que leurs îles, dans les abîmes de la mer, et dans le bien court espace d'un jour et d'une nuit. Par suite d'une telle submersion, l'océan atlantique n'est point navigable. Si Platon eût vécu de nos jours, il eût vu que nos marins n'ont pas été arrêtés par ce limon qu'il suppose avoir été formé par l'Atlantide, et obstruer le passage des vaisseaux.

Si l'on compare ce récit avec l'histoire des Amazones d'Afrique de Diodore de Sicile, l'on y découvrira aisément que ces traditions, malgré des circonstances particulières et des différences de nọms, viennent de la même source. C'est à l'occasion des Atlantes que Diodore 
parle des Amazones d'Afrique; ces femmes guerrièes euvahissent les mêmes contrées que ceux-ci, y fondent de grandes cités, et périssent en majeure partie avec leur reine Myrine, dans une bataille que Mopsus, né en Thrace, et Sipyle, Scythe de nation, leur livrent. Le reste se réfugie dans. la Lybie. Le lac Tritonide, sur lequel elles avoient construit la ville de Cherronèse (presqu'île), disparut, dit-on, entièrement, par la.rupture de tout le terrain qui le séparoit de l'océan.

Je n'avois pas d'abord été éloigné de croire que l'Afrique n'eût été le théâtre de ce bouleversement, et des convenances de noms m'avoient porté à fäire l'application du passage de Diodore à l'extrémité orientale du royaume de 'Tripoli; mais je ne doute pas aujourd'hui que ces traditions, entremêlées de fables, n'aient pour objet les cliangemens physiques qui se sont opérés dans cette proviuce de la Perse qu'on appelle le Mékrân, et dont j'ai parlé dans mon mémoire.

L'Imaus ou le Caucase des anciens, cette grande chaîne de montagnes qui traverse l'Asie dans toute sa ląrgeur, est désignée, dans quelques langues oricntales, sous le nom de Caf ou de V atad, et dont le pluriel cs\& Autad (I). Il dérive de $P a l$, qui signifie pivot; ces montagnes étoient censées envirouner le globe dela tcrre et lui servir d'appui. De là plutôt que de l'invention de l'astronomie, l'origine de cette fable, dans laquelle Atlas porte le ciel sur ses épaules. L'application de ce nom et de

(1) Parmi les géans fameux du pays des singes, cités par l'historien de Thahamurath Nameh, on distingue Antaloun ou Antalous (l'Amlchialus des Grecs), et quil compare a la colonne couleur de poix d'Alexandre (marbre thébaïque noir); de lì est peut-être encore venu la dénomination d'A talantes ou Allantes. 
cette fable ne peuvent convenir que par extension à cette chaîne de montagnes qui traverse la partie septentrionale de l'Afrique. En préposant un $a$ au radical $T a l$ ou Talas, qui en hébreu veut dire je porte, on a fait Atlas, et de là l'origine du nom d'Atlantes, donné aux peuples du Caucase, et à ceux de l'Atlas proprement dits; mais il est constant, d'après un grand nombre d'autorités, que la pointe la plus élevée et la plus occidentale de cette dernière chaîne de montagnes, s'appeloit primitivement Dyris. Or, selon Arrien, dans sa relation de l'Inde, faite sur le voyage de Néarque, une chaîne de montagne de la Gédrosie, celle que Ptolomée nomme Arbiti Montes, et qui séparent le Malàn du Mékràn, étoit appelée Irus par les habitans de ce pays. C'est de là précisément que partirent, suivant nous, les Syranges de Ptolémée, ou les Saranges d'Arrien, aujourd'hui les Guanches, pour aller s'établir d'abord en Palestine, et en dernier lieu sur la côte occidentale d'Afrique, près de Mogador, après s'ètre arrêtés quelque temps dans le royaume de Tripoli. Le mot Dyris dérive peut-être de Div on Dew, nom sous lequel les Persans désignoient les génies ou les géans.

Le port de la Gédrosie, qu'Arrien nonme, d'après la langue du pays, port des femmes, parce que le premier qui y avoit commandé étoit une femme, devoit être peu éloigné du cap appelé aujourd'hui Guadar, ce qui nous prouve encore qu'un mode de prononciation, espagnol peutêtre, a converti en gua la première syllabe du mot $S y$ rangce. Peut-être encore trouverons-nous dans la race de ce peuple ou de celle des Cananéens, les premiers habitans de l'Espagne.

Le portrait que nous fait Arrien de ces hommes sau- 
vages ct féroces, tout couverts de poils, sans en excepter le visage, à demi-nus, n'ayant pour habillemens que des peaux d'animaux, vivant de chair crue, de poissons, ne connoissant point l'usage du fer, se servant de leurs ongles à la manière des bêtes, ayant pour armes des lances de bois, longues de six coudées, eî aiguisées au mojen de feu, de ces hommes, dis-je, que Néarque irouve à l'embouchure du fleuve Tomerus (le Kurène), convicnt parfaitement aux Gorilles ou aux Gorgones des anciens, les Balouches des modernes (I). Ce sont les chélonophages, ou mangeurs de tortue de Ptolémée. Des Persans désignent les faunes et les satyres sous le nom de div-mard.

L'histoire des Amazones d'Afrique et des Gorilles a été puisće dans les anciens romans des Perses, et particulièrement dans ceux qui ont pour sujet Huschenk et

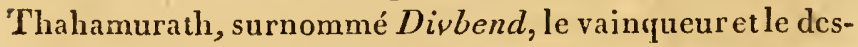
tructeur des géans, rois de la dynastic des Pischdadian ou Peischdadiens. On peut consulter d'Herbelot au sujet de cette partie de la mythologie persane. "Dans le temps, nous dit-il, que Thahamurath régnoit, il y avoit une espèce de créatures, qui avoient gouverné le monde avant le siècle d'Adam, mais qui étoient pour lors confinécs dans la montagne de Caf. Les Arabes appellent ces créatures du nom de ginn, et les Persans de celui de div, et ce sont les mêmes que les Grecs ont appelés démons. Cependant elles ne laissent pas d'être confondues avec les géans, desquels l'Écriture parle dans le premier âge du monde, ct dont les mythologues grecs ont fait presque

(r) C'est du moins ce que je présume, car les caractères physiques et les mours dic ce peuple, ainsi que çux des habitans maritimes du Mćkrân, me sont ipconuus. 
une histoire suivie. Le pays que ces créatures habitoient du temps de Thahamurath, s'appelle Ginnistan, c'està-dire le royaume des ginn, lequel a la même étendue que la montagne de $\mathrm{Caf}$, qui fait une ceinture autour de la terre, et qui embrasse également l'orient, l'occident, le septentrion et le midi."

Les Atlantes, que Myrine, reine des Amazones, attaque' au commencement de son expédition, sont ces Div ou mauvais génies. Effrayés de ses succès, ils se soumettent, apportent à Myrine des présens magnifiques et lui rendent toutes sortes d'honneurs. Argenk, fameux géant, voyant que les Péris ou bons génies remportoient de grands avantages, lui envoie une ambassade solennelle. Le Thrace Mopsus et le Scythe Sybile, ayant réuni leurs forces, remportent une victoire complète sur $\mathrm{My}$ rine, qui périt dans l'action. Thahamurath, d'après les sollicitations de la fée Mergiane, s'engage dans une guerre contre le géant Hondkour, et y perd la vie. L'histoire des Gorgones paroît avoir été puisée, ainsi que nous l'avons dit, dans celle d'Huschenk. Les Mahisers, hommes à têtes de poisson, vaincus par lui, sont̂ transformés en Gorgones, en monstres marins ou tritons, et leur pays devient naturellement celui des Tritonides. Ce sont les Rhamnes, les Parisènes (I) et les

(i) Cette dénomination, celles d'Armiana, de Borgi, et quelques autres, paroîtroient appuyer l'analogie que l'ọn a remarquéc entre la langue teutonique et celle des anciens Perses.

Suivant Hérodote, ce peuple étoit appelé dans les temps les plus anciens, Artcei, et de là le nom d'Artcea, donné à leur pays. Nous avons vu que Caïn, l'Artès ou le Mars des Egyptiens, y avoit formé le premier des habitations. Les Parthes, Scythes d'origine, disoient que leur nom signifioit dans leur langue des hommes bannis ou crrans. Or, les Scythes, sclon nous, descendent de la race de Caïn. 
Arbites (Arabies, Arr.) de Ptolémée. La dernière dénomination, ainsi que celle du fleuve Arabis, le triton: de Diodore, paroît dériver du mot casa-arab, arabe noir. On retrouve une signification analogue, et tirée de l'arabe, dans le nom de Loubi que ce géographe donne à une île de ces parages. Il a été dit précédemment que les Mahisers habitoient l'Isle sèche ou le nouveau 'eontinent. Selon d'Herbelot (article Caf), cette tradition orientale a pris sa source dans les idées de Platon sur l'Atlantide; il faut, je pense, renverser la proposition, ou, pour plus grande exactitude, dire que Platon l'avoit puisée elıez les Egyptiens, colonie asiatique, et l'avoit ensuite communiquée aux Grecs, peuple trop moderne dans l'histoire de l'antiquité pour être le premier eanal d'où elle soit sortie. Le fait géologique et trèsimportant que j'ai rapporté, étayé d'ailleurs par d'autres considérations de même nature, nous semble prouver que la partie maritime de la Gédrosic, d'abord couverte d'eau, a étć ensuite divisée en plusieurs îles, dont quel. ques-unes des plus avaneées ont pu être rejetées plus loin ou même disparoître, tandis que les autres auront été incorporécs avec la terre-ferme. Il ne faut pas oublier que la provinec de Makrân est contiguë au Sedjestan, où, dans mon opinion, le déluge de Noć a commencé. Ces éréncmens, dont on a pu confondre les époques, se licnt d'ailleurs à d'autres faits géologiques antérieurs à la civilisation ou qui datent du moins de son origine. Au nombre de ces idées mythologiques persanes, et qui remoutent encore à quelques-unes de ces traditions antédiluviennes, il faut plaeer ee que raconte Diodore de Minerve, fille du flewe Triton, et pommée, pour celte raison, Tritonide. 
Selon Bérose, Amélon, troisième roi chaldéen, prédiluvien, et Amelon et Métalarus, deux de ses successeurs, étoient natifs de Pantabibla, nom qui signifie en grec recueil ou livre. Celui de Nichâbour, ville du Khoraçan, et dont l'emplacement paroît correspondre à $\boldsymbol{N y s a}$, patrie de Bacchus ou de Noé, a pour racines, dans la langue persane, $N e i$, roseau, et Chábour ou Sapor. La province d'Aria de Ptolémée nous offre encore une ville, celle de Nisibis (roseau, ville), dont la dénomination présente un radical semblable. Dicu ordonne à Xisuthrus ou Noé de mettre par écrit les traditions existantes, et d'enfermer ce dépôt dans Sippara, la cité du soleil. Le rapprochement de ces étymologies avec cette dernière circonstance me permet de soupconner que, du temps de Noé, on avoit déjà trouvé l'art d'employer pour l'écriture ou de faire du papier soit avec le souchet papyrier ou le papyrus, soit avec le bambou. Le personnage du zodiaque du grand temple d'Esiné, représentant la constellation du capricorne, me semble même tenir d'une main une branche de papyrus. Cettè supposition admise, le passage de Pline, relatif à l'antiquité de la découverte de l'écriture, et la tradition chinoise dont le sujet est le même, s'expliquent aisément. La période de 720,000 et de 49,000 (voyez plus bas) k rapportée par Pline, n'est que fictive, et dérive du premicr cycle lunaire établi du temps de Noé. Cette tortue ( $\iota$. radiata), sur laquelle, d'après une tradition chinoise, et dont Bailly fait remonter l'origine à trente-trois siècles. avant l'ère chréticnue, on traça des caractères historiques, est évidemment l'emblême du phénix, la constellation de la lyre ayant d'abord été représentée sous la figure d'un crocodile et ensuite par celle d'une tortue. 
L'étymologie chaldéenue du surnom de Liber donné à Bacchus, nous fournit une nouvelle preuve que ee dieu est le même que Bacehus; ear le mot de liber paroît dériver de kelaphi, coffre de bois, arche, ayant pour radical kelipha, éeorce (Harmonie des Langues, de Guichard).

Je eiterai eucore à l'appui de mon opinion les saerifiees que faisoient les Egyptiens à la lune et à Baechus. Dans ces eérémonies, ils immoloient des pores, animaux réputés immondes, et il leur étoit interdit de les offrir à toute autre divinité.. Ils mettoient le bout de la queue avec la graisse et la rate dans la panse, et brûloient le tout dans le feu saeré; ils mangeoient ensuite le reste de la viande le jour de la nouvelle lune, exelusivement eonsaeré à ce festin. Suivant quelques autres traditions, le déluge étoit arrivé le jour d'une nouvelle lune, jour remarquable parce qu'on voyoit le soir à l'horizon einq autres planètes (Aldébaran, Régulus, Antarès, Fomalhaut et $W_{\text {ega }}$ ). Or, la réunion de ees phénomènes a pu avoir lieu en décembre de l'an 3 ı́r avant notre ère, et même trois à quatre sièeles plus tỏt. Une partie de ce mois eorrespond précisément à une partie d'un signe de l'aneien zodiaque des peuples du nord de l'Asie, eelui du pore. La constellation égyptienne du loup et du centaure ct eelle de l'autel (Zod. ésypt. de MM. Joll. et Dev.) me paroissent se rapportcr à ces eouturnes. Il seroit difficile, daus une autre hypothèse, d'expliquer des analogies ausși frappantes. Un passage de Bérose, relatif aux rois ehaldéens prédiluviens, très-obscur il est vrai, mais que l'on peut éclaircir par l'étude du zodiaque du grand temple d'Esné; deux autres passages, dont l'un a pour objer le sagit- 
taire et l'autre le phénix ou le Simorg, passages tirés d'un manuscrit en langue turquie et eités par d'Herbelot; et ce que Diodore de Sicile nous dit d'Atlas ou le Thoth des Egyptiens, nous prouvent que l'astronomic, au siècle de Noé, avoit déjà fait des progrès très-sensibles. Le ciel d'hiver, si je puis m'exprimer ainsi, présentoit des constellations remarquables par des étoiles de la premic̀re grandeur, et dont la position pouvoit détermincr les équinoxes et les solstices; ellcs fixèrent plus particulic̀rement l'attention dcs premiers astronomcs. Des eirconstances astronomiques propres à ce temps d'observations facilitèrcnt l'étude du ciel. La constellation du taureau, ceiles d'Orion et des gémeaux, étoicnt peu éloignées du point équínoxial du printemps; le point opposé, ou cclui d'automnc, étoit annoncé par la proximitédd'Antarès, la première étoile du scorpion. Regulus indiquoit le solstice d'été, et Fomalhaut celui d'hiver. Le tablcau suivant, et fondé sur lcs bascs indiquées plus haut, nous fera connoitre l'ordre qu'on a suivi dans l'institution du premier zodiaque.

1. Orion. 'Bérose rapporte à la première année du règne d'Alorus l'apparition du deni-dieu nommé oannès; mais il me paroît qu'il s'est mépris sur l'époquc. La constellation d'Orion fut d'abord réunie à cellc des gémeaux, et consacrée à Adam et Evc : c'est ce qui résulte de la comparaison du zodiaqque du grand temple d'Esné avec celui du temple au nord de eette ville. Le premier mois des Arabes et des Turcs cst nommé muharram, mot qui semble n'ètre qu'une corruption de celai de marrhat (cä̈ou-marhat) donné par les Persans au premier roi de la dynastie des Peischdadiens, et qui, d'a= près toutes les vraiserabląnces, doit être Adam. 
Les Arméniens et les Chaldéens me paroissent avoir consacré le premier mois de leur annéc à Noé, Navazard, Nisan ou Abib (Nouh-al-Abi ou Nouh-al-Agi, sauvé et sauveur); la dénomination du second tire son origine d'Adam, hori en arménien, mois qui commence au io septembre, et ijar ou zius, en chaldéen.

2. Fomalnuet, Al-Hout, Al-Genoubi, noms arabes qui ont de grands rapports avec ceux d'Hanoch et d' $A$ nubis. C'est la première étoile de la constellation du poisson austral, confondue d'abord avec celle du capricorne, distinguée ensuite par les Egyptiens (l'aigle, zodiaque du temple au nord d'Esné, Jollois et Devilliers). Nous avons dit que cette constellation avoit pour sujet un phoque, l'oannès de Bérose. Cet auteur le fait sortir de la mer Rouge; ce qui confirme mon idée qu'ón désignoit sous le nom de Phonicie les pays situés près des côtes orientales de la mer Caspienne.

Cette constellation fut observée sous Amélon, troisième rói chaldéen, au bout de 26 sares, à dater de la première année d'Alorus. On reconnoît son origine dans l'Anubis égyptien, qui est représenté sous la figure d'un homme avec la tête d'un chien ou plutòt d'un chicn de mer.

3. Le Scorpion, le Sagittaire, la Lyne et le Crgne, désigné d'abord sous le nom de vautour tombant. Ces denx dernières constellations paroissent avoir formé, par leur rapprochement, le phénix (zodiaque du temple au nord d'Esné). Le vautour converti en harpie, et placé sur une bouteille qui étoit censée renfermer les reptiles et les insectes sortant du limon du Nil, a donné lien à la fable de la boîte de Pandore. Les deux autres constellations sont l'anedotus qui, suivant Apolloplore, 
parut sous Aménon (Hercule), quatrième roi chaldéen. Voyez ce que j'ai dit plus haut, à l'occasion des Amazones et d'Huschenk.

4. Constellations relatives à l'agriculture : le BeLrer, le Taureau, le Cocher et le Bouvier. Ces nouveaux ounnès (evedocus, eneugamus, eneubulus et anementus) paroissent sous Doanus ou l'Ammon des Egyptiens.

5. Régulus (Al-Sarcat des Arabes), première étoile de la constellation du lion; l'Odacon qui parut sous Euédoreschus.

Selon Diodore de Sicile, Hesperus, fils d'Atlas, étant monté au sommet du mont Atlas, fut subitement emporté par un vent impétueux, et on ne le vit plus depuis. Le peuple, touché de son sort', et se ressouvenant de ses vertus, lui décerna des honneurs divins, et consacra son nom à la plus brillante des planètes. Le sens naturel de ce passage paroît convenir à la planète Vénus, ou du moins à Mercure. Mai je crois que les prenières observations astronomiques de ces astres sont d'un àge postérieur, ct que nous les devons à Pétosiris et Nécepsos, contemporains de Sésostris. Une figure dı zodiarque du grand temple de Dendérah, représentant un singe assis sur ses pattes de derrière, placé dans un bateau, et ayant sur la tête une étoile trèsgrande, seroit-elle l'emblême d'un lever héliaque de Vénus? Je le soupçonne. J'avois d'abord pensé qu'on aroit voulu désigner l'étoile Canopus, qui se montre peu de temps sur l'horizon de la Thébaïde, et qui pouvoit, par son apparition, indiquer le midi, l'Ethiopie, ou le pays des nègres et des singes.

Il me semble donc plus probable qu'on consacra d'abord à Thoth la belle étoile de la lyre, nomméc $T^{\prime} \operatorname{cg} a_{2}$ 
et qu'à raison de son épithèté, elle a été confondue arec la planète Vénus, désignée par les Egyptiens sous une dénomination eorrespondante à eelle de très-belle; eette planète est nommée zoharah par les Arabes. L'auteur du Caherman Nameh, en parlant d'un grand eombat que Caherman eut avee un fort géant, dit que Vénus, du haut du ciel, quitta son instrument de musique pour être mieux attentive à ec speetaele. Vénus, ehez les Musulmans, est représentée eomme Apollon, tenant une Jyre à la main. L'allégorie que je viens de eiter ne peut guère s'entendre que du déluge et de l'étoile de la constellation de la lyre. Je erois aussi, d'après divers rapprochemens, que le premier Zoroastre ou Zerduseht des Perses étoit eontemporain dù Thoth égyptien ou de l'Enoeh, de la raee de Seth, de la Genèse.

D'Herbelot, à l'artiele Thahamurath, a eité un passage très-eurieux concernant le phénix, et que Bailly, à ce qu'il paroît, n'a point connu, ou dont il n'a pas eru devoir faire usage. Cet oiseau est appelé en langue turque simorg, anka, ou le griffon merveilleux, nom qui a des rapposts avee celui d'Almoraerek que les Arabes ont donné à la constellation de la lyre, ainsi qu'avec la dénomination d'al-vuralié imposée, eneore par eux à son étoile principale, appelée autrement $W$ ega. Personne ne doute que le phénix ne soit une allégorie astronomique, et je me bornerai à eiter le passage qui peut nous en déroiler Je sens.

"Le Caherman Naneh rapporte que Simorg étant interrogé sur son âgé, répondit : Ce monde est fort aneien; çar il s'est déjà trouvé sept fois rempli de eréatures et sept fois entièrement vide de toutes sortes d'animaux. Le siècle d'Adam, dans lequel uous sommes, 
doit durer 7,000 ans, qui sont un grand cycle d'années, et j'ai déjà vu douze de ces révolutions, sans que je sache combien il m'en reste à voir. "

Simorg nous prévient que 7,000 ans forment un grand cycle d'années. En prenaut ces ans pour des jours, et divisant la somme par 360 , nombre des jours dont les Egyptiens et quelques autres peuples composoient l'année, antérieurement à l'observation précise de la révolution solaire, nous aurons 19 ans et quatre neuvièmes, fameuse période dont la découverte est fondamentale en astronomie. .

- Le pliénix avoit vu s'écoulcr douze de ces cycles ou 84,000 ans, et la durée du siècle d'Adam dans lequel,il étoit, étoit égale à l'un d'eux. Les douze cycles font 233 ans trois neuvièmes; ct si l'on suppose que le phénix a voulu dire, d'après la solution du problème précédent, que le siècle d' $\Lambda$ dam dureroit encore un cycle, nous aurons $2 \sqrt[5]{2}$ ans sept neuvièmes ou près de 253 ans. Or, ce nombre d'années se rapproche beaucoup de celui de la durée totale des règnes des neuf demi-dieux égyptiens; il est de 214 , et si on y ajoute une génération de plus ou 30 ans, pour que la somme de ces demi-dieux corresponde au nombre des patriarches, nous nous rapprocherons encore plus du calcul précédent, puisque nous avons 244 ans, nombre qui ne diffère que de neuf de celui de 252 .

L'histoire des deux plus anciennes monarchies de l'Asie, celle des Chinois et des Indiens va nous offrir la même identité d'origine et de traditions. Commençons par les premiers.

Ainsi que les Persans, les Indiens et les Grecs, ils établissent un âge intermédiaire entre la civilisation du 
genre humain et l'existence de l'univers. Panliou ou Puonku, qui paroît à la tête de cet àge, est moins, selon Bayer et Menzelins, le nom d'un prennier homme que celui dc l'immense durée qui a précédé sa formation. Sous Tyen-Hoang, successcur immédiat de Pankou, l'csprit céleste, après avoir détruit le grand dragon qui avoit mis tout en désordre dans le ciel ct sur la terre, commence à se répandre dans le monde; il adoucit et commence à rapprocher les hommes. Deux sortes de lettres ou de signes, qui servircnt ensuite à composer le cycle sexagénaire, sont inventés. Au bout de treize générations règue $\mathrm{T} y-H o a n g$, qui partage le mois en trcnte jours, et s'illustre par des observations astronomiques. Après lui viennent encore, jusqu'à JinHoang, treize autres rois ou chefs de tribus, sur les actions desquels l'histoirc garde le plus profond silence. Il paroît que les Chinois voulurent partager cet âge en un nombre d'intervalles correspondant à eelui des jours dont se compose une lunaison synodique, et que, pour donner à ces prcmiers temps unc couleur historique, ils eurent recours à des traditions de l'âge suivant.

Jin-Hoang (Ycou-Tsao-Chi), qui porta ensuite la couronne, avec neuf princes de sa famillc, réunit en un corps de société ses sujets, qui avoicnt été jusqu'alors dispersés. On croit que le partage qu'il fit de scs états en neuf portions, dont une servoit d'habitation à son peuple, et dont les huit autres étoient pour la culture, donna lieu à l'invention de l'astronomie. Son règne fut le siècle d'or. Ces renseignemens, fortifiés de ceux que présente l'histoire de Jin-Hoang, nous fait rcconnoître cn lui le prenier homme ou Adam. Yeu ou Yu, second empereur, qui fait la découverte du feu ct cons- 
truit le premier des cabanes, doit être Caïn. Dans Susu (Soui-Jin-Chi), qui lui succède, nous pourrions voir le patriarche Seth de l'Ecriture. Sclon les meilleurs historiens chinois, les sciences et les arts doivent leur origine à Fou-Hi, Chen-Noung et Hoang-Ty, qui viennent immédiatement après et dans lè mème ordre. Le premier, ou Fout-Hi, surnommé le roi des bois, a tous les attributs dont Auubis jouit dans la théogonie des Egyptiens. Chen-Noung nous représente leur Ammon, et nous trouvons dans Hoang-Ty leur Apollon et leur Hercule.

Trois constellations, le dragon-volant, le rat et le cheval, sont observées, et deviennent les bases du zodiaque dont les peuples de l'Asie orientale font usage. On compose un cycle de soixante ans, avec deux divisions, $l^{2}$ une de dix, l'autre de douze. On invente une mesure linéaire ou un pied, que l'on partage en dix pouces, divisés chacun en dix lignes, et dont chacune est représentée par l'espace qu'occupe un grain de millet.

Chao-Hao, fils et successcur de Thang-Ty, recommandable par son esprit religieux, et sous lequel paroît un oiseau analogue au phénix (espèce de manucode), est le Thoth égyptien. Tchuan-Hiu, neveu ou petit-fils de Hoang-Ty, lui succède. Il règle le calendrier, fixe, d'une manière astronomique, le commencement de l'année, en prenant aussi pour point de départ le renouvellement de la nature, et fait des changemens dans la méthode d'observer et de calculer les mouvemens célestes; il invente mème des instrumens astronomiques. $11 \mathrm{y}$ cut sous son règne une conjonction remarquable de cinq planètes dans la constellation Clié. Il occupa le trône 78 ans, et mourut dans un âge très-avancé. 
D'après les rapprochemens que nous avons établis, nous croyons que ce souverain est le même que Noé. Si l'on prend pour terme de comparaison le milieu de la durée de la vie de l'un et de l'autre, la Genèse, en suivant le texte liébreu, et la chronologie chinoise, nous offriront à eet égard un synehronisme parfait.

Ty-Ko prend, du consentement unanime de tous les ordrés de l'Etat, les rênes de l'empire, et se montre digne de le gouverner. Il meurt âgé de $10 r$ ans; la trentedeuxième année du sixième eycle. Il avoit épousé quatre femmes; de chacune d'elles il avoit eu un fils. Ty-tehé, le dernier de ces enfans, lui succéda, mais il ne régna que huit ans, ayant été détrôné la quarantième aunée du même cyele.' Yao, le troisième de ses fils, devint empereur et le modèle des héritierș de sa puissanee. Toutes les années de sa vie sont employées à des travaux continucls. 11 aplanit des montagnes, perce des routes, construit des canaux, fait rentrer les rivières dans leurs lits; et le pays, auparavant inondé, est desséché et devient propre à la culture. Il règle les douze mois lunaires, et il établit des mois intercalaires, qui revenoient sept fois tous les dix-neuf ans. Chun, quoique de basse extraction, est déclaré par lui son unique héritier, à l'exclusion des princes du sang:

La Genèse nous montre aussi Aram, fils de Sem ou petit-fils de Noé, ayant quatre enfans : savoir, Us, Hul, Géther, Mas; et se tait sur les deseendans de ceux-ci. Aram seroit donc le Ty-ko des Chinois, ét dans Géther, troisième fils d'Aram, que l'historien Josèphe dit être le père des Bactriens, nous reconnoîtrions l'empereur Yao.

Au rapport d'Arrien, l'histoire des Indiens ne remon- 
toit pas au-delà de Bacchus ou Dionysus, qui, avant que de quittcr pays, leur avoit donné pour roi Spatemba, un de ses amis. A celui॰ci avoit succédé Budya, son fils, gui avoit pareillcment transmis l'empire à son fils Cradeva, et' cet ordre de succession s'étoit ensuite continué, de Bacchus à Sandrocotus. On comptoit 153 rois dans l'espace de 6042 ans. L'Hcrcule des Indiens étoit postérieur de quinze àges à Bacchus. Les Surasèncs lui rendoient un culte particulicr, et lc représentoient sous les mêmes formes quc les Thébains donnoient à lcur Hercule. Il avoit fondé, près du fleuvc Jobares, deux grandes villes, et il avoit donné à Pandéc, sa fillc unique, l'autorité suprême sur une contrée dc l'Inde, où elle étoit née, et qui avoit reçu d'elle le nom de Pandée, Pandcea.

Anquetil du Perron, dans scs recherches historiques et geographiques sur l'Inde, a réduit à une juste appréciation le nombre considérablc d'années que les Indiens supposoient s'être écoulées cntre Bacchus et Sandrocotus. Mais je suis bien éloigné d'admettre avec lui que Dionysus soit Brahma ou Vishnou, que Spartembas représentc le rajah Spart, ct d'adopter ses autres analogies. D'abord, à l'égard de l'Hercule indien, je pense qu'on a confondu avec lui deux personnages très-distincts; l'un, antérieur à Bacchus, est l'Hcrcule égyptien, celui auquel les Surasènes, pcut-être les mêmes quc les Syrangcs, peuple indo-scythe, devoient rendre un hommage religieux, comme étant un de lcurs ancêtres; l'autre, postérieur à Bacchus de quinzc âges, sera le conquérant Sésostris. Nous trouverons dans Athirte, sa fille, la Sémiramis des Babyloniens, et la reine Pandée ip peut-être 
même pourrions-nous y voir encore cette Zarine, reine des Saces, qui, selon Diodore, civilisa ces barbares.

Sésostris établit des colonies égyptiennes aux extrémités orientales de son empire. Les irruptions que faisoient souvent les peuples situés sur les bords l'Oxus, dans les parties méridionales de la Perse, ont pu déterminer ces colons à transporter leur domicile dans l'Inde, à passer ensuite dans les contrées plus crientales de l'Asie, et de proche en proche, jusqu'à la Chine. On croit qu'une de ces émigrations a eu lieu i 200 ans avant notre ère. Par là, et par ce que noùs avons dit précédemment, s'expliquent les rapports que l'on a trouvés entre certaines coutumes égypticnnes et celles de la Chine. Près de deux siècles auparavant, la race antique des Pandvans aroit cessé de régner dans l'Inde. Après tout, nous n'avons pas besoin de rechercher quels ont été ces rois qui, d'après Arrien, ont fondé la monarchie des Indous. M. Anquetil nous a fourni le moyen de supplêer à ces difficultés par son catalogue des rajahs de l'Inde, et par la détermination d'une ère célèbre dans les fastes de l'histoire de ce peuple, l'ère du kaliougam. Elle est selon les uns de 3093 ou 3 ro2 avant notre ère; elle remonte un peu plus haut, à 3 r 56 , selon d'autres. Màis une observation qu'on n'avoit pas encore faite : c'est que cette ère est commune aux anciéns péuples de l'Asic et à ceux auxquels ils l'ont communiquée; c'est la période de rgans, ou le cycle de Méton, autrement le nombre d'or, dont j'ai parlé à l'occasion de l'allégorie da phénix. Son institution date de la fin de l'Enoch de la Geinèse, le Thoth des Egypticns, l'Otiartès des Chaldéens et le Chao-Hao des Chinois. Elle détermine l'époque à laquelle Noé de- 
vint le chef unique de la grande famille caucasique. Les Chinois partageoient ce cycle en soixante parties, auxquelles ils domoient le nom d'années, et qui se fcomposoient chacune de 288 jours, ou de dix lunaisons synodiques, dont la durée étoit un pen moins de 29 jours (voyez plus bas); ce nombre de 6o, multiplié par ses différens facteurs, a fourni la plupart des grandes périodes fictives astronomiques.

Bhart, souche de la seconde race des Indiens, ou de la race Kethri, est l'Adam de la Gesèse ou l'Horus égyptien. Jabel, Jubal ct Tubalcaïn, fils de Lamech, sixième descendant d'Adam par Caïn, appartiennent, ainsi que nous l'avons vu, à toutes les anciennes théogonies ou à l'histoire des héros primitifs. Dans le catalogue des rajahs de l'Inde, un de ces trois fils, Tubal-Caïn peutêtre, paroît ici sous le nom de Kour, et commc huitième descendant de Bhart; il fonde une ville considérable, celle de Kourkehit, proche de Thansic, à l'ouest de Dehi; et ses enfans prennent aussi le nom de Kourvans. Le Kâboul forme donc leur habitation; et c'est là aussi que nous avons placé une partie de la race de Caïn. Celle de Seth est présentée dans le même catalogue sous la dénomination de Pandvans, mentionnée précédemment. Ces denx races se font perpétuellement la guerre; les Kourvans enfin sont totalement détruits, et l'ainé des Pandvans, Djadaschter, règne trente-six ans sur l'Inde entière. Il voit la fin de l'ère nommée douaparïougam et le commencement d'une autre, celle du kaliougam. Il quitte la couronne et lá remct à son petit neveu Paritschhat, fils d'Abhman, qui étoit fils d'Ardjen. Ses quatre frères et lui abandonnent Hastnapour, vont à l'est, parcourent le Bengale, 
le Dikan, le Guzarate, le pays de Tatta, le Moultan; et s'arrêtant dans les montagnes du Penjab, ils y mènent une vie pénitente, pour expier le crime qu'ils avoieut commis, en tuant leurs frères et leurs parens.

Paritschhat est le Noé de la Genèse. Ses enfans sont pris pour ses frèrcs, et, comme dans la théogonie de Sanchoniathon, on lui en donne un de plus. Le règne des Kourvans et des Pandvans est en tout de 125 ans; on voit ainsi que le nombre d'années qui, selon le texte hébreu, s'est écoulé entre Scth et la fin d'Énoch, est singulière. ment réduit.

Si l'on compare, à l'égard de la durée de la vie des premiers hommes, la Genèse avecles autres traditions analogucs, on trouvera d'énormes différcnces, ce qui ne peut dépendre que de la variété de l'estimation des années. Les plus longs règnes des premiers empereurs chinois ne dépassent pas 140 ans; cette durée diminue même assez brusquement dès qu'on arrive à l'époque où l'institution de la période de dix-neuf ans entraîna une réforme dans le calcndricr. Parmi les demi-dieux égyptiens, Sosus ou Noé, dont le règne est le plus long, n'a cependant occupé le trône que 32 ans. Dix-huit sares sont le maximum que Bérose assigne aux règnes ou à la vie des rois chaldéens antédiluviens.

Alsstraction faite de l'évaluation qu'il faut donner aux années dont l'auteur de la Genèse s'est servi, il est certain que quelques patriarches, en admettant même qu'ils aient été très-précoces, ont vécu fort long-temps, puisqu'Adam a vu, avant que de mourir, huit générations. On ne peut guères, d'après cela, lui refuser i 20 ou i 30 ans de vie. Le changement qui s'opéra dans la composition de l'année, par suite de l'établissement de cette 
période de 19 ans, est indiqué dans la Genèse. Dieu, peu de temps avant le déluge, déclara que la vie des hommes, en punition de leurs crimes, ne seroit désormais que de r 20 ans ( $\mathrm{I}$ ). Si rous prenons l'espace de six siècles comme terme moyen de la durée de la vie des premiers patriarches, et si nous supposons que cette durée fut toujours essentiellement la même, mais avec des différences dans les évaluations des années, chacune de ces années primitives, en la composant de 360 jours, sera réduite au cinquième, ou ne sera plus que de 72 jours, nombre qui est un des multiples des périodes chaldéennes et chinoises. Nous voyons par la Genèse que certains patriarches ont eu des enfans à l'àge de 65 ans; c'est le terme le plus bas ou le plus rapproché de l'époque de la virilité. Or les 65 ans, en les évaluant chacun à 72 jours, nous donnent juste 156 mois de 30 jours, ou 13 années.

En Perse, seloi Chardin, les filles sont déclarées nubiles à l'âge de neuf ans, et les garçons à treize ans et un jour, comme chez les Juifs; dans des affaires importantes, on émancipe même plus tôt les garçons. Pour mettre la durée des règnes ou celle des vies des demidieux égyptiens en harmonie avec notre calcul, les années égyptiennes auroient été, à cette époque, des périodes de quatre ans, ou de 50 lunaisons. (Voyez plus

(i) Le but des écrivains sacrés est de ramener tous les événemens à la Providence. Dans le temps où Esdras rassembloit les anciens monumens historiques des Hébreux, il a pu ignorer de quelle manière s'étoient formées leurs années primitives, et attribuer ces disproportions simplcinent apparentes des durées des vies des hommes, à une cause surnaturelle. Telle étoit peut-être aussi l'opinion générale, et à laquelle il s'est conformé. L'Ecriture nous fournit plusieurs autres exenples semblables. 
bas.) La composition des sares chaldéens a varié. Bérose les évalue à 3600 jours, assimilés à des annés, ce qui en feroit dix de 360 jours chacune, ou 125 révolutions lunaires synodiques, telles qu'on les estimoit dans les premiers tenıs.

Selon Suidas, le. sare est composé de 222 (ou plutôt 223 ) mois lunaires, qui font dix-huit ans et six mois. Fréret et Bailly, qui ont souvent parlé de cette période, n'ont point développé le principe de sa formation. Ce fut d'abord la période de I 9 ans; elle étoit censée comprendre 23 ᄀ révolutions lunaires synodiques et demie, chacune d'elles étant évaluée à 28 .jours et 19 heures, de sorte que deux de ces lunaisons et la moitié d'une composoient une petite période de 72 jours (I). Les

(I) Dix de ces périodes, ou 720 jours, en supposant que l'année n'en ait que 56o, eomposent 25 lunaisons; eent périodes feront 7200 jours ou 250 lunaisous, et ainsi de suite.

La période de 49 ans, ou de 7 multiplié par 7 , est établie sir la même basc ou de $612 \div$ lunaisons; donc celle de 490 ans est de 6, 125 lunaisons : si on la triple, on aura la période sothiaque, celle 1,470 ans, ou 1,461 , l'année étant de 365 jours $\frac{1}{4}$. Cette période, multipliée par 5o, composera un grand eyele de 2, 400 lunaisons, et quili ne faut pas eonfondre avee la révolution sidérale. Simorg, d'après le passage relatif au phénix, cité plus haut, avoit déjà trouvé le monde rempli sept fois de eréatures, et sept fois entièrement vide. Ces paroles font probablement allusion, soit à la période solhiaque, soit à une demi-révolution lunaire. La constellation du grand ehien ne se troure point sur le plus aneien zodiaque égyptien, eelui du grand temple d'Esné. On l'avoit néanmoins déjà observée; car clle fait prartie du zodiaque des peuples de l'Asie orientale, et ee signe y correspond au wois de novembre. Sirius se levoit alors peu de temps après le eoucher du soleil.

L'institution de la période solhiaque, chez les Egyptiens, paroit xcmonter à l'an $278_{4}^{\prime}$ avant Jésus-Christ, peu de temps après la fondation de Thèbes; elle fut'renouvelée l'an 1323 , ainsi qque ccla 
Chaldéens ayant ensuite observé que ces lunaisons étoient d'environ $\mathbf{z}$ heures plus longues, et que sur la période entière il y avoit un excédant d'erreur de six mois, ou d'un trente-huitième, retranchèrent cette quantité des 19 ans, et eurent ainsi un sare de 18 ans et six mois, qui répondoit astronomiquement au précédent.

Je pense donc que les sares employés par Bérose, dans sa liste des rois chaldéens antédiluviens, étoient composés de dix années de 360 jours. Ainsi la durée du règne d'Alorus ou d'Adam sera d'un siècle. Horus ou le premier des demi-dieux égyptiens, règne $\mathbf{2 5}$ ans selon Manéthon; si ces années sont, comme nous l'avons dit, des périodes quadriennales (1), la durée de son règne sera encore la même. Quelques uns de ces rois chaldéens vivent 18 sares ou 180 ans; or si nous réduisons les années de la vie des patriarches à $\eta_{2}$ jours, les longévités les plus grandes de ces patriarches différeront peu de l'estimation précédente. De cette manière, l'intervalle compris entre la création et le déluge ne seroit plus que d'environ trois siècles.

résulte d'un passage de Censorin. La manière dont est représentée la constellation dulion, sur le zodiaque du grand temple de Dendérah (la vierge tenant une hache à la main, comme pour couper la queue du lion), nous fait présumer qu'à l'époque de l'établissement de ce zodiaque, on changea l'ordre des mois. Leur année, à en juger d'après les coutumes des Hébreux, commençoit au 7 octobre, qui coincidoit avec la retraite des eaux du Nil. Le premier jour de l'année fut reporté, d'après la position du soleil dans le zodiaque, au 24 juillet, et probablement à l'époque ou la période sothiaque fut renouvelée.

(1) Pour se rapprocher davantage du calcul de la Genèse, corrigé d'après les bases que j'ai établies, il faudroit peut-être composer ces nériodes de cinq ans. 
D'après un calcul fondé sur la durée des règnes des anciens rajahs de l'Inde, l'ère du kaliougam eommenceroìt la première année du règne de Parischhat ou de Noé, l'an 3 i 56 avant notre ère. Le déluge ayant eu lieu lorsque ce patriarche avoit à peu près atteint les deux tiers de sa vie, l'époque de 3 ror, que les auteurs arabes et Anquetil donnent pour eelle de ee déluge, s'aecorderoit avee mes premiers ealeuls sur la eluronologie égyptienne. Ainsi l'origine eonnue de l'espèce humaine ne remonteroit guère au-delà de 5200 ans.

Les faits que j'ai eités prouvent que l'étude du eiel, la connoissance de plusieurs constellations zodiacales, et de quelques périodes astronomiques fondamentales, datent des premiers temps historiques; que les points équinoxiaux et solsticiaux de l'écliptique avoient été alors déterminés par la position de quelques étoiles de la première srandeur; que Fomalhaut, par exemple, ou la première du poisson austral, et que l'on réunissoit alors à Ja constellation du capricorne, dont l'observation ne peut être contestée et a été faite dans le sièele d'Adam, étort à eette éporque sous le colure des solstices, celui d'hiver. Je pourrois appuyer cette assertion par de nouveaux faits; ainsi le zodiaque des aneiens peuples du nord et de la jartie orientale de l'Asie eommenee par le signe de la souris ou du rat, qui répond à eelui, du eapricorne. C'est probablement pour retracer le même souvenir astronomique que les Parthes ont représenté sur un eôté de quelques unes de leur's médailles existantes eneore, le même signe. Nous sommes bien persuadés que eette observation céleste ne peut pas être eomparée a eelles que nos instrumens nous permettént aujourd'hni de prendre; et nous ne voulons pas aftrmer que Fomal- 
It se trouva rigoureusement sous le colure des solsss; il nous suffit de savoir qu'elle en étoit très-près, ı éloignement du point solsticial fût-il de quatre à cinq rrés. Mais dans la supposition qu'elle se trouvàt rigoussement en ce point, il faudroit remonter à 330 o avant re chrétienne. Il me paroît certain que le commenceent de la monarchie égyptienne est d'environ cinq scles et demi postérieur à cette époque; et comme dans on hypothèse, Sosus, l'avant-dernier demi-dieu égypən, est Noé, et que Zéus, son successeur, est Cham ou Jupiter des Egyptiens, il s'ensuit que Mesraïm ou [enès, un de ses enfans, sera postériou. à Noé de deux únérations, et que la mort de ce patriarche coïncidera resque avec la fondation de la monarchie égyptienne. 'ette chronologie s'éloigne peu de celle des Septante, aivie par la plupart des Pères de l'Eglise. C'est ainsi n'avec le secours de l'astronomie, nous sommes parvetus à établir une ligne de démarcation aussi précise que ossible entre l'histoire des temps postdiluviens et des ıges précédens.

Loin de reculer au-delà des limites de la chronologic la plus généralement admise les premiers temps historiques, je les rapproche bien au contraire de notre âge. La question que j'ai tâché d'approfondir, et dans l'examen de laquelle j'ai porté le caractère le plus impartial, n'a pour objet que l'origine des sociétés humaines. Elle est absolument étrangère à ces parties des sciences physiques et naturelles qui embrassent l'antiquité de la terre et la formation des êtres. Nous avons vu que la Genèse étoit la clef de l'histoire et de la mythologie. Tous les faits géologiques recueillis jusqu'à ce jour nous prouvent qu'en fonsidérant les jours de la création comme de grandes 
époques d'une durée indéterminée, le système cosmogonique de la Genèse est encore, de tous ceux qu'on a imaginés, le plus ingénieux et le plus vraisemblable. Des mêmes faits nous pouvons aussi conclure que la succession des êtres organisés, telle qu'elle nous la prćsente, est conforme à nos observations, et que l'espèce humaine est récente. Des trois principales races dont elle se compose, l'origine de l'une d'elles, celle des Nègres, semble être ccpendant hors de ligne, et l'on seroit presque tenté de se rejeter dans le système des préadamites. Si cette race n'est qu'une altération de la' race caucasique, quel long intervalle de siècles n'a-t-il pas fallu pour produire des différences d'organisation aussi remarquables que celles que l'on remarque entre elles? Les peintures des monumens de Thèbes, ville dont la fondation n'est postérieure que de cinq à six siècles à la civilisation, nous représentent les Nègres tels qu'ils sont aujourd'hui; et si l'on admet l'universalité du déluge, la difficulté sera encore plus grande, puisqu'on a à peine deux ou trois siècles pour rendre compte de ces changemens. Peut-être les anciens, comme le font quclques naturalistes modernes, considéroient-ils les nègres comme des étres intermédiaires entre l'homme et le singe. Les connoissances géographiques des premiers temps s'étendant à peine au midi jusqu'au tropique du capricorne, la dénomination d'éthiopien (I) ne s'appliquoit point au nègre proprement dit.

(x) Le pays des Div ou Dew des Persans est pour les Arabes celui de zeng ou des zinges, dénomination qu'ils ont ensuite étendue aux contrées qui sont au sud de l'Ethiopie, et qu'on a appliquée aux animaux appelés singes, parce que les premiers qu'on a connus sont veuus de ce pays. Les zinges on les habitans de la partic orientale et 
Quoique l'histoire des premiers âges de l'empire de Ja Chine, ou celle qui préeède la dynastie des Hia, nous paroisse venir de la même source que les autres traditions de la race caucasique, nous sommes eependant bien éloignés de confondre la race mongolique, dont les Chinois font partic, avee la précédente. Réussiroit-on à expliquer les différences d'organisation qui lẹs distinguent l'une de l'autre, on seroit arrèté par une difficulté non moins grande, eelle que préscutent les élémens primitifs et si dissemblables des langues de ees deux raees. Si nos rapprochemens, tant historiques que ehronologiques, sont vraisemblables, l'histoire particulière de la Chine perdra de son antiquité, et le commeneement de la première dynastie de ses sonverains, eelle des Hia, en supposant même qu'elle soit eertaine, ne datera guère que du vingt-troisième siècle avant l'ère vulgaire, ou du sièele de Sésostris et de Sémiramis; ear, selon les annales chinoises, $Y_{и}$ fonda la dynastie des Hía en 3205 . Or Chun, que l'on dit être son prédécesseur immédiat, n'est postérienr à T'chouan-Hiu, ou Tehuen-Hio, que de trois générations. Ce dernier souverain nous paroît être, ainsi que noụs l'avons dit plus haut, le Noé de la Genèse. Il étoit surnommé le père des eaux, et on lisoit autrefois dans le Chon-Ki, qu'il avoit été père de huit enfans, portant tous le nom de Caï : telle est aussi la dénomination commune des neuf rois de la seconde dynastie des anciens rois de Perse, et dont le dernier, Darab troisième, le Darius Codoman des historiens grees, fut vaincu par Alexandre. Quoi qu'il en soit de ees rapprochemens, le maritime de la Perse, ceux du Malân, étoient pour les Grecs des Indicns noirs. L'habaschad des Arabes, ou l'Ethiopie, confinoit, du côté de l'ouest, au pays des zinges. 
commencement du règne de Chủn est postérieur à la fin de Noé d'environ $9^{o}$ ans. L'histoire de la Chine nous offre dès-lors une lacune de près de sept siècles entre Chun et le premicr souverain de la dyuastie des Hia, dynastie sur la certitude de laquelle on a même élevé des doutes. Mais je pense qué les Chinois ont, de même que les Perses et les Tartares, vieilli leur histoire en l'incorporant avec celle de la Genèse, et qu'ils l'ont ornée dans le goût oriental. Le vide de faits que me présente l'histoire des deux premières dynasties chinoises, lcs beaux discours de morale qui rcmplacent cette nullité, un système chronologique aussi bien suivi, malgré les difficultés que semblent lui opposer le temps, les révolutions, ainsi qu'une écriture hiéroglyphique très-compliquée et sujette à des variations, ces durées de vie presque séculaires que l'on accorde à plusieurs de ces rois, font naître bien des soupçons, soit quant à l'authenticité de l'histoire de ces premières dynasties, soit quant à l'intelligence ou à la bonne foi de ceux qui en ont rédigé les matériaux. Les Tibetains ne font pas semonter leur origine au-delà d'un peu plus de treize siècles avant l'ère chrétienne, et leur premier roi est nême postérieur d'environ deux siècles.

Il y a lieu de présumer qu'une partie des descendans de Noé forma des établissemens dans les contrées qui avoisinent les sources de l'Indus et du Gange, et que, s'avauçant progressivement vers les parties orientales de l'Asie, elle aura transmis scs traditions et ses usages atx Chinois, qui les auront ensuite présentés comme un héritage de leurs ancêtres. L'analogie que l'on observe entre quelques coutumes de ce peuple et celles des Égyptiens, peut s'expliquer de cette manière. 
Il n'est pas d'ailleurs nécessaire de supposer que les Chinois aient reçu ces traditions d'un autre peuple, si l'on admet, comme il est infiniment probable, que leur première habitation fut plus rapprochée du centre commun de ces traditions, ou de la mère-patrie du genre humain. Peut-être même ce peuple, ainsi que les Tartares Mongoux, descendent-ils d'une branche de cette postérité de Caïn, nommée d'abord Heniochi, ensuite $S i n$, Since, et à laquelle on attribue précisément les premières déeouvertes dans les seiences et dans les arts. Le seeau de réprobation que Dieu imprima sur la face de Caïn, seroit-il plus spécialement l'emblème de ces traits qui caraetérisent la raee mongolique? Lcs Tibetains, plus oceidentaux, et qui, par leur physionomie, leurs mours et leur langage, tiennent des Persans et des Mongoux, seroicntils ces géans que l'Écriture nous représente eomme le produit de l'alliance des descendans masculins de Seth avee les filles les plus belles de la race caïnite?

Voilà des conjectures qu'amènent naturellement ees passages de la Genèse, et qui me paroissent bien se concilier avee les autres faits rapportés dans ee mémoire. S'il est vrai, ainsi que je l'ai dit, que Caïn soit le Mars des Égyptiens, ou leur demi-dieu Arès, nommé encore ainsi par les Chaldéens (Diod. de Sic., liv. 2.), les dénominations d'Arimaspi, d'Arimi, données à des peuples situés dans les montagnes au nord de l'Inde, celle d'Ahriman, sous laquelle les Perses désignoient le mauvais génie, ce Typhon ou Typhceus, relégué dans les antres du Caucase, toutes ces dénominations, dis-je, auront pour radical celle d'Arès ou Caïn. Les tableaux plus ou moins mêlés de fables que nous ont fait de divers 
peuples da nord de l'Asie; quelques historiens grees, ne conviennent qu'à des hordes de la race mongolique. Nous' rangerons avec elle les Anaréens (Camard, Singe) de '’olémée. Le nom de Satyre peut dériver du mot hébreu Srin; de là les Sères ou les Géans de la Genèse, les premiers habitans du Zabulistan et du Tibet ou ceux de la montagne de Caf ou de l'Imaüs, auront été transformés, par les anciens Perses, en démons, mauvais génies, géans, etc. D'eux descendent les Syranges de Ptolémée, ou les Atlantes de Diodore. J'ai soupçonué qu'ils avoient étendu leurs colonies jusqu'en Espagne. Des rapports que j’ai observés depuis, entre différens mots de la langue des Basques et celle du Tibet, et donit quelques uns se retrouvent en Afrique, me confirment, de plus en plus, dans cette idée. Suivant le père Georgi (Alphab. Tibet.) les docteurs du Tibet fixent l'an 210 o avant l'ère chrcéticnne, pour l'époque du déluge universel; c'est, à une quinzaine d'années près (2205), l'époque à laquelle $\mathrm{Yu}$ fonda la première dynastie des empereurs chinois, celle des $\mathrm{Hia}$; d'où il résulteroit que les souverains auxquels il a succédé, appartiennent à l'histoire des temps antédiluviens ( $\mathrm{r}$ ).

Les anciens Persans désignoient l'Être-Suprême sous

(x) Selon les annales chinoises, Cou-Kong, aieulde Ouen-Ouang, chef de la 'dynastie des Tcheon, qui succéda à celle des Chang, quitta, l'an r327, avant l'ère chrétienne, son pays de Pin, pour aller demeurer au pied du Ki-Chan, montagne à 50 lis vers l'ouest de Fong-Siang-Fou, dans le Chensi. Il y bâtit une ville, qui devint la capitale du pays. Ne seroit-il pas le Prasrinpo ou le Prasriumo des Tibétains, celui qui les civilisa? Et leur premier roi, GuiaThritz, ne seroit-il pas le fondateur de la dynastie des Tchcon? J'ai tout lieu de le présumer. 
les noms d'Yezad, d'Izad, d'Izud, d'Ormuzd, Hormuz et d'Hormizda. De là dérivent ceux de Zeus (I), de Deus et d'Horus. Peut-être désigna-t-on les dcscendans d'Adam, par la ligne Seth, ceux que l'Écriture appelle fils de Dieu, sous les dénominations d'Orosman, Orosmasdes ou Oromasides. Une partie de cette race caucasique pure, et formant une branclue de la postérité d'Aram, fils de Sem, continua d'occuper, après la dispersion de cette race, sa terre natale, ou s'étendit dans l'Asie supérieure; tels sont les Scythes, nommés d'abord Araméens, ensuite Saces, et qui fondèrent l'empire des Perscs, et ceux des Parthes et de l'Inde, en deçà du Gange. Les Tibetains et les Sères s'établirent encore dans cette dernière partie de l'Asie, ainsi que dans les contrées au-delà du Gange (2).

(1) Le nom de Dionysius peut être formé des mots Dieu et Nysa on Dieu de Nysa. Yses (Josèphe) signifioit en égyptien, préservé; ce seroit aussi Dieu sauvé; enfin, ionah est en hébreu le nom de la colombe.

(2) J'ajouterai à ce que je viens de dire quelques observations sur les premiers temps historiques des Chaldéens, des Babyloniens, des Assyriens et des Perses. On a vu par le tableau comparatif des principales théogonies, les rapports de celle des premiers, ou de leurs dix rois anté-diluviens, avec les autres théogonies, ct l'identité d'origine des unes et des autres. Le Nermrod ou Nembrod del'Ecriture, le même que l'Évéchoos d'Eusèbe, fonde, peu de siècles après le déluge, l'empire de Babylone ou de Chaldée. Six autres rois lui suecèdent et forment avec lui une dynastie qui a duré $22 f$ ans. Les Arabes s'emparent ensuite de ce royaume et lui donnent six souverains, jusqu'à Bélus, roi d'Assyrie, qui le fait passer sous sa dömination. Cette seeonde dynastie dure 216 ans, et remplit avec la précédente un intervalle de temps de 440 années. Bélus nous paroît être le même que Sésostris, roi d'Égypte, et le mêne encore que le Sistosichermes du Canon des rois de Thèbes, d'Eratoșthène. Si nous suivons cet auteur, et que nous rétrogra- 
dions de treize générations, Évéchoos ou Évéchoüs répondra positivement à Apappus-le-Grand, ou l'Osimandué de Diodore de Sicile, que cet historien nous présente comme un des plus grands rois qui ont gouvernél'Égypte. Il vivoit selon moi (Chronol. Egytt.) environ 26 siècles avant l'èrc chrétienne; or, plusieurs chronologistes avoient déjà placé à la même époque le règnc d'Évéchoüs et celui de Nemrod. Elle est postérieure d'environ deux siècles et demi à ee Busiris (Cham ou Salurue) que Diodore de Sicile dit être le huitic̀me de sa race, et qui bâtit la grande ville de Diospolis ou de Thèbes. Dans la personne de Darius, roi des Perses, défait par Alexandre, s'étcignit la seconde dynastie de leurs rois, eelle des Caïanides ou Kćaniens (géant, en Pehlvi, fils de la terre), composéc de neuf souverains, dont le premier fut Ke Kobâd ou Caicobad, et auquel succéda Ké Kaoûs (Caikaus d'Herb.). L'listoire de celui-ci ne peut convenir qu'à Cyrus. On le disoit fils ou petit-fils de son prédéccsseur; le premier est donc Cambyse ou plutôt Astyages, roi des Mc̀des. La dynastie antérieure, celle des Peischdâdiens, composée de neuf rois, a duré 2451 ans. Elle est en grande partie anté-diluvienne. Kaïomorts ou Caïoumarrhat, est le premier roi et représente Adam après sa elıute. Tahamurath ou plutôt Tehmourets, Sapidvar et Kharéh, appelé la lumière de Tchin (Voy. Fou-Hi), sont trois frères, et dans lesquels nous retrouvons l'Hereule, l'Ammon et l'Apollon des Egyptiens. Djcms shid, célèbre par une ère astronomique, nous rcproduit le Thoth de ce même peuple. Féridoun, père de trois enfans, entre lesquels it partage la terre, devient Noé. Minotcher, son petit-fils, est le le même que Mesraïm ou Menès. Son treizième descendant est le second Zoroastre (le troisi c̀me est le prophètc Daniel) ou le grand Sésostris. On distingua d'abord les signes suivans du zodiaque, le bélier, le taureau, les gemeaus, puis la balancc, cusuite le lion, l'épi et le scorpion, constellations qui paroissent $\mathrm{cn}$ hiver. C'est sous Féridoun qu'on observa celle du scorpion, ct nous pouvons dès lors présumer qu'elle étoit voisine de l'équinoxe d'automne. Je ne sais si par le mot d'arc, qui parut sous Féridoun, on a voulu désigner le sagittaire ou l'arc-en-ciel. 


\section{DISSERTATION}

SUR L'EXPÉDITION

\section{DU CONSUL SUÉTONE PAULIN \\ EN AFRIQUE,}

Et sur diverses parties de la Géographie ancienne de cette contrée.

Plusieurs savarus avoient déjà pensć qu'il falloit restreindre lcs idées généralement reçues sur l'étendue des connoissances géographiques des ancicns, relativement surtout à l'Afrique. Mais leur opinion, quoique bien motivée, n'a eu encore pour elle qu'un petit nombre de partisans. L'auteur (M. Dureau de la Malle) d'un ouvrage très-recommandable par l'abondance des recherches, et les idées ingénicuses qu'il renferme, la Géographie physique de la mer Noire, de l'intérieur de l'Afrique et de la Méditerranée, semble même à cet égard prêter aux anciens plus de lumières qu'on nc leur en avoit accordé. Je ne mc propose pas ici de chcrcher à résoudre une difficulté d'un sujet aussi vaste, et qui effraieroit le géographe le plus consommé. C'est au célèbre M. Gossclin, dont les études se dirigent plus particulièrcment sur cct objet de controverse, qu'il est réservé de fixer nos incertitudes dans une matière scientifique aussi épineuse, et de nous indiquer les points où s'arrêtent les tra- 
ditions géographiques des Grecs et des Romains. Le consul romain Suétone Paulin s'est-il avancé, dans son expédition d'Afrique, jusqu'au Niger des modernes, comme on le prétend dans l'ouvrage que je viens de citer, p. I I o ? Quel étoit le fleuve Niger de Pline? Tels sont les deux points que je soumettrai à la discussion. Si je n'adopte pas le sentiment le plus accrédité, ce n'est point par un esprit de système. J'ai toujours été, et je serai toute ma vie pénétré d'une profonde vénération pour nos maîtres dans les sciences, ceux qui nous frayèrent la carrière avec tant de pénibles efforts. Je sais que de nos jours on oublie trop communément la justice et la reconnoissance qu'on leur doit; que, pour aspirer à la renommée, l'on fronde les autorités les plus respectables. Abandonnons ces hommes téméraires 2 t ingrats à la vengeance de la postérité.

Les réflexions que je vais présenter sont en quelque sorte des doutes dont je demande l'éclaircissement. Je les propose, parce que je suis convaincu qu'ils sont fondés. Si je me trompe, j'aurai du moins contribué à raffermir l'opinion générale, ¿̇ lui acquérir par mon opposition quelque nouveau degré de certitude, et mes écarts même seront avantageux à la science (1).

(I) J'ai vu, avec une extrême satisfaction, que dans un précis de géographie ancienne, terminant l'Abrégé de géographie moderne de MiM. Pinkérton et Walckenaer, édition de 181 I M. Barbié du Bocage avoit adopté mon sentiment. Le suffrage de ce savant est la plus douce récompense de mon travail. 


\section{PREMIERE PARTIE.}

De l'expédition du consul Suctone Paulin en Afrique.

Pline l'ancien nous a donné quelques renseignemens sur les conquêtes du consul Suétone Paulin en Afrique; maisce qu'il nous en rapporte, nous autorise-t-il à croire que ce général romain a pénétré jusqu'au Niger ou Joliba, ou plutôt, comme on le suppose, jusque dans les pays situés entre les sources du fleuve du Sénégal, de celui de la Gambie, et de la rivière Joliba': c'est ce que nous allons examiner.

Lorsque je réfléchis aux difficultés qu'ont à vaincre pour traverser l'immense désert de Sahara de simples caravanes, formées des naturels du pays, instruits des localités, accoutumés par une longue habitude à supporter les chaleurs excessives de ces climats et les privations les plus fortes, j'éprouve, je l'avoue, une grande répugnance à me persuader qu'une armée, ou du moins un corps de troupes assez considérable, ait pu, même avec de bons guides, franchir tant d'obstacles, et mon imagination effrayée réclame, pour se rassurer, des autorités bien positives. Je me dis encore : comment les Romains, si jaloux de leur gloire, n'ont-ils pas laissé à la postérité des monumens historiques qui perpétuassent le souvenir d'une expédition si propre à les illustrer? Je consulte presque vainement leurs annales; Pline est le seul qui m'éclaire à cet égard : traduisons littéralement son. passage.

"Suétone Paulin, que nous avons vu consul, est le " premier des généraux romains qui se soit avancé au- 
") dclà de l'Atlas de quelques mille pas, aliquot millium

" spatio. Ce qu'il raconte de la hauteur de cette mon" tagne ne diffère point des autres récits. Il nous dit que " ses racines sont chargées d'épaisses et hautes forêts, " et d'arbres inconnus; que ces arbres sont remarquables " par leur élévation, leur écorce unie et sans nouds; " que leurs feuilles ressemblent à celles du cyprès, et " par leur figure et par une odeur forte; qu'elles sont " couvertes d'un duvet très-fin que l'on pourroit em" ployer pour les vêtemens comme le Bombyx. Il nous " a appris que la cime de cette montagne est couverte, " même pendant l'été, d'épaisses couches de neige; qu'il " y parvint au dixième campement, qu'il passa ontre, n et se porta jusqu'au fleuve appelé Niger, à travers " des solitudes d'une poussière noire, où s'élèvent par " intervalles des pointes de rochers qui sont comme "brûlés ( 1 ); que ces lieux, à raison de la chaleur, sont " inhabitables, même dans l'hiver, ainsi qu'on l'a " éprouvé. "'Hist. nat., livre 5, chap. I.

Il est facile de présumer que le principal fondeneut de l'opinion où l'on nous donne le Joliba ou le Niger des modernes pour le Niger de Pline, repose sur une identité de noms : d'abord on lit dans quelques manuscrits de cet auteur Ger au lieu de Niger; mais ensuite ignore-t-on que de semblables conformités nominales ont donné lieu en géographie à plusieurs fausses applications. $\Lambda$ la rigueur, si Pline n'étoit entré dans aucun détail sur la marche du consul Suétone Paulin, s’il se fût borné à nous dire qu'il vint jusqu'au fleuve Niger, l'in-

(I) Léon l'Africain nous apprend que le château d'Ummhelhefen, près de Segelmessa, a ses murailles construites avec des picrres si noires, qu'clles resscmblent à du charbon. 
duction tirée de cette ressemblance de noms offriroit, au premier aperȩu, quelque chose de spéeieux. Mais la narration de cet historien écarte même cette conjeeture.

Le général romain n'atteint l'Atlas qu'au dixième campement, et il paroît presque aussitôt sur les bords du $\mathrm{Ni}$ ger; si ce Niger est le Joliba, Suétone Paulin aura traversé deux fois la Libye intérieure ou l'Éthiopie occidentale, c'est-à-dire, qu'il aura franchi avee ses soldats, en bravant une foule de périls de toute espèce, le plus affreux et le plus vaste désert eonnu, dont l'extrémité méridionale, confinant au Niger, est éloignée de l'Atlas d'environ 450 lieues, sans que Pline, qui travailloit sur les mémoires de ee chef d'armée, et qui nous rend compte du nombre de ses campemens, ne nous ait instruit en aucune manière de l'entreprise la plus étonnante et la plus mémorable de son expédition, entreprise unique dans l'histoire.

Ce silenee paroîtı très-naturel, si le général romain n'a point traversé le désert de Sahara, et si dès lors son expédition rentre dans la série des faits ordinaires. $\mathrm{Or}$ la négative est démontrée par ees paroles de Pline, si formelles et si décisives : "Suétone Paulin est le premier " des généraux romains qui se soit avancé au-delà de "l'Atlas de quelques mille pas, aliquot millium spatio. " Voilà les bornes de ses conquêtes et de sa eourse, quelques mille pas au-delà de l'Atlas; donnez au sens de ce passage de Pline la plus grande extension dont il soit susceptible, vous ne pourrez pas supposer que le eonsul romain ait dépassé de plus d'une vingtaine ou d'une trentaine de lieues eette chaîne de montagnes, et nous serons eneore bien loin du Niger; nous ne toucherons même pas encore aux limites septentrionales du désert de Saharaa 
Reprenons le texte de Pline; tous les faits se lient entre eux et se soutiennent mutuellement. "Les bois les plus " proches (des solitudes de l'Atlas), et qui sont remplis "d'éléphans, de bêtes féroces et de serpens de toute " eśpèce, servent d'habitation à un peuple nommé Ca"nariens, Canarii, parce qu'il se nourrit de la chair " de cet animal et des entrailles des bêtes sauvages. Il ") est assez constant que cette nation confine à celle des "Éthiopiens, qu'on appelle Pérorses, Perorsi. " (Pline, ibidem.)

Comme cés peuples étoient sur les confins des pays ou pénétra le consul romain, tâchons, d'après Pline luimême, de connoître leurs positions géographiques; cette sétermination nous mènera à l'autre, et les contrées qu'arrose le $\mathrm{Niger}$ de Pline, ne seront plus désormais ignorées. Si je viens à prouver que les Canariens et les Pérorses occupoient des contrées situées entre l'Atlas et le grand désert, le Niger de Pline, coulant dans le voisinage, ne pourra plus être le Niger des modernes ou le Joliba.

En terminant son exposition sommaire de la navigation de Polype (liv. V, chap. ı $^{\text {er }}$ ), Pline observe que tous les autres écrivains s'accordent à placer l'Atlas sur les limites (méridionales) de la Mauritanie. Il puise dans le même historien la connoissance des différens peuples de cette province, et de ceux avec lesquels ils confinoient au midi. Les Éthiopiens Pérorses (I) viennent immédiatement après le fleuve Salsus. A leur dos sont les Pharusiens, Pharusii, ou les Phaurusiens de Ptolémée,

(1) Ce mot est, suivant des auteurs, moins un nom propre qu'une épithète, venant du verbc perordiri; de tous les peuples de l'Ethiopie, celui-ci étant le plus voisin de l'Europe, et $\rfloor_{e}$ premier des Ethiopiens à partir de la Mauritanic. 
contigus, d'un côté, aux Gétules Dares, Gatuli Darce, situés dans l'intérieur des terres, et d'un autre côté, ou vers les bords de l'Océan, avec les Éthiopiens Daratites, Ethiope Daratitce, chez lesquels eoule le fleuve Bambotus, rempli de crocodiles et d'hippopotames.

Discourant sur l'Éthiopie, chapitre huitième du même livre, il reproduit encore les Pérorses. \& Quant au cir" cuit intérieur de l'Afrique, et vers le midi, par-delà " les déserts qui les séparent des Gétules, les premiers " habitans que l'on rencontre sont les Liby-Égyptiens, "Liby-Egyptii; suivent les Éthiopiens blancs, Leu" cathiopes. Au-dessus d'eux, sont des nations éthio" piennes; les Nigrites, Nigritae, ainsi nommés de leur " fleuve (Niger); les Gymnètes, Gymnetes; les Pha"ruses, Pharusi; ct près de l'Océan, Oceanum attin" gentes, les Pérorses, Perorsi, que nous avons dit être " sur les confins de la Mauritanie. "Il redonne encore aux Pérorses la même position dans le chapitre trentième du sixième livre.

Il est donc certain que ces Pérorses, de même que les Canariens situés dans leur voisinage, ainsi que les Pharuses et les Nigrites, possédoient au sud des contrées adjacentes à l'Atlas ou à la Maûritanie, ou qui en étoient peu éloignées. C'est donc dans ces régions qu'il faut placer le Niger de Pline.

Strabon, au livre dix-septième de sa géographie, article Mauritanie, nous donne quelques moyens pour déterminer la situation des Pharusiens ou Pharuses, et des Nigrites ou Nigrc̀tcs. Il nous dit que ces peuples détruisirent les établissemens et un grand nombre de cités fondés par les Phéniciens dans cette partie de l'Afrique. Tinga, Tinga, petite ville peu distante du promontoire 
Cotes ou cap spartel, ville qu'Artémidore nomme Linga, et Ératosthènc, Lixus, étoit, d'après les rapports, à trente jours de marche des Nigritcs. Nous pouvons supposer, et c'est l'opinion commune, que Tinga répond à Tanger, ou du moins qu'elle étoit peu éloignée de l'emplacement qu'occupe cette ville moderne. Évaluons à sept lieues communes de Francc l'espacc moyen parcouru par jour ; les trente journées de chemin, pour aller de Tinga au pays des Nigrites, feront 2 I o lieues; réduisons cettequantité d'un cinquième, pour rapporter la courbe itinéraire à une ligne droite ou presque droite, nous aurons 168 licucs ou six degrés et environ 45 minutes d'un grand. degré du cercle. Tanger étant, à très-pcu de chose près, au $35^{\text {e }}$ degré 47 minutes latitude nord, si les Nigritcs étoient sous le même méridien, on lcs placcroit donc au $29^{\text {e }}$ degré 2 minutes, ou dans le Darah ou Dras; mais comme, suivant Prolémée, et Pline l'insinuant d'ailleurs par l'ordre qu'il met dans l'énumération des raccs éthiopiennes limitrophes de la Mauritanie, les Nigrites devoient être un peu plus reculés vers lc Lcvant, cette latitude scra un peu plus sep tcntrionale. Il s'ensuivra quc les Pharuses, plus occidentaux et plus méridionaux, et que Strabou fait contigus aux Nigritcs, auront habité le pays que nous eussions donné à ces dernicrs s'ils cussent été sous le méridien de Tanger; c'est-à-dịrc, qu'ils auront dû occuper le Darah méridional, ou s'étcndre un peu plus bas, vcrs cette partie du désert qui avoisine lcs Monselmines. Les Nigrites remonteront plus au nord, ou vers le pays des Dattes (I). C'est là effectivement que coule

(1) La position que leur assigne Ptolémée nous paroît répondre à cette portion méridionale du royaume d'Alger, qu'ou nomme lc. Wadréag. ( Voyez plus bas.) 
le Niger ou le Nigir de Ptolémée, d'où ce peuple a pris son nom. Les Pérorses ayant à leur dos les Pharuses, et se rapprochant des bords de l'Océan, nous les trouverons dans cette partie limitrophe du grand désert qu'occupe la tribu de Beni Sabi. On ne peut déterminer d'une manière précise la position des Canariens; mais l'on sait par Pline qu'ils devoient être près des Pérorses. Les traits de conformité qu'ils avoient avec les Labitans de l'ile Canarie, Canaria, leur aura valu la même dénomination. Ce géographe (liv. VI, chap. 32) dit formellement que cette île avoit été ainsi appelée de la multitude des chiens extrêmement grands que l'on y voyoit. Shaw, dans son voyage en Barbarie et au Levant (tome I, page 168 ), rapporte que les habitans du district de Zaab mangent encore les chiens, tout comme faisoient les anciens Canarii, leurs prédécesseurs; usage qu'avoient aussi les Carthaginois. L'auteur de la géographie physique de la mer Noire, etc., place les Pérorses sur les côtes de l'Océan, au-delà de la Gambie et près de la Guinée.

A tant de preuves qui réfutent l'opinion de l'identité du Niger de Pline et du Niger des modernes, j'en ajouterai encore d'autres que me fournit cet historien. " $\mathrm{Le}$ ) sentiment le plus vrai est celui qui sépare les deux "Éthiopies, en mettant entre elles les déserts de l'Afri") que. Ce sentiment étoit celui d'Homère, qui, le premier ") des écrivains, divisa les Éthiopiens en deux, les orien"taux et les occidentaux. "(Liv. $V$, chap. 8.) Dans Ptolémée, ces divisions répondent : l'une, ou l'Éthiopie orientale, à l'Éthiopie sous l'Égypte ; l'autre, ou l'Éthiopie occidentale, à la Libye intérieure. Pline (Livre $V$, chap. 4) voulant faire connoître les peuples et les cités les plus remarquables de l'Afrique propre, et fixer les 
limites de cette province, y comprend toute la Gétulie, jusqu'au fleuve Niger, qui divise, dit-il, l'Afrique de l'Ethiopie (la partie occidentale). Les Gétules s'étendoient au-dessous de la chaîne de l'Atlas, au midi de la Mauritanie et de la Numidie, jusqu'aux Garamantes. C'est donc sur les confins de leurs possessions et de la partie septentrionale du Sahara que rouloit ses eaux le Niger, puisque son cours servoit de bornes naturelles à la Gétulie et à l'Éthiopie occidentale ou la Libye intérieure: ainsi, nous le chercherions inutilement ailleurs que dans le Biledulgérid, qui correspond à l'ancienne Gétulie.

Dansle chapitre qui concerne l'Éthiopie (liv. $V, c h .8$ ), Pline nous offre quelques particularités sur le Niger. Sa nature est la même que celle du Nil. On y trouve également le calamus et le papyrus. Ses animaux sont aussi les mêmes, et ses crues ont lieu à des époques pareilles. Il prend sa source entre les Éthiopiens Taréléens, $T a$ relei, et les Éthiopiens OEcalices, OEcalica. Quelques uns placent Mavis, ville de ces derniers, dans des solitudes, et auprès d'eux les Atlantes, Atlanta. Par le chapitre $30^{e}$ du livre $6^{e}$, on voit que les OEcalices habitoient le désert, et qu'ils n'étoient pas éloignés des Pharuses, puisqu'ils n'en étoient séparés que par la distance de cinq jours de marche, suivant Dalion, auteur dont les Mémoires ont servi à l'historien latin. Ce passage, sans être très-précis, nous fait cependant entendre que le Niger venoit des contrées occidentales rapprochées de l'Atlas. C'est aussi de la Mauritanie inférieure, ainsi que je l'exposerai bientôt et plus au long, que Pline fait sortir le Nil ; d'où nous concluerons ensuite que c'est encore son Niger présenté sous une dénomination différente.

Les rapports que l'on observe, soit pour les produc- 


\section{EN AFRIQUE.}

tions naturelles, soit pour les inondations, entre le $\mathrm{Niger}$ et le Nil, ne prouvent rien en faveur de ceux qui croient reconnoître le $\mathrm{Niger}$ de Pline dans le Joliba ou le Niger de notre temps. Strabon (liv. $I^{\mathrm{e}}$ ) avance, d'après une opinion commune, que le Nil et les fleuves de la Mauritanie se ressemblent à cet égard. Ise Me-Jerdah, ou le Bagradas des anciens, a, au rápport de Shaw ( $\dot{V}_{\text {oy }}$ en Barb. tom. 1, pag. I84), les propriétés du Nil.

Voilà plus d'autorités et plus de raisonnemens qu'il n'en est besoin pour nous convaincre, $\mathrm{I}^{\circ}$. que le Niger de Pline étoit au nord de l'Afrique, entre l'Atlas et la Libye intérieure ou le grand désert; $2^{\circ}$. que le consul Suétone Paulin n'a point étendu ses conquêtes jusqu'au Niger des modernes. La mémoire de son expédition semble mème s'ètre conservée dans ces parties septentrionales de l'Afrique. "Quelques historiens rapportent, dit "Léon, dans son livre sixième de la description de l'A" frique, qu'un général romain étant parti avec son armée n de la Mauritanie, s'empara de toute la Numidie; que " puis eufin, s'avançant au couchant, il bâtit une ville ») qu'il nomma Sigillumessa, comme étant sur les con" fins du territoire de Messa, et le sceau ou le terme " de ses victoires. Par une corruption de noms, cette " ville a commencé d'être appelée Segelmessa. " Or, c'est précisément dans ce canton que devoit être le Niger. Les données que nous avons ainsi acquises sur les positions de quelques anciens peuples limitrophes de la Mauritanie peuvent nous conduire, par une suite de rapports, à la détermination de quelques autres peuples et de quelques rivières ou fleuves de cette côte de l'Afrique.

Si, prenant Ptolémée pour guide, nous suivons cette côte, en allant du nord au sud, nous aboutirons aux plages 
qui avoisinent le eap Bojador. Tel est le terme des connoissances géographiques des Anciens, dans cette partie occidentale du monde aneien; tel a été aussi long-temps le nôtre. Les mêmes difficultés qui nous ont arrêté pendant tant de siècles, ont dû, à plus forte raison, opposer une barrière à la témérité des premiers navigateurs, et fixer aussi leurs eourses maritimes, puisqu'ils avoient été moins favorisés par une longue expérience, et qu'ils étoicnt privés des secours que l'astronomie et la physique ont fourni à la marine moderne. Si le cap Bojador détermine, pour eette partie de l'Afrique, les limites de leur navigation, il s'ensuit qu'ils ne se sont point avaneés, en allant vers l'équateur, au-delà du ${ }_{2} 6^{\text {e }}$ degré de latitude nord; et Ptolémée eependant prolonge cette côte jusqu'à ro degrés au-delà de la ligne équinoxiale. Selon M. Gosselin, le géographe gree auroit formé eette côte de trois itinéraires mis au bout l'un de l'autre, de sorte que les mêmes objets seroient reproduits trois fois dans sa carte. Mais eette erreur a d'autres sourees et plus naturelles, comme : la difficulté de réduire des mesures nautiques, souvent inexactes, ou d'une estime purement approximative, recueillies le long d'une côte très-sinueuse; et les fausses données qu'avojt Ptolémée sur son. gisement, et quilui ont fait diriger presque entièrement cette côte sous le même méridien, tandis qu'clle s'avance beaucoup vers l'ouest. Il est résulté de là qu'une partie de la longueur de cette courbe a été reportée au sud. Il suffit de jeter un coup-d'oeil sur la earte de l'Afrique, construite d'après la graduation de ee géographe, pour se convainere que telle est en partie l'origine des défauts qu'elle présente. La partie orientale, ainsi que généralement toutes les contrćes dont les Grecs et les Romains 
ont été possesseurs ayant été mieux connues que la partie occidentale, il étoit difficile de les bien accorder. Il en est de même, à plus forte raison, des pays compris entre l'Atlas et l'équateur. Cette lacune immense, formée par le Sahara, paroît avoir été inconnue à ce géographe, puisqu'il rapproche les peuplades du nord du grand désert, de celles qui sont situées sur sa lisière méridionale, le long du Joliba.

Nous prendrons pour point de départ le petit Atlas, Atlas minor, de ce géographe, et c'est là, en effet, que commencent les plus grandes difficultés. Un simple tableau comparatif des dénominations anciennes et modernes de quelques lieux principaux, suffira pour le but que nous nous sommes proposés d'atteindre.

Subur, fluv. - La rivière Subu.

SALA , fluv. - Le Bunasar.

Dưs, fluv. - Le Buragrag.

ATLAS MINOR, mons. - La branche de l'Atlas qui s'étend depuis l'embouchure de la rivière précédente et enviroune, à l'est, le bassin des quatre suivantes.

Cuss, fluv. - Le Guir.

Asalis, Diur, fluv. - Rivières de la province de Temecena, royaume de $\mathrm{Fez}$; voyez la carte des côtes de Barbarie, 1816 , chez Collin.

Pнснеті , fluv. - La rivière Morbèse, mais dont l'embouchure est confondue avec celle d'une autre rivière, située entre les précédentes et Azamor, Herculis promontorium.

USADIUM, prom. - Cap Blanc.

$\mathrm{U}_{\mathrm{NA}}, f_{u v}$ - - Inconnue; mais la ville de Vala, placée sur elle, paroît répondre à Voladia, ville de la province de Dukela.

AGra, fluv. - Le Gir, passant près d'Aguz et déchargeant ses eaux dans l'Océan, près de Safi.

Cerive, insula. - Isle Duquela.

SALA, fluv. - Le Tensiff. 
Atlas Major, mons. - Mont de Fer, chaîne de l'Atlas.

Subus, fluv. - Rivière partant près de Tednest, et débouchant près de Sidi Mustapha. Entre elle et le grand Atlas étoient placés les Autolates, Autolata, et les Phorusiens, Phorusii; les premiers occupoicnt les bords de la mer et avoient les seconds au Levant.

Junonis, insula ou Actoloa. - Isle de Mogador.

Salathus, fluv. - Le Savensio.

Salathus, ville. - Héla, près de Mogador ou Soira.

Chusarus, fluv. - Rivière de Tegsedell. Entre elle et la précédente sont placés les Siranges, Sirangae, ou les Guanches.

Gannaria fxtrema. - Tamaïa ou Tamara, près du cap Ger.

OpHodus, fluv. - La rivièrc de Sus, sur laquelle est Tarodant, Tagana.

BAGAZI, ville. - Alganziza?

Nuius, fluv. - Petite rivière débouchant près de Samola?

Massa, fluv. - Rivière de Maça.

Darades, fluv. - Le Bambotus de Polype, rivière dont l'embouchure est près d'Alcangar.

Magnus portus. - Suanée?

Arsinarium, prom. - Cap Noon ou de Nun.

STAchir, fluv. - Rivière de Nun.

Ubrix, ville. - Soke Assa.

Jåziтна, ville. - Akka.

Ptolémée paroît avoir prolongé intérieurement la rivière de Nun, ainsi que la précédente, au moyen de l'Ouad Darah, qui vient dc l'Atlas et se perd sur les confins du grand désert, en formant un lac ; c'est aux environs de ce lac que ce géographe met les Pharusiens. Les Darades habitoient les bords de l'Océan. Les Zalmasiens, Zalmasii, les Daphnites, Daphnitae, et les Salathes, Salathi, occupoient la partie orientale du royaume dc Maroc, depuis la contrée de Guzzula jusqu'à celle de Tedles inclusivement. Ici sont placés le Nigrites Palus du même géograplıe, et les deux branches occidentales de son fleuve Nigir. Sur une route qui conduit d'Akka (Jarzitha ) à la ville de Fez, en passant par Tagavost, Tarodan, Tenès, Fraga, Hascara (Tucaba?) paroissent se trouver les villes de Thubce, de Punse, de Ptolénée, et qu'il met sur les bords du Nigir. 
Nis, fluv. - Rivière près du fort Laba. Les Ethiopiens blancs, Leuccethiopes, en occupoient les rives.

Hesperi Corvu. - Cap Suby.

Massitholds, fluv. - Rivière Boca. Les montagnes d'où elle naît sont le Char des Dieux, Deorum Currus, mons. Les Pérorses, Perorsi, étoient situés derrière. C'est le pays qu'occupent aujourd'hui les Arabes Beni Sabi. Des Ethiopiens ichtyophages habitoient le lọng du reste de la côte, jusqu'aux environs du cap Bojador. On y voit aujourd'hui les Arabes nommés Hilit. Les montagnes Noires, appelées par d'autres les Monts d'Or, pan roissent représenter celles que Ptolémée place en cette partie; et qu'il désigne sous les noms de Dauchis et d'Ion.

Dans les considérations géographiques et accessoires que je viens d'exposer, qu'on ne voie, j'en supplie mes lecteurs, que des conjectures auxquelles mon sujet m'amenoit. Les notions que nous puisons, dans les Anciens, à l'égard de ces peuples de l'Afrique, sont si imparfaites et souvent si discordantes, que d'Anville lui-mème, avec toute sa pénétration et toute sa sagacité, n'auroit peut-être pu ici rien asseoir de positif. D'ailleurs, les guerres que ces nations se sont faites dans tous les temps, ont dû entraîner dans leurs positions des changemens continuels. Il faudroit presque une géographie pour chaque siècle.

Maintenant que faut-il entendre par le $\mathrm{Niger}$ de Pline? Voilà l'objet de la discussion que nous allons établir dans cette seconde partie.

\section{SECONDE PARTIE.}

Du fleuve Nigen de Pline, ou du Nigrn de Ptolëmée.

Nous ne pouvons refuser aux Grecs et aux Romains une grande instruction sur la géographie des pays avec tes peuples desquels ils avoient eu des relations habi- 
tuelles. Mais en leur accordant ce juste tribut de notre estime, nous devons éviter un écueil opposé, celui de leur supposer plus de connoissances que ne le permettoient l'état des sciences mathématiques, les bascs de la géographie, le défaut d'instrumens, des difficultés inbérentes à cette science, et souvent presque insurmontablcs, comme celles de franchir des montagnes inaccessiblcs de leur nature, ou dont l'accès est défendu par des hommes courageux qui y ont cherché un asile contre des oppresseurs; de pénétrer dans des contrées sauvages qui ne tcntent ni l'ambition, ni la cupidité, habitécs par des nations pauvrcs et féroces, ayant toujours les armes à la main, éloignées de tout esprit de civilisation, parlant une langue tout-à-fait inconnue ; les obstacles qu'offrcnt cncore les différences si grandes dans les températurcs des climats, obstacles même qu'augmentoient lcs préjugés des Grecs et des Romains, imbus de cette idée que la terre sous la zone torride et sous la zone glaciale étoit inhabitable : toutes ces difficultés, dis-je, et bicn d'autres, s'opposoient à un prompt accroissement de cette masse d'observations et de faits qui servent dc fondement à la géographie. Si, environnés de tous les secours dc l'astronomie et de la physiquc, nous sommes encore aujourd'hui dans l'incertitude sur un grand nombre de positions, si l'on rectifie même des fautes commises par des hommes célèbres qui paroissoient avoirobservé avcc soin; si nos voyages dans les mêmes pays se contredisent perpétucllement, est-il raisonnable de croire que les Anciens auront mis plus d'exactitude dans les déterminations qui étoiènt soumises aux mêmes difficultés?.... C'est dans la direction des chaînes de montagnes, dans lindication des sources et du cours des fleuves et des ri- 
vières, que l'on doit s'attcndre à trouver le plus d'crreurs. Souvent aussi ccs errcurs dépendent-elles d'un vice principal, qu'il faut tâchcr de découvrir, parce que cette solution une fois acquise, tous les défauts secondaires qui en dérivent seront connus.

Pour bien traiter le sujet que nous discutons, ayons encore recours à Ptolémée, et profitons de ses connoissances plus solides et plus détaillées que celles de Pline. Efforcons-nous, d'après notre propre conseil, de distinguer l'erreur principale qui affecte la carte de l'Afrique dressée sur ses déterminations géographiques; peut-être atteindrons-nous plus promptement le but que nous nous sommes proposé.

C'est un fait avoué de tous les hommes instruits, que la plupart des positions locales données par les anciens géographes étoient, en majeure partie, établies plutôt sur des mesures itinéraires, soit terrestres, soit mari-. times, que sur des obscrvations astronomiques. Il s'en suit qu'il doit y avoir dans ces déterminations, celles principalement qui ont eu pour base des courses nautiques, des errcurs considérables. Car, plus les côtes sont. sinueuses, plus il étoit difficile, faute de boussole, de les bien orienter, d'en connoître les irrégularités, et de faire une réduction exacte des distances. La projection de la carte de l'Afrique ancicnne de Ptolémée nous en fournit un exemple frappant. La côte septentrionale qui longe la Méditerranée, et celle qui après le détroit de Gibraltar se prolonge au midi dans l'Océan atlantique, forment deux lignes, se coupant presque à angle droit. Les ports situés sur la première de ces côtes se trouvent a un ou deux degrés près sous le parallèle d'Alexandrie, et ceux des bords de l'Océan atlantique 
sont, à la même différence près, placés sous le méridien de Tingis, Tanger. L'Afrique propre, ou la partie orientale de lá Barbarie, s’avánee peu dans la Méditerranée. Le cap de Ptolémée le plus septentrional, II crmcea extrema, le cap Bon, est au 33e degré 36 minutes latitude nord, et Alexandrie au $31^{\text {e }}$ degré. La différence en latitude ne seroit donc, suivant lui, que de 2 degrés 36 minutes, tandis qu'elle est de près de 6 degrés, Alexandrie étant au $3 \mathrm{I}^{\mathrm{e}}$ degré 13 minutes, et le rap Bon, ou Hermcea, au $3 j^{\circ}$ degré et quelques minutes. Le promontoire Cotes, ou le cap Spartel, est presque d'un degré plus au midi que le précédent; et daus Ptolémée, au contraire, il est porté en avant de plus de deux degrés, puisqu'il le place au 35e degré 56 minutes. La côte occidentale, qui du cap Spartel au cap Blane s'incline toujours de plus en plus vers l'ouest, et forme une eourbe grande et sinueuse, deseend, dans Ptolémée, presque perpendieulairement, étant, eoname nous l'avons dit plus haut, ì un on deux degrés près sous le mème méridien. A commencer au promontoire Arsinarium, cette côte s'incline à l'est et dessine faussement un très-grand golfe. On doit sentir combien des erreurs aussi importantes cn ont dû produire d'autres dans le détail, et combien elles ont dù influer sur la détermination des longitudes et des latitudes. Pour ne pas nous écarter de notre sujet, nous nous bornerons à faire eonnoìtre les altérations qui s'en sont suivies à l'égard des rivières Nigir et Gir de Ptolémée.

Dès qu'on eut pris nne fois le Niger de Pline pour notre Niger on le Joliba, on devoit naturellement reconnổtre la même rivière dans le Nigir de Ptolémée. On a été plus loin. Le géographe grec ayant indiqué 
wec détail le cours de son Nigir, les villes qu'il arrose, les peuples des contrées qu'il parcourt, on a voulu rectifier, en quelque sorte, nos cartes d'après les siennes, et on s'est donné beaucoup de peine pour retrouver la position de ces villes et de ces nations.

On .convient donc de l'identité du Niger de Pline et du. Nigir'de Ptolémée. S'il y avoit encore des doutes à ce sujet, il seroit aisé de les détruire par l'inspection de la carte de l'Afrique générale du dernier. Pline, il est vrai, n'a presque rien dit du cours de son Niger, ct il ne fait point mention des établissemens qu'on avoit formés sur ses rives; mais nous avons vu qu'il avoit parlé de quelques peuples, tels que les Pérorses, les Pharuses, etc., situés dans les pays adjacens au Niger. Ptolémée nous présente la mème correspondance. Son $N$ igir sépare aussi la Gétulie de la Libye intérieure et de l'Éthiopie occidentale. Ayant prouvé, à ce qu'il me semble, que le Viger du géographe latin n'est pas le Niger moderne, il faut déduire une conséquence semblable relativement au Nigir du géographe grec.

On auroit pu voir que ce Nigir et ses rivières tributaires descendent aussi de l'Atlas ou de quelques uns de ses rameaux; que Ptolémée fait couler le $N$ igrir un peu avant le parallèle des îles Fortunées ou Canaries. C'étoit donc dans cette partie de l'Afrique située immédiatement au-dessous de l'Atlas qu'on devoit le chercher.

Qu'on me permette cette réflexion que je crois juste. D'une part on donne à Ptolémée des connoissances que probablement il n'avoit pu acquérir ; d'autre part on lui en refuse qu'il devoit posséder. Car, supposons que le Nigir soit le Niger: I $^{\mathrm{o}}$. il y aura dans sa carte de I'Afrique une grande lacune.' L'intéricur de la Gétulie, les 
nalions situées à son couchant, eette partie de la Libye intérieure qui répond au grand désert lui auront été presque inconnus, quoique les relations des peuples de la Mauritanie, de la Numidie et de l'Afrique propre, avec les habitans de ces contrées, que Ptolémée auroit passées sous silence, eussent dù procurer naturellement à cet égard des instructions même étendues. $2^{\circ}$. Ce géographe au contraire aura cu d'assez bons mémoires sur des pays barbares, très-éloignés des colonies greeques et romaines; il aura eu, chose incroyable, des connoissances sur cette portion de l'Afrique qui s'étend au midi du Sénégal et du Joliba, puisque sa Libye intéricure, dont il énumère les peuplades, les montagnes, sera rejetée au-delà ; les Éthiopiens Agisymbes, Agisymba regio, la nation la plus méridionale, seroient portés plus loin que la ligne, et dans ces climats brûlans, où les voyageurs les plus intrépides n'ont pu encore pénétrer. Telles sont les conséquences qui résultent de eette supposition. Nous allons voir que, dans notre sentiment, les lumières de Ptolémée sont plus conformes à la marche de l'esprit humain. Il a connu ce qu'il étoit possible de savoir, et ignoré ce qui devoit être eaché pour son siècle.

Du revers méridional du mont Allas, entre les neuvième et sixième degrés de longitude occidentale (méridien de Paris), sortent quatre rivières principales; le Dras ou Darah (Wad drah), la rivière de Tafilet, le $\mathrm{Ziz}$ et le Ghir ou le Ger. Ces quatre rivières, les trois dernières principalement; sont tellement rapprochées à leur naissance, que des sources de la première ou du Darah aux sources de la dernière ou du Ghir, la distance n'est environ que de soixante lieues communes. La convergence de leur cours supéricur devient encore 
plus sensible, en ce que des torrens ou de petites rivières remplissent plusieurs dcs espaces intermédiaires. Ces quatre rivières principales, parvenues aux confins du grand désert, se pcrdent dans autant de lacs particuliers. Qu'on examine sur la cartc de l'Afrique de Ptolémée la place qu'il assigne à son fleuvc $\mathrm{Nigir}$, la correspondance de cette position avec celles des pays adjacens et connus, tels quc la Gétulie, la Mauritanie, les coutrécs habitées par les Darades, lcs Phaurusiens ou Pharuscs, et on sera forcé de placer l'origine du Nigir dans les provinces de Darah, de Tafilet ct de Sedjelmessa : lcs deux prcmièrcs sont arrosécs chacune par une rivière portant le nom de leur contréc respective; le Ziz et le Ghir parcourcnt la dernière province. Ces rivières doivent donc, commc étant lcś sculcs qui parcourent ccs provinces, rcprésenter le cours supéricur du Nigir, ou du moins sa portion principale. Mais, me direz-vous, ce sont des rivières distinctes, ct dans la carte de Ptoléméc on n'cn voit qu'une qui va se terminer bien au delà, au Libya Palus, J'expliquerai plus bas ce prolongement à l'est ou le cours inférieur du Nigir.

Observons d'abord que ce Nigir est formé de la rétınion de plusieurs rivières. Il en reçoit deux qui paroissent venir du midi ou de la Libye intéricurc; la plus occidentale et la plus courte se tcrmine près d'Any gath; l'autre, ou l'orientale, part du mont Thala. Le pays, où le Vigir a son cours principal, devant être beaucoup plus élevé, à raison dc sa proximité avcc l'Atlas, que les contrées inférieurcs ou celles qui touchcnt au grand Désert, on ne peut pas supposer que ces rivières méridionales viennent tomber dans le $N$ igir; elles doivent 
plutôt descendre et finir par se perdre. Sans parler dả Libya Palus dont nous ferons connoître la correspondance, Ptolémée indique en cette partie de l'Afrique deux lacs : le Nigrites Palus, près des sources du Nigir, et celui qu'il met chez les Phaurusiens, et dans lequel passe son fleuve Stachir. Nous pensons que ce dernier lac est celui oì s'écoule le Darah, lac que ce géographe paroît avoir réuni à son Stachir, dont il allonge trop le cours. Les deux branches supérieures et occidentales du Nigir, et dont la méridionale forme le Nigrites $P a$ lus, pourroient bien, d'après les villes qu'il place sur leurs bords, se composer, non-seulement des affluens supéricurs du Darah et de la rivière de Tafilet, mais cncore de quelques autres petites rivières du revers opposé de l'Atlas. La rivière de Tafilet, celles qu'on nomme Ziz et Ghir étant, comme nous l'avons dit plus haut, très-rapprochées vers leur origine, auront été confondues en une seule; et tel est le Nigir de Ptolémée, pris dans son cours supérieur. Un peu au-dessous du lieu nommé $T$ hyge par ce géographe, le $N$ iggirjette une branche qui se prolonge directement au sud, et se termine près d'Anigath; il seroit possible qu'elle représentàt uné portion supéricure de la rivière de Darah. Nous pouvonis reconnoître une autre branche du Nigir, mais beaucoup plus étendue, venant du mont 7hala, et se dirigeant du sud-est au nord-ouest, dans le cours de la rivière de Tafileț. Sa portion supérieure forme peut-être cette rivière intermédiaire qui part du mont Usargala, an nord-est, et vient se réunir au Nigir, près de Nigira Metropolis, ville qui pourroit être, selon M. Barbié tu Bocage, Sedjelmessa. Plus loin, en tirant vers l'est, le Nigir finit en so divisant en deux grands rameaux, 
dont l'inférieur se perd dans le Libya Palus. D’après. la même analogie, ce lac seroit celui qui reçoit les eaux de la rivière de Ziz. Ptolémée pourroit avoir formé l'antre branehe du Nigir avee le eours supérieur du Ger. Il u'auroit pas eonnu la portion inférieure de eette dernière rivière, ou supposé que son Libya Palus fût le lac Beny Somi, où se déeharge le Ger, la branche occidentale et méridionale du Nigir ne seroit plus le Darah, mais la rivière de Tafilet. Voilà tous les rapprochemens que je puis offrir au sujet de la manière dont Ptolémée a eomposé le cours inférieur de son Nigir. Dans un tel bouleversemen d'idées géographiques, dans la pénnrie où nous sommes d'itinéraires exaets pour cette partie de l'Afrique, attendu eneore que les dénominations loeales varient et ont dû éprouver des altérations majeures, il est bieu difficile, pour ne pas dire impossible, d'établir aujour d'hui une correspondance exacte entre les géographies ancienne et moderne de ces contrées. Le $N$ iogir de Ptolémée, du Nigrites Palus an Libya Palus, eomprendroit urie étendue d'environ 19 degrés d'un grand cerele, tandis que si mon lyppothèse est fondée, eette longueur, d'après nos meilleures cartes, ne seroit guère que le tiers de la préeédente, ou de 6 degrés 20 minutes. ' En partant de eette base, je trouve que le lieu nommé $V^{\top}$ ellegia, par ce géographe, répond à l'Oumellıejin de nos cartes, dénomination très-rapprochée de l'autre. Tafilet est très-voịsin du lieu préeédent. Il s'en suivroit dès-lors que Sedjelmessa seroit plutôt le Tagama de Ptolémée que son Nigira Metropolis, assez éloignée de Vellegia, et à son nord-ouest. La situation de Gher, une des premières villes de ce canton, conviendroit beaucoup mieux à celle de Nigira. Nous retrouverions le 
Panagra de Ptolémée, l'habitation la plus orientale de celle qu'il place sur le $N$ igir, dans Mazalig.

Le fleuve Gir, de ce géographe, prend sa source à l'extrémité méridionale du mont Usargala, d'où nous avons aussi vu sortir une des branches du Nigir; carl'on pourroit aussi bien croire que ce géographe le fait couler de l'est à l'ouest, qu'en sens opposé. Le Gir se prolonge au Levant, presque sous le même parallèle, et après avoir reçu une rivière d'une montagne méridionale qui fournit les eaux du $N u b a$ Palus, il remonte vers le nord-est, pour se terminer un peu au-delà du mont Girgeris, ou des monts Eyrès, bornes méridionales du Fezzan (I), dans le lac des tortues, Chelonidce. J'avois cru d'abord ( ${ }^{\text {re }}$. édit. de ce mémoire) que ce Gir de Ptolémée étoit formé du Wad Djedyd et de quelques rivières du royaume d'Asben, placé au sud-sud-est du Fezzan. Mais comme le pays arrosé par le Gir paroît, d'après ce géographe, avoir été bien peuplé et assez connu, comme aucune de ces données ne peuvent guère s'appliquer au royaume d'Asben, situé au milieu de l'extrémité orientale du grand désert, j’ai abandomé ma première opinion, et je suis maintenant $d$ 'avis que la rivièrede $W$ ad $D j e d y d$ represente le Gir de Ptolémée. Ayant reçu le tribut de ses rivières afluentes, elle se dirige au sud-est et se perd dans le lac. Melgic, dont ce géographe ne fait point mention, et à peu de distance des monts Saluban. ( Vallis Garamantica, mons.) Ce bras du Gir, qui vient du lac des Tortues (Chelonida Paludes), n'est autre chose que la

(I) Je rectifierai ici quelques erreurs relatives ì la nomenclature de cette contrée. Les lieux nommés par Ptolémée : Gelanus, Salce, Bouta, Bedirum et Garama, sont : Zeghen, Sebbah, Teygaryes, Mourzouk et Hemara. 
portion inférieure de la rivière Wadi, séparée de celle de'Serkan, formant son eours inférieur, et réunie par Ptolémée avec.le lac Loudéah. On avoit cru jusqu'ici que ee lac représentoit ceux de Tritonis, de Pallas et de Libya, formés par la rivière Triton; mais une étude suivie de l'Afrique proprement dite, de ce géographe, nous montre dans cette rivière, qui part du mont'Fissato, et qui, après s'être brusquement élargie, tombe dans la mer, en faee de l'île Zerby, Lotoplagites insula, le fletuve Triton de eet auteur. Cette portion du pays des Dattes, renfermée par deux branches de l'Atlas, le mont Auras et le Gebelaura au nord, et les monts Saluban, du côté du désert, traversée dans toute son étenduc par le Wad Djedyd, fut le séjour des Garamantes, et c'est là, en effet, que Ptolémée les place: mais en les recılant trop à l'est et trop au sud, de manière que l'extrémité orientale de ee pays est portée sous le Fezzan et même un peu au-delà; quoiqu'élle en soit distante d'environ douze degrés de 25 lieues ( $\mathrm{r}$ ). Un itinéraire qui mène de Constantine au mont Sidi Ruges, passe près de Shbaihée, l'Anigath peut-être de Ptolémée, et peu éloigné d'un lieu nommé Burg Tuil, situé dans cette chaîne de montagnes, lieu dans lequel nous croyons reconnoître celui que Ptolémée appelle Buthuris. Un peu plus loin et au midi d'Anigath est Thabudis, ou le Tabidium de Pline, connu par les trophées de Cornelius Balbus. Il paroît que les ruines de cette ville se voient

(r) Ptolémée encore prolonge trop au midi le fleuve Bagrailas ou le Mejerdah, ainsi que le Cyniphus. Il réunit au premier le Wadi ou l'Abéad, branche dı Wad Djedyd. Quant au second, il l'accroît, je présume, de quelque rivière du grand déscrt, celle principale ment qui parcourt, en descendant, le pays d'Asben. 
encore près de l'endroit où la rivière de Wadi, réunie par Ptolémée avec le Bagradas, et qui vers sa source porte le nom de Serkan, se fraie un passage dans le mont Auras (1). Mais le Gira Metropolis de ee géographe, qu'il place au sud-sud-est de Thabudis, doit être à son sud-ouest. L'erreur que nous arons observée à l'Łgard de la longueur, qu'il donne au cours du Nigir afiecte aussi, et presque dans les mêmes proportions, celui du Gir. En employant, pour la recherche des positions, la méthode dont nous avors fait usage relativement à la première de ces rivières, nous trouverons l'emplacement de Gira, capitale des Garamantes, dans la ville actuelle de Deusen (Desena). Lynxama, situće à l'extrémité opposée, sur le lac des Tortues, est représenté par El Hammah; Zerib, Liaina, el Fit, Tummarach, paroissent nous reproduire, et dans le même ordre, les lieux suivans : Artagira, Thuspa, Ischeri et Tucrumuda; Thycimath, qui se trouve placé, par suite de l'erreur géographique signaléc plus haut, sous le mont Girgeris, doit trouver sa place dans le voisinage de Bescara. Nous croyons enfin que le Nuba Palus de Ptolémée est le lac Kottoko du royaume de Bormou. La contrée située au levant de ce lac porte le nom de Phallate, qui a quelques traits de similitude avec celui de Calitce, peuple que le même géographe met au nord de son $\mathrm{Nuba}$ Palus. S'il n'a pas eu de connoissance positive du graud désert, il est néanmoins certain, d'après cette multitude de peuplades qu'il disperse dans la partie centrale de l'Afrique, qu'on avoit des relations avee les diverses hordes

(1) Il me paroît que d'Anville a confondu le Thuspa de Ptolémée, ville située sur le Gir, avec le Thabulis, que ce géographe place sur le Bagradas. 
de Nègres qui habitent le Soudan, depuis le royaume de Bornou jusque près de celui de Tomboueton.

Toutes ees conjectures, il est vrai, sont établies sur un grand renversement d'idées géographiques; mais il est plouvé que ces dérangemens sont réels. Il falloit bien concilier Ptolémée avec lui-même; les erreurs que je lui prête sont d'ailleurs moins les siennes que celles de son temps; et dans l'opinion eontraire elles sont bien plus déraisonnables.

Cette explication en amène une autre qui peut éelaireir un point historique. Une opinion très-ancienne faisoit venir le Nil des contrées occidentales de l'Afrique. Hérodote (livre second) ne paroît pas en douter. Strabou (livre dix-septieme) dit aussi que des auteurs placent son origine aus extrémités de la Mauritanie; mais Pline (livre cinquiène, clıapitre neuvième) développe beaucoup plus que touş les autres cette tradition.

" D'après les informations que le roi de Juba put " faire, il résulte que le Nil prend sa souree dans une " montagne de la Mauritanie inférieure, à peu de disn tance de l'Océan, dans un lae qui se forme subite" ment, et qu'on a nornmé Nilide. On tronve dans ee " lae les poissons alabète, coracin, silure, et même le " crocodile; témoin eelui que Juba dédia dans'le temple. » d'Isis, à Césarée, et qu'on y voit encore aujourd'hui.

"On a aussi observé que les crues du Nil sont plus ou " moins fortes, selon qu'il tombe plus ou moins de pluie " ou de neige dans la Mauritanie. Au sortir de ce lae, " indigné de ne rencontrer que des sables et des lieux " ineultes, il dérobe son cours à uos yeux pendant l'es" pace de quelques journées de elemin. Bientôt il sort "d'un autre lae, mais plus grand, chez la nation des 
"Massasyles, Massasyles, dans- la Mauritanie, se re-

" produisant dès qu'il trouve des réunions d'hommes,

" et offrant encore les même animaux qu'auparavant.

"Il s'abîme encore de nouveau sous les sables du désert

" l'espace de vingt jours de marche, jusqu'aux Éthio-

" piens les plus proches; mais, recommençant à sentir

" la présence de l'homme, il jaillit d'une source qui,

" suivant les apparences, est celle qu'on a nommée $N i$ " gris. De là, séparant l'Afrique de l'Éthiopie, sans

" couler cependant dans des contrées habitées, mais

" arrosant des pays abondans en bêtes féroces et indomp-

" tables, chargés de forêts, il partage l'Éthiopie en deux,

" et s'appelle Astapus. "Je vois dans le Nigir et le Gir de Ptolémée, le Niger de Pline, cette branche et cette origine supposées du Nil, présentés sous d'autres noms, mais ayant les mêmes rapports.

Le géographe Pomponius Méla (livre troisième, chapitre neuvième) met aussi sur les confins des Éthiopiens occidentaux (I) la source du Nil, et il dit que les habitans du lieu l'appellent Nuchul. Il le dirige également de l'ouest à l'est, et, à l'cxemple de Pline, il le fait disparoître et reparoitre. On y trouve le papyrus, des animaux plus petits que ceux que le Nil produit dans son cours inférieur, mais de la même nature (2). Ponponius Méla confirme notre sentinent à l'égard de la situation

(1) Il placc sur la côte les îlcs Gorgades ou Gorgones, et près de là le cap Hesperu Ceras, l'Hesperi Cornu de Ptolémée. La relation du capitaine Hannon ne parle que d'une seule île, et qui étoit située prèsdu cap Notu-Ceras, plus au midi quc l'autre. Pline a commencé cette confusion.

(2) Le géographe de Nubie (page 74) compare aussi le Ziz ou la rivière de Sedjelmessa au Nil, quaut is ses accroissemens et ses praductions. 
des Pharuses et des Nigrites, en les plaçant sous le parallèle des îles Fortunées et dans les pays qui avoisinent l'Atlas.

Ethicus présente aussi les mêmes anciennes idées sur cette prétendue origine du Nil. Les Barbares nomment cette source Dara, et les autres habitans Nuchul. Les Darades de Ptolémée n'étoient pas loin des sources du. Nigir, et cette conformité dans les dénominations prouve encore plus ce que nous avons avancé à ce sujet.

Le Ger, dans l'anonyme de Ravenne, traverse l'Éthiopie Biblobatis et la Mauritanie des salines, ou Perosis. Il répond probablement au $N i g i r$ de Ptolémée. Cette confusion des rivières du Belel-ul-Dejerid, ce cours du Gir, tel qu'on le voit dans Ptolémée, se sont perpétués daus un très-grand nombre de cartes anciennes, telles que celles de Mercator, d'Hondius, de Dapper, etc.

Ces anciennes traditions annoncent qu'on avoit une idée confuse du Nil des Nègres, et que l'on prolongeoit son cours jusque dans la partie occidentale de l'Afrique.

Puissent ces observations avoir répandu de la lumière sur une question de géographie ancienne aussi importante que difficile! tant d'autres y ont échoué, peut-être auraije le mème sort; mais ces considérations sont neuves. A force d'envisager la matière sous des aspects différens, il sera possible de saisir enfin le bon côté. 


\title{
OBSER VATIONS
}

\author{
SUR L'ORIGINE
}

\section{DU SYSTEMME MÉTRIQUE}

DES PEUPLES ANCIENS LES PLUS CONNUS,

Considéré dans son application aux distances itinéraires ( $\mathrm{I}$ ).

I $_{\mathrm{A}}$ quesioion que je vais traiter semble bien étrangère à la science de la nature que je cultive, et j'appréhende

(s) Ce Mémoire a été lu, dans le courant du mois d'août de l'année 1817 , à l'Académie des Sciences et à celle des Inscriptions ct Belles-Lcttres. Eu le livrant à l'impression, je l'avois terminé par des extraits, en forme de uotes, de deux autres Mlémoires inédits, dont l'un est relatif aux Sériques, on les lieux d'oi l'on tiroit primitivement la soie, et dont l'autre a pour objet la Chronologie égyptienne. Mon opinion sur l'origine du Système métrique des auciens, est une suite des recherches géographiques, qui font le sujet du second Mémoire. Je pcnse que ce système fut établi sur les proportions relatives et moyeunes des mcubres du corps humain, élémens naturels, très-simples, et qui ne supposent poiut de grands progrès en géométrie et en astronomie. Par l'exposition de mon sentiment sur les autiquités historiques de l'Egypte, j'ai voulu pronver que, soumises à l'examen le plus rigourenx et le plus impartial, ces antiquités ne sortaicut poiat des limites de la chronologie sacrée, donnée par les Septante; et que les Ėgyptiens n'avoient pas cu le temps d'acquérir ces connoissances mathématiques sur lesquelles des savans veulent que ce peuple ait posé les bases de son Système métrique. 
que cette sorte d'infidélité ne vous inspire de la méfiance. Mais vous n'ignorez pas, messieurs, que vos études et les miennes ont souvent des points de eontaet, et sc prêtent mutuellement du secours. L'emploi ou la comnoissance de diverses seiences nat urelles nous viennent de l'antiquité, et le naturaliste qui désire d'approfondir son sujet sous toutes ses faees, suit pas à pas ces traditions pour tâcher d'en découvrir l'origine. Souvent il interroge l'helléniste, le géographe et l'historien; conx-ci, à leur tour, réclament quelquefois ses lumières. L'Aeadémie des Sciences et eelle des Inseriptions et BellesLettres voient ainsi les liens qui les unissent se fortifier de plus en plus par des besoins réciproqnes. Elles rendent un nouvel hommage aux lumières et à la sagesse de l'auguste monarque qui a reconnu cette dépendanee, et proelamé par une loi solennelle et protectriee la fraternité des quatre Aeadémies.

L'histoire du commeree primitif de la soie se rattache à eette branche des scienees naturelles qui a pour objet la connoissance des insectes, et qui, depuis quarante ans, fait les délices de ma vie. Des savans du premier mérite ont essayé d'éelaircir ee point historique et géographique, mais je ne erois pas qu'ils aient dissipé tous nos doutes. La solution de cette difficulté exige une foule de reeherches sur l'élat ancien et moderne de l'Asie. Les géographes grecs et latins n'indiquant point la valeur ou la nature des mesures itinéraires qu'ils emploient, les modernes offrant souvent de la dissidence à cetégard, je me suis vu entrainé dans un autre dédale, et plus inextricable 'eneore que le prenier. Cependant, à force de pareourir l'un et l'autre en tout sens, et d'en étudier les sinnosités, j’ai cru en avoir entrevu les is- 
sues, et mes idées sont fixées. Deux mémoires, l'un relatif au commerce ancicn de la soie, ct l'autre ayant pour objet le fondement sur lequel le systèmc métrique primitif me paroît reposer, mais envisagé seulement dans ses rapports avec lcs distances itinéraires, sont le fruit de mes vcilles. Etant entraîné par mes goûts comme obligé par mes dcvoirs, dc consacrer la majeure partie de mon temps à l'histoire naturelle, je n'ai pu termincr encore la rédaction du premier de ces mémoires, dont l'étendue est d'ailleurs considérable. Je me suis borné à énoncer mon sentiment dans deux ouvrages d'entomologie. Mais en attendant que je puisse développer les résultats de mes recherches à cet égard, je dois à la justice de déclarer que $\mathbf{M}$. Gosselin, par l'ordre ct la clarté qu'il a mise dans ses discussions sur la Sérique et sur les limites du mondc connu des anciens, m'a aplani la voie, dans les points même où je ne partage point l'opinion. de ce savant géographe.

Accoutumé par mes études journalières à découvrir et à comparer les rapports, à analyser avec précision lcs faits que l'obscrvation nous fournit, j'ai porté cet esprit de méthode dars l'cxamen des anciennes mesures itinéraires. Combinées et décomposées d'une infinité de manières, elles m'ont enfin présenté quelques aperçus et des rapprocheinens curieux et dignes d'intérêt. J'ai soumis les faits quc j’avais rasscmblés au jugement de M. Barbié du Bocage, et la bicnvcillance avec laquelle il a accueilli inon travail, m'a déterminé à le communiquer à l'Académic des Sciences, lc 4 août dernier. Profitant de ses conscils, j'ai revu cc mémoire et lui ai donné beaucoup plus d'étenduc. Veuillez bien ccpendant, messicurs, ne considérer cc travail que comme uu premier essai que 


\section{DES ANCIENS.}

livre à vos méditations, et dont les conclusions se reseignent à de simples probabilités (1).

Un géomètre grec du moyen âge, Héron, dont l'ourage, sür les mesures employées de son temps en Égypte, été pour M. Le Tronne le sujet d'un travail que vous vez couronné, avoit déjà énoncé cette vérité imporante, que les premières mesures avoient été prises des roportions relatives des membres du corps humain, et 'est aux Égyptiens qu'il attribuoit l'honneur de cette nvention. D'Anville a senti la justesse de ce principe, t en a souvent fait usage. M. Girard, l'un de nos collègues, en a aussi déduit quelques applications ingénieuses dans un mémoire faisant partie du magnifique ouvrage ur l'Égypte, qui se publie en France. M. Jomard nous donné l'extrait de son immense travail sur les anciennes mesures égyptiennes, dont le système, selon lui, a pour base des observations et des calculs géodésiques et astronomiques. Les pyramides de ce pays déposeraient même, depuis bien des siècles, en témoignage de la réalité d'un fait aussi étonnant. Telle est, messieurs, dans ses opinions, la singulière divergence de l'esprit humain; Bailly essayoit, avec tous les charmes du style, de nous faire croire à l'existence d'un peuple antique, qui, sur les bords de l'Obi, ou dans quelques unes des contrées qui a voisinent notre cercle polaire, auroit en des Newton, des Euler, des Lagrange, des Cassini, etc. Aujourd'hui les contrées que féconde le Nil, et qui sont en proie à tous les feux du soleil, nous rappelleroient le glorieux souvenir d'une nation non moins éclairée,

(r) On sent que dans une discussion semblable, on ne peut préscnter que des conjectures, et qu'il y a, nécessairement, de l'arbitraire dans quelques points. 


\section{$g^{S}$ SYSTEME MÉTRIQUE}

et dont l'histoire se perdroit encore dans la nuit des temps.

Il m'a paru que les premiers peuples s'étoient vus dans la nécessité d'inventer des mesures bien antérieurement à leurs progrès daus les sciences, et surtout avant d'avoir pris la mesure d'un grąnd degré de la terre. Je ne doute pas que, parvenus à la civilisation, quelqu'un d'eux n'ait formé avec les premières mcsures un corps de système, et ce mémoire en offrira la preuve. Mais on a dû le faire d'une manière simple, naturelle, convenable, en un mot, à l'état des lumières, des bcsoins et de la situation de la société qui a établi ce système. Voyons s'il en est ainsi.

${ }^{\circ}{ }^{\circ}$. Toutes les mesures de l'antiquité ont pour premicr élément une quantité variable, fondée sur une progression arithmétique, dans un ordre décimal ou duodécimal de pas, dont la mesure a pour étalon une longueur divisée le plus souvent en douze ou seize partics, tantôt égale à celle du pied moyen ou de la coudée de l'homme, tautôt plus grande et composéc alors de la longueur de ce pied ou de cette coudée, augmentée d'un certain nombre de ses parties aliquotes.

D'Anville estime la longueur moyenne du pied humain à neuf pouces quatre cinquièmes de ligne ( $\mathrm{r}$ ), et l'évaluation qui résulte de mes calculs sur les mesures linéaires anciennes ne s'éloigne pas, en effet, de plus d'une ligne de cette première donnée. Pour éviter de petites fractions, j'ai porté cette longueur à neuf pouces une ligne (2); il paroît cependant que dans la plupart des

(1) Etant obligé de comparer d'anciennes mesures, je ne ferai point usage du système décimal, qui est d'ailleurs peu familier aux étrangers.

(2) Il faut lui donner près d'une demi-ligne de plus pour que 6ou 
estimations, elle est réduite, en compte rond, à neuf pouces. Le double de cette longueur et sa moitié seront la mesure d'un pas commun.

Le même géographe porte la coudée, la main étant censée étendue, à dix-sept pouces; mais on en a formé de plus petites, suivant la partie de la main où elles se terminoient.

Je dis maintenant que les anciens pieds, ainsi que plusieurs de ceux dont on se sert aujourd'hui, semblent dériver les uns, et tel est le plus grand nombre, de la longueur moyenne du pied de l'homme (I), et les autres de celle de sa coudée.

pieds naturels fassent juste le stade de 76 toises ou de 750 au degré le pas naturel seroit alors de 22 pouces, Io lignes..

(1) On adopta, dans le principe, une marche bieu plus simple : des semences de plantes très-usuelles fournirent les élémens des premières mesures. Les Chinois employèrent pour cela des semences de choux ou des grains de gros millet. L'étendue en longueur de l'espace qu'occupent cent de ces grains, placés à la file, en ligne droite, et se touchant par leur plus court diamètre, représenta primitivcment la longueur du pied. On le divisa en dix parties égales, répondant à nos pouces, et chacun de ces pouccs fut pareillement divisé en dix parties ou lignes. La longueur du pied fut de 9 pouces, 4 lignes de notre pied-de-roi. Chaque pouce valoit ainsi i lignes plus un cinquième. Quatre-vingt-un grains, rangés de la même manière, mais se touchant par le plus long diamètre, ou disposés transversalement, représentèrent une longueur semblable, mais que l'on divisa de neuf en neuf, de sorte que ce pied, qu'on employa pour l'harmonie, et qu'on nomma, en conséquence, musical, fut composé de $8 \mathrm{I}$ lignes. Le king des Chinois, instrument de musique, et formé d'une pierre sonore, est taillé en manière d'équerre échancré. On en distingue deux sortes, le cheng-king et le soung-king, et leurs différences consistent dans les proportions que l'on donne aux longueurs dcs branches de linstrument et à son épaisseur. Les côtés du cheng - king offrent, en prenant notrc picd pour 
D'Anville avoit déjà remarqué que le pied servant de base au stade arménien, nommé vetavan par Moyse de Khorène, et asparèze par d'autres, s'identifioit arec le pied naturel. Ce pied arménien étoit divisé en six parties, appelées mates, graduation qui diflère de celle des autres pieds, puisquils sont composés tantôt de seize doigts, tantôt de douze parties, les onces, uncice dés Látins, et quelquefois même de ces deux manières. La stade vétavan, que d'Anville, d'après la comparaison qu'il en fait avec l'asparèze, estime de 750 au degré, paroît avoir été en usage, comme on le verra, depuis l'Asie orientale, jusqu'aux limites occidentales de l'Europe.

Selon ce géographe, l'opinion commune évaluoit, dans l'usage ordinaire, l'ancien $l i$ chinois à 250 au degré ou à 228 toises. Cette mesure étoit composée de 300 pas ou même de 366 ; chaque pas étoit formé de six coudées ou ché. Le nombre de ces pieds, en supposant le li de 300 pas, est de 1800 ; or, la somme de 228 toises, divi-

mesure, les longueurs suivantes : 6 pouces, 9 p. , 18 p. , 27 p.; les rapports des eôtés correspondans du soung-king sont : 8 pouees, 12 p. , 24 p. , 56 p. Ces iustrumens ayant servi d'étalons à plusieurs mesures, il étoit néeessaire d'indiquer leurs proportions, qui sont, eomme l'on voit, établies sur deux progressions arithmétiques, dont les différenees sont 3 et 4 . La longueur du pied ehinois s'est aecrue graduellement, quoique toujours divisée en dix parties, et subdiviése de même, de trois pouees, de sorte qu'clle est maintcnant d'un eentième plus grande que notre pied-de-roi. D'autres anciens peuples, tels que probablement les Chaldéens, se servirent de grains d'orge. Quarante-huit de ees grain s, placés à la file, forment une longueur de 6 pouces ou de 72 lignes; le double représente ainsi notre pied-de-roi.

Telles sont les deux bases sur lesquelles reposent les premières mesures linéaires de l'antiquité. Il sera faeile d'en déduire les valeurs des autres mesures qui sont le résultat de leurs combinaisons. 
sée par 1800 , donne pour quotient une longueur égale à eelle du pied naturel. Cet aneien li chinois n'est, en effet, que la réunion de trois de ces stades arméniens que je viens de mentionner, et a pour élémens constitutifs les mêmes prineipes. S'il étoit encore formé de 360 pas, c'est que ehacun d'eux ne se eomposoit alors que de einq pieds naturels, au lieu de six.

Je sais que le li ehinois a reçu suecessivement diverses augmentations, que, faute de documens positifs, il est très-diffieile, surtout pour nous, de bien déterminer. Mais toujours paroît-il eonstant que ees mesures sont établies sur le même prineipe que les stades des Grees, puisque chaque tiers de li, l'analogue d'un stade, étoit composé de 600 pieds et de ıoo pas.

On convient encore que le pied moderne chinois a deux doigts de plus que l'ancien, ou io au lieu de 8. Le moderne ayant I I pouces 9 lignes 7 dixièmes de celui de Paris, l'aneien avoit un einquième de moins, ou environ 9 pouces 5 lignes 4 dixièmes (voyez la pag. 99), et ne différoit ainsi que de quelques lignes du pied naturel.

Si on s'appuie ensuite sur la tradition, toute ineertaine qu'elle est, dont j'ai fait usage, il n'est plus vraisemblable que les aneiens Chinois aient cu aussi le stade arménien de 750 au degré.

Les pieds dont nous allons maintenant nous oecuper ont tous une longueur supérieure à eelle du pied naturel, mais ils n'en portent pas moins le caraetère de leutr commune origine. La diversité de leurs proportions n’est même pas irrégulière, eomme elle le paroît d'abord; elle remonte à l'établissement des stades.

Pythagore nous avoit appris, et l'observation le confirme, que ces mesures étoient toutes composées d'un 
même nòmbrc de pieds, savoir 600 , à raison de six par pas double; unité de principe bien rcmarquable, puisqu'il suffisoit de connoître la valeur d'un pied pour déterminer cellc du stade dont il étoit le module.

Un picd de dix pouces trois lignes, de notre pied de Paris, employé en Espagne, en Pologne, et même à Strasbourg, du moins avant la révolution, s'assimilc au pied naturel, augmenté d'environ deux doigts, ou en ayant en totalité dix-huit; il est pcut-être la coudée do Samos d'Hérodote; doublé, il forme une coudée de vingt pouces six lignes, en usage chez les Hébreux, et dont la détermination pcut se déduire du nombre de coudées 2000 , d'un de leurs milles appelé bérath par quelques commentateurs. Les sept stades et dcmi qui composent ce millc, sont encore de 750 au degré ou de 76 toises.

Le pied romain ( 1 ), très-rapproché du pied suédois, est de trois seizièmes ou doigts plus grand quc le pied naturel. Il résulte encore de vingt trente-sixièmes de cctte coudée hébraïque.

Quinze parties du pied naturel, divisé en douze doigts, donnent le pied grec, plus grand d'environ une ligne que lc pied anglais. La moitié de la longueur d'un pas commun, évalué à vingt-deux pouces, huit à neuf lignes, équivaut à ce pied grec; et si nous supposons avec d' $\Lambda_{11}$ ville la coudće naturellc de dix-sept pouces, les deux tiers de cette coudée reproduiront encore ce niême pied.

(I) J'ai adopté à son égard, ainsi que pour le pied grec, l'estimation établie par M. Gosselin; il me paroîtroit cepeuḍant d'après la comparaison de ees pieds, soit avee celui qu'Héron nomme philitéréen et qui est de treize pouces, soit avee le pied naturel, que leur évaluation est trop forte d'environ une ligne ; mais dans tous !es cas les rapports des stades seroient les mêmes. 
Tous le trouverez aussi dans le pied naturel, augmenté d'un palme ou de quatre doigts.

Notre ancien pied-de-roi ou de Paris, n'est que le pied naturel accru de ses quatre douzièmes. Des voyageurs, tels que Boullaye-lé-Gouz et un missionnaire, dont la relation est citée par d'Anville, ont cru reconnoitre l'emploi de ce pied de Paris, dans les proportions des briques dont se composent quelques monumens présumés babyloniens, et maintenant en ruine.

Si l'on ajonte trois seizièmes au pied de dix pouces trois lignes, dont j'ai parlé plus hant, on aura une mesure presque équivalente au pied drusien ou drusus, dont quelques peuples du nord ont hérité des anciens Germains, et qui paroît avoir servi de base à des milles, tels que le lombard et celui d'Angleterre de 69 et demi au degré. Trois pieds drusiens forment presque notre mètre. Un pied égyptien, mentionné par Héron, et dont la détermination nous intéresse d'autant plus qu'il est le radical de plusieurs autres mesures, est le pied philitéréen ou royal. Cet auteur le compare, et plus d'une fois, avee le pied italique, et ses rapports avec lui sont comme six est à cinq. J'avois d'abord pensé, contre le sentiment formel de d'Anville, qu'il s'agissoit ici du pied grec, appelé aussi ptolémaïque, dont la dénomination auroit été changée en celle des nouveaux maîtres de l'Egypte, et que les Grecs s'appliquèrent souvent à eux-mêmes, après. la chute de l'empire d'Occident. Ce pied philitéréen, dans mon opinion, auroit formé la coudée du pied naturel, et m'auroit donné le module du stade de 500 au degré, ou de 114 toises.

Mais si ce pied avoit existé, l'Egypte l'auroit probablement conservé, ou nous offriroit, du moins, quel- 


\section{Iof SYSTEME MÉTRIQUE}

que coudée qui, par ses divisions et leurs rapporis, représenteroit ce pied. Notre collègue, M. Girard, m’ayant assuré qu'une telle mesure linéaire ne se trouvoit point en Egypte, et que les deux tiers de la coudée du nilomètre faisoient $\mathrm{r} 3$ pouccs, valeur qui, à une fraction de ligne près, répond à celle que d'Anville assigne au picd philitérćcn, je suis revenu à l'opinion de ce grand géographe. Dans un ancien manuscrit de la bibliothèque royale, relatif encore aux mesures anciennes de l'Egypte, et composć, à cc qu'il paroît, sur l'ouvrage de Héron, le mot romain remplace celui d'italique ; c'est un fait que j'ignorois, et que M. Girard a eu la complaisance de me communiquer. Ce savant a développé et comparé avec beaucoup de sagacitć lcs rapports de la coudée naturelle, avec celle du nilomètre, estimé I9 pouces 6 lignes. Six de ces coudécs nilométriques représentent une longucur formée de treize picds naturels, ayant chacun 9 pouces de long.

On peut considérer lc pied philitéréen comme une petite coudéc, ayant pour mesure la distance du coude à la naissance du petit doigt de la main. 11 formc la base d'un stade dont l'évaluation peut varier de 108 à rog toises, sclon la manière d'apprécier la longueur du pied romain. Il sera de 108 toises 2 picds, si les deux ticrs de la coudće nilométrique égalent, ainsi qu'il y a licu de le croire, le pied philitérćen. Ce stade entre dans la composition d'une espèce de schène ou de parasangce, et nous le reconnoîtrons bientôt dảs cette mesure que Moyse de Khorène nomme le stade des stades.

$2^{\circ}$. Lesmesures itinéraires ancicnnes proprement dites, sont de deux sortes; les uncs, plus petites, sont uniquement formées avec les pieds ou les coudécs, tels sont les 
stades; les autres, d'une étendue plus grande, sont eomposées d'une quantité indéterminée des précédens. On les a désignées sous les dénominations de schènes, de parasanges et de milles ou miliaires. Les unes répondent aux lieues, aux gaus, aux eoss, aux farsangs de la géographie moderne; les autres ont eonservé le nom de milles. Puisqu'elles ne sont qu'un eomposé plus ou moins grand des préeédentes, il suffira de rechercher l'origine de eelles-ei ou des stades.

On en distingue plusieurs, et d'après les rapports de leurs longueurs avec celle d'un degré du méridien terrestre.

L'existenee de quelques-uns est contestée; mais il en est deux dont l'emploi chez les aneiens est irrécusable : ce sont ceux de 600 et de $7_{7} 50$ au degré. Le premier est l'olympique, et personne ne lui refuse eette dénomination. Mais il n'en est pas ainsi de celle du pythique, donnée au seeond par quelques géographes modernes. Censorin mentionne trois sortes de stades : l'italique, qui n'est que le suivant évalué en pieds romains, l'olympique et le pythique. D'Anville a soupeonné que le dernier étoit celui de 76 toises ou 750 au degré, que nous voyons, en effet, très-répandu, et dont les dix forment le mille romain. Censarin dit que le stade pythique est composé de mille pieds; or, la millième partie de 76 toises, égale 5 pouees 5 lignes et demie, ce qui fait juste la moitić du pied romain, tel que M. Gosselin l'estime. Ce fait semble eonfirmer l'opinion de d'Anville, et, d'après ee motif, je eonserverai au stade de 750 au degré, le nom de pythique, employé aussi par M. Barbié du Bocage. Cette mesure étoit plus particulièrement en usage dans les comptes nautiques. 
Le stade olympique est plus grand de r 9 toises que le. pythique, et ce même nombre ig les divise l'un et l'autre sans fraction. Il est compris cinq fois dans le premier, et quatre dans le second. La longueur de ce diviseur commun répond à celle que forment $\mathrm{i} 50$ pieds naturels, ou 60 pas simples. Si nous composons le pas de six pieds au lieu de deux et demi ou de cing, le nombre des pas sera réduit à vingt-cinq; multiplié par quatre, ce diviseur nous présentera une mesure très-avantageuse par son expression décimale, et la quantité de ses sous-diviseurs; car nous aurons 600 pieds naturels et roo pas géométriques; or c'est précisément le stade de 750 au degré, ou de 76 toises. Sa consécration au dieu Apollon, son usage général, son module ou le pied naturel, annoncent l'antiquité de son origine. Il est, je pense, le type des autres stades, car leur principe générateur étant le même, le stade pythique me paroît être le seul qui ait pu servir de modèle ou de règle.

J'ai dit plus haut que le stade nommé ainsi par Censorin, étoit composé, suivant lui, de mille pieds, et que chacun d'eux, en supposant que notre application soit juste, valoit la moitié du pied romain. Ce demi-pied égale le pied naturel, diminué de quatre dixièmes, ou trois cinquièmes de ce pied. Ainsi, en n'estimant le dernier que neuf pouces, comme il me semble qu'on a généralement fait, le pied romain n'auroit que 10 pouces 9 lignes trois cinquièmes, et le mille romain ne seroit que de 750 toises; en supposant que le pied philithéréen soit représenté par les deux tiers de la coudée du nilomètre, le pied romain acquerra deux cinquièmes de plus, ou sera porté à ro pouces ro lignes. Dans ce cas, le pied naturel aura aussi un tiers de ligne 
de plus que dans l'estime précédente. Le pied grec devroit aussi être diminué à proportion, et se rapprocheroit encore plus du pied anglais, dont l'origine est peut-être la même; mais ces mesures ont dû varier un peu avec le laps du temps.

Nous trouvons dans le stade olympique une longueur équivalente à celle que forment $7^{50}$ pieds naturels, et 300 pas simples; mais ces pieds, par leur rédaction au nombre de 600 , s'allongent de 27 lignes un sixième; ils deviennent ainsi des pieds grecs.

Puisque ce stade a i 9 toises de plus que le précédent, l'on doit en conclare, qu'en augmentant le pied pythique ou naturel, d'un six ccntième da diviseur commun, on lui donnera la valeur du pied d'Olympie. Ce diviseur est composé de 16,419 lignes. Les trois premiers chiffres à ganche, 164 , représentent la coudée du pied naturel, et le diviseur général est cette coudée multipliée par roo, ou plutôt il forme lui-même une sorte de petit stade de 600 pieds, ayant chacun pour valeur sa sixcentième partie ou 27 lignes un sixiène.

Héron nous dit que le stade égyptien est composé de six plètlıres. Les Arméniens partageoient aussi leur pied, le même que le naturel, en six parties ou doigts. Le stade est alors formé de 3600 de ces parties, de sorte que l'on pent établir, dans une marche parallèle, les deux progressions suivantes :

3600 doigts ou parties du pied........ 100 pas naturels

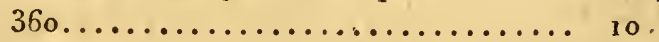

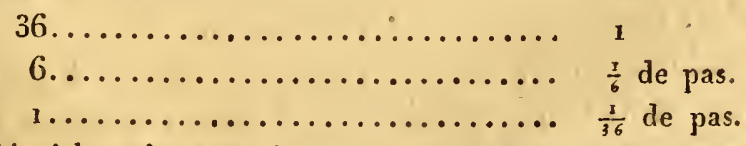

Ainsi la valcur du facteur principal des stades, une fois 
déterminée, il a été facile de former le stade olympique; il ne s'agissoit que d'ajouter $x 50$ pieds naturcls aux 600 qui composent le stade pythique, ou plus simplement d'augmenter le pied naturel de 27 lignes un sixième, et de multiplier cette longueur par 6oo. Une addition semblable, faite au stade olympique, le transformera en un stade de 500 au degré, ou de 114 toises, qui aura ainsi 900 pieds naturels, formant 360 pas simples, nombre correspondant à celui des divisions du cercle et des jours de l'année ancienne de plusieurs peuples, des Egyptiens particulièrement, les cinq derniers jours ou les épagomènes, non compris. En un mot, l'on peut établir plusicurs autres stades, tant supérieurs qu'inférieurs, en augmentant ou diminuant progressivement de 27 lignes un sixième, le pied du stade, qui sert de point de départ. Ainsi de ce que 600 stades olympiques ou 500 stades de II 4 toises, sont la mesure d'un degré terrestre du méridien, on n'est pas en droit, par ce seul motif, de conclure qu'on avoit connu la valeur de ce degré, au moycn d'opérations trigonométriques, puisque la composition dc ces stades se déduit naturellement d'un principe général, savoir une mesure équivalente à 150 pieds naturcls, ou à 60 pas simples, et ajoutée successivement à elle-même selon l'étendue du stade. Le nombre des pieds I5o du diviseur commun, n'étant pas susceptible d'être partagé sans fraction par douze, aura pu être doublé pour former 3 oo demi-pieds, quantité numérique assujétic à des divisions décimales, duodécimales ct sexagésimalcs, dont on sent tous les avantages.

Considérons maintenant ces stades sous un autre point de vue, dans leurs rapports avec la durée moyenne de temps que l'on met à les parcourir. D'Anville évalue à 


\section{DES ANCIENS.}

2; 100 toises la longueur du chemin que fait un homme de stature moyenne, dans une marche ni trop lente, ni trop accélérée. Mais cette estime me paroît généralement trop forte pour un terme moyen, surtout si l'on a égard à la nature du climat et du sol des pays, où le système métrique paroît avoir pris naissance, lesquels sont beaucoup plus chauds que les nôtres. L'ancienne lieue gauloise étoit formée de I r 4 o toises, ou d'un mille romain et demi ; celle des Germains étoit le double et s'appeloit rast, qui veut dire repos, station. J'en inférerai que la première suppose une demi-heure de marche, et la seconde une durée double. L'une et l'autre paroissent provenir de l'antiquité, ainsi que l'indiquent leurs rapports avec une espèce de parasange et de schène, dont je parlerai plus bas. Je ne me dissimule pas que les divisions horaires des anciens étoient inégales; mais on a pu choisir comme terme moyen les heures des jours équinoxiaux, et cette hypothèse deviendroit même presque inutile, si le système métrique avoit été établi par les Egyptiens, lorsqu'ils étoient en Ethiopie.

J'évalue ainsi à 2280 toises la distance que franchit un homme de stature moyenne, durant une heure de marche ordinaire. Le diviseur 19 toises répondra à 20 secondes, de sorte que les trois stades dont je viens de parler, nous offriront les mesures temporaires suivantes:

Stade de 500 au degré......... trois minutes.

Stade de 600 au degré......... deux min. $\frac{x}{2}$.

Stade de 750 au degré......... deux minutes.

Ainsi, dans leurs rapports avec la durée de temps, ces mesures nous présentent encore une combinaison et ne harinonie très-remarqquables. Tous les stades ont 
pour étalon le pied naturel dél'homme; mais celui de Héron, qui a pour élément le pied philitéréen, semble venir de la coudée naturelle. Sa valeur, en supposant le pied philitéréen de 13 pouces ou 156 lignes, est de 108 toises 2 pieds. Les sept et demi forment le mille, ou 8 12 toises, 3 pieds. Le schène est composé de quatre milles, ou de trente de ces stades, et vaut ainsi 3,25o toises.

J'ai dit plus haut que le stade arménien, que Moyse de Khorène nomme vétavan, étoit le même que le stade pythique. Les dix formoienţ le mille qui, dès lors, ne diffère plus du mille romain. Il falloit trois de ces milles arméniens, pour une parasange, ce qui nous donne 2,280 toises, ou la lieue des Germains. Les quatre milles donneront une autre parasange de 3040 toises : c'est, je présume, le schène dont parle Hérodote, à l'occasion de l'étendue de la côte maritime de l'Egypte. Ce schène, suivant lui, étoit composé de 60 stades; le soixantième de 3040 toises, est de 50 toises deux-tiers, valeur trèsapprochante de celle du stade de i i I au degré. Mais ce schène se compose aussi de 40 stades pythiques, consacrés plus spécialement à l'évaluation des courses maritimes.

Moyse de Khorène dit que le stade des stades aroit 43 pas de plus que le stade vétavan. Ces rapports donnent au premier 108 toises 2 pieds, et c'est juste le stade de Héron, dont les trente composoient un des schènes Esyptiens, celui de 3,250 toises (I). Le plèthre de ce stade est de 18 toises 4 pouces, ou de 15,600 lignes, ce qui équivaut au pied philitéréen, multiplié par 100. Le sixième de ce pied est 26 lignes, et a pu servir,

(I) C'est à peu près l'espace que parcourt, en une heure, un bon chameau, chargé. 


\section{DES ANCIENS.}

de. même que la différence de 27 lignes un sixième, dont j’ai parlé précédemment, à établir d'autres stades.

En diminuant d'environ une demi-ligne la valeur de la coudée du nilomètre, on trouvera les rapports suivans, et qui contribuent à éclaircir la formation des mesures qui en découlent. Le stade de Héron est composé de 4 ao coudées, de I/44 pas géométriques de six pieds naturels. Nous avons vu que Moyse de Khorène ne lui en donne que I 43 ; mais tout porte à croire que les anciens avoient établi une division duodénaire. Le plèthre aura donc 24 pas géométriques; le mille sera de 3,000 coudées; et le schène en aura 12,000 .

La coudée du nilomètre paroìt tirer son origine d'une. coudée naturelle, augmentée d'un sixième de sa longueur primitive. Si on la partage en 32 doigts, on en déduira la coudée naturelle que d'Anville estime de 17 pouces, et notre ancien pied-de-roi. La division duodénaire de ce pied, paroît annoncer qu'il vient de cette source.

Je n'entrerai point dans d'autres détails : il me suffit d'avoir indiqué le principe général de la formation des stades.

Lcs grandes mesures itinéraires de l'Inde, de la Perse, la plupart de celles de l'Europe, se décomposent toutes, du moins à peu de chose près, en un certain nombre de quelques-uns de ces stades.

Le farsang ou la parasange des Perses est, suivant le major Rennell, de 23 trois-quarts au degré, ou de 2,400 toises. On y trouve, à 6 toises près, 2r stades de I I 4 toises, et 25 stades olympiques, en supposant le pied un peu plus grand d'environ une ligne.

Le coss de l'Inde, de/42 au degré, a un peu moins 
de 1 a stades de I 4 toises, et se compose de 12 stades et demi de celui de Héron ( $\mathrm{roS}$ toises, 2 pieds.)

Le coss de 40 au degré, comprend i 5 stades olympiques.

Celui de 37 et demi au degré, en renferme 16 semblables, ou 20 stades pythiques.

Celui de 3 i un quart au degré, donne 16 stades de I 4 toises, ou 24 stades pythiques.

Celui de 29 trois-quarts..... 20 stades olympiques.

L'ancienne lieue gauloise est composée, soit de ro stades de Irít toises, soit de I 2 stades olympiques, ou de I5 stades pythiques.

Le rast ou la lieue germanique, introduite dans les Gaules par les Francs, comprend le double de ces stades, et quatre mille hébraïques de 5 go toises chacun.

Ainsi, selon moi, le système métrique des anciens, considéré dans ses premiers élémens, est parfaitement simple, très-régulier, et n'exige qu'une application de nos moyens naturels, eí des connoissances arithmétiques. Il paroît avoir été établi à une époque très-ancienne, et avoir passé de l'Orient, où la civilisation étoit concentrée, peut-être même de l'Egypte, qui, dans les premiers temps, formoit un vaste empire, en communication avec l'Inde, en Europe où il a dû nécessairement subir des modifications (1).

(I) L'harmonie que l'on a pu remarquer dans la comparaison de ces diverses mesures ne peut être le produit du hasard. Hérodote dit que la géométrie passa d'Egypte en Grèce, et qu'à l'égard du pôle, du cadran solaire et de la division du jour en douze parties, les Grecs les tiennent des Babyloniens. Hérod. trad. de Larcher. éd.

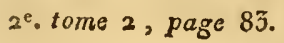




\section{N O T I C E \\ SUR LES PEUPLES}

DÉSIGNÉS ANCIENNEMENT SOUS LE NOU

DE SĖRES.

CitésIAs me paroît être le premier qui ait fait une mention expresse des Sères, dénomination qui a pour racine $z a r$, ancien mot persan qui veut dire or, ou ser qui a la même signification chez les Tibétains. Ce peuple appelle l'empereur de la Chine Ser-kji, roi de l'or. $K$ in, dans la langue chinoise, est le nom de ce métal, et c'est de là ou du mot $\sin$ que dérive celui de sinae, sous lequel les auteurs anciens désignoient les contrées de l'Asie, situées immédiatement à l'est ou au sud-est de l'Inde. La tribu des tatares Mantchoux se faisoit appeler tribu de $l$ 'or. Des idées grandes, comme celles qui annoncent l'élévation, la puissance, l'éclat, l'astre du jour, se rattachent au mème mot deser, considéré avec quelques légères modifications, dans l'acception que lui donnent ou que lui ont donnée divers autres peuples orientaux. Les anciens croyoient, et l'on trouve déjà dans Hérodote des traces de cette opinion, qu'il existoit aux extrémités les plus reculées de l'Asie une contrée très-favorisée par la nature, une sorte d'ophir, et que plusieurs auteurs ont nommée syria ou seria (I).

(I) Ces divers noms tirent leur origine, $\mathrm{I}^{0}$. du soleil et de ses proriétés, cet astre ayant été, dans la religion primitive, le symbolecle la 
Je distingue trois sériques. La première est celle de l'Asie supérieure, la sérique propre de Ptolémée. Quoiqu'elle n'ait été guère connue que depuis cet auteur, il y a cependant lieu de présumer que ee fut la première d'où k'on tira la soic. Les Assyriens, les Perses et les Prrthes en faisoient le eommerec. Cette sérique n’cmbrasse dans Ptoléméc que la partie septentrionale et occidentale de la petite Bucharie, et avoit pour métropole Turfan (sera metropolis). Trois routes, longeant la chaîne des monts Alak, Auzacii, et dont deux sur leur revers méridional et l'autre au nord, conduisoient et conduisent eneore des contrées occidentales limitrophes, à cette ville. L'une de ees routes, l'intermédiaire, vient de la Sungarie; les deux autres partent de la grande Bucharie, ctl'une d'elles passe près des sources du Sir (Jaxartus ); la route du nord se lie à celle du milieu par une Jranche sur laquelle on reneontre Oramtchi. La rivière nommée OEchardes par ce géographe, ne paroît être qu'une réunion du Tehis ou Tecas et de quelques autres rivières de la Sungarie, à l'est de la précédente. Celle qu'il appelle Bautisus est l'Hajitou, branehe de la rivière d'Yarkand ou d'Yerghien, et à laquelle il en joint aussị quelques autres, coulant des monts Alak. Les Huns septeutrionaux (Essedones), les Ygours ou Ouigours (Ithaguri), et d'autres hordes tartares qui occupoient alors la portion orientale et boréale de la petite Bucharic jus-

Divinité. $2^{\circ}$. De la richesse du pays. Aussi des lieux où les Sères s'établirent furent-ils appelés le pays de l'or, ou le séjour des fortunés. Zal ou Zalzar, fils de Sam Nérimaa, fut surnonmé Zer, parce qu'il vint au monde avec des poils blonds et dosés. Taba siguifie or en pehlvi; de lì peut-être l'origine du nom tabin, donué par Pline au promontoire le plus orieutal de l'Asie. 


\section{SUR LES SËRES.}

qu'au lac Lop, inconnu à Ptolémće, et jusqu'au désert de Cobi, conposent sa sérique. Des peuples de races scythiques s'étendent au nord-oucst et au couchant. Solana, Ottorocora, Orosana se trouvent sur la route méridionale qui alloit de Sera dans la Sogdianc. La carte générale du Tibet de d'Anville nous ollre sur une route que nous croyons être la mème, Soulona, Concour, Acsou, etc. La route septentrionale, après sa communication avec l'intermédiaire, se prolunge vers l'est jusquíà Actas, cu inclin.nt un peu vers le midi; et c'est dans ccttc partic surbaissée, que je placerai l'Asmirca Regio de Ptoléméc. Le lieu qu'il désigne sous le nom de Throana semble trouver son analogue dans Toboron de nos cartes, simué sur cette route. On voit qu'il avoit cu quelques renscignemens sur les pays qu'occupent maintenant, entre les monts Alak et Ulug-Tag, les Kirgises et les Kalmouks. Il y indique mème les premiers, $S y z i-$ ges. On ne pourra jamais établir une telle correspondánce, si on place la sérique dans le Tibet. Cette partie ccntralc de l'Asie, ainsi que la portion de la petite Bucharic, située en-dcçà de la rivière d'Yarkand, ont été inconnucs à Ptolćmée, de sorte qu'il a placé la sérique immédiatcment au-dessus des monts Himmala, Emodi montes, et de ceux qui borncnt au midi le royaume d'Assam, ou les Garrous (Ottorocoras qui et sericus mons). Des Sèrcs ont émigré de l'Asie cn Amériquc et - forment encore dans cette province du domaine de l'Esa pagne, nommée provincia de Sonora, un peuple particulier, très-distinct de ceux qui l'environuent, et qui a conservé sa dénomination primitive, Seri. Ainsi s'expliquent naturellement les rapports que $M$. le baron de Humboldt a reconnus entre les connoissances astrono. 
miques des Mexicains et eelles des Tatares et des Persans.

La.seconde sérique est celle du nord de l'Inde, le Ser-hend ou Sirhind (Serinda). Les invasions que firent sueeessivement dans la sérique supérieure les différentes hordes de Tatares du nord-est de l'Asie, les Huns particulièrement, obligèrent les peuples de cette sérique de s'expatrier. La Sogdiane, la Bactriane, le Tibet et l'Inde furent leur asile, et les révolutions qu'éprouvèrent ees eontrées par suite de ees eonquêtes, ehangèrent même l'état d'une partie de l'Europe. Denis le Périégète nous montre déjà des Sères sur le bord du Sir. Jornandès étend aussi leur domination jusque dans la Bactriane. Le Ser-hend fut une de leurs colonies. Ils y établirent la eulture du ver-à-soie, et e'est de là que des Missiomnaires grecs transportèrent, du temps de Justinien, les oufs de eet insecte à Constantinople.

La troisième sérique, celle dont les aneiens ont le plus généralement parlé , et que j’appelle Série (Seria), est l'Inde au-delà du Gange de Ptolémée, le pays que Cosmas-Indieopleuste nomme Juvia, et qui forme aujourd'hui l'empire des Barmas, ou les royaumes de Pégu et d'Ava. Dans la ville eapitale du dernier, je erois reconnoître celle que l'auteur du périple de la mer Erythrée appelle Thina, et qu'il dit être située sous la petite Ourse; eelle encore que Ptolémée désigne d'une manière presque analogue, sous le nom d'Urathince, placée sur le fleuve Serus, ou fleuve d'or; la grande Sère, Sera major, d'Ethicus et des tables de Peutinger; le lieu nommé Sinia Sinarum par l'Edrisi, ete., ete. De Dacca, située près de l'embouchure du Gange, partent deux routes, dont l'une conduit par Cospour, Munnypour, it 
la ville d'Ava; et dont l'autre, suivant au sud la côte maritime, aboutit à Aracan (Besynga). Le royanme de ce nom est l'Argentea regio de Ptolémée. Sa Chersonèse d'or se compose de la côte qui vient à la suite de l'extrémité occidentale du Delta, formé par le fleuve Irraouady. Les attérissemens qui se sont faits à son embouchure, depuis le sièclc de Ptolémée, l'incertitude de nos documens sur l'intérieur du pays, les changemens de noms, rendent très-difficile la détermination positive des lieux indiqués par ce géographe. Ses comoissances, pour cette partie, s'étendoicnt jusque près des limites occidentales ct méridionales de la Chinc, l'Y Yunnan. Le nom de la ville de Monchaboo semble nous rappeler celui du peuple septcntrional, qu'il place immédiatement sous le mont Ottorocoras, les Cacobce. Les Montagnards du Sillet et du Tipera, y sont désignés sous les noms de Tiladce et de Basadae. Deux espèces de bombyx ( $m y-$ litta de Fabricius, et cynthia de Drury) y sont très-communs, et fournissent, depuis un temps immémorial, une soie d'un grand usage. Je me suis assuré, par un manuscrit chinois, accompagné de figures, et qui m'a été communiqué par. M. Hüzard, que les chenilles de ces bomby $x$ sont les vers-á-soie sauvages de la Chine. Il esi probable qu'une partie des soieries que les anciens se procuroient par leur commerce maritime avec les Indiens, provenoient de ces insectes. Les peuples du Yunshan, ceux qui paroissoient être les Sésates de l'auteur du périple de la mer Erythrée, les Basanarce et les $A$ cadrce de Ptolémée, faisoient un trafic des produc- . tions naturelles de leur pays, et laissoient sur les lieux où ils se rendoient pour cet objet, des roseaux avec lesqquels on faisoit trois espèces de paniers, nommés généri- 
quement Malabsthrum. C'est dans cețte sérique qu'il faut placer l'ile Seria de Pausanias, arrosée aussi par le fleuve Ser, dont les hahitans cultivoient l'iusecte qui produit la soie, et que eet auteur compare à une araignéc.

Ie golfe Martaban fut long-tenips, pour ectte partie orientale dn monde, la limite des connoissances géographiques; mais l'on voit, par celles que nous out transmises Pline et Pomponius Méla, que la navigation avoit 'déjà fait d'autres progrès, et qu'on étoit parvenu jusqu'à l'Archipel Mergui. Ptolémée et Cosmas-Indicopleuste contirncut ces renseignemens. Le dernier nous dit qu'on pouvoit aller au pays de Tsin par terre et par mer; il compte quatre eents journées de trente milles chaque, depuis le commencement de cette route jusqu'à Cadix, en traversant la contrée qu'il nomme Juvia, l'Inde, la Bactrianc, etc., et la longueur de cette route est la mesure de la longueur de la terre. En supposant que ces milles soient des milles grecs, de $9^{\circ}$ au degré, ou que les trente égalent 200 stades olympiques, estime des marches journalières, nous aurons s 33 degrés et un tiers. Si nous en déduisons un tiers pour ramener cette route à une ligne droite, il restcra 88 degrés 53 minutes, valeur trèsrapprochée de celle de l'arc formé par cette route.

Tel est le résumé de mes obserrations principales sur les sériques ou les entrepôts du commeree de la soie dans l'antiquité. Je me proposé de développer ees idées dans un mémoire spécial. 


\title{
ÉGLAIRCISSEMENS
}

\author{
S U R
}

\section{LA CHRONOLOGIE ÉG Y P T I ENNE.}

O B S E R VAT I ON.

CE mémoire a paru en ${ }^{2} S_{1} 7$, et les améliorations dont il est susceptible pouvant être indiquées par forme de remarque, je le reproduis ici tel que je l'ai publié. Ces changemens sont relatifs à la durée de la monarchie égyptienne et aux temps antérieurs à Sésostris. Dans la supposition que ce personnage soit le même que le Sistosicherınes de la table des rois de Thèbes, du Laterculus d'Eratosthène, et que le commencement de son règne précède d'environ vingt-trois siècles l'ère chrétienne, l'origine de cette monarchie seroit antérieure d'environ neuf siècles et demi, ce qui reporteroit l'époque du déluge vers 3 ı $о$ r, ou l'ere du haliougam. Mais j'ai reconnu depuis que ces calculs devoient être rectifiés. $1^{\circ}$. L'institution de l'ère du kaliougam n'est fondée que sur la durée des règnes des premiers rois de l'Inde, et cette durée estévidemment exagérée. La premiere dynastie, composée de trente rois, à commencer à Djedaschter, prédécesseur immédiat de $\mathrm{Pa}$ ritschhat ou de Noé, remplit un intervalle de temps de ${ }_{7772}$ années et onze mois; et d'où il résulteroit que le règne de chacun de ces rois seroit presque de 60 ans, hypothèse inadmissible, puisque la moitié de ce nombre est déjit trop forte comme terme moyen. $2^{\circ}$. Le canon des rois de Thibles, 
d'Eratosthène, a pour base une réduction des douze premières dynasties des rois d'Egypte, mais qui n'est pas moins vicieuse, par le nombre des doubles emplois.

La généalogie de Zoroastre, donnée par Anquetil du Perron, dans le Zend-Avesta, nous permet enfin de débrouiller ce chaos. Observons d'abord avec cet auteur, que le nom de Zoroastre est formé du Zend, Zerethoschtrô, ministre d'Ormuzd. Je distingue trois personnages de ce nom; le premier auroit vécu avant le déluge, et pourroit bien être le Thoth égyptien, sous une autre dénomination. Le second, celui qu'il nous importe le plus de connoître, descendoit de Minotcher, petit-fils de Féridoun, le Noé des Parses, et parut quatorze générations après celui-ci. Le troisième, et qu'on a confondu avec le second, existoit du tenips de Guschtasp ou de Darius, fils d'Hystape; et tout ce que le Parses disent de lui, ne peut convenir qu'au prophete Daniel. Le second Zoroastre fut le premier législateur des Perses, ou plutôt des Saces, qui avoient vécu jusqu'alors à la manière sauvage des autres Scythes. Sésostris, nom qui n'est que celui de Zerethoschtrô, abrégé et adouci, est représenté non-seulement comme un Hercule et un puissant conquérant, mais encore comme un prince législateur et religieux. Zoroastre, quinzième descendant de Féridoun, par Minotcher, a pu être contemporain de Sésostris. Il eut trois filles, Pari, Sarit et Poursische. Diodore dit que Sésostris fut très-secondé daus ses glorieuses entreprises, par sa fille Athirthe, et nous soupçonnons qu'il l'établit reine d'Assyrie et des autres pays asiatiques qu'il avoit conquis; telle est probablement la fameuse Sémiramis. Le passage de Diodore relatif à Belıs et l'époque a laquelle remontent les observations astronomiques trourées à Babylone par Callisthène, nous indiquent que ce Belus est encore le même que Sésostris. Le huitième roi de la seconde dynastie des rois d'Égypte, ou le seizième de tous, est nommé Sésochris. On assure qu'il avoit cinq coudées de hauteur et trois de largeur. Son règne fut de $4 \hat{S}$ ans. Telle est aussi 'a 
durée du règne de Sésostris. Ce rapport, et celui que nous offre le nombre des rois qui ont précédé Sésochris, comparé avec la généalogie de Zoroastre, nous pronvent que les deux premières dynasties des rois d'Egypte, celles des Thinites, représentent sous d'autres noms, mais dont quelques uns cependant décèlent l'identité d'origine, représentent, dis-je, cette même filiation. Afrasiab, petit-fils de Tour, s'empara des états de Dorasroun ou Naoudhar (Athothis, Tosorthus, Othoés), fils de Minotcher ou Ménès. S'il est le même, comme je le soupçonne, qu'Evechoüs, il précédera Belus (Syncelle) de treize générations, et l'on en comptera quinze entre celui-ciet Minotcher. Le catalogue des rois d'Égypte, de Manéthon, nous donne le même nombre entre Ménès et Sésochris. Dans le canon des rois de Thèbes, d'Eratosthènes, Phiops, le même encore qu'Evechous, est pareillement antérieur à Sistosichernès, de treize générations; analogies trèsfrappantes, et qui confirınent les identités des personnages que nous avons reconnues, ainsi que la réalité de la généalogie de Zoroastre on de Sésostris, que nous offre le Zend-Avesta. Minotcher avoit le surnom de Firouz. Suivant Manéthon, Suphis, second roi de la quatrième dynastie des rois d'Egypte, avoit vu les dieux, et composé un livre sacré, très-honoré des Egyptiens. Il appartieut donc à la première dynastie, plutôt qu'à la quatrième, et il doit être le mềne que le fils de Menès, désigné dans cette dernière sous le nom de Soris, correspondant à celui de Firous. La troisième dynastie, composée de neuf rois, ainsi que la précédente, et dont le second, Tosurthrus, l'Esculape égyptien, se confond , malgré des dissemblances nominales, avec la précédente, ou lui est du moins parallèle. Ainsi cette multitude de rois qui composent les onze premières dynasties égyptiennes de Manéthon, ne formera avec les deux premiers rois de la douzième, que quinze générations au plus, èt dont la durée totale et moyenne, en prenant pour règle les deux dynasties des Thinites, sera de 472 ans. Les observations astronomiques trouvées à Baby- 


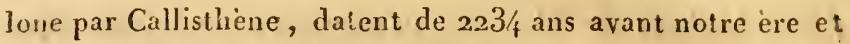
du temps de Sémiramis ou de celui de Belus (qu'il ne faut pas confondre avec le dieu Bel ou Baal). Sésostris, d'aprés Manéthon, régna 48 ans. En supposant que ces observations aient commencé lorsqu'il étoit au milieu de sa carrière, il aura pris les rênes de l'empire égyptien vers 2260. La première année du règne de Ménès sera donc antérieure de 472 ans, et remontera à 2732 . La fondation de Thebes, que j'attribue à Cham, le Saturne des Grecs et des Romains, le Busiris de Diodore, auroit précédé celte époque de quel. ques années. J'ai dit (Mém. sur le Premier Age du Monde), que l'institution de la célèbre période de I 9 ans coincidoit presque avec l'époque du déluge, et que le cycle caniculaire dérivoit naturellement du précédent. L'année 1323 avant Jésus-Christ a été la première d'une période sothiaque. Si cette période a été établie en même temps que celle de sgans, $I_{4} 61$ ans ajoutés á 1323 , nous donneront 2784 , et telle sera l'époque du déluge; calcul qui s'accorde très-bien arec ceux que je viens de présenter. Fallût-il, au surplus, rapprocher d'un siècle cette époque, l'erreur, pour des temps historiques aussi incertains, ne seroit pas tres-importante, et je crois avoir pris, afin de découvrir la vérité, des moyens beaucoup plus rigoureux et plus généraux que ceux dont on s'est servi jusqu'à moi pour un but semblable.

Presque tous les interprètes de la Bible, qui ont suivi le texte lébreux, fixent le déluge à l'an 23400 avant l'ére chrétienne, date postérieure à la nôtre de près de quatre siecles et demi. Mais comme il n'est ici question que d'un point litigieux de chronologie, et n'intéressant point la foi, on peut, lorsqu'on a des motifs raisonnables, s'écarter de l'opiuion commune, et c'est ce qu'avoient fait avant moi dessavans très-recommandables et qui n'ont pas été blàmés. Ils ont pris pour guide la version grecque des Septante; mais je crois que lintelligence de certains passages communs aux divers textes de l'Ecriture Sainte, exige la reclification que j’ai proposée. Tonte la difficulté consistc dans l'évaluation du temps com- 
pris entre Abraham et la délivrance des Israélites par Moyse, ou leur sortie d'Egypte. On voit d'abord que du temps d'Abraham, les pays situés entre la Méditerranée et l'Euphrate étoient divisés en petits états, ce qui ne peut convenir qu'à une épocque antérieure anx conquêtes de Sésostris et à la formation de l'empire d'Assyrie. Dien aunonce à ce père des croyans que sa postérité sera esclave dans une terre étrangère, qu'elle y sera afligée pendant quatre cents ans, mais qu'il fera justice de ses oppresseurs, et qu'elle reviendra avec prospérité daris son pays natal, la quatrième génération (ou plutôt le quatrième âge ). C'est à l'époque de cette prophétie que les interprètes font commencer ces quatre siècles de servitude. Mais ce point de départ ne tombe-t-il pas plus naturellement à la mort de Josepls, ou du moins àu témps oì son père se retira, avec sa famille, en Égypte? Pourra-t-on concevoir que Moyse soit sorti de ce pays avec une armée de 600 , noo liommes, non compris les enfans, si la postérité de Jacob n'y a demeuré qu'environ deux siècles? L'Ecriture ne dit-elle pas formellement (Exode, chap. 12, vers. 40.) que le séjour des eufans d'Israël en Ėgypte, a été de 430 années? IN'est-il pas évident d'après cela que les quatre âges, au bout desquels les Hébrenx devoient retourner dans la Palestine, ne commenceut qu'à l'époque de leur émigration en Egypte? Je conclus que cet événement, ainsi que le siècle d'Abraham, doivent être beaucoup plus reculés qu'ils ne le sont dans la clironologie généralement admite. Selon quelques auteurs anciens, Abraham fut contemporain de Sémiramis; mais je crois qu'il lui est antérieur de quelques années. Josephe rapporte à cet égard un passage curieux tiré d'Alexandre Polyhistor: İe propliète Cléodène, surnommé Malch, qui, à l'exemple du législateur de Moyse, a écrit l'histoire des Juifs, dit qu'Abraham eut de Céthura, entre autres enfans, Apliram, Sur et Japhram; que Sur donna le nom a la Syrie; Aphram, à la ville d'Afie, et Japhram, à l'Afrique, el qu'ils combattirent dans la Libye contre Anthée, sons 
la conduite d'Hercule. Il ajoute, selon Josephe, qu'Hercule épousa la fille d'Aphram, et qu'il en eut un fils nommé Dédore, père de Sopho, et qui a donné son nom aux Sophaces. Si on pouvoit avoir quelque confiance dans ces traditions, nous pourrions conjecturer que cet Hercule est Sésostris. Les Perses croient généralement que Zoroastre est le même qu'Abraham. Parmi les enfans qu'on lui donne, on en distingue (Zend-Avesta) trois : Esderaster, chef des Athornés; Orouertour, chef du Varljemguerd (terre basse); et Khorschidtcher, chef des soldats, demeurant dans le Kanguedez. Nous observerons aussi que, selon Bérose, il a vécu dans le neuvième âge apres le déluge, et que dans des auteurs arabes il n'eșt que le petit-fils de Tharé; de manière que le nombre des patriarches qui ont vécu apres le déluge, seroit de onze au lieu de dix. Quoi qu'il en soit, si nous admettons avec quelques chronologistes, que la sortie des Israélites précède d'environ dix-sept siècles l'ère chrétienne, Jacob se sera retiré en Egypte vers 2r3o, et à une époque où la partie inférieure de cette contrée étoit occupée par des peuples pasteurs, et dont une partie, comme originaire de Phénicie, devoit être bien disposée en faveur de ces nouveaux venns. Ce roi nouveau et persécuteur des Hébreux, dont parle l'Ecriture, ne peút être qu'un de ces souverains légitimes qui commencèrent l'expulsion des peuples pasteurs. La naissance d'Abraham sera reportée vers 2420 avant notre ère. Elle est postérieure au déluge de 352 ans, ou même de quelques années de plus, si l'on admet qu'il ne fut que le petit-fils de Tharé; cette époque du déluge sera dès-lors parfaitement concordante avec celle que nous avons établie sur d'autres données.

SI l'on pouvoit ajouter foi à des traditions rapportées par Diodore et Manéthon, les plus anciennes pyramides d'Égypte, ces monumens de despotisme et de tyran- 
inie, pour me servir des expressions d'Aristote, auroient été élevées peu de temps après la fondation de cet empire. Suivant le premier de ces auteurs, on donnoit à la plus grande, celle de Chemmis, 3400 ans d'antiquité, . lors de son voyage dans ce pays. S'il en étoit ainsi, les connoissances des Egyptiens en géométrie et en astronomie, devoient être très-foibles à cette époque. Leurs plus beaux monumens, quoique d'un style grandiose, attestent même qu'ils n'étoient point ou presque pas instruits dans la géométric des courbes. Les rois et les grands de cette monarchie ne vouloient pas que leurs dépouilles mortelles fussent confondues avec celles du peuple ou plutôt de leurs esclaves; et ces pyramides étoient destinées à recevoir les premières. Voilà tout ce que l'histoire nous apprend sur le but de la construction de. ces édifices (I). Qu'ils en aient coordonnéles dimensions générales et particulières au système métrique usuel, cela est possible. J'accorderai même qu'on s'est proposé, en érigeant ces monumens, de perpétuer la mémoire de l'établissement de ce système. Je ne contesterai pas non plus la valeur que l'on assigne à ces ștades, dont on regarde l'établissement comme la conséquence d'une mesure géodésique; mais nous avons vu que la formation du stade pythique ne supposoit pas de connoissances en trigonométric et en astronomie, et que cette base une fois posée, les autres stades en dérivoient naturellement; en un mot que le.système métrique des anciens n'ofiroit qu'une simple combinaison des longueurs moyennes du pied et de la coudée de l'homme et oumise à un calcul décimal et duodécimal (2).

(1) Nul doute que cette forme n'ait étél'emblême du feu, le prenier agent de la nature, dans leur cosmogonic.

2) M. leCher. Delambre, dans son rapport sur les travaux mathéma- 
Fiers de leur antiquité et de leurs lumières, les FEgrptiens auroient-ils fait un mystère aux Grecs et aux homains, qui venoient s'instruire clez eux, de ces comnoissances sur lesquclles est censé avoir été fondé leur système métrique, et qui auroient rehaussé leur gloire? Que de tâtonncmens et de calculs ils eussent épargné aux géomètres ct aux astronomes qui essayoient de déterminer l'éteudue de la circonférence de la terre!

L'antiquité que donne Diodore, d'après quelques opinions populaires, à la graude pyramide d'Egypte, est établie sur un nombre de génćrations que les Grecs évalnoient à 30 ou 33 (trois par siècic) ans; cétoitl'àge auquel on avoit légalcment la faculié de. se marier. II rapporte que les prètres du pays comptoient depuis Horus, le dernier des demi-dicux, jusqu'à la ro8e. olympiade, temps auquel il visitoit cette contrée, gouvernée alors par Ptolémée Denis', 15000 ans. Les règnes de quatre cent soixante-dix rois et cinq reines, remplissoient l'intervalle de temps qui s'étoit écoulé depuis Horus jusqu’à la conquète de ce pays par Cambyse : les rois de Perse en étoient restés maîtres pendant cent ireute - cinq ans; enfin les Macédoniens l'avoicnt occupé l'espace de deux cent soixante-scize années. Les quinze mille ans se composent de cinq cents générations de trente années chaque, savoir vingt-cinq pour la dynastic des Perses et des Macédoniens, et quatre cent soixante-quinze ans pour lcs antérieures. Cc nombre diffère peu de celui de quatre ccnt quatre-vingt-six quc donue Africain dans sa liste des rois d'Egypte depuis Ménès inclusiveliques de l'Acalémie des Sciences, pour 1817 , a bien voulu confirmer ces observations par de nouveaux raisomnevens mathísnatigues. 
ment jusqu'à Cambyse, en supplćant à la lacune qu'offre la quatorzic̀me dynastie, celle des Zoïtes, au moyen du catalogue des mèmes rois, publié par Eusèbe ; cette dynastie comprend soixante-seize rois. En admettant qu'il a pu se glisser l'erreur d'une dizaine, soit dans ce nombre, soit dans d'autres semblables et relatifs à des dynasties incertaines, ces supputations seront presque identiques. Si on considère qu'en Egypte, ainsi que dans tous les pays très-chauds, la virilité est très-précoce ct qu'on y a souvent des enfans à un âge où l'on est à peine nubile dans les contrées plus éloignées de l'équateur, l'on concevra la nécessité de restreindre pour ces cas particuliers la valeur des générations. Une note de M. Langlès, insérée dans la traduction françoise du voyage de Forster au Bengale, nous apprend (tome $\mathrm{I}^{\mathrm{er}}$. page 297) que le Kachemyr avoit été gouverné jusqu'à l'an 1586 par cent quatre-vingt-onze souverains, qui avoient régné en tout quatre mille cent neuf ans, onze mois et neuf jours, de sorte que le commencement du règne du premier remonte à près de deux mille cinq cent vingt-quatre ans avant notre ère. La durée moyenne des règnes seroit d'un peu moins de vingt-deux ans. Newton n'évalue même une génération qu'à vingt ans; mais d'après des calculs particuliers et relatifs à l'histoire de l'Egypte, nous estimerons à vingt-quatre ans la durée de chaque règne : évaluation que l'on pent encore déduire du nombre des souverains qui composent la troisième race des rois de France. Manéthon, suivant Syncelle, comptoit cent treize rois en ligne successive, depuis Ménès inclusivement, jusque vers la quinzième année qui précéda la conquête de l'Egypte par Alexandre, et la durée totale de ces règnes étoit de trois mille cinq cent cinquante- 
cinq ans, ce qui nous donneroit environ trente et un ans par génération. Si aux trois mille cinq cent cinquante-cinq ans, nous ajoutons les quinze années qui précèdent l'expédition d'Alexandre, nous aurons trois mille cinq cent soixante-dix ans, qui font juste cent dixneuf générations de trente ans; et peut-être faut-il lire dans le texte de Syncelle ou de Manéthon, cent dixneuf, au lieu de cent treize. Les cent dix-neuf générations à vingt-quatre ans chaque, font deux mille huit cent cinquante-six. La conquête de i'Egypte par les Masédoniens étant antérieure de trois cent trente-un ans à l'ère chrétienne, la fondation de l'empire égyptien remonteroit à trois mille cent quatre-vingt-sept ans avant la même ère. Mais, en n'admettant que cent treize générations, ainsi que le porte le texte, cette époque seroit moins éloignée de cent vingt-neuf ans, ou dateroit de 3058. Dicæarque comptoit depuis Sésonchosis, qui régna après Horus, fils d'Osiris et d'Isis, deux mille cinq cents ans jusqu'à Nilus, et depuis celui-ci jusqu'à la premic̀re olympiade ( 776 ans avant notre ère) quatre cent trente-six ans. Il s'est écoulé douze cent douze ans entre Nilus et la première année de notre ère. Les deux mille cinq cents ans qui ont précédé Nilus font quatre-vingttrois générations et un tiers, de trente ans; mais si nous diminuons la durée de chacune d'elle d'un cinquième, nous aurons deux mille deux années, qui avec les douze cent douze, feront trois mille deux cent quatorze. Si Dicæarque a compté trois générations par siècle, les deux mille cinq cents ans répondant à soixante-quinze générations, qui multipliées par vingt-quatre, donneront dix-huit cents ans; alors le règne de Sésonchosis dateroit de trois mille douze ans avant l'ère chrétienne. MIais ce 


\section{EGIPTIENNE.}

personnage est-il le même que Ménès?.C'est ce que je suis fondé à croire. Tout semble annoncer que Dicæarque a voulu indiquer une époque historique; et Sésonchosis ou Ménès étant le premier des rois mortels, qui, dans le gouvernemeni de l'Egypte, ont succédé aux demi-dieux, Dicæarque a pu considérer Sésonchosis comme fils, ou plutôt comme descendant d'Horus, le premier de ces demi-dieux. Nous avons vu que d'après Manéthon, la durée totale des règnes des souvcrains d'Egypte, depuis Ménès inclusivement jusqu'à la conquête de cet empire par Alexandre, étoit de trois mille cinq cent soixante-dix ans. De cette époque au commencement de notre ère, il s'est écoulé, comme nous l'avons dit plus haut, trois cent trente-un ans, qui ajoutés à la somme précédente, font 390 r ans. Or, d'après le calcul de Dicæarque, le règne de Sésonchosis auroit précédé motre ère de 3713 , date qui, pour des temps aussi reculés, ne diffère pas essentiellement de celle que nous venons de donner, d'après Manéthon. Au témoignage de Justin, les Scythes, après avoir mis en fuite Vexoris (I), roi d'Egypte, qui avoit porté la guerre dans leur pays, rendirent l'Asie leur tributaire, et ils conservèrent leur dénomination jusqu'à Ninus, l'espace de quinze siècles. Or Ninus, qui, d'après mcs conjectures, fut établi roi d'Assyrie par Sésostris, le Belus que Diodore de Sicile dit fils de Neptune et de Lybie", régnoit vers 2250 avant

(1) On voit par ce passage de Justin que les Scythes poursuivirent 'Vexoris jusqu'à l'Égypte, et que ses marais, ou plutôt ceux du Deltu, les empêchèrent d'y pénétrer. Cela confirmeroit l'opinion de ceux qui, d'après Hérodote et les observations de l'exhaussenient graduel du sol de ce pays, pensent qu’a l'exception du Sayd, il étois anciennement couvert d'eạu, et dès lors inbabitable. 
l'ère chrétienne. Vexoris, antérieur de quinze siccles, auroit donc vécu vers 3750 , avant cette èrc, et pourroit être encore le même que Ménès. Il paroît d'après Africain et Eusèbe, qui avoicnt cxtrait leur liste des rois d'Egypte de l'ouvrage de Manéthon, que Thèbes ou Diospolis a cessé d'être la résidcnce des souverains de ce pays, ou d'en avoir de particulicrs, vers le temps que Smédès ou Smendis, quc nous croyons être le Chemmis dc Diodore ou le Chéops d'Hérodote, fonda unc nouvelle dynastie, la vingt-unième et la première des Thinites; la précédente est la dernière des Diospolites. On peut conclure d'un passage de Diodorc relatif à Chemmis, qu'il vivoit environ dix siècles avant le voyage de cet historien cn Egypte, voyage antérieur à notre ère d'environ soixante ans. Le nombre des rois de Thèbes, d'après le canon qu'en avoit donné Eratosthène, est de quatrevingt-onze. En supposant la durée de chacun de leurs règnes de vingt-quatre ans, leur durée totale sera de deux mille cent quatre-vingt-quatre ans, qui avec mille soixante indiqueront l'époque du commencement du règne de Ménès ou Minès, trois mille deux cent quarante-quatre. Mais il est possible que la dernière dynastie des Diospolites, ou la vingtième de Manéthon, ait régné conjointcment avec la vingt-unième, ce qui rapprocheroit de nous cctte époque. Les observations de M. Girard sur l'cxhaussement progrcssif du sol de l'Egyptc, qui est produit par les inondations du Nil, nous prouvent que la fondation de Thèbes doit remonter au moins à deux mille huit cents ans avant l'ère chrétienne. Nous verrons plus bas, par des calculs de détails ou de petites époques lićes enscmble, que la date de cette fondation s'accorde arec notre chromologic, et que plusieurs difficultés que 
présente à cet égard l'histoirc ancienne de l'Egypte se. ront aplanies, si l'on accorde que eet empire a eommencé environ trente siècles et demi avant l'ère cliréticync.

Suivant Diodore, on donnoit trois mille quatre cents ans d'antiquité à la grande pyramide de Memphis. Ce nombre répond à cent treize générations et un tiers, de trente années ehaeune. En diminuant ees générations d'un cinquième, nous aurons deux mille sept cent quatorze ans, auxquels il faut ajoutcr soixante ans pour l'époquc antéricure à notrc c̀re, à laquelle Diodorc visitoit l'Egypte. Ainsi la fondation de la grande pyramide précéderoit notre ćre dc deux mille scpt cent soixantequatorze ans. L'Imandès de Strabon, qu'on eroit être 'Osymandyas ou l'Osymanduć de Diodore, fut enterré, selon le premier de ces historiens, dans une de ccs pyramides d'Egypte; or, nous verrons que ce roi a vécu environ deux siècles plus tard. On attribuoit, au rapport le Manéthon, la fondation de la plus grande de eelles yui sont auprès de Memphis, à Suphis, seeond roi de la fuatrième dynastie, ou le onzième des deux premières lynasties des Memphites, réunics. Ces dynasties, ainsi fue celles des Thinites et des Eléphantins (la race de Susiris, de Diodore; celle des Ethiopicns, d'Hérodote), ont composées de rois, qui, à l'exception dc Ménès, ñt régné simultanément sur autant de pctits états; il s'en uivroit que Suphis seroit postérieur à Ménc̀s, d'environ ix générations ; et si aux deux mille sept eent soixanteuatorze ans, nous ajoutons deux cent soixante-quatre our les onze générations, Ménès aura commeneé à réner trois mille trente-huit ans avant notre c̀re. Une traition de Coptes porte que les pyramides ont été Jâties 
par un roi nommé Saurid, et l'on cite même à l'appui une inscription. Mais sans ajouter foi à ces récits apocryphes ou dénaturés, il n'est pas moins remarquable que le nom de ce prétendu fondateur des pyramides est presque semblable à celui de Soris, prédécesseur immédiat de Supliis. Manéthon dit encore qu'on regardoit Vénéphès, le troisième roi après Ménès, comme auteur des pyramides de Cochome.

Je terminerai cette note par l'indication de quelques époques principales de la chrónologie égyptienne, coordonnée à mon système.

Années is vant J.C.

331. Fondation d'Alexandrie. (Larcher.)

525. Conquête de l'Egypte par Cambyse. (Larcher.)

763. Sabacos (Sabbacon, d'Africain et d'Eusébe, le $1^{\text {er }}$. roi de la $25^{\mathrm{e}}$. dynastie) roi d'Ethiopie, fait la conquête de l'Egypte. (Larcher.)

La durée de la $22^{\mathrm{e}}$. dynastie et celle de deux suivantes est, suivant Africain, de 215 ans : 763 et 2,5 font $97 S$ ans. Or Sésac ou Sésonchis, chef de la $22^{\mathrm{e}}$. dynastie, a commencé à régner vers 970 , d'après des rapprochemens chronologiques établis par Larcher.

1 100. Smédès ou Smendis, le Chemmis de Diodore, $\mathrm{I}^{\mathrm{er}}$. roi de la $2 \mathrm{I}^{\mathrm{e}}$. dynastie, monta sur le trône d'Egypte 130 ans (Africain) avant Sésac. Il paroît, d'après Diodore, que Chemmis vivoit environ mille ans avant lui.

1309. Sethos, le Cétès ou le Protéc des Grecs, le Céthosis Ramessès de Josèphe, frère, selon lui, d'Armaïs ou de Danaüs, et appelés l'un et l'au- 
tre Egyptus, fonda la r $9^{\mathrm{e}}$. dynastie, qui dura, suivant Africain, 209 ans. Il régna 59 ans, au rapport de Josèphe; et si la prise de Troie eut lieu ell I $27^{\circ}$, il put être témoin de cet événement.

Etablissement ou renouvellement du cycle caniculaire sous Aménophis ou Mémophis, dernier roi de la $18^{e}$. dynastic (Africain), le Mlénophrès de Théon, et non Sésostris, comme le prétend Larcher.

La durée de cette dynastie est de 393 ans, selon Josèphe; elle ne seroit cependant que de 329 ans, en additionnant les durées partielles des règnes dont il la compose. Dans le catalogue qu'Africain a donné de cette dynastie, il a omis Armecesmiamun, dont le règne fut, selon Josèphe, de 66 ans et deux mois, et la durée de celui d'Amos ou Amosis Thémosis. On découvre aussi quelques autres différences; mais au reste la succession des rois, à quelques changemens de noms près, est la même. Si l'on augmente la durée de quelques règnes, d'après la comparaison du texte de Josèphe avec ceux d'Africain et d'Eusèbe, relatifs à la même dynastic, on trouvera que la durée de cette race diffère peu de celle de $39^{3}$ (I), que lui assigne Josèphe; d'ailleurs 17 générations à $2 / 4$ ans, font 408 , somme d'années très-rapprochée

(r) Elle ne seroit que de 329 ans, moins un mois, d'après sa citation du passage de Manéthon, relatif à la durée des règnes de cette dynastie. Mais il dit ailleurs que cette dusée est de 393 ans. Cette différence, au surplus, ne seroit gुuère que d'un demi-siècle. 
Annćes avant J.C.

de la précédente. Il faut placer dans cette dynastie le roi que Diodore nomme Mendès ou Marus, que l'on regardoit comme l'auteur du labyrinthe, et qu'Hérodote a confondu avec Maris. Cette erreur étoit d'autant plus facile, que le lac creusé par ce dernier est situé dans le même lieu. Il'est d'ailleurs impossible que $9^{\circ o}$ ans avant cet historien, le Nil inondàt la partie de l'Egypte, située sous Memphis, lorsque sa hauteur n'étoit que de huit coudées.

7702. Amosis ou Thmosis, fondateur de la I 8 e. dynasa tie, délivra l'Egypte de la domination des peuples pasteurs (I), composés de Phéniciens, d'Arabes et Pelasges qui, s'étoient établis daus sa partie inférieure. Josèphe dit qu'après l'avoir occupée paisiblement, l'espace de 5 I I ans, depuis leur invasion, les rois de la Thébaïde et des autres portions de l'Egypte qui n'avoient pas subi le joug, se réunirent et leur firent une guerre qui dura long-temps. Le pèré d'Amosis les obligea de se retirer dans un lieu nommé Avaris. Supposons que le commencement de la guerre ait précédé l'expulsion de ces étrangers d'une vingtaine d'années, leur invasion sera antérieure à cette expul-

(3) Fréret et d'antres savans critiques distinguent ecs peuples pasteurs des Hébreux ou des Juifs, et pensent que l'expulsion des premiers ne coïneide pas avec la sortic des. seconds. On voit cependant que la quinzième dynastie des rois d'Egypte est composée, d'après Africain, de peuples phéniciens, dénomination qui pourroit s'appliquer au: Hébrcux. 
sion, de 53r ans: elle remontera à 2233 ans. Fréret et Bailly prétendent, d'après un passage de Syncelle, que les pasteurs entrèrent en Egypte la $700^{\circ}$. année d'un cycle sothique, et qui tomberoit en l'an 2082 avant notre ère; mais, outre que ces calculs ne peuvent s'accorder avec ce passage de Josèphe, il est évident que Syncelle, pour établir son système de chronologie, fixe de sa propre autorité la première année de cette période à la première du règne de Ménès. L'invasion des pasteurs se fit, selon Josèphe, sous un roi nommé Timaüs, que je présume, d'après plusieurs rapprochemens, être le même que l'Amurtceus ou ''Amythantceus d'Eratosthène. Africain et Eusèbe. placent Sésostris, qui me paroît être le Sistosichermès d'Eratosthène, dans la $\mathrm{I}^{\mathrm{e}}$. dynastie. Les quatre rois qui viennent après lui et qui terminent cette dynastie, régnèrent peu de temps. La durée totale de ces quatre règnes est de. 28 ans, selon Africain, et de 5o, selon Eusẻbe. Le canon des rois de Thèbes d'Eratosthène nous offre quatre rois entre Sistosichermès et Amurtxus, qui est le $38^{\mathrm{e}}$., et le dernier de ceux dont le Syncelle nous a transmis les noms. La durée totale des règnes de ces qua tre souverains est de 67 ans. Les lacunes que nous présente le cataloguedes rois d'Egypte, dans Africain et Eusèbe, immédiatement à la fin de la $12^{e}$. dynastie, nous prouvent qu'il y eut de l'anarchie et que cet empire fut divisé, par suite. probablement de l'invasion que firent les peuples. pasteurs. En évaluant, avec Africain, le temps qui. s'est écoulé entre Sésostris et la fin de sa dynas- 
Annies

vant J. C.

tie, à 28 ans, la mort de Sésostris dateroit de 2261 , ou d'une vingtaine d'années de plus quand on se rapprocheroit d'Eusèbe pour l'estimation précédente.

2309. Sésostris ( 1 ), suivant Africain, et qui en cela s'accorde avec Eusèbe, régna 48 ans. 11 prit donc les rênes de l'empire vers 2309 . Eratosthène donne 55 ans de règne à Sistosichermès. Il est le $33^{\text {e }}$. roi de Thèbes et le treizième depuis Phiops ou Apappus. Les noms de Nitocris, de Merès ou Meurès, d'Anchunius Ochy, ou Schuniosochos, que l'on voit dans cet intervalle, nous rappellent et dans la même séric la reine Nitocris d'Hérodote, le roi Moeris de Diodore et celui qu'Africain met à la tête de la $12^{e}$. dynastie, Geson

(1) Au rapport de Simplicius, les observations astronomiques trouvées à Babylone, par Callisthène, neveu d'Aristotè, remontoient à 1905 ans avant le $19^{\mathrm{e}}$. du règne d'Alexandre, ou à 2234 ans avant notre ère. Si Sésostris est, comme je le soupconne, le même que le Bélus, fils de Neptune et de Libye, et qui établit un observatoire dans cette ville, le règne de Sésostris peut se déterminer par cette époque ; il doit lui être antérieur de quelques années. Si Sésostris, d'autre part, est le même que le Sistosichermès de la table des rois de Thèbes, tirée du Laterculus d'Eratosthène, nous pourrons fixer l'époque de la première année de Ménès, car la durée des règnes des trente-huit premiers rois est de 1055 ans. Si nous. en ôtons 185 ans, somme composée de la durée du règne de Sţtosiehermès et des cinq autres derniers rois qui lui succèdent, il restera $8_{70}$ ans. Supposons maintenant que le commeneement $d u$ règne de Sistosiehermès remonte ì 2280 avant notre ère, la première année de Ménc̀s tombera à l'ân 3,50. 


\section{ÉGYPTIENNE.}

Goses ou Sésonchoris, auquel succède Ammanmès ou Amménémès. Sésostris vient immédiatement après lui. Eratosthène nous offre, entrc Shuniosochos et Sistosichermès, Penteathyris et Straménémès. La durée de leurs deux règnes réunis est de 39 ans, et forme, un an de moins près, celle qu'Africain assigne au règne d'Aunménémès. L'on peut donc soupconner que le Sistosichermès d'Eratosthène ést Sésostris. Les trente-deux générations qui le précèdent font, sur le pied de vingt-quatre ans chaque, 768 années, qui ajoutées à 2309 donnent 3077 , époque de la première année de Ménès. La durée totale de ces règnes seroit de 870 ans ou d'environ un siècle de plus, d'après cet autcur; mais il doit y avoir de l'incertitude relativement aux premières générations, d'autant plus qu'à cette époque les années des Egyptiens pouvoient être lunaires; et c'est ce qu'indiquent les longueurs excessives de quelques règnes, de celui de Phiops ou d'Apappus notamment, que je crois être l'Osymandyas de Diodore. Cet historien compte vingt-huit générations entre ce dernier et Sésostris : mais je présume qu'elles ne sont point toutes successives; il paroît en effet, d'après Africain et Eusèbe, que lorsque la sixième dynastie s'éteignit avec la reine Nitocris, l'Egypte fut divisée en trois états ou dynasties particulières, les Memphites, les Héracléopolites et les Diospolites, sur lesquelles ces auteurs n'ont point eu de connoissances certaines. Mais Eratosthène nous tire d'embarras, puisqu'il nous donne le nom des rois de Thebes intermé 
diaires et la durée de leurs règnes, qui forme, en totalité, ${ }^{96}$ ans. Selon Diodore, Moris est antérieur à Sésostris de sept générations; dans le canon d'Eratosthène Sistosichermès est le cinquième roi après Mérès ou Meurès le philosophe. Moeris ou Miris étant plus ancien d'environ onze siècles que Mendès ou Marus, il n'est pas surprenant'qu'à cette époque les eaux du Nil pussent fertiliser les terres de Memphis, lorsqu'elles s'élevoient simplement à la hauteur de huit coudées au-dessus de leur niveau ordinaire; ce fait rapporté par Hérodote est exact, si l'on admet qu'il s'est mépris sur l'époque du règne de Moris, en le confondant avec Marus ou Maris. Entre lui et Phiops ou Osymandyas doit être placé l' $U$ choreus de Diodore, qu'il dit être le huitième descendant du précédent, et qui, 'selon cet auteur encore, bâtit la ville de Memphis.

Le quatrième roi de la sixième dynastie, en suivant Africain, est Phiops; il régna 94 ans; Eusébe le place dans la cinquième et le fait régner un siècle entier. Ces deux auteurs terminent également la sixième dynastie par Nitocris. Selon le premier, Nitocris succède à Mentésuphis, qui vient jmmédiatement après Phiops, et qui règne un an. Le vingtième roi de Thèbes, dans le canon d'Eratosthène, est Apappus le grand (Maximus) qui régna cent ans, moins une heure. Echescus Caras lui succéda et ne régna qu'un an. Nitocris occupa ensuite le trône pendant six années, et quoique tous ces auteurs diflèrent à l'égard de la durée de son règne, il n'en est pas moins vrại yu'il fut 
Anncés

avant J.C.

très-court. Je conclus de ces rapports, que Phiops et Apappus sont le même personnage, et c'est ce qu'on avoit déjà présumé avant moi. L'épithète de grand, donnée au dernier par Eratosthène, me fait soupconner que ce roi est encore l'Osymandyas de Diodore, l'un des souverains les plus illustres qu'ait eu l'Egypte avant Sésostris. On ne croira pas sans doute qu'Apappus ait tenu le sceptre de l'Egypte l'espace d'un siècle entier, composé d'années solaires, et c'est peut-être trop accorder que de porter la durée de ce règne à 80 ans. Ce nombre ajonté aux $19^{6}$ ans qui forment la durée totale des règnes, depuis Pliops jusqu'à Sèsostris ou Sistosichermès exclusivement, déterminent l'époque suivante.

2585. Phiops ou Apappus, l'Osymandyas de Diodore, commence à régner. Je pense, d'après ce que cet historien raconte d'Osymandyas qu'il réformal'annéc égyptienne et qu'il la composa de 365 jours; qu'il établit encore le zodiaque de Lathopulis ou d'Esné. Trois étoiles de la première grandeur avoient alors des positions remarquables : Aldebaran, ou la première de la constellation dı taureau, étoit très-voisine du point équinoxial du printemps; Régulus, la première encore de la constellation du lion, répondoit presque au solstice d'été; et l'Épi de la vierge, éloignée de la précédente d'environ 49 deģrés, annonçoit l'approche du moment où le Nil alteignoit sa plus grande élévation. Le soleil parcouroit, du solstice d'été au 20 juillet, l'autre partic de la constella- 
tion du lion et le commencenient de celle de la vierge; ces étoiles réunics composoient le signe du sphinx, représcntant le corps d'un lion, avec la tête d'une femmc. Le signe de la balance indiquoit encore plus le terme de la crue du $\mathrm{Nil}$, que l'équinoxe d'automne. Un homme tenant à la main la coudéc du nilomètre et de l'autre main une balance, remplace ce signe dans un ancien zodiaque égyptien. Les caractères des signes de ces zodiaques n'étoient primitivement que de simples hiéroglyphes des mois de l'année rurale égyptienne, qui, je présume, commençoit ałors vers l'équinoxe d'automne, ou lorsque les eaux du Nil commençoient à se retirer. A cette époque, Fomalhaut, la première étoiledu poisson austral, désignoit sous le symbole d'un monstre amphibie, et par son lever vers la fin de juin, peu de temps après le coucher du soleil, le commencemcnt de l'inondation. Trois mois après, Aldébaran, par un semblable phénomène, annonçoit la retraite des eaux du fleuve. Sirius (I), ou la belle étoile de la constellation $\mathbf{d u}$ grand chien, devint ensuite le signe précurseur de l'inondation, ce qui proluisit un changement dans l'ordre des mois de l'année.

2835. Fondation de Thèbes, par Busiris x I., suivant Diodore.

(1) La constellation du grand chien ne se trouve point dans le zodiaque du portique du grand temple d'Esné, zodiaque le plus simple de tous; mais on la voit sur celui qu'offre le portique du temple situc au nord de cette ville. 
M. Girard, dans un excellent mémoirc sur l'exhaussement progressif du sol de l'Egypte, occasioné par les dépôts qu'y forme le Nil chaque année, a prouvé que le terrain, qui se trouve aujourd'hui au-dessus du niveau primitif de la plaine de Thèbes, n'a pu arriver à sa hauteur actuellc que par le laps de 46 siècles.

3०41. Ménès établit l'empire égyptien.

Selon Eratosthène, il est antérieur à Apappus de 19 générations, formant 574 ans, mais qui restreintes à 24 années chacune, font 456 ans. L'Egypte fut divisée, après lui, en troissouverainetés, cellc de This, de Memphis et d'Eléphantine. Les deux premières offrent chacunc deux dynasties, dont le nombre total des rois est également de dix-sept. Il y a de l'incertitude relativement it la dynastie des Eléphantins; Hérodote nous dit que parmi les rois d'Egypte, il y en avoit dix-huit d'Ethiopiens, et nous avons vu qu'Eratosthène ne compte que dix-huit rois, depuis Ménès ou Minès jusqu'à Apappus.

Ainsi les antiquités historiques de l'Egypte ne peuvent guèrc remonter au-delà de $3 o$ siècles et demi, avant notre ère, et ne dépassent pas les limites de la chronologie sacrée de la version des Septante, que la plupart des Pères de l'église et plusieurs savans modernes ont suivie. Ces mêmes antiquités coïncident parfaitement avec celles de l'histoire de la Chine et de l'Inde. 
Dynasties des Rois d'Egypte, depuis la fondation de cet empire jusqu'au Règne d'Alexandre.

\section{MÉN亡 S.}

\section{L'Égypte est ensuite partagée en trois Etats.}

\section{THINITES.}

Les deux premières Dynasies.

Bocchus, chef de la scconde, est peut-ĉtrele Bocchor dont parlc Josèphe, dans sa réponse à Appion (liv. 2, cli. 1, et liv. 5 , ch. 12), et qu'il faisoit vivre 1700 ans avant la sortie des peuples pastcurs de l'Egypte, parni lesquels il comprcnoit les Juifs. En comptant trois générations par siècle, il auroit précédé cctte ćpoque de 51 générations. Bocchus (suivant Africain et Eusèbe), fut le neuvième coi d'Egypte. Lcs 51 générations à 24 ans, feroient 122 ; ; lexpulsion des peuples pasteurs est de 1702 avant l'ère chrétienne; donc Bocchus ou Bocchor auroit vécu 2926 ans avant la même ére. Suivant la chronologic de Josèphe, les Juifs sortirent de l'Egypte 2598 , après la création du monde. Il comptoit 42,5 ans depuis cette dernière époque jusqu'à la destruction de Jérusalem par Tite.

Duréc. . 5/3 ans.

HÉRACLÉOPOLITES D'AFricaIn ET D'EusÈbE.

Teuviòne el dixième Dynasties.

Durée...

MEMPHITES.

ÉLEPHANTINS OU ÉTIIOPIENS.

Deux Dynasties : la Une Dynastie : la cintroisième et la quatrième.

Elle est formée de neuf rois dans Africain, de trentc-deux dans Eusèbe, qui y rapporte deux rois placés par Africain, dans la sixième dynastie. Il paroît, en eflet, que la dynastie des Eléphantins ou des Diospolites se maintint, finit par dominersur toute l'Egypte, et forma la sixième dynastie ou la troisième des Memphites. Elle se compose des 22 premiers rois de Thèbes, du canon d'Eratosthène, et se termine à Nitocris.

MEMPHITES.

DIOSPOLITES。

Septième et huitième Dynasties.
Onzième Dynastie.

23-20 rois de Thẻbes, d'Eratosthène.

go ans. 


\section{DIOSPOLITES.}

Treizième Dynastie. $30-37$ rois de Thèbes, d'Eratosthène.

Durée... 175 ans.

zoÏTES. DIOSPOLITES. ROIS PASTECRS. ROIS PASTEURS. Puatorzième Drnastie Treizième $D_{y}$ GRECS. nastie d'Afri-Seizième Dynastain et d'Eusè - tie d'Africain. be.

Ouinzième Dyd'Eusèbe.

Durée... 53 5 ans. nastie d'Africain , la dix-septième d'Eusèbe.

ROIS PASTEURS. THÉBAINS, ou ceux de la petite Diospolis. Dix-septième Dynastie d'Africain, la seizième d'Eusèbe.

\section{DrosPoLrTES.}

Dix-huitième et dix-neuvième Dynasties.

Durée... 602 ans.

\section{TANITES.}

Yingt-unième Dynastie.
DIOSPOLITES.

\section{Vingtième Dynastie.}

Il paroît que le royaume de Thèbes finit vers la fin de la dynastie des Tanites : il avoit eu gr rois. Syncelle nous a conservé les noms et la durée des règnes des 38 premiers.

Duréc... $₫ 30$ ans.

\section{BUEASTINS.}

Vingt-deuxième Dynastie.

TANITES.

Vingt-troisième Dynastie.

SAÏTES.

Vingt-quatrième Dynastie.

ÉTHIOPIEXS.

Vingt-cinquième Dynastie.

SAÏTES.

Vingt-sixième Dynastie.

Durée des cinq Dynasties précédentes.... 445 ans.

Les Perses s'emparent de l'Egypte.

Vingt-septième Dynastie, celle des Perses.

Les Egyntiens, souc Darius-IYothus, recouvrent leur indépendance. 


\section{SAITES.}

Vingt-huitième Dynastie. MENDÉSIENS.

Vingt-neuvième Dynastie.

SÉBENNYTES.

Trentième Dynastie.

Durée des quatre Dynasties précédentes.... 19i ans.

Alexandre fait la conquête de l'Egypte 33i ans avant l'ère clurétienne, et commence la dynastie des MacÉvoniexs. La première année de MÉxìs, fondateur de cet empire, précède notre ère de $304 \mathrm{r}$ ans; et, quand bien même l'on adopteroit la durće des règnes des 37 premiers rois de Thẻbes, donné par Eratosthène, le commencement de cet empire ne dateroit que de 32 à 33 siècles avant notre ère ; mais nul doute qu'il ne faille diminuer la longueur des règnes des 19 premiers rois, puisque la durée totale est de 5 ;4 ans, ce qui donne 30 ans par génération, évaluation trop forte. Il est d'ailJeurs probable que l'année égyptienne ne fut fixéc à $36 j$ jours que sous Osymandyas, l'Apappus d'Eratosthène, ou l'Epaphus de la mythologie de: Grecs, auxquels ils attribuoient la fondation de Memphis. 


\section{DES INSECTES}

PEINTS OU SCULPTÉS

\section{SUR LES MONUMENS ANTIQUES}

\section{DE L'ÉGYPTE.}

N

ous savons que les prêtres égyptiens ont représenté dans leur langage symbolique diverses productions uaturelles de leur pays, soit usuelles ou réputées dangereuses, soit rappelant par les qualités qu'on leur attribuoit le souvenir de ecrtaines idées religieuses ou cosmogoniques. L'explieation de ces énigmes a exercé longtemps et presque sans aucun résultat positif la sagacité des Kireher, des Montfaucon, des Caylus, des Jablonski, et de plusieurs autres? savans antiquaires. Mais aujourd'hui que l'Egypte a été explorée sous toutes les faees et ayec le plus grand détail, que nous avons les dessins les plus exaets de ses précieuses antiquités, que ses productions naturelles ont enriehi nos collections, que nous avons enfin sur cette terre classique un ouvrage vraiment national, aussi digne peut-être de notre admiration que ses monumens et qui leur survivra, ne pouvons-nous pas espérer qu'en profitant de tant de moyens, il nous sera enfin permis de découvrir le sens de quelques uns de ees symboles.

Les hiéroglyphes représentant des animaux et des plantes sont eeux dont nous devons d'abord nous occuper', pirce que la plupart de leurs sujets d'imitation 
étant en notre pouvoir, l'éture de ees hiéroglyphes prúsente moins de diffieultés. Mais pour ne pas s'égarer dans la recherche du sens mystérieux qui leur est attaché, il faut, an préalable, fixer s'il est possible la détermination des objets figurés, et tâcher de eonnoître leurs propriétés physiques ainsi que celles dont ils jouissoient dans l'opinion du peuple. Voilà le premier pas à faire dans ce sentier ténébreux; et pour n'avoir pas snivi avee assez de soins et de persévérance eette première direetion, plusicurs antiquaires sont tombés dans de graves erreurs. C'est ainsi, par exemple, que Montfaucon nous donne une grenouille pour un searabée.

Dans l'exploitation d'un champ si vaste et si hérissé d'épines, j'ai dû nıe restreindre au défrichement d'une petite portion de terrain : eelle qui eonvenoit au sujet de nies études, la division du règne animal qui traite des inseetes. Les hiéroglyphes relatifs à ces animaux seront done l'objet de ce mémoire.

Quel est d'abord le prineipe général d'après lequel on a tracé ees figures symboliques? Tantôt elles représentent un animal entier et au naturel, mais sous des proportions qui varient selon l'esprit du dessin prineipal et de la grandeur du eadre qui le renferme; tantôt ees hiéroglyphes n'offrent qu'une partie de l'animal, et la signification de cette partie est nécessairement plus restreinte. Voulant enfin donner plus d'extension au sens allégorique de ces symboles, les Egyptiens, soit en retranehant à un animal une de ses parties, et en la renplaẹant par une autre empruntée d'un animal étranger, soit en eombinant diverses portions d'animaux, eomposìrent des êtres imaginaires, auxquels ils ajoutèrent même parfois de noureaux caractères symboliques. On 
peut sous ce rapport appliquer à l'Egypte ee que les anciens disoient de l'Afrique en général : qu'elle étoit le pays des monstres. Les seuls insectes proprement dits que m'aient offerts les monumens des Egyptiens et lẹurs pierres gravées, que les antiquaires nomment searabées, sont le searabée, pris dans une aceeption générale, et ui petit animal qu'on a regardé jusqu'ici eomme une abeille. MM. Durand, Jollois et Devilliers m'ont eommuniqué avec une extrême complaisanee les pierres gravées de leurs eabinets.

Les habitudes de quelques uns de ces insectes appelśs Cantharoi par les Grees et Scarabcei par les Latins, fixèrent Yattention des Egyptiens. Messagers du printemps, annonçant par leur reproduction le renouvellement de la nature, singnliers par eet instinct qui leur apprend à réunir les molécules de divers excrémens en manière de eorps sphériques, et qui doivent renfermer les germes de leur race, occupés sans eesse, eomme le Sisyplıe de la mythologie, à faire rouler ees eorps, disa tingués des autres insectes par quelques formes partieulières, ees animaux parurent offrir aux prêtres Egyptiens l'emblême des travaux d'Osiris ou du soleil; leur effigie fut multipliée de mille manières. Il ne suffisoit pas à la superstition que ectte effigic se trouvàt dans tous les temples, sur les bas-reliefs et les ehapiteaux des colonnes, sur les obélisques, et qu'elle exerȩầ le talent du statuaire, elle exigeoit eneore qu'elle fùt gravée, avec d'autres hiéroglyphes, sur des pierres de diverses natures et façonnées en manière de médaillons; sur des eornalines taillées en demi-perles, percées dans toute la longueur de leur axe et propres à composer des colliers, ainsi que des anneaux servant de eachet. L'image de. 
ce dieu tutélaire suiroit partout les Egyptiens, et descendoit même avec eux dans la tombe.

De tons les auteurs anciens qui ont parlé du scarabée, Hor-Apollon est eclui qui a traité ce sujet avec le plus d'étendue. Il lui a consacé le chapitre dixième d'un ouvrage qui passe pour avoir été traduit de l'égyptien en gree par un nommé Philippe, et qui a pour titre: De la Saggesse symbolique des Egy $E_{\text {griens; }}$ le père Caussin en a donné une traduetion latire. Notre confrère M. Miot a eu la bonté de me communiquer la version française qu'il avoit faite du chapitre précité. Voici l'analyse du passage, mais disposée dans un ordre plus méthodique que eelui qu'a suivi Hor-Apollon.

Tous les searabées, suivant lui, ont trente doigts, à raison du nombre de jours que le soleil met à pareourir chaque signe du zodiaque. On en distingue trois espèces; la première, ou le scarabée proprement dit, présente des sortes de rayons, et a été, par analogie, consacréc au soleil; elle ressemble à un chat; car les Egyptiens disent que le cluat mále suit par le mourement de ses prumelles le cours de cet astre; qu'elles se dilatent le matin au lever du dieu, qu'elles s'arrondissent vers lc milieu de sa eourse, et qu'elles s'obseurcissent vers son coucher. C'est pour cela qu'on voit à Héliopolis une statue qui représente ce dieu sous la forme d'un ehat. Tous les individus de ce scarabée sont du sexe masculin. Lorsque l'inseete veut se reproduire, il cherche de la fiente de bœuf; ct, après en avoir trouvé, il en compose une boule dont la figure est eelle du monde; il la fait rouler avec les pieds de derrière, en allant à reculons et dans la direction de l'est à l'ouest, sens daus lequel le monde est emporté par son mouvement. Celui 
des astres se fait dans une direction opposée; ou du vent du eouchant vers eclui du levant. Le scarabée enfouit sa boule dans la terre, où elle demeure eachée pendant vingt-huit jours, espace de temps égal à celui d'une révolution lunaire, et pendant lequel la race du searabée s'anime. Le vingt-neuvième jour, que l'inseete connoît pour être celui de la conjonction de la lune avec le soleil et de la naissanee du monde, il ouvre eette boule et la jette dans l'eau. Il sort de cette boule des animaux qui sont des searabées. C'est par ees motifs que les Egyptiens, voulant désigner un être uniģ̀ne ou engendré de lui-même, une naissanee, un père, le monde, l'homme, peignoient un scarabéc. La sceonde espècc de searabée a deux eornes et la forme du taureau; elle est consaerée à la lune, déesse dont le taureau eéleste, à rapport des Egyptiens, indique l'élévation. La troisième espèee est unicorne et d'une figure partieulière. On croit que, eomme l'ibis, elle a été eonsacrée à Mereure. Tel est l'extrait du passage d'Hor-Apollon, ayant pour objet le searabée. Aristote dit à l'égard de la première espèee, le Cantharos, que eet insecte passe l'hiver dans les boules de fiente qu'il a faites, et qu'il y dépose des oufs qui le reproduisent. Le même animal est le coprion ou bousier d'Hippocrate.

De tous les. insectes connus, eeux riu'on désigne aujourd'hui sous le nom d'ateuchus, et que j'appellerai dans notre langue pilulaires, sont les seuls qui forment, avee des excrémens, des boulettes dans. lesquelles ils placent leurs œufs, et qu'ils font rouler souvent deux par deux, avee leurs pieds de derrière, en marchant à reculons, jusqu'à ee qu'ils aient reneontré un endroit où ils puissent les enfouir d'une manière fayorable à la cona 
servation de leur raee. La première espèce de scarabée d'Hor-Apollon est done un pilulaire. Un des caractère's distinctifs de l'espèce qu'on a nommée sacrée est d'avoir le eontour de la tête divisé en six dentelures imitant des rayons, et n'est-ce pas aussi la manière dont ret auteur nous dépeint le mème searabée. Dans la plupart des figures des scarabées que nous retracent les monumens égyptiens et les pierres grarées, eette forme de tête est exprimée d'une manière semblable et souvent avee une grande vérité. Ce qui lève jusqu'au moindre donte, e'est qu'une momie apportée d'Esypte, par notre confrère M. Geoffroy de Saint-Hilaire, renfermait, outre d'autres inseetes, un pilulaire sacré d'une parfaite conservation. Il est vrai que d'antres pilulaires du midi de l'Europe et d'Afrique offrent le mème earactère; mais on a dût ordinairement préférer cette espèce, attendu qu'elle est plus cormune en Egypte que les autres et d'une taille plus propre à frapper les regards. Je dis ordinairement, car, sur plusieurs scarabées des pierres antiques, les sillons des étuis reeourrant les ailes étant fortement prononcés, il seroit possible que les graveurs eussent pris pour modèle une espèee voisine de la précédente (laticollis), et qui s'en distingue par là (1); mais sur toutes les figures de scarabées des monumens égyptiens, peintes ou seulptées, ees étuis sont représentés unis, ainsi qu'ils le sout dans le pilulaire saeré.

Les pilulaires mâles, fait extraordinaire dans les insectes de la même famille. ne dillèrent presque pas de

(1) On trouve en Egypte deux autres cspèces de pilulaires, savoir ccllc qu'on nomme variolosus, et un autre plus voisinc du p. sacré, (ie moilie plus petite cl sans tubercules sur la tête. 
deurs femelles, et partagent, à ee qu'il m'a paru, les travaux et les soins qu'exige la conservation de leur postérité; il n'est done pas étonnant que les Egyptiens, surtout à une époque où l'on n'avoit que des idées fausses sur la génération des inseetes, aient pensé que les searabées étoient unisexuels, et que, dans le choix du sexe, ils aient préféré eelui qui a le plus de prérogatives, le sexe maseulin.

Il est inutile de reehereher l'origine de la eomparaison qu'on a faite du scarabée avee le ehat (I), et de celui-ci avec le soleil : ear si l'on exeepte son aetivité qui se développe avee l'aetion progressive de la ehaleur, le searabée présente à peine quelque analogie avec l'astre du jour.

Les travaux du pilulaire durant environ un mois, l'on conȩoit que les Egyptiens, si toutefois Hor-Apollon ne leur prète pas des idées qui lui étoient particulières, ont pu assimiler ee laps de temps à la durée d'une révolution lunaire. Ils auront ensuite suppléé au silence de l'obserration par des fables puisées dans leur système sur la formation des inseetes et dans leur goût pour l'allégorie. Ils avoient vu que le searabée enterroit sa boule; mais ignorant la vraie manière dont il se perpétue, et admettant pour lui la génération spontanée, il falloit bien que l'insecte déterrât sa boule et la jetât dans l'eau : élément qui, dans leurs prineipes, produisoit avee le coneours de la chaleur les êtres qui étoient eensés n'avoir ni père ni mère.

On seroit d'abord tenté de mettre au rang de ces fictions ce que dit Hor-Apollon du nombre de doigts des searabées; il est selon lui de trente. Cette supputation,

(i) Il étoit le symbole de la vigilance. 
d'après la manière dont il envisage le pied ou le tarse de ces insectes, est cependant parfaitement juste; car cette partie est composée de cinq articulations; et si l'on prend chacune d'elles pour un doigt, les patcs étant au nombre dc six et terminées par un tarse de cing articles, les scarabécs ont évidemment trente doigts. Cette explication est d'autant plus naturelle qu'une dc ces pierres dites abpaxas, figurée par Montfaucon d'après Kircher, représcnte un scarabée ayant à chaque pate antérieure une main étenduc et à cinq doigts.

Au rapport de Théophraste et d'Elien, l'odeur des roses fait périr lc scarabée; peut-être cette idée vicntelle de ce qu'il disparoit à l'époque de leur floraison; peut-être encore supposa-t-on à cet insecte, d'après la nature très-différente des matières dont il sc nourrit, une grande antipathie pour les fleurs, et par opposition surtout avcc un autre scarabée, le mélolonthe, qui vit sur elles.

Les pilulaircs n'offrent point ces éminences fixes et inarticulées auxquclles les naturalistes ont donné exclusirement le nom de cornes; mais beaucoup de málcs de vrais scarabées et de bousiers en sont pourvus; et c'cst dès lors dans ces genres que nous devons chercher la seconde et la troisiène espèces de scarabées mentionnées par Hor-Apollon. Celle-ci ou l'unicorne que l'on a voit consacrée à Mercure pourroit bien être le bousier paniscus, commun dans les contrées méridionalcs de l'Europe, en Barbarie et en Egypte. M. Savigny, qui a fait une étude si approfondie des insectes de cette derniẻre partie de l'Afrique, soupconnc qu'un grand bousier à dcux cornes, très-voisin de celui qu'on a nommé midas et qu'il a trouvé dans la Haute-Egyptc, est la 


\section{DES ÉGYPTIENS.}

seconde espèce de scarabée d'Hor-Apollon, celle qui étoit dédiée à Isis. En effet, un de ces scarabées est représenté dans le temple de Karnak (Antiquit. tom. 3, pl. 34) avec la tête échancrée en devant, et portant dans son milieu deux petites cornes assez distinctes; mais la forme générale de l'animal et les proportions de quelques unes de ses parties indiqueroient plutòt une espèce d'onite, le moris ou le calcaratus par exemple. Millin, dans sa notice des pierres gravécs égyptiennes du Muséum des antiques de la Bibliothèque royale, nous apprend qu'on voyoit dans celui de Ste. Geneviève un scarabée qui selon lui étoit évidemment le mitmas de Linnous. S'il ne s'est point glissé à l'égard de ce nom une faute typographique, ce célèbre antiquaire s'est trompé, puisque le scarabée mimas est exclusivement proprc à l'Amérique méridionale; mais aux couleurs près, cette espèce a les plus grands rapports avec le bousier midas; et l'on pourroit conclure de la méprise même de Millin que cet insecte est le sujet de cette pierre gravée égyptienne. Je préviens cependant qu'aucune collection de ces pierres gravées ne $m$ 'a offert des scarabées analogues à ceux que je viens, de citer. Parmi ccux de la Bibliothèque royale, il en est un dont la tête est celle d'Isis. Millin paroît suspecter son antiquité; mais on retrouve ce même insecte allégớique sur la table isiaque, et nous allons voir que les Egyptiens ont opéré des métamorphoses encore plus bizarres. Transformoient-ils la tête du bousier midas en celle d'Isis, ou bien, supposé que le pilalaire sacré fùt l'unique sujet de ces échanges, ne pourroit-il pas être arrivé qu'HorApollon eût pris un être mythologique pour un être réel? c'est ce qui scroit possible, mais ce que je n'ose 
allirmer. On trouve eneore en Esypte un autre scarabée à deux eornes, le phalangiste, typhous ; mais comme elles ne sont pas situées sur la tête et que l'inseete est de petite stature eomparativement aux préeédens, je ne présume pas qu'il ait été remarqué des Egyptiens, et qu'il ait mérité les honneurs de la eonsćeration. Le pilulaire sacré et une autre espèee très-voisine dont les étuis des ailes sont sillonnés, paroissent avoir servi de type général aux graveurs de pierres-searabées; l'imitation est parfaite daus quelques unes, mais il en est beaueoup d'autres dont les figures sont très-grgrossières, et l'on exagéreroit singulièrẹment le nombre des espècess, si dans cette distinction l'on tenoit eompte de ees différenees produites par le eaprice ou l'inexpérience des artistes. On ne peut méeonnoître sur quelques unes de ces pierres, mais beaucoup plus rares, le dessin d'un searabée qui vit sur les fleurs, et qu'on place aujourd'hui dans un genre propre, eelui de eétoine. Mlillin avoit déjà fait la même observation relativement à une de ces pierres de la Bibliothéque royale. MM. Jollois et Devillers en possèdent une autre non moins eurieuse, paree que l'existenee de l'éeusson, earactère qui distingue les cétoines des pilulaires, y est parfaitement sentie et que la figure est double. On trouve en grande abondanee, dans les contrées méridionales de l'Europe, des eétoines, telles que ia fastueuse, remarquables -par leur taille et leur eouleur, qui est d'un vert-doré éclatant. Je déduis de quelques passages d'auteurs anciens, eomme du seoliaste d'Aristophane, de Suidas et de Pollux, que ees insectes avoient reẹu des Grees le nom de mélolonthe, mentionné par le père de la zoologie, Aristote. Ainsi que du temps d'Aristophane et de Pollux, les enfans 
grecs jonent encore aujourd'hui avec ces insectcs, commo le font les nòtres avec le hanneton ordinaire. C'est dans Pollux le jeu de la Galéruquc. Unc de ces cétoines, probablement la fastueuse, cst le scarabée vert de Pline (liv. 25. chap. 6.), celui qui, dit-il, a aiguisé la vue (exacuit) de ccux qui ont jeté les yeux sur lui, et que lcs graveurs en picrres précicuses ou gemmes se plaisent à contempler. Ce passage nous prouve qu'on étoit déjà dans l'usage de représenter des cétoines sur des pierres, obscrvation qui avoit échappé Millin. Quelques figures de pilulaires tracées sur les monumens égyptiens sont tellement vagucs et indétcrminées, que, sans celle du globule qui les accompagne, on sauroit tout au plus qu'on a représenté un insecte à étuis. Dans quclques unes la tête n'offre point de divisions, ce qui pourroit faire soupçouner qu'on a imité une autre sorte de pilulaire (r). La détermination du scarabée de la table isiaque, cclui dont l'effigie y est le plus souvent répétée, me paroît incertaine; la tête est pctite et entière ainsi que dans les cétoines, le corps est d'ailleurs assez semblable à cclui d'un pilulaire.

Le pilulaire sacré est souvent représenté sur les moIumens des Egyptiens, les ailes étendues; ce qui, par a manière centrale dont il est placé, contribue beaucoup aux ornemens de la sculpture et de la peinture. On a même quelquefois porté l'exactitude de l'imitaion au point de rendre sensible le pli des ailes inféieures.

Parmi les figures de scarabées, il en est qui sont encore plus symboliques, et c'est d'elles que je -vais vous ntretenir.

(x) Ateuchus pilularius, Latr, ou Y'A. flugellatus. 
Nous signalerons d'abord le scarabée des bas-rcliefs du temple d'Erment : les ailes sont dévcloppées; il embrasse avee ses quatre pieds antérieurs une tige cylindrique, qui semble naître du dos et former le manche d'un corps ¿figuré en manière de hache ou de couteau de sacrificateur (une plume ou une palme, selon quelques antiquaires), placé cn avant de la tête. Sur le zodiaque seulpté au plafond du temple, au nord d'Esné, le belier est représenté avec un instrument semblable, situé de même et avee quatre ailes, qui paroissent être celles d'un épervier ou d'un aigle. Le grand temple d'Edfou nous montre un searabéc à double tête, savoir , celle du belier et eelle de l'épervier; l'une porte une sorte de bonnet royal, l'autre est coiffée d'une espèce de mitre fendue ou à deux branehes. D'autres figures nous font voir que ces objets étoient cn usage pour eouvrir la tête. Sur le tableau astronomique, ou présumé tel, peint au plafond d'un temple de Thèbes, un scarabée tenant sa boule paroît remplacer le signe du belier. La comparaison de ees divers hiéroglyphes nous donne lieu de présumer que la figure du searabée étoit, aussi-bien que eelle du belier, le symbole du renouvellement de la nature ou du retour du printemps (I).

(I) La crue des eaux du Nil, devenue assez forte pour frapper les regards des Égyptiens, leur fournit par sa coïncidence avec le solstice d'été, un point de départ très-naturel, à la fois astronomique et d'accord avcc les idécs qu'ils s’étoieut formées sur l'origine des êtres organisés et dont je parlerai plus bas. Le commencement de la retraite des eaux de ce fleuve, qui a lieu vers l'équinoxe de l'automne, devint encore pour ce peuple lindicateur d'une autre. mesure du temps. Transportons-nous sous le ciel de Thèbes, rcmontous à une époque peu éloignće de la fondation de cette ville, environ vingt-huit siècles avaut l'c̀re clréticnne, époquc à laquelle 


\section{DES EGGYTIENS.}

Les dessins des bas-reliefs du $4^{\mathrm{e}}$. et du $5^{\mathrm{e}}$. tombeaux des rois de 'Thèbes, situés à l'ouest, nous confirment dans l'idée que le scarabée étoit le symbole du retour du printemps ou du principe d'une nouvelle végétation.

le lever de Sirius ou de l'étoile de la canicule, précédoit de quelques instans, vers le solstice d'été, le lever de l'aurore; admettons que l'étnde des saisons, les travaux de l'agriculture qui leur étoient propres, les phénomèmes du Nil, quelques observations générales de la marche du soleil, aient servi de base à l'établissement d'une année rurale, et que les circonstances locales auront fait diviser en trois saisons, de quatre moiș chacune; supposons enfin que cette année rurale ait alors commencé, d'après les indications naturelles exposées plus lraut, au solstice d'été, nous verrons que les hiéroglyphes des mois de cette sorte de calendrier agricultural s'expliquent très-simplement et sans l'intervention d'un système uranographique. Le point de la course annuelle du soleil le plus rapproché du zenith, le comınencement de l'inondation du Nil, l'époque de sa plus laute élévation, la renaissance du printemps, l'ouverture des travaux de la campagne, la floraison et la fécondation des végétaux, la marche rétrograde de l'astre du jour, la puissance de son action et la maturité des grains, l'égalité des jours et des nuits et le retour des vents étésiens, tel fut uniqquement, dans l'origine, le sens des hiéroglyphes, qui forment maintenant les signes des constellations zodiacales.

Nous aurions pu reculer l'origine de ces symboles et remonter au temps où les Égyptiens, après avoir quitté leur terre natale, le mâzendérân et le khoraçân, étoient descendus sur les rives du cours inférieur de l'Euphrate, fleuve analogue au Nil par l'époque et la durée de ses inondations; cette situation, plus rapprochée du centre de l'Asie, nous eût fourni le moyen d'expliquer ces rapports généraux et communs que nous offre la comparaison des principales splières de l'antiquité.

Létude des phénomènes célestes, qui par leurs coïncidences avec les phénomènes terrestres en devenoient les signes indicateurs, fit bientôt de nouveaux progrès, et la division duodécimale de l'année fut appliquée à cette zone du ciel que le soleil parcourt annuellement. Immédiatement après son coucher, la constellation de la 
'írois tableaux placés sur une même ligne transversale représentent chacun un bateau à rame, ayant dans son milieu un pilulaire dont le corps est élevé sur les pạtes de derrière. Dans le premier tableau, à droite, l'animal

vierge se montroit la première à l'orient, vers la fin de janvier. Le soleil devant entrer dans cette constellation six mois après, époque rlu renouvellement de l'année annoncé par une crue considérable du Nil et l'apparition de Sirius, cette constellation forma le premier signe du zodiaque. Les autres constellations de cette zone é́leste paroissant successivement, de mois en mois, vers le même point de lhorizou, lorsque le soleil venoit de le quitter, devinrent, d'après le même principe, les emblèntes des autres divisions de l'année; l'état du ciel présentoit ainsi, chaque jour, après le coucher dụ soleil, une sorte d'alınanael. C'est, je présıme, sur une telle base qu'Osymandué établit, près de 2600 ans avant notre ère, le plus ancien et le plus simple des zodiaques égyptiens, celui du portique du grand temple d'Esné, et qui ne diffère guère du zodiaque du temple au nord de cette ville qu'en ce qu'il a quclques constellations de moins.

L'observatign continue du lever héliaque de Sirius ayant fait découvrir le mouvement apparent des étoiles fixes, ou la précession des équinoxes, le signe du libn fut alors le premier. Cctte époque est indiquée par l'institution du cycle canieulaire qui eut lieu eu 1325 , et n'est pas moins remarquable dans l'histoire de la Grece, sous le rapport de l'astronomie. Les deux zodiaques de Dendérah, composés d'un plus grand noubre de constellations que les précédens, et dès lors postérieurs, paroissent avoir été construits vers cctte dernière époque. L'un d'eux cependant, celui qui est sculpté au plafond du portique du grand temple, pourroit être plus ancien d'environ trois siècles. Mais tous ces zodiaques étoient très-imparfaits, et leurs élénıens, ainsi que les autres eomoissances uranographiques, ne furent rassemblés et assujétis à un systènte général que peu de siècles avant l'ère chrétienue. Uu des caractères qui me paroît distinguer les splì̀res établies sur cette coordination de faits, et qui suppose une commoissance précise de la situation respective des étoiles uommées hyades, c'est que le signe du taureau u'est représenté que par la moitié autérieure du corps de l'animal. 


\section{DES ÉGYPTIENS.}

cst figuré dans son état naturel; il est accompagné d'Anubis et de quelques autres personnages, de pontifes pcut-être. An tableau du milieu, le pilulaire est représenté avec une tête de belier, ct des harpies composent alors son cortégc. Lc dernicr tableau, celui du côté gauche, est semblable au précédent, mais avcc cette difrérence que l'insecte tient maintenant sa boule entre les pates. Ne semble-t-il pas que, par ces allégories vraiment ingénienses, on ait voulu indiquer soit les approches successives du printemps, soit le décroissement graduel des eaux du Nil après son inondation, jusqu'au moment où il rentre dans son lit, et que la terre cst découverte? Cet cspace de tcmps est partagé en trois époques, et probablement de dix jours en dix jours, ce fleuve employant environ un mois à se retirer, depuis qu'il commence sensiblcment à décroître. Dans le premicr tableau, l'insectc est invité à revenir; au second, il est en marche; et le troisième annonce son retour, puisque l'insecte porte déjà le corps renfermant les germes de sa postérité. Il est représenté sur le zodiaque du portique-du grand tomple d'Esué à la place du cancer, parce qu'il peut, comme lui, marcher à reculons.

Dans les principes de la philosophie égyptienne, principes qui ont été ceux de l'antiquité, la génération se fait de deux manières, savoir, par la voie commune ou l'union des sexes, et par la génération spontanéc, dont les deux agens principanx sont la chaleur et l'hnmidité; le premier concouroit aussi dans le mode précédent. Tcl a été le sujet de l'allégoric que l'on voit sur les peintures du cinquièrne tombcau des rois de Thèbes, situé à l'cst : lc pilulairc y sert d'excmple et d'une manière très-bizarre pour la géuération spontanée. 
Essayons maintenant de découvrir quel est l'insecte représenté sur presque tous les monumens égyptiens, et particulièrement sur les obélisques de Lonqsor, insecte regardé jusqu'à ce jour comme une abeille. Cette figure est le plus souvent accompagnée d'une autre qui offre l'apparence d'un petit rameau à quatre branches et crochu à son ćxtrémité supérieure. Le ventre de l'insecte finit par une pointe courbée, ce qui paroît indiquer l'existence d'un aiguillon. Ce caractère et l'ensemble de la figure désignent évidemment un insecte de l'ordre des liyménop̣tères; mais si le dessin ne s'éloigne pas de la nature, $m$ ceil tant soit peu exercé n'y apercevra jamais une abeille, il y trouvera plutôt des rapports avec les cinips. Ũne espèce de ce genre, représentéc par Réaumur, ressemble tellement à l'insecte de cet hiéroglyphe, que j'avois d'abord cru que celui-ci étoit le cinips du figuier du sycomore, analogue au cinips psenes, employé depuis un temps immémorial dans l'orient, pour la caprification, et dont Pline fait une espèce de cousin. Mais ayant vu par les descriptions, qu'on a données de ces insectes, qu'ils étoient extrêmement petits, j'ai abandonné cette conjecture; l'hiéroglyphe dont j'ai parlé plus haut et qui accompagne presque toujours l'autre, étoit d'ailleurs inexplicable dans cette supposition. Repoussant ainsi l'idée que cet insecte fùt un cinips, et toujours persuadé qu'il n'avoit aucune ressemblance avec les abeilles, j'ai parcouru la série des autres liyménoptères, ct je me suis arrêté áux genres sphcx et guêpe, comme étant les seuls dont les espèces cussént pu, par leur manière de virre, fixer l'attention des Egyptiens. Je vais cxposer les motifs de cette nouvelle hypothèse, quoiqu'en dernière analyse, 
il nous faille peut-être revenir, comme nous le dirons plus bas, à l'opinion commune, celle qui nous fait voir dans cet insecte symbolique l'abeille domestique propre à l'Egypte.

Des espèces d'araignées ordinairement assez grosses et vivant à terre, la tarentule et les galéodes par exemple, étoient connues des anciens sous le nom de phalanges; on croyoit leurs morsures mortelles ou du moins trèsdangereuses; cette opinion s'est 'perpétuée en Italie et dans les pays orientaux. Les anciens avoient observé que des insectes leur faisoient une guerre cruelle et leur donnoient la mort. Le fait est constant d'après un passage de Pline, où ces insectes sont appelés guếpes-ichneumons, vespa ichneumon, dénomination que Réaumur et d'autres naturalistes ont conservée. Ils sont du genre sphex de Linnæus et très-communs dans les lieux sablonneux des contrées méridionales. A une époque où l'étude des insectes étoit généralement négligée, Belon et Prosper Albin remarquèrent néanmoins les habitudes de ces guêpes-ichneumons et positivement en Egypte. Plusieurs pompiles, genre démembré du précédent, solit assez grands et assez forts pour attaquer et se saisir des plus grandes araignées. De même que le crocodile étoit réputé avoir pour ennemi le quadrupède nommé ichneumon, de même le phalange, autre sujet de terreur, auroit eu dans la guêpe-ichneumon un adversaire formidable. Il est probable que le surnom d'ichneumon que Pline donne à cet insecte tiroit son origine d'une tradition égyptienne; je soupçonne même qu'un passage d'Hor-Apollon en offre les vestiges. La guêpe, sphex, du crocodile, nous dit-il, voltigeant dans l'air, désigne ou le sang pernicieux du crocodile ou le carnage. Les 
Egyptiens qui, suivant lenrs principes religieux, opposoient toujours à l'influence du mauvais génie, celle du génie bienfaisant, purent aussi représenter l'insecte destructeur des phalanges.

Mais quel est l'objet que les sculpteurs ou les peintres se sont plus à lui associer. Ici l'allégorie cst encore plus fine et plus spirituelle. Cet objet cst représenté sur les bas-raliefs du temple d'Edfou plus nettement et sous des dimensions beaucoup plus grandes que partout ailleurs. On y voit que les quatre branches du corps qui nous a paru avoir la forme d'un rameau, quoique très-rapprochées par leur base de leur tige intermédiaire, en sont néanmoins distinetes; que ce sont des espèces de filets, dont les deux supérieurs sont plus longs, et que le corps mitoyen et filiforme est fourchu à son cxtrémité supérieure. Représentons-nous les quatre étamines et le pistil d'une fleur de la famille des labiées et nous aurons un dessin parfaitement semblable. Tel a donc été, je pense, le sujet de cet hiéroglyphe. Un autre tableau allégorique ayant pour bordure une guirlande de fleurs, nous offre la même différence dans les proportions relatives de leurs étamines. Plusieurs plantes de la même famille, comme le dictam̄e de Crète, l'agnus castus, l'hysope, la monthe, le thym, l'origan, etc., sont réputées anti-vénéneuses, et quelques unes d'elles sont précisément recommandées par Pline contre la morsure des phalanges. Les organes sexuels d'un de ces végétaux, ceux peut-être de l'origan d'Egypte, dont les fleurs et les feuilles sont très-employées dans ce pays, seroient ainsi le sujet de l'hiéroglyphe accolé à celui de la guêpe-ichneumon. On auroit indiqué aux personnes mordues par des phalanges, le remède que l'expérience avoit fait counoitre 


\section{DES EGYPTIENS.}

comme le plus efficace contre la puissanee de leur venin. La figure des organes sexuels de la plante auroit annoncé qu'il falloit en employer les fleurs; peut-être y voyoit-on encore l'emblême d'un des prineipes de la génération exposés ei-dessus. Tout étoit dans ee langage mystérieux un sujet d'instruetion, et quelques lignes d'hiéroglyphes tenoient lieu d'un volume entier.

Si, généralisant davantage, nous nous borıons à dire que les Egyptiens, par ee demier emblème, ont simplement désigné une fleur, celle probablement d'une labiée, notre explication sera, nous avons du moins eette confiance, à l'abri de toute censure raisonnable. Mais avons-nons été aussi heureux dans l'explication de l'autre énigme? C'est, nous l'avouons avec franchise, ce qu'on pourra nous contester. Il est eertain qu'à l'égard du pilulaire sacré, l'imitation en est souvent très-grossière ou mème presque entièrement dénaturée. Ne pourroit-il pas en être ainsi de l'inseete hyménoptère en question ? On est d'autant plus porté à se décider pour l'affirmative, que de toutes les figures de eet animal, celle du temple de Karnak, et qui, tant par ses détails que par ses couleurs, seroit le plus susceptible d'une détermination approximative, présente néanmoins des earactères faux ou inconciliables avee ceux qui sont propres aux insectes de eette division. Cette fignre est accompagnée de dessins d'instrumens d'agrieulture, eomme de faux, d'un eouteau, d'un outil analogue à celui que M. Mongez regarde eomme la eliarrue simple et primitive des Egyptiens, et d'un corps plane et demi-circulaire, figure de la terre.

Ces eonsidérations nous ramènent à l'histoire des moeurs et des usages de ce peuple. Elle nous apprend 
que l'abeille étoit en honneur chez lui et l'une des sources de sa richesse. Cet insecte, selon Hor-Apollon, étoit le symbole d'un peuple soumis aux ordres de son souverain. S'il a fourni le sujet d'un hiéroglyphe, il est tout naturel qu'on ait placé à eôté de lui l'image d'une fleur. Dans la figure peinte de eet insecte, eelle du temple de Karnak, l'abdomen est représenté avec une eouleur jaunâtre, eoupé alternativement par des raies orangées et bordées d'une teinte plus obscure. Cette partie du corps de l'abeille d'Egypte nous offre en effet un mélange de couleurs presque semblable; elle est fortement tronquée à sa naissanee; et dans une autre figure de l'inseete (bas-reliefs du temple d'Edfou) ee earactère y est bien exprimé. Ainsi, eomme on l'avoit déja pensé, mais d'après une simple présomption, le petit animal figuré dans ces hiéroglyphes, pourroit être l'abeille domestique de cette eontrée.

Il seroit néanmoins possible que quelques uns de ces symboles eussent eu pour objet l'insecte dont j'ai parlé plus haut, ou une espèee de pompile; des différences que l'on observe dans ees figures comparées les unes aux autres pourroient le faire soupçonner. Toujours cst-il vrai qu'elles ne sont susceptibles d'aueune autre explication plausible (1).

(1) Les insectes dont je viens de parler n'étoient pas les seuls de cette classe d'animaux qui fussent l'objet de la vénération des Ėgytiens. J'ai trouvé dans une de leurs momies l'escarbot unicolor, une espèce de nécrobie et la mouche César. Peut-être soupçonnera-t-on que ce dernier inseete a pu éclore ct se développer dans ces momies ; car il vit de matières cadavéreuses; mais outre que le défaut d'air et les substances dont on faisoit usage pour embaumer les corps eussent fait périr la larve de ce diptère, je vois par un passage de Polux que les Grecs, qui cmpruntèrent tant de coutumes et de 
La science des insectes n'est donc point aussi futile et aussi dénuée d'intérêt que le pensent des esprits superficiels. Humble et modeste, elle ne jouit pas, il est vrai, d'une brillante renommée; on a vu cependant qu'elle pouvoit être utile à l'une de ses sours, la science de l'Archæologie, qui jusqu'à ce jour avoit fait peu de cas de ses services.

traditions des Égyptiens, avoient donné quelque attention à celte mouche ou à une espèce analogue, puisque les enfans avoient un jeu qu'on nommoit, jeu de la mouche bronzée.

J'ai reconnu dans une matière graisseuse et calcinée, qui remplissoit l'intérieur d'un vase de terre et de forme sphérique, les fragmens d'une espèce de coléoptère, du genre tagénie. M. Desmarets. m'a dit avoir retiré des enveloppes d'une momic les débris d'un autre coléoptère voisin du précédent, ceux d'un akis.

Pour compléter le travail relatif aux animaux de la classe des insectes de Linnæus, réputés sacrés par les Ėgyptiens, je présenterai les obervations suivantcs.

$\mathrm{I}^{\circ}$. Un abraxas figuré par Montfaucon a pour sujet une espèce de galéode. Peut-être y voyoit-on un emblême de la période sothiaque ; car l'animal représente l'unité; ses mandibules, assimilées pour leur forme à quatre mâchoìres (tetragnatha), indiqueront le chiffre 4 , ses pieds, au nombre de six dans la figure, composeront un chiffre correspondant, les deux yeux très-rapprochés sur un tubercule formeront un zéro, nous aurous ainsi 1460 , nombre d'années du cycle caniculaire.

$2^{\circ}$. Le scorpion figuré sur les zodiaques égyptiens est l'espèce décrite par Olivier sous le nom de crassicauda.

3․ Le crustacé représentant le signe du cancer se rapporte tantôt à une espèce de leucosie ou de pinnothère (zod. égypt. et ind.), tantôt à un portune (zod. arab. et ind.) ou au crabe fluviatil (zod. grec), quelquefois à une espèce de langouste (zod. ind.), mais, le plus souvent, surtout dans les zodiaques plus modernes, à une écrevisse. Dans ceux de l'Inde, le zébù y remplace notre taurcau. 


\section{INTRODUCTION}

\section{A LA GÉOGRAPHIE GÉNÉRALE}

\section{DES ARACHNIDES ET DES INSECTES,}

O U

DES CLIMATS PROPRES A GES ANIMAUX (x).

UN sujet des plus curieux et qui n'a pas eneore été traité, la détermination, du moins approximative, des climats propres aux races des arachnides et des insectes, se rattache à celui qui a pour objet leur nutrition. En effet, puisque l'auteur de la nature a répandu sur tous les points de la surface de notre globe, suseeptibles de les nourrir, les corps vivans, puisque ces êtres ont dî varier avee les climats, il faut que les substances alimentaires des animaux diffèrent pareillement, à raison des lieux où ils passent leur vie, ct que dès lors ees substances ainsi que ces animaux aient une même circonseription géographique.

Indépendamment de cette considération, la température qui convient au développement d'une espèce n'est pas toujours propre à celui d'une autre; ainsi l'étendue

(1) Ce Mémoire a été lu à l'Académie des Sciences, en 1815 , et fait partie du tome 3 des Mémoires du MIuséum d'histoire naturelle, qui se publient chez A. Belin, imprimeur, ì Paris, rue des Mathurins S.-J., $n^{\circ}$. 1 /. 
des pays qu'occupent certaines espèccs a nécessairement des bornes qqu'elles ne peuvent franchir, du moins subitcment, sans cesser d'exister.

Ces principes amènent une autre conséquence : là où Innit l'empire de Flore, là se termine aussi le domaine de la zoologie. Les animaux qui se nourrissent de végétaux ne pourroient vivre dans des lieux tout-à-fait stériles, et ceux qui sont carnassiers y seroient également privés de matières alimentaires ou des aninaux dont ils font leur proie; ils ne peuvent donc s'y établir.

L'observation nous apprend que les pays les plus féconds en animaux à pieds articulés, en insectes surtout, sont ceux dont la végétation est la plus riche et se renouvelle le plus promptement. Tels sont les effets d'une chaleur forte et soutenue, d'une humidité modérée et de la variété du sol. Plus, au contraire, on s'approche de cc terme, où les neiges et les glaces sont éternelles, soit en allant vers les pôles, soit en s'élevant sur des montagnes, à un point de leur hauteur qui, par l'aflaiblissemcnt du calorique, présente les mêmes phénomènes, plus le nombre des plantes et des insectes diminue. Aussi Othon Fabricius, qui a publié unc bonne faune du Groënland, n'y mentionne que 468 espèces d'animaux, et le nombre de celles des insectes, en y comprenant, à la manière de Linnæus, les crustacés et les arachnides, n’y est porté qu'à r ro (1). Enfin, dès qu'on aborde ces régions que l'hiver obsède sans cesise,

(I) Cet auteur n'a probablement mentionné que les espèces les plus sailantes et n'a point voulı donner une Entoınologie complète de la partie du Groënland, dont il a étudié les productions. Mais on n'en est pas moins en droit de conclure que le nombre des insectes y est très-borné. 
les êtres vivans ont disparu, et la nature n'a plus la force de produire. Les plaines qui avoisinent les pôlcs se trouvent, à cet égard, dans le même état d'inertie que lcs parties où commence la région des glaces perpétuelles dans les montagnes de la Zone torride, ou dans celles des contrées les plus fécondes. Ccs montagnes, envisagées sous le rapport des végétaux et des animaux qui leur sont propres, forment graduellement et par superposition des elimats particuliers, dont la température et les productions sont semblables à eelles des plaines des eontrées plus septentrionales. C'est ainsi que les Alpes sont l'habitation de plusieurs espèces d'insectcs que l'on ne trouve ensuite qu'au nord de l'Europe. Le prionus depsarius, qui sembloit jusqu'ici n'avoir d'autre patrie que la Suède, a été découvert dans les montagnes de la Suisse. J'ai pris moi-même au Cantal le lycus minutus, qu'on ne reçoit que des provinces les plus boréales de l'Europe. Ainsi eneore le papillon nomımé apollon par Linnæus, très-eommun dans les rampagnes et les jardins des environs d'Upsal, ainsi que dans d'autres parties de la Suède, n'habite en France que les montagnes dont l'élévation est' au moins de 600 à 700 toises au-dessus du niveau de la mer. Le carabus auratus (I), l'acrydium grossum, plusieurs de nos papillons, la vipère commune (coluber berus), ete., vivant ici dans nos plaines ou s'élevant peu au-dessus de l'horizontalité du sol, ont dans le midi de la France, en Italie, ete., leur domicile sur les montagnes alpines ou sous-alpines. Là

(i) Les carabes propres ont leur siége principal dans les zanes tempérées, en se rapprochant plus du Nord ou des parties élevées. que du Sud. On en trouve en Espagne, en Barbarie; mais les cspèces de ce genre y sont en petit nombre. 


\section{DES INSECTES.}

ces animaux retrouvent la même température et les mêmes matières nutritives. L'entomologiste éclairé tiendra compte de la hauteur, au-dessus de la mer, des lieux où il prend des insectes, et il observera avec soin leur température moyenne.

Ainsi que les géographes, les naturalistes ont partagé la surface de la terre en divers climats. Cenx-là ont pris pour base les différences progressives de la plus longue durée du jour naturel; ceux-ci ont fondé leurs divisions sur la température moyenne des régions propres aux animaux et aux végétaux. Dans la philosophie entomologique de Fabricius, l'acception du mot de climat est générale et embrasse l'universalité des liabitations des insectes, ou de tous les animaux à pieds artiticulés. Il divise le climat en huit stations, ou en autant de sous-climats particuliers, savoir : l'indien, l'austral, le méditerranéen, le boréal, l'oriental, l'occidental et l'alpin. Mais il est aisé de voir, par l'énumération des contrées qu'il rapporte à chacun d'eux, que ces divisions ne sont pas toujours établies sur des documens positifs, et qu'il faudroit, si l'on suit rigoureusement le principe sur lequel elles reposent, la chaleur moyenne, en supprimer quelrgues unes. Le sous-climat, qu'il appelle méditerranéen, comprend les pays adjacens à la mer Méditerranée, et en outre la Médie et l'Arménie. Le boréal s'étend depuis Paris jusqu'à la Laponie. L'oriental est composé du nord de l'Asie, de la Sibérie et de la portion froide ou montagneuse de la Syrie. L'occidental renferme le Canada, les Etats-Unis, le Japon et la Chine. Ce simple exposé suffit pour nous convaincre qu'il y a dans ces divisions beaucoup d'arbitraire. Plusicurs de ces contrées peuvent avoir et ont réellement 


\section{0

une température moyenne identique; elles ne sont pas cependant rangées sous le même climat. Mais outre que ces distinctions ne sont presque d'aucune utilité pour la science, puisque des lieux où cette température est la même ont des animaux différens, il est impossible, dans l'état actuel de nos connoissances, d'assurer sur une base solide ces divisions de climats. Les diverses élévations du sol au-dessus du niveau de la mer, sa composition minéralogique, la quantité variable des eaux qui l'arrosent, les modifications que les montagnes, par leur étendue, leur hauteur et leur direction, produisent sur sa température; les forêts plus ou moins grandes dont il peut être couvert, l'influence qu'exerce encore sur sa température celle des climats voisins, sont des élémens qui compliquent ces calculs, et qui y jettent de l'incertitude, vu la difficulté où l'on est d'en apprécier la valeur, soit isolément, soit réunis. Je considérerai les climats sous un autre point de vue, celui qui nous offre les genres d'arachnides et d'insectes exclusivement propres à des espaces déterminés de la surface de la terre. Nos catalogues, relativement aux espèces exotiques, sont trop imparfaits pour qu'il soit en notre pouvoir de suivre un autre plan; on n'a même encore yu'ébauché l'entomologie européenne (1). Mais supposé que nous n'eussions pas à nous plaindre de cette péuurie de matériaux, irois-je vous fatiguer par d'ennuyeuses nomenclatures d'espèces? par tous les petits détails où ce sujet m'entraîneroit? Ne faudroit-il pas toujours se fixer à quelques idées sommaires et générales, et aux résul-

(I) Eût-on tous les talens de M. de Ilumboldt, il seroit impossible de faire sur la géographie des insectes ce qu'il vicnt d'exćcutes relativement à celle des végétaux. 
tats les plus importans? Tcl est le but que je dois ne proposer; et quoiqu'avec plus de secours je pusse mieuxl'atteindre, j'cspère cependant qu'un bon emploi des foibles moyens que mes études m'ont fournis me conduira à des vues nouvelles, et que je crois dignes d'intérêt. Je vais, au reste, fraycr la route, ou plutôt je planterai le premier les jallons qui pourront servir à la percer, et mes efforts, fussent-ils infructueux, mériteroieut au moins quelque indulgence.

On doit reprocher à plusieurs naturalistes voyageurs de l'incurie ou de la négligence au sujet de l'indication précise des lieux où ils ont pris les objets qui enrichissent nos Musées. Cette première faute commise, on ne doit pas être surpris qu'ils n'aicnt pas remarqué les qualités particulières du sol, considéré physiquement et sous des apcrçus minéralogiques. Ces détails sont cependant une partie essentielle de l'histoire des animaux. Les licines, le papillon cléopátre, plusieurs dasytes, quelques lamies, etc., ne se trouvent que dans les terrains calcaires. J'ai observé que la pimélie biponctuée, trèscommunc aux environs de Marseille, ne s'éloignoit guère des bords de la mcr. Si l'intćrieur des terres, en Barbarie, en Syrie, en Égypte, etc., offre d'autrcs espèces du même genre, c'est que lc sol y est imprégné de particules salines, ou abonde en plantes du genre soude, salsola; ainsi ces pimélies habitent toujours un terrain analogue à celui où vit la première. Les insectes des pays qui bordent la Méditerranée, la mer Noire et la mer Caspienne, ont de grands rapports entre eux, et se tiennent pour la plupart à terre ou sur des plantes peu élevées. Ces contrées semblent être le siége principal des coléoptères hétéromc̀res, des lixes, des brachycères, des 
buprestes à forme conique, etc.; et quoique le cap de Bonne-Espérance en soit très-distant, beaucoup de ses insectes ont cependant encore avec les précédens des traits de famille. Nous pouvons déduire de ces faits que le terrain et les productions végétales de ces diverses régions ont plusieurs caractères d'affinité naturelle.

Il est facile de sontir qu'on doit porter les mémes soins dans l'observation locale, tant des espèces qui vivent dans les eaux et dont il faut distinguer la nature, que de celles qui sont littorales. Toutes ces connoissances accessoires peuvent nous éclairer sur les babitudes particulières des ces animaux, ou faire naître à leur sujet des présomptions raisomnables.

Ayant ainsi réveillé l'attention des naturalistes voyageurs, et présenté quelques observations préliminaires, je viens directement à mon sujet.

Les propositions suivantes sont établies sur l'étude que j'ai faite d'un des plus beaux Musées de l'Europe, des collections privées de Paris, et sur les rensejgnemens que j’ai pu acquérir tant par les ouvrages que par mes recherches et une correspondance très-étendue.

I․ La totalité, ou un très-grand nombre des arachnides et des insectes qui ont pour patrie des contrées dont la température et le sol sont les mêmes, mais séparées par de très-grands espaces, est composée, en général, d'espèces différentes, ces contrées fussent-elles sous le même parallèle. Tous les insectes et arachuides qu'on a rapportés des parties les plus orientales de l'Asie, comme de la Cbine, sont distincts de ceux de l'Europe et de l'Afrique, quelles que soient les latitudes et les températures de ces contrées asiatiques.

¿. La plupart des mêmes animaux difièrent encove 
spécifiquement, lorsque les pays où ils font leur séjour, ayant identité de sol et de température, sont séparés entre eux, n'importent les différences en latitude, par des barrières naturelles, interrompant les communieations de ces animaux ou les rendant très-difficiles, telles que des mers, des ehaînes de montagnes trèsélevées, de vastes déserts, ete. Dès lors les araehnides, les inscetes, les reptiles même de l'Amérique, de la Nouvelle Hollande, ne peuvent être confondus avee les animaux dés mêmes classes qui habitent l'ancien eontinent. Les insectes des Etats - Unis, quoique souvent très - rapproehés des nôtres, s'en éloignent eependant par quelques caractères. Ainsi eeux du royaume de la Nouvelle-Grenade, du Pérou, eontrées voisines de la Guiane et pareillement équinoxiales, diffèrent néanmoins, en grande partie, de eeux de la dernière, les Cordilières divisant ees climats. Quand l'on passe du Piémont en France par le eol de Tende, on aperçoit aussi un changement assez brusque. Ces règles peuvent souffrir quelques exceptions relativement aux espèces aquatiques. Nous eonnoissons eneore des insectes dont l'habitation s'étend très-loin. Le papillon du shardon (cardui) ou la belle-dame, si commun dans nos elimats et même en Suède, se trouve au cap de BonneEspéranee. La Nouvelle Hollande offre aussi une espèee qui en est très-voisine. Le sphinx du nérion, le sphinx celerio ont pour limites septentrionales notre elimat, et pour bornes méridionales l'Isle-de-France. Parmi les inseetes aquatiques, le dytiscus griseus, qui vit dans les eaux de la ei-devant Provenee, du Piémont, ete. , n'est pas étranger au Bengale. Je ne parle pas d'après les auteurs qui confondent souvent des espèces de prays 
très-éloignés lorsqu'elles ont des rapports communs, mais d'après mes propres observations ( 1 ).

3०. Beaucoup de genres d'insectes, et particulièrement ceux qui se nourrissent de végétaux, sont répandıs sur un grand nombre de points des divisions principales du globe.

$4^{\circ}$. Quelques autres sont exclusivement propres à une certaine étendue de pays, soit de l'ancien, soit du nouveau continent. On ne trouve point dans le dernier les suivans: anthie, graphiptère, érodie, pimélie, scaure, cossyphe, mylabre, brachycère, némoptère, abeille, anthophore, ni plusieurs autres de la famille des scarabéides, etc. Mais cet hémisphère occidental en présente aussi qu'on ne rencontre pas ailleurs, et dont voici les principaux : agre, galérite, nilion, tetraonix, rutèle, doryphore, alurne, érotyle, cupès, corydale, labide, pélécine, centris, euglosse, héliconien,

(I) Quoique les animaux de la classe des crustacés soient exclus de mon sujet, voici néanmoins quelques observations générales à leur égard et qui complètent ce travail.

$\mathrm{I}^{\circ}$. Les genres lithode, coriste, galathée, homole et phronyme sont propres aux mers d'Europe.

$2^{\prime 2}$. Ceux d'hépate et d'hippe n'ont encore été trouvés que daus l'Océan américain. .

30. Du même et des côtes de la Chine et des Moluques viennent les limules.

$4^{\circ}$. Les genres dorippe et leucosie habitent particulièrement la Méditerranée et les mers des Indes orientales.

50. Celles-ci nous donnent exclusivement les orithyes, les inatu. tes, les ranines, les albunées et les thalassines.

$6^{\circ}$. Les autres genres sont communs à toutes les mers. Miais les ocypodes ne sc trouvent que daus les pays chauds. Les grapses les plus grands viennent de l'Amérique méridionale et de la Nourelle- Hollande. 
érycine, castnie, etc. Nos abeilles y sont remplacées par les mélipones et trigones. On n'a encore observé les genres manticore, grapliiptère, pneumore, masaris, etc. , qu'en Afrique; le premier et le troisième sont même restreints à la colonie du cap de Bonne-Espérance. Les colliures sont propres aux Indes orientales. Les genres lamprime, liélée, paropside, panops, viennent uniquement de la Nouvelle Hollande ou de quelques îles voisines ( 1 ):

$5^{\circ}$. Plusieurs espèces, dans leur pays natal, affectent exclusivement certaines localités, soit dans les parties basses, soit dans celles qui sont élevées et à une hauteur constante. Quelques papillons alpins sont toujours confinés près de la région des neiges perpétuelles. Lorsqu'on s'élève sur des montagnes à une hauteur où la température, la végétation, le sol, sont les mêmes que ceux d'une contrée bien plus septentrionale, on y découvre plusieurs espèces qui sont particulières à celui-ci, et qu'on chercherait en vain dans les plaines et les vallons qui sont au pied de ces montagnes. J'ai cité plus haut des exemples qui appuient cette règle. Si dans le même pays la température de quelques unes de ses parlies basses, ou au niveau de l'horizon, est modifiée par des circonstances locales, ces cantons ont ausși plusieurs espèces que l'on trouve plus fréquemment, soit un peu plus au nord, si la température moyenne s'est abaissée, soit un peu plus au midi, dans le cas de son ascension. C'est ainsi que nous commençons à voir au nord du département de la Seine des insectes spécialement proores aux départemens plus froids, à l'Allemagne, etc.,

(1) Les plus grandes espèces de cossus, de zeuzères, d'hépiadss, riennent de ces eontrées. 
et que les terrains chauds et sablonneux situés au midi ct à l'est de Paris nous offrent quelques espèces méridionales.

$6^{\circ}$. On divisera l'ancien et le nouveau eontinent en zones, s'étendant suceessivement dans le sens des méridiens, et dont la largeur est mesurée par une portion de ecrcle parallèle à l'équateur. Les espèces propres à une de ees zones disparaissent graduellement et font place à celles de la zone suivante; de sorte que d'intervalle en intervalle, les espèces dominantes, ou même la totalité, ne sont plus les mêmes. Je eompare ees changemcns à eette suite d'horizons que le voyageur découvre à proportion qu'il s'éloigne de son premier point de départ.

La Suède a beaucoup d'cspèces d'insectes qui lui sont partieulières, ct dont quelques uncs sont reléguées dans ses provinces les plus boréales, comme la Laponie. Mais son midi, la Scanie, par exemple, offre, quoiqu'en petite quantité, plusicurs inseetes de l'Allemagne. La France, jusque vcrs le $45^{\mathrm{e}}$. à $44_{4^{\mathrm{e}}}$. degré de latitude, cn a plusieurs que l'on retrouve dans ees mêmes eontrées. Mais il semble que le Rhin et ses montagnes orientales forment, à l'égard de quelques autrcs espèees, une sorte de frontière qu'clles n'ont point franehie. Les premières de celles qui sont propres aux pays chauds de l'Europe oceidentale, se montrent vers le cours inférieur de la Seine, précisément au point où la vigne commence à prospérer dans lcs terrains en plaine, et sans le secours de quelques circonstances locales. L'ateuchus flagellé, le mylabre de la chicorée, la mante religieuse, la cigale hamatode, l'ascalaphe italique, ete., annoncent ce changement. Il est plus manifeste à Fontainebleau, 
àx environs d'Orléans, qui ofirent, outre ces espèces, le phasma Rossii, la mantis pagana, le sphinx celerio, etc.

Mais ces insectes, si je puis m'exprimer ainsi, ne sont que les avant-coureurs de ceux qui sont propres aux contrées vraiment méridionales. On reconnoît le domaine des derniers à l'apparition de quelques autres espèces de cigales, de mantes; à celle des zonitis, des akis, des scaures, des termès, etc., mais surtout à la présence du scorpion européen et de l'ateuchus sacré( $(\mathrm{I})$. La culture de l'olivier, la croissance spontanée de l'arbousier, du grenadier, de la lavande, parlent encore plus sensiblement aux yeux. Ce changement est extrèmement remarquable, lorsqu'en allant de Paris à Marseille, on atteint le territoire de Montélimart. Les bords de la Méditerranée sont un peu plus chauds; les mygales, les onitis, les cébrions, les brentes, les scarites, etc., y paroissent pour la première fois. Si nous pénétrons dans l'intérieur de l'Espagne, et si nous y visitons les belles contrées de l'est, óù les orangers et les palmiers viennent en pleine terre, un nouvel ordre d'espèces d'arachnides et d'insectes, entremêlées de quelques unes déjà observées dans lc midi de la France, frappera nos regards. Nous y voyons des érodies, des sépidies, des zygies, des némoptères, des galéodes, et beaucoup d'autres insectes analogues à ceux de Barbarie et du Levant. La connoissance de ces espèces nous étant devenue familièrc, l'entomologie des contrées

(I) Les papillons de la division des equites ont aussi leur siég: principal dans les pays chauds, et surtout, entre les tropiques. Ceux que Linnæus désigne sous le nom de troyens, sont propres a la partie de l'Asic qui est au-delà de l'Indus, et à l'Amérique. 
atlantiques de l'Afrique, ou de celles qui sont situées sur la Méditerranée jusqu'à l'Atlas, ne nous eausera point une surprise extraordinaire. Nous y déeouvrirons cependant des genres d'inseetes qui ont leur centre de domination dans les régions comprises entre les tropiques, comme des anthies, des graphiptères, des siagones, ete.

Nous n'avons sur les insectes du sud-est de l'Europe que des notions très-imparfaites. Je remarque seulement que le papillon clirysippus de Linnæus, eommun en Egypte et aux Indes orientales, paroît déjà dans le royaume de Naples. La plupart des espèces d'Egypte sont étrangères à l'Europe, sans qu'elles sortent néanmoins des familles naturelles où se placent les nôtres. Son extrémité méridionale, en tirant ver's la Nubie, offre une de ces grandes sortes de bousier, le midas, qui, tels que le bucephalus, l'antenor, le gigas, n'habitent que les elimats les plus chauds et rapprochés de la ligne équinoxiale de l'aneien continent.

Transportés sur les rives du Sénégal, et gagnant de lì les contrées plus au midi, nous ne vojons plus aueun inseete d'Europe. C'est de ces régions brûlantes que viennent les plus grandes espèces du genre goliath de M. de Lamark; les autres nous sont fournies par l'Amérique méridionale. La eolonie du eap de Bonne-Espérance abonde surtout en espèees des genres anthie et brachycère. On y trouve encore les genres manticore, pneumore, doryle et enrychore. M. Savigny a déeouvert en Egypte une nouvelle espèee du dernier; et dans les inseetes recueillis au Bengale par Macé, j'ai trouvé mne espèee de celui de doryle. L'Afrique et les Indes orientales nous offrent encore des sagres, des paussus 


\section{DES INSECTES.}

et dés diopsis. L'Isle-de-France a même une espèce inédite du secoud de ces genres. M. Palisot de Beauvois a rapporté du royaume de Benim celui qu'il a nommé petalocheirus, voisin des reduves, mais très-singulier par la forme en bouclier ou en rondache de ses deux jambes antérieures. Celui d'encelade est propre à la côte d'Angole. Quelques excursions que M. Desfontaines a faites sur le domaine de l'entomologie, durant son voyage dans les états Barbaresques, et qui nous font regretter qu'il ne se'soit pas livré plus long-temps à la recherche des insectes de cette partie de l'Afrique, nous ont procuré le genre masaris, dont le midi de l'Europe et le Levant nous présentent l'analogue, celui de célonite. Enfin cette grande division de l'ancien continent a plusieurs lépidoptères qui forment des coupes particulières, et beaucoup d'autres insectes, qui resteront long-temps inconnus.

Toutes les successions d'espèces s'opèrent encore raduellement de l'ouest à l'est, et réciproquement: Plusieurs de celles que l'on trouve dans les ci-devant orovinces de Normandie et de Bretagne habitent encore la partie méridionale de l'Angleterre. Les départemens situés sur la rive gauche du Rhin, au nord, cont, à cet égard, en communauté de bien avec lés proinces voisines de l'Allemagne, mais pour une simple cortion. Quelques insectes du Levant, tels que la canharide orientale, le mylabie crassicorne, une belle ariété du hanneton occidental, rapportée par Olivier, les lépidoptères diurnes, semblent avoir voyagé vers e couchant et s'être fixés dane le territoire de Vienne n Autriche. Il me paroît, d'après la collection que ce élèbre naturaliste ayoit formée dans l'Asie maineure, 
en Syrie, en Perse, etc., que les insectes de ces régions, quoique très-affiliés à ceux du midi de l'Europe, en sont cependant distincts, pour la plupart, d'une manière spécifique. Je porte le même jugement sur ceux de la Russie méridionale et de la Crimée. Les arachnides et les insectcs de la côte de Coromandel, du Bengale, de la Chine méridionale, du Thibet même, dont quelques uns m'ont été communiqués par mon généreux ami , M. Mac-Leay, secrétairc de la Société Linnéenne, ont de grands rapports entre eux; mais ils sont absolument distincts de ccux de l'Europe, quoiqu'ils puissent être classés, pour la plupart, dans les mêmes genres et dans quelques uns de ceux de l'Afrique. On n'y trouve point de graphiptères, d'akis, de scaures, dc pimélies, de sépidies, d'érodies, genres dont la nature paroît avoir accordé la propriété exclusivc aus parties méridionales et occidentales de l'ancien continent. Fabricius donne pour patrie, à quelques espèccs de brachycères, les Indes orientales; mais je n'en ai pas vu un seul dans les collections nombreuses qui y ont été formées. Le genre anthie se retrouve encore au Bengale; mais plus loin on n'en trouve aucune espèce.

L'ille de Madagascar se rapprochc, sous quclques points : quant aux familles naturelles desinsectes, de l'Afrique ( $\mathrm{I}$ ). Mais ces espèces sont très-distinctes, et plusieurs mêmt n'ont pas d'analogues. Les îles de France et de Bourbon offrent aussi des vestiges de ces mêmes affinités: les insectes de ccs colonics paroissent cependant, en général, tenir davantage de ceux des Indes orientales: leur nombre est très-borné.

Quoique l'entomologie de la Nouvelle-Hollande formc (I) On y trouve des brachycires. 
un type spécial, elle se coinpose néanmoins, en grande partie, d'espèces analogues à celles des Moluques et du sudest des Indes (r). Le genre des mylabres, dont les espèces sont si abondantes au midi de l'Europe, en $\Lambda$ frique et en Asie, sembleroit ne pas dépasser l'île de Timor. La Nouvclle-IIollande auroit, à cet égard, des traits de similitude avec l'Amérique. On y trouve pareillement des passales, genre dont les espèces habitent plus particulièrement le Nouveau-Monde. Je soupçonne que les productions naturelles de cet hémisphère occidental, considéréès sous le rapport des groupes génériques, se rapprochent plus de celles de l'est de l'Asie que des nôtres. On sait que les animaux à bourse sont confinés dans les extrémités orientales de l'ancien continent, et qu'on les retrouve ensuite dans le nouveau. Je pourrois alléguer d'autres exemples, et dont quelques uns seroient pris de la classe des crustacés.

Les insectes de la Nouvelle-Zélande, de la NouvelleCalédonie, et ceux probablement des îles circonvoisines, me paroissent avoir beaucoup' d'affinité avec les insectes de la Nouvelle-Hollande. Je présume qu'il en est de même de ceux de quelques autres archipels du grand Océan austral. Ces îles, composées, en grande partie, d'aggrégations de polypiers, forment une chaîne qui les unit à l'ouest aux précédentes, et ont pu recevoir d'clles leurs productions. Cette communication, faute de tels moyens, n'a pu avoir lieu du côté de l'Amérique. Ainsi plusieurs de ces îles sont américaines par leur position géographique, et peuvent être asiatiques, quant aux productions animales et végétales de leur sol.

(r) La Nouvelle-Hollande est moins riche, son sol, celui du moins des parties connues, étant plus sec et moins boisé. 
Le nouveau continent présente une marche progressive semblable, dans les changemens des espèces, relatifs aux différences noțables des latitudes et des longitudes. Notre collègue, M. Bosc, a recueilli dans la Caroline beaucoup d'espèces qu'on ne trouve point en Pensylvanie, et encore moins dans la province de New-Yorck. Les recherches d'Abbot sur les lépidoptères de la Géorgie nous prouvent qu'on y voit déjà quelques espèces de cet ordre, dont le siége principal est aux Antilles. Les bords de la rivière de Missouri, à une vingtaine de degrés environ, à l'ouesi de Philadelphie, servent d'habitation à plusicurs insectes particuliers, et dont je dois encore la communication à M. Mac-Leay. J'ai vu aussi une collection formée à la Louisiane, et j'y ai remarqué d'autres mutations. L'entomologie des Antilles, à quelques espèces près, contraste absolument avec celle des Etat-Unis, L’île de la Trinité, à so degrés de latitude Nord, a des espèces équatoriales, comme des papillons de la division de ceux qu'on nomme menelaus, teucer, etc., qu'on n'observe pas à St.-Domingue. Ici encore se trouvent des tatous, quadrupèdes inconnus dans cette dernière île. Le Brésil a des espèces que Cayenne offre également; mais il en possède une foule d'autres qui lui sont particulières.

Cependant si l'on compare les parallèles de l'ancien ct du nouveau monde, sous le rapport de la température convenable aux diverses espèces d'insectes, l'on verra que ces parallèles ne se correspondent point à cet égard. Les insectes méridionaux de l'hémisphère occidental ne remontent pas si haut que dans le nôtre. Ici, comme nous l'avons obscrvé, ils commencent à paroître, entre le $48^{\circ}$. et le $19^{\mathrm{e}}$. degrés de latitude nord; là ce n'est guère que 
vers le $43^{\mathrm{e}}$. Les scorpions, les cigales, les mantes, etc. sont toujours nos signes indicateurs. Quand on réfléchit sur la constitution physique de l'Amérique, quand on considère que son sol est très-arrosé, considérablement montagneux, couvert de grandes forèts, que son atmosphère est très-humide, l'on conçoit sans peine que certains genres d'insectes de l'ancien continent, qui aiment les lieux sccs, sablonneux, et très-chauds, tels que les anthies, les pimélies, les érodies, les brachicères, etc., n'auroient pu vivre sur le terrain gras, aqueux et ombragé du nouveau monde. Aussi, proportions gardées, le nombre des coléoptères carnassiers y est-il moins considérable que dans l'ancien continent. La grandeur des insectes ayant les mêmes habitudes est souvent inférieure à celle des nôtres. Les scorpions de Cayenne et des autres contrées équinoxiales de l'Amérique ne sont guère plus gros que celui du sud de l'Europe qu'on a nommé occitanus. Ils sont donc bicn loin d'égaler en volume le scorpion africain, afer, qui est presque aussi grand que notre écrevisse fluviatile. Mais aussi l'Amérique ne le cède point àux contrées les plus fécondes de l'ancien monde, à l'égard des espèces qui se nourrissent de végétaux, et stirtout en lépidoptères, en scarabéïdes, en chrysomélines, en cérambycins, eic., particulièrement en guêpes, fourmis, orthoptères et aranéïdes. Cependant la Chine-méridionale et les Nioluques semblent conserver une sorte de supériorité, en donnant naissance à des lépidoptères tels que le papilio priamus, le bomby $x$ "tlas, etc., dont les dimensions surpassent celles des lépidoptères de l'Amérique. Un fait que je ne dois point omettre est que l'Europe, l'Afrique et l'Asie occidentale h'ont presque pas d'insectes du genre plasme ou spectres 
et que les espéees qu'on y trouve sont petites, tandis que les Moluques et l'Amérique méridionale nous en présẹntent d'une taille très-remarquable. L'humidité atmosphérique et habituellc du nouveau continent, sa forme étroite et allongée, la vaste étendue des mers qui l'environnent de toutes parts et la nature de son sol, nous fournissent l'explication de la discordance que l'on observe entre ses climats et ceux de notre hémisphère, considérés sous les mêmes parallèles. Le nouveau monde est à l'ancien continent ce qu'est l'Angleterre à une grande partie de l'Europc. La Normandic et la Bretagne comparées aux provinees de la France situées à leur levant, pourroient encore nous offrir des rapprochemens analogues.

Nous avons dit que la distinction des climats donnée par Fabricius étoit vieieuse et arbitraire sous plusieurs points. Nous venons de le confirmer par nos observations générales sur les localités propres aux genres des arachnides et des insectes. Mais est-il possible d'établir avec les ressources de la géographie des divisions qui se coordonnent avec nos connoissances zoologiques aetuelles, et même avec celles que l'on aequerra dans la suite; c'est ce que je vais entreprendre.

Le Groënland a, été pour les naturalistes le deruicr terme de leurs reeherches, vers lc pôle Arctique. D'après l'étude qu'Othon Fabricius a faite de ses insectes, et qui avec les araehnides, ne eomposent que 8r espéces, il parôî que ces animaux sont, en totalité, les mêmes que ceux du Danemarck, de la Sucde, et surtout de la portion de la Laponie qui relève de ce dernier royaume. On peut considérer les extrémités septentrionales du Groëmland et du Spitzberg, . c'est-à-dire, le $8 I^{\text {e }}$. degré de latitude nord, comme les points où se termine la ré- 
gétation. Mais pour obvier à toute difficulté, et pour l'établissement d'une division duodécimale qui sera commode et s'accordera souvent avec mes observations, je remonterai ce dernier terme de la végétation trois degrés

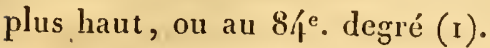

Nous avons vu que la Laponic avoit une faune spéciale; que celles du midi de la Suèdc, du nord de la France jusque vers le climat de Paris, et de la plus grande portion de l'Allemagne offroient une grandc ressemblance; que des insectes méridionaux se montroient, pour la première fois, au sud de Paris, et positivcment dans les lieux où la vigne commence à prospérer, par la scule influence de la tcmpérature moyenne; nous avons dit que la culturc de l'olivier, qui commence en France, entre le $45^{\mathrm{e}}$. et $44^{\mathrm{e}}$. degré dc latitude, annonçoit plus particulièrement le domaine de ces insectes méridionaux; que dcs espèces encore plus australes paroissoient deux ou trois degrés plus bas, vcrs lcs limites septentrionales de ces contrées, oủ les orangers et les palmiers réussissent en plcine terre. La Barbarie, où le dattier parvient à maturité, où l'on peut cultiver la canne à sucre, l'indigot, le bananier, etc., nous a offert quelques genres d'insectes propres aux pays qui avoisinent l'équateur. Enfin nous u'avons pu doutcr quc nous en étions encore plus près, à la vue des espèces du sud de l'Egyptc, du Sénégal, etc. Or, si nous partageons de douze en douze, et à commencer au 84 $4^{\mathrm{e}}$. degrć de latitude nord, un méridien qui partiroit des parties occidentales du Spitzberg, ou les plus voisines du Groc̈nland, nous aurons une

(x) On trouve encore an Spitzberg quelques plantes, comme des saxifrages, le cochlearia du Groënland, l'oie qui fournit l'édresdon, etc. Voyez les Mém. de l'Acad. de Stockholn. 
suite de latitudes qui correspondront successivement $\dot{a}$ celles des limites des pays, que nous venons d'examiner sous les rapports généraux de la zoologie et de la botanique. Nous prolongerons les sections, et toujours d'une manière duodécimale, au-delà de l'équateur, vers le póle Antarctique, et nous nous arrêterons au $60^{\mathrm{e}}$. de latitude, sous le parallèle de la terre de Sandwich, qui est, de côté, le nec plus ultra des découvertes géographiques.

Ces intervalles peuvent être subdivisés par des parties aliquotes de leur différence, douze. Ainsi, par exemple, l'arc compris entre le $48^{\mathrm{e}}$. et le $36^{\mathrm{e}}$. de latitude, diminué successivement de quelques unes de ces parties, domnera les nombres : $45,42,39$, latitudes auxquelles se rattachent plusieurs de mes observations précédentes. 'Toujours me paroît-il constant qu'un espace en latitude, mesuré par un arc de douze degrés, produit, abstraction faite de quelques variations locales, un changement très-sensible dans la masse des espèces, qu'il est même presque total, si cet arc est double ou de 24 degrés, comme du nord de la Suède, au nord de l'Espagne. Ce changement a également lieu dans une direction perpendiculaire à là première ou dans le sens des longitudes, mais d'une manière plus lente, et à une distance plus grande, puisque la chaleur moyenne, sans des causes particulières et modifiantes, seroit uniforme sous le même parallèle. A mesure qu'on approche des pôles, l'étendue des races peut embrasser un plus grand nombre de divisions géographiques; car celle des parallèles de longitudes diminue progressivement, à partir de l'équateur. Mais aussi d'autres circonstances tendent à en zéduire le nombre. 
Les insectes de l'Amérique, ceux même de ses provinces septentrionales, du moins jusqu'au Canada, différent spéeifiquement des nôtres, tandis que eeux du Groënland semblent être européens; ectte dernière contrée ou le Groënland sera, pour notre géographie des inseetes de l'aneien eontinent, le point de départ de notre premier méridien. Elle seroit, dans toute hypothèse, intermédiaire entre les deux hémisphères. Les Canaries, les îles du Cap Vert, Madère, sont africaines, par la nature de leurs produetions. Notre méridien suivra donc une direction mitoyenne entre ees îles et le Cap de l'Amérique le plus avancé vers l'est, celui de St.-Roch, près de Rio-Grande, au Brésil. Il passera près des îles occidentales de l'Archipel des Aẹores, de eelles de l'Ascension, et aboutira un peu à l'ouest de la terre de Sandwieh. Sa longitude sera de 3í degrés, à l'ouest du méridien de Paris. D'après mes observations sur les insectes reeueillis en Perse, par Olivier, d’après les rapports qu'ils ont avec eeux du midi de l'Europe, du nord de l'Afrique, et les différences essentielles qu'ils présentent, dans leur eomparaison avec ceux des Indes orientales, je suis porté à eroire que les plus grands changemens dans ces espèees ont lieus, au midi, vers les frontières de la Perse et de l'Inde, et au nord, à peu de distanee du revers oriental des monts Oural, de la mer d'Aral, un peu au-delà du méridien qui est au $60^{\mathrm{e}}$. degré, à l'est de Paris. Nous pouvons approximativement fixer eette limite au $62^{\mathrm{e}}$. (I), un peu à l'ouest de l'Obi,

(t) A la chute occidentale des montagnes qui séparent le Mekrân, le Sedjestân de l'Indoustan, et de celles qui sont intermédiaires entre la grande Bucharie et la petite, vers les sources du Jihon et du Gihon. 
de Balk, de Candahar, etc., ce qui nous donnera le moyen de continuer notre division duodécinale; car si nous ajoutons ce nombre de 62 à celui de 34 , différence de notrc premier méridicn et de celui de Paris, nous aurons 96 , quantité susceptible d'ètrc divisée, sans fractions, en huit parties, dont chacune égale la trentic̀me portion du cercle. Nous séparerons ainsi l'aucien continent, en deux grandes bandcs, dont l'une occidcntale et l'autre oricntale. Si nous donnons à celle-ci la même étendue en longitude, ou $9^{6}$ degrés, le méridien qui la tcrminera à l'est, sera de 158 degrés plus oriental que celui de Paris. Il partira du Kamtchatska, se dirigera aux îles Carolines, et de là entrc la NouvellcHollande et la Nouvelle-Zélande. Augmentée d'un quart ou de 24 degrés, cctte bande aura pour limite orientalc un autre méridien qui à 182 , à l'cst de Paris, passera à peu de distance du Cap-Est, sur le détroit de Béring, se prolongera au-delà des îlcs des $\Lambda$ mis, et formera, sans crreur importantc pour notre objet (I), unc ligne de démarcation, entre l'Asie ct l'Amérique. Les autres I 44 degrés compléteront le ccrcle de l'équateur et seront l'étendue en longitude de la grande zone propre aux insectes de l'Amériquc. Nous la partagcrons également, et

(I) Il est probable que les animaux et les végétaux des pays qui terminent le nord-est de l'Asie et le nord-ouest de l'A mérique, ou qui sont adjacens au détroit de Béring, ont beaucoup de rapports entre eux; ainsi ce détroit ne formeroit qu'une démarcation artificielle, comme celle que produit le détroit de Gibraltar, entre l'Europe et l'Afrique. Le méridien qui nous sert de limite cntre l'Asic et l'Amérique coupe en deux parties égales l'étendue moyenne de l'Océan comprise entre les côtes maritimes de la province de Canton, et celles de la Californic, qui sont sous le même parallèle. Il formeroil ainsi, géographiquement, une division plus naturelle. 
sớr les mêmes dénominations, en deux portions égales, de $z_{2}$ degrés ehaeune. Ainsi le eerele de l'équateur sera divisé en quatre ares, dont les valeurs seront : $\eta^{2}$, $72,9^{6}$ et 120 , ou dans les rapports de six trentièmes, de huit trentiènes et de dix trentièmes. L'étendue en longitude de l'aneien continent eomprendra 216 degrés, et celle du nouveau r 44 ; comparées avee la mesure entière de l'équateur, elles nous donneront les rapports suivans : dix-huit trentièmes, douze trentièmes, ou neuf quinzièmes, six quinzièmes.

Nos petites zones ou nos elimats seront arctiques ou antarctiques, selon leur situation en deçà ou au delà de la ligne équinoxiale. Le elimat eompris entre le 8 . climat polaire. Viendront ensuite et jusqu'à l'équateur, et en continuant toujours la division duodéeimale, les climats suivans : sous-polaire, supérieur, intermédiaire, sur-tropical, tropical, équatorial; mais comme j'ai eoupé en deux grandes parties ehaque hémisphère, je distinguerai les climats de ehacune d'elles, par l'épithète d'occidental ou d'oriental. Les elimats antaretiques ne seront que de trois sortes, puisque nous n'allons pas plus loin que le $6 o^{\mathrm{e}}$. degré de latitude sud; eeux que j'appelle polaire et sous-polaire sont par là supprimés, au pole sud. Les divisions et les dénominations seront les mêmes pour les deux eontinens. Faisons sentir leur usage par quelques applications à la partie septentrionale et oecidentale de notre continent, celle qui nous est plus connue.

Le elimat polaire présentera les inseetes de la plus grande portion du Groënland, eeux de l'Islande et du Spitzberg. Dans le climat sous-polaire nous trouverons . 
ceux de la Norwège, du nord de la Suède et de la Ruśsie européenne. Voilà les insectes des contrées les plus froides. Nous placerons dans le climat supérieur ceux de la Grande-Bretagne, du midi de la Suède, du nord de la France, jusqu'au cours inférieur de la Loire, de la Prusse, de l'Allemagne propre, du midi de la Russie, jusqu’à la Crimée, exclusivement. Le climat intermédiaire, à égales distances du polaire et de l'équatorial, comprendra tous les autres insectes du midi de l'Europe, et d'une portion occidentale de l'Asie. Ceux du nord de l'Afrique, jusqu'à l'équateur, appartiendront aux climats que j'ai désignés sous les noms de sur-tropical, tropical et d'équatorial. Ces climats de l'ouest peuvent être divisés, par un méridien, en deux parties égales, de 48 degrés chaque (I). Ce méridien passeroit ঐ̇ 4 degrés à l'est de Paris, près de Vienne en Autriche, rejeteroit au Levant la partie la plus méridionale de l'Italie, la Turquic d'Europe, l'Egypte, etc. Or, nous avons déjà observé que plusieurs des insectes dẹs environs de Vienne se trouvoient aussi dans le Levant, et que ceux du royaume de Naples, de l'Egypte et du sudest de l'Europe, paroissoient différer, pour la plupart, des espèces méridionales et occidentales de cette division de la terre; nous pouvons ionc former ici des sousclimats. Si on coupe la partie orientale, dont l'étendue en longitude est de r 20 degrés, en quatre sections égales, ou de trente degrés chacune, par des méridiens, on aura des sous-climats dont les borues sont naturelles. Ainsi le premier comprendra l'Indostan, le Thibet, la petite Bucharie, la Sibérie, etc. Le second détachera presque toutes les îles Philippines, la Chiue propre et les régions

(I) Et ensuite de 2' 
au Nord, jusqu'un peu au delà de la rivière de Léna. La Corée, le Japon, le pays des Manchous et des Tongouses, etc., seront dans le troisième. Enfin le quatrième offrira le Kamtchatska et les autres contrées qui terminent le nord-est de l'Asie. L'Amérique pourra aussi être subdiviséc de la même manière, ou en parties de 36 degrés (I).

Je sens bien que la nature, dans sa distribution des localités propres aux espèces de ces animaux, s'écarte souvent de la marche régulière que j’ai tracée ; que ces lignes d'habitation forment des courbes, des sinuosités, et qui sont même interrompues on croisées par d'autres. Mais j'ai simplement voulu esquisser une sorte de carte géographique ; j'ai tâché de la circonscrire aussi bien qu'il

(1) On pourroit adopter, pour l'uniformité, la division de $24^{\circ}$, soit pour l'ancien, soit pour ke nouveau continent; ou chaque climat auroit 12 degrés en latitude et le double en longitude. L'ancien continent renfermeroit, dans la partie en deçà de l'équateur, 63 climats, et le nouveau, toujours vers le même pôle, 42 . Si on distingue ces deux hémisphères par les lettres $A$ et $B$, leur situation en deçà ou au delà de la ligne équinoxiale par $n$ et $s$, ou nord et sud, l'étendue en latitude par les premiers chiffres, et celle en longitude par les seconds, précédés d'un point, l'expression suivante $\mathrm{A} n .5$. 2. indiquera, par abréviation, le climat supérieur arctique, qui comprend la Grande-Bretagne, le nord de la France, l'Allemagne, etc. Ce climat se termine au $48^{e}$. degré de longitude, à partir de notre premier méridien; si on en retranche 34 degrés, on aura la différence en longitude, $14^{\circ}$, comprise entre le méridien de Paris et celui qui termine, à l'Orient, ce climat: On ajouteroit ce nombre 34, s'il s'agissoit d'un climat situé dans la partie septentrionale du nouveau monde. On pourroit faire usage de ces divisions, pour la commodité de la géographie. Ainsi le climat : A $n .3,6$, renferme la plus grande partie de la Chine, ou l'espace compris entre le 24 et le 36 '. degrés de latitude nord, et Ga 86e. au 120\%. degrés de longitude, à l'est de Paris. 
é:oit possible; de la diviser, d'après quelques principes fixes, en parties qui fussent en harmonie avec mes observations, et de manière que les vides ou les cases pussent être remplis, à mesure que l'on découvriroit les objets qui doivent y être placés. J'ai fait abstraction des modifications particulières. Je me suis proposé, en un mot, d'accorder la géographie avcc l'entomologie, d'une manière générale et qui n'étoit pas susceptible d'une extrême rigueur. Au reste, c'est un essai, ainsi que je l'ai dit, et qui a besoin de nouvelles méditations.

La progression croissante de l'intensité et de la durée du calorique, influe sur le volume, le développement du tissu muqueux et sur les couleurs des arachnides et des insectes. Plus, en général, on s'avance sur les régions équinoxiales, plus l'on trouve d'espèces remarquables par leur taille, les éminences et les inégalités de leur corps, l'éclat et la variété du coloris. Je crois pouvoir assurer que l'augmentation de la lumière tend à convertir le jaune en rouge ou en orangé, et que sa déperdition fait passer ce jaune au blanc. Ce fait s'applique aussi à des coquilles. L'helix nemoralis, ou la livrée, qui dans nos climats a le fond jaune, est rouge ou rougeâtre, en Espagne. Dès qu'en allant du nord au midi, l'on arrive à l'île de Ténériffe, l'on s'aperçoit déjà que notre papillon du chou (papilio cheiranthi, Hübn.), et celui qu'on nomme le vulcain (atalanta), ont éprouré une modification dans leurs couleurs. Les papillons diurnes de nos montagnes ont ordinairement le fond des ailes blancs, ou d'un brun plus ou moins foncé.

Ces observations sur les climats des insectes et des autres corps vivans intéressent, non-seulement le naturaliste, mais encore le géographe. Elles peurent être utiles 
au dernier, dans la détermination des limites naturelles de quelques parties litigieuses, comme des îles situées entre deux continens, supposé toutefois que l'éloignement respectif de ees îles soit assez grand pour empècher les végétaux ct les animaux de se propager des unes aux autres. Nous avons vu que le Groënland, qu'on joint à I'Anjérique, se rapproehe davantage, d'aprc̀s la faune d'Othon Fabrieius, de l'Europe, ou peut du moins être regardé comme une terre mitoyenne, que ehaque continent peut revendiquer. Ainsi les îles Canaries et de Madère doivent être associées à l'Afrique; car les insectes qu'on y trouve sont parfaitement analogues à ceux dẹ la Barbarie et des eontrées adjacentes. L'Amérique diffère aussi, sous les mêmes rapports, des régions oceidentales de notre hénisphère, et il faut en conclure qu'elle n'cn a point été détachéc, dans la dernière révo-lution de notre planćte. Enfin, lorsque je vois que les insectes des pays qui eirconscrivent lc bassin de la Méditerranée, ceux de la mer Noire et de la mer Caspienne se ressemblent singulièrement, quant aux genres et aux familles, où ils se groupent; lorsque je eonsidère que la plupart d'entre eux vivent exelusivement sur un terrain sablonneux, ordinairement salin, peu boisé ; que les végétaux de ees contrées présentent aussi de grands rapports, il me vient aussitôt en pensée qu'elles sortirent les dernières, du sein des eaux; mais j'appréhende de me laisser entraîner, malgré moi, par un esprit de système. Je prierai seulement les géologues, au jugement desquels jc soumets mes conjeetures, de me permettre de leur exposer l'analyse d'un passage curieux de Diodore de Sieile (liv. 2, art. 7o), qui semble nous conserver, sous le voile de l'allégorie, une tradition re= 


\section{I94 GEOGRAPHIE GENÉRALE}

iative aux changemens qu'ont subi ces contrées; il me semble qu'il s'applique très-bien à mon sujet.

La terre enfanta l'égide, monstre horrible, dont la gueule vomissoit une épouvantable quantité de flammes. Il parut d'abord en Phrygie, brûla cette contrée, qui prit son nom de ce désastre, suivit, jusqu'aux Indes, la chaîne du mont Taurus, en réduisit tous les bois en cendres; puis se repliant vers la Méditcrranée, il entra dans la Phénicie, incendia les forêts du Liban, traversat l'Egypte, porta ses ravages jusque dans les parties occidentales de la Lybie, et changeant, encore une fois de direction, vint s'arrêter sur les monts Cérauniens. Il désola le pays, fit périr une portion de ses habitans, et força les autres à s'expatrier pour échapper à la mort. Minerve, par sa prudence et son courage, tua ce monstre, et depuis en porta toujours la peau sur sa poitrine, comme une arme défensive. La terre irritée de sa mort, donna naissance aux géans, qui furent vaincus'par Jupiter, aidé de Minerve, de Bacchus et des autres dieux.

Ici, coinme dans toutes les mythologies de l'antiquité, les divers agens de la puissance de la nature sont divinisés ou personifiés. L'action des feux souterrains et volcaniques est représentée sous l'allégorie d'un monstre épouvantable, vomissánt des torrens de'feu, qui parcourt successivement les montagnes de lisie-Mineure, de l'Arménie, de la Médie, de l'Hyrcaüie, le Libản, l'Atlàs, et gagnant celles de la Grèee, vient têrminer sa conrse dévastatrice aux monts de la Clinére ou Kimera, en face de l'Italie: Or ce sont précisément les' montagnes où les minéralogistes ont distingué des'traces de volcan.

Du temps mêne d'Homère, les connoissances géographiques des Grecs, relatives all sud-oúest de l'Europe, 
étoient très-obscures, et il n'est pas étonnant qu'à une époque bien plus ancienne, les traditions n'aient pas em brassé une plus grande étendue de pays.

Le calme de la nature, le repos qu'elle accorda à cés régions malheureuses, par l'extinction de ces feux dévorans et le rétablissement de l'ordre, furent attribués à une divinité bienfaisante et consolatrice, à la sage. Minerve, et telle est, peut-être, l'origine primitive de la consécration que lui firent de leur ville les Athéniens.

Qu'on me pardonne cette digression. J'ai cru entrevoir que le souvenir des dernières éruptions volcaniques; dont une partie occidentale de l'ancien continent a ét le théàtre, s'étoit perpétué; qu'on l'avoit revêtu, comme tous les premiers faits historiques, des déguisemens de la fable; et i'ai dû produire lés motifs de mes soupçons, n'y altachant d'autre intérêt que celui qu'inspire la recherche de la vérité. 


\section{DE L'ATLA NTIDE}

\section{DE PLATON.}

Lu. ¿i l'Académié cles Sciences, dans sa séance dut 5 juillet $181 \mathrm{~g}$.

L existe une prévention si forte et si générale contre les écrivains qui sortent du cercle de leurs études habituelles, que craignant d'être moi-mème en butte à cette défaveur, i’ai long-temps hésité à vous offrir ce mémoire de géograplie historique, malgré l'importance de son sujet et la multitude de faits propress à captiver votre attention, que j'y ai rapprochés. Je sais qu'il est surtont des honmes qui considèrent ces entreprises comme des invasions de leur domaine littéraire. S'ils ne vous traitent pas en enneuis, du moins vous reçoivent-ils de mauvaise gràce, et ne vous accordent-ils qu'une hospitalité contrainte et de pure convenance politique. Il ne semble cependant que je pourrois bien leur dire, pour ce qui me concerne: L'histoire naturelle n'a-t-elle point aussi ses antiquités? ne se lie-t-elle pas quelquefois aux moeurs et aux usages des anciens peuples? Si nous vous demandons à cet égard des renseignemens, nous en donnez-vous toujours de positifs et qui aient obteuu tous les suffrages? Vos opinions sont-clles discordantes? Pour laquelle opterons-nous, si nous ne les soumettons point à notre propre discussion? Je rous intcrroge, par 


\section{DE L'ATLANTIDE DE PLATON.}

exemple, sur la position de cctte nation des Sèrés d'où l'on tiroit anciennement la soie et d'autres productions naturelles? Vous' convicndrez que l'histoirc de cc commerce n'est pas étrangère à mes études, et qu'elle doit piquer ma curiosité; hé bien! vous me promenez dans une grande partie de l'Asic, et, après m'avoir fait errer comme certains peuples nomades qui l'habitent, vous ne m’indiquez, après tout, aucun lieu où je puisse me reposer avec assurance. Je n'examinerai pas, messieurs, qúcllc scroit l'issue de ce procès avec des savans aussi exclusifs. Il n'en est pas moins vrai que j'ai été entraîné dans ces écarts littéraires, dont vous pourricz $\mathrm{mc}$ fairc le reproche, par le désir que j’avois d'approfondir la question précédentc, et que cclle de l'Atlantide, bien éloignée originairement de ma pensée, est venue s'y rattacher par une sorte de filiation.

Deux de nos confrères, dont les noms font autoritó en géographie, MM. Barbié du Bocage et Walckenaer, ont vaincu, par lcurs sollicitations, la répugnance que j'avois à vous entretenir sur un sujct semblable. Lc premier, en adoptant, dans son excellent traité élémentaire de géographie ancienne, mon sentiment à l'égarldu fleuve Niger des Anciens, a reconnu que mes travaux n'avoient pas été inutiles à cette science. Le mémoire que j'ai l'honneur de vous présentcr lui a paru digne d'intérêt par les vues neuves qu'il renferme. Le second de ces savans, qui avoit fait ụne excursion sur mon territoire, et qui, par un ouvragc classique et fondamental sur les aranéïdes, a bicn su légitimer ses conquêtes, s'est empressé d'accueillir mes cssais géographiques avec cette amitie encolrageante que je lui avois témoignée lorsqu'il s'occupoìt d'histoire naturelle, Un neveu de M. le comte Chaptal, 
M. le baron Lajard, et qui a visité, en profond connoisseụr de l'antiquité, le pays que je prends pourl'Atlantide, m'a paru singulièrement frappé de la justesse de mes applications. C'est, messicurs, sous de tels auspices que je vous présente mes idées sur cette contrée fameuse, objet de tant d'investigations.

Mrnerve, Në̈th, en égyptien, étoit la divinité protectriee de la ville de Säis en Egypte, ainsi que d'Athènes. Aussi les Saîtes aimoient-ils beaucoup les Athéniens, dont ils se disoient même parens, et témoignèrent-ils à Solon, lors de son voyage en Egypte, les effets de cette bienveillanee partieulière. Discourant sur les événemens aneiens, avec les prêtres les plus inștruits de Saïs, le sage voyageur apprit d'un des plus âgés d'entre cux, qu'il y avoit eu jadis une île plus étendue que la Libye et l'Asie (l'Asie-Mineure), nommée Atlantide, île très-fertile, et gouvernée par des rois d'une grande puissance; que lesancêtres des Grees, après leur avoir gloricusement résisté, a voient conservé leur indépendanee; que eette Atlantide, ainsi que les libérateurs de la Grèce, avoient été engloutis dans la mer; et que cette mer où elle s'étoit perdue et à laquelle l'île avoit donné son nom, avoit cessé, depuis cette époque, d'être navigable. Solon avoit fait de cet événement le sujet d'un poëme, et Dropidas, son parent et son intime ami, auquel il avoit raeonté cette histoire, l'avoit transmise à son fils Critias. De la bouche de celuici, elle avoit suecessivement passé par celles de Timée, de Soerate et de Platon. Nous la tenons de ce dernier philosophe, qui l'a consignée dans seș dialogues intitulés, Timée et Critias. Il étoit bien naturel qu'un fait si méquorable exerçâs la sagacité des critiques. Aussi plusieurs 


\section{DE PLATON.}

hommes célèbres en ont-ils traité; et quelques uns, dans leurs recherches, ont fait preuve d'une vaste érudition. Qui pourroit oublier une de nos plus ingénieuses et des plus attrayantes productions, les lettres sur l'Atlantide, de Bailly? L'Isle - Sèche ou l'Isle-Continent des Orientaux, et qu'ils placent au-delà de la montagne Caf, le Callcase des Anciens, pourroit être, selon d'Herbelot, l'At lantide de Platon et notre Amérique. On a cru aussireconnoître cette Atlantide dans la Palestine, dans quelques îles de l'Afrique occidentale et de la Méditerranée ; on l'a même transportće jusque dans la Scandinavie. D'autres savans, peu satisfaits de ces opinions et ne voulant pas aller plus loin, ont vu dans ce narré du philosophe grec une simple fiction; parti très-commode e qui nous mettroit fort à notre aise, si tous les faits obscurs, mais dont l'intelligence n'est pas au-dessus des efforts de la sagacité humaine, étoient exclus du domaine de l'histoire. Celte Atlantide, jusqu'ici introuvable, n'est cependant pas un rêve de l'imagination; son existence est certaine et la description qu'on en a donnée a tous les caractères de l'exactitude. Elle a été réellement submergée, mais non pour toujours, et l'Asie nous la montre, depuis long-temps, comme une de ses plus belles et plus intéressantes contrées. Vous voyez, messieurs, que je prends une direction diamétralement opposée à cellequ'on a généralement suivie. On s'est obstiné à chercher l'Atlantide du côté de l'occident, et c'est vers les parties orientales de notre globe que je porte mes pas. Donnons une analyse aussi succincte que fidèle du passige de Platon, relatif à l'Atlantide.

Sur les bords de la mer Atlantique, mer navigable à cette épaque, et vis-à-vis l'embouchure nommée Colonnes 
d'Hercule, étoit située une île plus grande que la Libye et l'Asie (l'Asie - Mineure) ensemble, l'Atlantide. De cette île on pouvoit passer à d'autres, et se rendre ensuite dans tout le continent opposé, sur les cótes de la mer appelée Pontus, le Pont-Euxin ou la mer Noire. Au dedans de l'embouchure citée plus haut, il y avoit un port, dont l'enitrée étoit fort étroite. Là étoit la mer, désignée sous le nom propre de Pelagus, et la terre qui l'entouroit de tous côtés étoit appelée, avec raison, le continent.

L'Atlantide formoit un carré assez régulier, mais oblong : ce qui lui manquoit provenoit des détours d'un canal qu'on y avoit creusé, et dont les dimensions étoient telles qu'on ne pouvoit s'imaginer qu'il eût été fait de main d'homme. La longueur de l'île étoit de 3,000 stades, et sa largeur, a prendre du milieu, depuis la mer jusqu'en haut, étoit d'un tiers plus conrte, ou de 2,000 stades : son territoire s'étendoit vers le sud. Dés montagnes, surpassant toutes celles d'aujourd'hui, en nombre, en grandeur et en beauté, le terminoient du côté du nord. Le pays étoit couvert d'habitations nombreuses et très-riches. Il abondoit en rivières, en lacs et en prairies, qui fournissoient une ample nourriture, soit aux hommes, soit aux animaux domestiques et sauvages, dont la quantité étoit considérable; il y avoit même beaucoup d'éléplans. Les forêts produisoient des bois propres à toutes sortes d'ourrages; des noix de toute espèce; les meilleurs fruits, celui, entre autres, que les Egyptiens font sécher pour leur servir d'aliment; les légumes encore dont ils se nourrissent; les fleurs les plus belles et les plus odoriférantes; les meilleurs végétaux; toutes ces productions, dis-je, se trouroient daus cette île sainte, belle, merveillense et extrêmement f́cr 
tile. Des mines de diverses sortes augmentoient sa riehesse. L'orichalque, le plus précieux des métaux après l'or, et qu'ou ne eonnoît plus aujourd'hui que de nom, y étoit très-eommun. Des travaux exéeutés par les rois de cette ile, durant un long espaee de temps, avoient accru les sources de sa prospérité.

La puissanee de ces rois s'étendoit sur beaucoup d'autres îles et parties du continent, sur tous les pays du côté de la Libye jusqu'en Egypte, et du eôté de l'Europe jusqu'à Tyrrhenia.

Les dieux, dans le principe, s'étant partagé la terre, l'Atlantide échut à Neptune. Il prit pour épouse Cliło, fille unique d'Evenor et de Leucippe; Evenor étoit l'un de ces hommes qui dès le eommencement avoient été formés de la terre ; l'un et l'autre ne vivoient plus à l'époque de cette union. Vers le milieu de l'île, du eôté de la mer, étoit une plaine qui passoit pour le canton le plus beau et le plus fertile. Proche du milieu de cette plaine; à la distance d'environ einquante stades, s'élevoit une petite montagne, dont Clito avoit hérité de ses pères, et qu'elle habitoit, ainsi qu'ils l'avoient fait avant elle. Afin de rondre ce sćjour inaceessible aux autres mortels, qui d'ailleurs ignoroient eneore l'art de la navigation, Neptune environna cctte montagne de trois fossés remplis d'cau, séparés par deux élévations de terre, l'une plus grande et l'autre plus petite; et donua au tout une disposition eireulairc. Les circonvallations nne fois établies, le dieu fit jaillir de dessous terre deux sourees d'eau, l'une chaude, l'autre froide. Il fit aussi produire à la terre une grande quantité de fruits de diverses eśpèees. C'est là qu'il éleva einq eouples d'enfans mâles, jumeaux, qui étoient nés de lui. Il divisa l'Atlantide 
en dix partics. L'aîné des enfans eut la demeure mater. nelle, avec le canton d'alentour, le plus grand et le meilleur de tous. Neptune le désigna roi de ses frères; eeuxci reçurent la dignité d'archontcs, et ehacun d'eux eut l'empire sur un grand distriet ainsi que sur un grand nombre d'habitans. L'aîné fut appelé Atlas, nom qui ḍevint celui de l'île et de la mer adjacente. Son frère jumeau, Eumelos en gree, Gadirus en langue du pays, eut en partage une des extrémités de l'île, celle qui est située vcrs les colonnes d'Hercule et dans la contrée appelée, de nos jours, Gadirica, du nom de son possesseur. Platon nc dit rien des pays qui formèrent les lots des autres cnfans; il s'est borné à nous donner leurs noms. L'aîné du troisième couple s'appeloit Mrneseus, et avoit pour frère Autochthon, dénomination pareille à celle que porte, dans la tlıéogonie phénicicnne de Sanclioniaton, un des enfans d'Eliun et de Béruth, et le même eneore qu'Epigée et Uranus, Les fils de Neptune et leurs dcseendans régnèrent pendant un grand nombre de générations dans l'Atlantide, et la famille d'Atlas fut surtout très-illustre.

Il seroit superflu, pour le but que je désire d'atteindre, dc reproduire ici les descriptions fabuleuses, ou du moins exagérées, quefait Platon, soit de ec templc magnifiquc, élevé à la gloire de Neptune ct de Clito; soit des palais des rois ct de leurs dépendances, des aquéducs, des ponts et des gymnascs de l'Atlantide; je ne parlerai pas non plus de la forme de son gouverncment et des usages eivils ou religieux de scs habitáns. J'observerai seulcment que le taureau étoit la principale victime de lcurs sacrifiees.

Les $\Lambda$ tlantes envahirent toute l'Europe et l'Asie; mais la république des Grecs résista à leurs forces ct garantii 
d'autres peuples de la servitude dont ils étoient menaeés. Durant plusieurs siècles, les Atlantes obéirent aux lois, en suivant l'impulsion de cette nature divine iunée en cux; les passions prirent enfin l'empire sur elle, et ee peuple ne connut plus de véritable félieité que dans l'aceumulation des richesses injustement acquises. Jupiter, le dieu des dieux, gardien et vengeur des lois par lesquelles il règne sur les hommes, est frappé de la corruption de ces mortels, autrefois si recommandables par leurs vertus. Il convoque les autres dieux pour prendre eonscil. La fin du passage de Platon manque et nous ne connoissons point direetement quclle fut la décision du maître des cieux et de la terre. Mais on peut devinęr, d'après les aniéeédens que la perte de ees prévaricateurs fut résolue. Ainsi que je l'ai dit plus haut, les abîmes de la mer engloutirent, dans le malheureux espace d'un jour et d'une nuit, l'Atlantide; le limon provenant de cettc submersion, ne permet plus de naviguer dans eette mer, et la soustrait à toutes les reeherehes. La mémoire des actions eélèbres des Grecs, victorieux des Atlantes, a péri par la destruction de ceux auxqucls elles avoient été transmises. On peut, en effet, eonclure, du passage de Platon, que ees événemens n'étoient fondés que sur une simple tradition orale. Ils se plaeent dans cet intervalle de dix sièeles, pendant lesquels Minerve avoit nourri et instruit les premiers Grecs, ainsi que les premiers Egyptiens. A partir de la fin de eette période, les derniers eonservoient une tradition écrite, embrassant, jusqu'au temps de Solon, une durée de huit mille ans. Voilà, messieurs, l'extrait de l'éerit de Platon, concernant l'Atlantide. Je vais maintenant essayer de prouver que cette île célèbre est la Perse. Exposons, au 
préalable, quelques observations générales qui sont, en partie, le résultat de mes recherches sur le premicr àģe dc l'histoire. Loin que ces faits soient étranger's à la question dont je m'occupe, ainsi qu'on pourroit d'abord le penser, ils ont avec elle une connexion évidente et trèspropre à l'éclaircir.

$\mathbf{r}^{\circ}$. L'histoire et la géologie attestent quc la majeure partie du golobe terrestre, considéré dans son état présent, abstraction faite de toute révolution, a été couverte par les eaux de la mer, et que les contrées les plus élcrées, comme celles de l'Asie supérieure, ont pu seules être habitées.

$2^{\circ}$. Privés des secours qui sont le fruit du temps et de l'industrie, les preniers hommes ont dû naturellement s'établir dans les licux les plus fertiles, comme plus appropriés à leurs besoins et à l'imperfection de leurs connoissanecs dans les arts. Ils ont pu comparativement désigner ces lieux sous les dénominations de jardin, de paradis terrestre, expressions que nous cmployons encore nous-mêmes aujoutrd'hui; et paradis, dans les langues orientales, ne signifie qu'un lieu excellent.

30. M'aidant des lumières de la géographie ancienne; de l'histoire uaturelle, des traditions orientales, et particulièrement de la Genèse et de la cosmogonie des Parses, publiée par Anquetil du Perron, dans le ZendAvesta, j'ai découvert que le Mazcnderân et le Khoraçan, ou l'Hyrcanie et la Bactriane des anciens, ont été le premier séjour connu de l'espèce humaine, ou du moins le berceau de sa civilisation. On considérait primitivement la mer Caspienne comme un fleuve qui communiquoit avec la mer Glaciale : c'est celui qui, selon la Genèse, arrosoit le jardin d'Eden. Les quutre. 
autres fleuves, dont le préeédent était censé former le point central de réunion, sont daus le même ordre que eelui de la Genèse, c'est-à-dire en allant de l'orient à l'oceident, le Syhhoûn des modernes ou l'Oxus des aneieus, le Tedzen, le Kisil-Ouzein ou le Mardus, et l'Euphrate. Ce seroit être un peu trop diffieile que de ne pas vouloir reeonnoître avec moi, dans cette montagne de l'Atlantide, qui avoit été le séjour des premiers hommes formés de la terre, que Neptıne renulit inaecessible et embellit de tous les dons de la nature, une tradition altérée de eelle du paradis terrestre.

$4^{\circ}$. Toutes les théogonies, n'importe quelques différenees, partent d'une source eomnune. Ainsi les dix patriarches antédiluviens, les dix rois ehaldéeus, pareillement antérieurs au déluge, les neuf demi-dieux égyptiens, la première dynastie des souverains de la Perse, les premiers rajahs de l'Inde, jusqu'à Parischat inelusivement et le même que Noé; les premiers monarques de la Chine, jusqu'à Chao-Hao, surnommé le Père des Eaux et qui est eneore Noé; enfin les dieux pliéniciens, eeux des Seythes et des Atlantes, sout en général des personnages identiques. Je ne cite point les Grecs ni les Romains, parce que leur mythologie, quoique très-dénaturée, a la unême origine. Là, eomme iei, figurent - presque toujours, du moins par les attributs qu'on leur suppose, un Mars, un Hereule, un Apollon, un Mercure, ete.

$5^{\circ}$. J'ai retrouvé dans quelques unes de ees traditions les élémens de l'astronomie antédiluvienne et ceux des premiers zodiaques d'Egypte : mes observations sont eonsignées dans un autre mémoire. Je crois cependant deyoir en mentionner ici denx des plus importantes, et 
qui démontrent une vérité un peu méconnue, que l'his: toire naturelle est au moins très-utile, si elle n'est paś quelquefois nécessaire, aux autres connoissances. Ce demi-dieu, moitié homme et moitié poisson, dont parle Bérose, sous le nom d'Oannès, et le phénix, avoient été jusqu'ici des emblèmes presque inintelligibles, ou sur le sens desquels on 'n'avait pu former que de simples soupçons.

La constellation du capricorne des zodiaques égyptiens nous offre la figure d'un phoque à oreilles; et voilà quel est le sujet allégorique de l'Oannès. La mer Rouge, sur les bords de laquelle on voyoit paroître ce demi-dieu, doit être la mer Caspienne ou l'Océan persique. L'épithète de rouge, par laquelle on désigne cette mer, ne doit pas nous surprendre, le séjour des premiers hommes, et Adan même, ayant reçu des noms qui avoient pour objet de rappeler. le culte symbolique du soleil. De là viennent les dénominations de terre d'or, de terre de feu, de Phénicie, etc. L'oiseau nommé phénix fut d'abord l'emblème de la célèbre période astronomique de dix-neuf ans, et dont la découverte donna lieu soit à des ères célèbres, telles que celles du Kaliougam, de Djemschid, soit à des réformes dans le calendrier, comme celle que les Chinois attribuent à Chao-Hao, soit encore à l'établissement de quelques autres périodes astronomiques, celle, par exemple, que l'on appelle sothiaque. Cet oiseau fut primitivement un aigle, le Simorgh des Parses, ensuite un vautour. Les Chinois prirent pour sujet de la même allégorie un manucode, ainsi qu'on peut s'en assurer par les dessins que nous en ont donnés les auteurs des mémoires sur la Chine. Le faisan doré paraît 
avoir remplacé, dans quelques circonstanees, ce manucode.

$6^{\circ}$. La géographie primitive, ou le monde connu vers l'époque du déluge, se composait de la Perse, de quelques contrées au nord, de celles qui sont situées sur les bords de l'Indus, des pays compris entre la mer Caspienne et la mer Noire, de l'Asie mineure, d'une partie de l'Arabie, de l'Egypte, de la Lybie et de l'Afrique propre。 C'est ce qui me paroît pouvoir se déduire du passage de Diodore de Sicile, relatif aux Amazones d'Afrique, et de quelques traditions orientales, où l'on avait puisé celles que rapporte cet historien.

$7^{\circ}$. D'autres traditions, très-obscures il est vrai, mais qu'appuient la géologie et l'observation surtout d'un voyageur digne de foi, Silva Figueroa, qui a trouvé des montagnes du Laristan couvertes de coquilles marines vivantes, nous laissent entrevoir que l'étendue de la mer Caspienne était très-anciennement beaucoup plus grande; que l'Océan s'avançait de plusieurs degrés dans l'intérieur des terres basses ou des plaines, et qu'une portion du midi de la Perse était regardée comme une acquisition faite sur la mer. En effet, dans l'histoire d'Huschenk, un des rois persans antédiluviens, ou l'un de ceux de leur première dynastie, l'extrémité sud du Mekrân est nommée terre sèche ou nouveau conti-s nent.

8०. Il est encore certain, je ne dis pas seulement d'après la Genèse, mais encore d'après les traditions chaldéennes rélatives à Xixuthrus le même que Noé, la cosmogonie des Parses, les zodiaques égyptiens, une des coutumes religieuses de ce peuple, le sacrifice du pore, que le déluge de -Noé ne peut ètre révoqué en 
doute; il est encore certain qu'il date d'une époque ano iérieure ì ceux de la Grèce, époque déterminable même par le secours de l'astronomie, et que le souvenir de ce cataclysme s'est perpétué. On en trouve plus particuliècment les traces chez les Guèbres. Mais il en est parmi eux qui nient son universalité; ils prétendent que ce déluge n'a couvert qu'une portion de la Perse, et qu'il s'est arrêté à un rocher près d'Hulwan, sur les confins du Khousistân et de l'Irâk. Par la disposition de leurs bassins, les provinces de Kouhestân et de Sedjestân me semblent être celles qui ont ressenti les premières les effets de ce cataclysme; car elles sont environnées de liautes montagnes, d'où descendent en rayonnant plusieurs rivières; ne seroit-il pas d'ailleurs possible que le lac Zerêh, où se rendent quelques unes d'elles, n'existàt pas encore. C'est à Nesaê ou Nysa, ville du Kouhestân, désignée aujourd'lui sous le nom de Nichâbour, lieu célèbre dans l'histoire de Bacclıus, où, suivant la cosmogonic des Parses, Ahriman, ou le mauvais génie, mit en doute le pouvoir du maître de la nature. Des traditions nous apprennent en ontre que le déluge de Noé arriva au mois de décembre ou dans une saison farorable aux inondations. La constellation du lion se levoit alors le soir, après le coucher du soleil, et les Egyptiens, pour assurer la mémoire de cet événement, représentèrent sur leurs zodiaques cet animal placé sur un serpent contourné en manière de barque. Je n'eus jamais osé, d'après cet unique motif, prêter un tel sens à cette figure allégorique, si le zodiaque circulaire de Dendérah, plus développé à cet égard que les autres, ne m'eût fait naître cette pensée. L'oiscau, auquel Noé, dans l'histoire du déluge, donne la liberté, osı figuré sur ce zodiaque aụ-dessus 
du bout de la queue du serpent. Dans les premiers zodia ques des peuples du nord de l'Asie, le porc remplace la constellation du lion. Voilà, avec le souvenir du déluge, l'explication bien simple et bien naturelle de l'usage où étoient les Egyptiens de sacrifier le premier de ces deux animaux à la lune lorsqu'elle était pleine, et de ne manger les portions de la chair qu'on n'avoit point brûlées que le jour de la conjonction de cet astre avec le soleil. $9^{\circ}$. Cette grande chaîne de montagnes, appelée par les historiens grecs et romains Caucase, Imaus, Taurus, qui traverse toute l'Asie, et sur les flancs desquelles sont adossés les pays qu'habitaient les premiers hommes, fut primitivement leur Atlas, mais avec d'autres dénominations, telles que Dyris, Irus, Pal, Caf, etc. Celle d'Atlas se forma postérieurement, soit par altération, soit par le changement que produisit la diversité des idiomes, et fut ensuite appliquée par les Grecs et les Romains à la chaîne de montagnes qui coupe, dans sa largeur, le nord de la partie occidentale de l'Afrique.

x $0^{\circ}$. Des peuples caucasiques ayant émigré et s'étant établis dans les contrées adjacentes à l'Atlas africain, recurent des Grecs et des Romains encore, le nom d'Atlantes. Considérés comme autocthones, toutes les traditions historiques qu'ils avoient portées de leur mère patrie ont été appliquées à leurs colonies, et avec d'autant plus d'apparence de raison, que ces peuples ont souvent désigné des fleuves, des montagnes et des habitations de leur nouvelle demeure sous des noms déjà consacrés dans leur premier séjour à des objets semblables. Voilà, messieurs, ce qui a induit en erreur la plupart des savans qui ont voulu découvrir l'Atlantide. Toutes leurs idées 
se sont portées sur l'Océan appelé ainsi, et sur les rivage? africains qu'il baigne.

Ces préliminaires une fois posés, je dis que la Perse satisfait pleinement et d'une manière exclusive à toutes les conditions du problème de l'Atlantide.

La mer Caspienne et l'Oxus au nord, I'Indus à l'es! et l'Euphrate à l'ouest, le golfe Persique et l'Océan at sud, circonscrivent la Perse, et cette contrée pourait être d'autañt plus assimilëe à une île, que la mer Cas. pienne et ces fleuves, particulièrement l'Indus, occupoient alors une étendue plus grande. La Perse a offectivement la figure d'un carré oblong; elle est parseméc de lacs et coupée par plusieurs rivières. Les embranehe 'mens au moyen desquels le Tigre s'unit'avec l'Euphrate à peu de distance de leur embouchure, représenteroient sans l'intervention de l'art, les 'canaux mentionnés dan: Je 'passage de Platon. Mais si l'on veut me faire grâc -de quelques siècles pour l'époque de leur construction, e qu'il suffise de montrer qu'ils sont de l'antiquité la plus haute, la Perse nous offrira ce nouveau trait de conformité avec l'Atlantide: Minotcher ou Manougeher, septième ou huitième roi de Perse, fit creuser de grands canąu par lesquéls il conduisit des branches entières de l'Eu. phrate èt du Tigre dans l'Irâk arałique ou 'la Chaldér (DHerbelot, Bibl. orient.). Or , ce röi , d'après nas rap. prochemens, est te même que le Mesraïm, fils de Cham: de la'Genèse, et se confond encore avec Ménès, fondateur de la monarchie égyptienne. 'S'il en eśt ainsi, sor einpire túra l'étendue que Platon assigne à celui de! souverains de l'Atlantide; et dans le 'fait, tant qu'on n'admettra point que certains rois d'Egypte ont eu une domination aussi vaste, il sera très-difficile, pour ne pas 
dire impossible, d'expliquer comment ils ont pu élever les monumens si imposans de cette terre antique, et dont plusieurs datent de l'origine de cette monarchie. L'Atlantide avoit au nord les plus belles montagnes du monde, et certes on ne me disputera point la justesse de l'application que je fais à cet égard.

La richesse territoriale de la Perse est connue, et l'on n'ignore pas que plusieurs de nos arbres à fruit, le noyer spécialement, ainsi que plusieurs de nos plantes potagères, sont indigènes de cette contrée. Je présume qu'il en est ainsi de quelqueș unes de nos plantes céréales, telle que le froment. Originaire, à ce que je crois, de la Sogdiane, il fut d'abord transporté en Egypte, passa de là en Mauritanie, et fut communiqué à l'Europe par la voie de la Sicile. Je n'ai point fait de recherches particulières surle métal nonmé orichalcum, qui étoit très-commun dans l'Atlantide, et inconnu en Egypte, au temps de Solon. Mais je soupçonne que c'est le fer natif, ou du moins la mine de fer spathique, autrement la chaux carbonatée ferrifére de M. Haüy. Je dois cette dernière observation à M. le baron Lajard, qui a fait une étude particulière de la minéralogie de la Perse. Ún passage de 'histoire de la Chine, un autre tiré de la cosmogonie des Perses, l'étymologie du nom que l'on donne au fer en hébreu, et la manière dont les Thibetains désignent 'oricalque, sont les fondemens de ma conjecture. Il n'est point d'ailleurs probable qu'on eût encore trouvé le se* cret d'extraire le fer de sa gangue. Si l'on considère ce nétal sous le rapport de son utilité, l'on ne sera pas urpris qu'on ait pu, dans le commerce primitif, lui sssigner, après l'or, le premier rang.

L'évaluation en surface que l'on donnoit à l'Attantide 
est parfaitement conforme à cclle de la Perse, en renfer mant celle-ci, d'après les méthodes géographiques et ses limites naturelles, entre la mer Caspienne, la rivière de Tedzen, l'Océan, l'Euphrate et les montagnes qui descendent du Candahar. Cet heureux accord est même un des puissans soutiens de mon opinion. La Perse, mesurée de l'ouest à l'est, ou vice versâ, a dix-huit degiés d'un grand cercle, et son diamètre, dans un sens opposé, est d'un tiers plus court que le précédent, ou de douze degrés. Si nous convertissons ces degrés en farsengs, mesures itinéraires du pays, estimées 3425 toises, ou une lieue et demie de nós anciennes lieues communes de France, et si nous divisons ces farsengs en dix parties, les dix-huit degrés nous donnerons juste 3000 de ces fractions décimales. Cette somme diminuée d'un tiers représentera la mesure de la longueur que nous avons portée à douze degrés. Voilà réellement et numériquement les 3000 et les 2000 stades de Platon. Il nous prévient qu'il a traduit de l'Egyptien en sa langue matesnelle les noms propres de l'histoire de l'Atlantide. Ces dixièmes de farsengs valent 342 toises, ou trois siades de 500 au degré ( I 4 toises), et la coudée dont ils dérivent égale deux pieds drusiens, mesure en usage chez les Germains, et principe élémentaire des milles lombards. Ces observations sont dignes de renıarques, et prouvent qu'à l'égard de ce partage des farsengs, je n'ai point procédé arbitrairement. Il est d'ailleurs cer. tain que la division décimale étoit la plus usuelle.

Neptune épouse Clito, fille orpheline d'Evenor et de Leucippe; c'est sous un autre voile allégorique la Vénus sortant de l'écume de la mer; et sous d'autres déguisemens encore, le premier des demi-dicux égyptiens, 
Horus. Il est représenté sur le zodiaque du grand temple de Dendérah, nu, assis sur une fleur de lotus, au milieu d'une barque, et portant sur la tête l'image du soleil ou celle de la terre. Son épouse, ou la première femme, $\mathrm{y}$ est figurée d'une manière semblable; mais avec cette différence qu'elle n'a point sur la tête ce dernier emblème, et que, comme Harpocrate, ou le dieu du silence, elle porte le doigt sur la bouche. Non loin d'elle se voit le génie du mal, sous le symbole d'un serpent, la vipère Haje, placé aussi au milieu d'une barque, élevé droit sur sa queue, et qui sort pareille-ment du milieu d'une fleur de lotus. Ces figures symboliques nous ramènent naturellement à la Genèse. Dans la cosmogonie des Parses, des germes de kaïomorts et du taureau, germes confiés à la terre, naît tout ce qui a vie. Le premier produit les hommes; le second les animaux et les végétaux : telle est l'origine du culte d'A pis. Meschia et Meschiané, venus les premiers du germe de kaïomorts, mettent au monde deux enfans, l'un mâle, l'autre femelle. Ormuzd, ou Dieu, leur enlève ces enfans, et prend soin dé leur éducation. Meschia et Meschiané donnent encore le jour à sept couples semblables. De l'un d'eux naît un autre couple, qui est l'origine de quinze auțres; chacun d'eux devient la souche d'un peuple : de sorte que le nombre des espèces de peuples issus de ces générations est de 25. Dans un autre endroit de cette cosmogonie, il n'est cependant parlé que de dix hommes, et nous avons vu Neptune et Clito produire cinq couples d'enfans mâles, jumeaux. De même aussi, dans la Genèse, la postérité antédiluvienne d'Adam se partage-t-elle en deux branches masculines. Il est donc évident que ces traditions relatives à l'ori- 
gine des Atlantes sc rattachent essentiellement à la théogonie persienne, et qu'il ne faut pas cherchér l'hąbitation de ce peuple sur les côtes d'Afrique, mais en Asie, la dépositaire naturelle de toutes ces traditions. L'Atlantide étoit une île sainte : les dieux y prirent donc naissance.

Le frère cadet d'Atlas, Eumelus, autrement Gadirus, régna sur une des extrémités de l'Atlantide, située vers les colonnes d'Hercule, ou dans la contrée appelée Gadirica. On a cru, d'après quelques resscmblances de noms, qu'il s'agissoit ici de Gades ou Cadix, et du détroit de Gibraltar. Nous sommes, d'après ce que je viens d'exposer sur le séjour des premiers hommes ou des Atlantes, à une grandc distance de cette extrémité méridionale de l'Espagne. Mais ne seroit-il pas possible que l'on se fût mépris, et que l'Asie revendiquât, à plus juste titre, cette contrée de Gadirica? C'est ce qui mc paroît certain, d'après la géographie de Ptolémée et quelques autres considérations.

Il résulte de ma concordance générale des théogonies que Mars, Hercule ct Apollon sont ricprésentés dans la Genèse par Caïn, et deux de ses descendans, TubalCain ou Thobel, et Jubal, opinion qui peut paraître étrange, mais qui est néanmoins la conséquence de nombreux rapprochemens. D'un passage de la Genése, relatif à l'habitation de Caïn et de sa famille, passage appuyé de quelques autrcs traditions, $j$ 'ai cru devoir fixer ce séjour dans la partie méridionale de la Perse, spẻcialement dảns la Gédrosie des anciens, où l'on trouve d'aillenrs plusieurs noms qui nous rappellent l'Hercule ou le Chun des Egyptiens, et leur Mars ou Arès, l'Alaparès des Chaldéens. Plusieurs des étymologies qu'on a 


\section{DE PLATON.}

21 s

tonnées du mot Gadir peuvent s'appliquer à l'un ou à l'autre de ces demi-dieux. Ce n'est donc point en Espagne ni dans les contrées opposées de l'Afrique qu'Hercule établit sa domination.

Pour aller de la Syrie dans la Mésopotanfe, et réciproquement, on passoit l'Euphrate près de la ville de Thapsaque, dans un lieu que Ptolémée ne désigue pas autrement que par ces mots : Vada Euphratis juxta Thapsacum, gué de l'Euphrate près de Thapsaque. Il devoit être dans le voisinage du lieu nommé Racca sur nos cartes modernes. Un peu en dessous étoit la ville de Gadirtha, dont l'emplacement ne diffère pas de celui de Gedica des mêmes cartes, et près de laquellẹ sont les ruines d'une ville appelée Cainn, dénomination, qui confirme ce que je viens de dire. Non bien loin de Gadirtha, au confluent du Tigre et de l'Euphrate, et à peu de distance de leur embouchure commune, étoient placés les autels d'Hercule, Herculis arae. Voilà les colonnes de ce demi-dieu, et l'on peut conclure de ce que je viens d'exposer que l'extrémité occidentale et méridionale de la Perse fut son véritable séjour. Les Phéniciens s'étant ensuite établis dans la partie sud de l'Espagne, en firent une seconde Atlantide, ou plutôt cette Hespérie de Diodore dọnt je parlerai ci-après.

Puisque nous sommes au premier âge du monde, nous aurons, je pense, de la peine à croire que l'Italie fût alors connue, et que la Tyrrhénie de Platon soit l'Etrurie ou la Toscane. La Syrie, bornant au sud-ouest l'Atlantide, nous retrouverons d'une manière aussi simple que juste cette Tyrrhénie, dans la Phénicic, ou la côte orientale de la Méditerranée, que possẹ́doient les $\mathrm{T}_{y}-$ riens. Telle a été aussi l'opinion de Baer, dans son Essai 
historique et critique sur l'Atlantique. Il est probable que la Toscane ne reçut le nom de Tyrrhénie que parce que les habitans de Tyr ou leurs descendans y fondèrent des colonies.

Ptolémée place près d'un autre passage de l'Euphrate, plus septentrional que celui dc Thapsaque, un lieu qu'il nomme Europs, et qui répond à peu près à celui de Byr de nos cartes. Cette dénomination, peu différente de celle d'Europe, a pu contribuer à la confusion qu'on avoit faite de la Tyrrhénie asiatique avec la Tyrrhénic européenne. Après tout, je pense que les géographes auroient bien de la peine d'assigner rigoureusement la position et les limites de cette partie du monde à laquelle on donna, dans les premiers temps historiques, le nom d'Europe. Peut-être que les Phéniciens ne désignèrent-ils ainsi d'abord que l'île de Crète et quelques contrées voisines. L'application du nom d'Europe, ainsi que celles des mots $A$ frica et $A$ sia, dûrent nécessairement être très-restreintes. Il est probable, par exemple, que la dénomination d'Asia, signifiant vigne et vin, dans la langue pehlvienne, ne fut donnéc, dans le principe, qu'au Khoraçan, où commença la culture de la vigne.

L'Euphrate formant la limite occidentale de l'Atlantide, on pouvoit, en traversant ce fleuve, aller de ce pays en Syrie, en Egypte, cn Arabic, passer les déflés du mont Amanus, gagner l'Asie - Mineure, le PontEuxin et la mer Égée. Celle que Platon nomme Pelagos, et que l'Atlantide cnvironnoit de tous côtés, est le golfe Persique. Elle aura d'abord porté le nom du fleuve principal qui s'y décharge, le Tigre réuni avec l'Euphrate. Un tigre, un léopard, ou quelque autre animal voisin, est appelé Paloğ en pellvi, et Palang 
dans le persan pur et primitif. De là, par une légère altération, sera dérivé le nom de Pelagos ou Pelagus. Quant au port situé sur cette mer, et dont l'entrée étoit fort étroite, c'est celui que Ptolémée appelle Teredon, et dont l'étymologie présente une signification analogue. Un peu au-dessous de Bassora, est aujourd'hui un lieu appelé Medhân, qui pourroit bien venir du mot Meghém, qui en Zend veut dire trou. Le nom de karoun, une des rivières adjacentes, dérive aussi des langues orientales, et signifie creuser.

La mer atlantique comprendra dès lors cette partic de l'Océan qui s'étend depuis le golfe persique jusqu'à l'Inde. Nous voyons, par un passage d'Arrien (périple de la mer Erytrhée), que lcs montagnes de la Gédrosie étoient appelées Irus, par des habitans du pays. Or, d'autres géographes nous apprennent que des peuples de l'Afrique désignoient sous une dénomination presque identique, celle de Dyris, l'Atlas des modernes. On conçoit maintenant que ce dernier nom aura pareillement été appliqué par les Grecs aux montagnes de la Gédrosie et à cette partie de la mer près des bords de laquelle elles se terminent. Myrinc, reine des amazones d'Afrique, mais originaires de Perse, après avoir ravagé la Libye, exterminé un grand nombre d'Arabes, rangé à son obéissance la Syrie, la Cilicie, la Phrygie et diverses -îles de la mer Egée, fut enfin vaincue par le scythe Sipyle, auquel s'étoit joint le thrace Mopsus. Cette reine périt dans le combat, avec la plupart de ces amazones. L'histoire d'Huschend et celle de Thahamurath, rois perses, de la dynastie des Peischdàdiens, ont fourni le principal sujet de cet épisode; et de la mème source découle l'histoire des conquêtes des Atlantes et de leur' défaite par les Grecs, dont a parlé Platon. 
L'île d'Hespérie de Diodore de Sicile, située au couchant du lac Tritonide, ne me semble point devoir être distinguée de l'Atlantide, ou du moins de son extrémité occidentale. Ce lac, ainsi nommé du fleuve Triton ( l'Arabius de Ptolémée), qui s'y dégorge, lac sur lequel fut bàtie la ville de Cherrouèse ou presqu'ìle, appartient, ainsi que l'île Mené (r.), réputée sacrée, et habitée par des Ethiopiens ichtyophages, à cette portion maritime du Mékrân, que des écrivains.orientaux appellent, ainsi que je l'ai déjà dit, Terre-Séche ou Nouveau-Continent. Là, et près de la mer d'Oman, étoit située, selon eux, l'île de Ramak, habitée par les Mahisers ou Sermahi, hommes à tête de poisson. Or, Ptolémée place précisément dans cette partie de la Gédrosie ou du Mékràn, un peuple nommé Rhamma, mot paroissant dériver de celui de Ramah, signifiant troupeau, en pehlvi. Les mots Gad, Gadir, Gadirica, ont-ils peut-être une origine semblable, ou indiquent-ilș la vie pastorale (2). Sur cette côte maritime étoit aussi un lieu appelé, par le même géographe et par Arrien, le port des Femmes, ce qui nous a mis sur,la voie de la recherche des Amazones. Là aussi demeuroient, au rapport du second, les Saranges, que nous retrouverons sur la côte occidentale d'Afrique. L'histoire de Perse nous présente leurs premiers, rois sans cesse occupés à faire la guerre à ces malheurcux Ethiopiens, ou Mahisers. On peut déduire de la comparaison de la cosmogonie des Parses avec la Genèse, que cette proscription avoit pour cause la

(I) Mona , roi , dieu, en pehlvi; Mino, céleste, en persan; de là probablement le nom de Ménès ou Minès, premier roi d'Égypte, ct le nême que Manougeher ou Minotcher.

(3) Kayid, bouc, en pehlvi. 
haine que les descendans de Seth portoient aux Caïnites, dont ce dernier peuple descendoit. Le Féridoun des Perses, le même que le Noé de la Genèsc et que le Parrischat des Indiens, le même encore que le Dinprepès de Platon, ou le dernier enfant jumeau de Neptune, acheva, dit-on, la conquête des pays que ces Ethiopiens possédoient. Contraints de s'expatrier, ils se réfugièrent dans la Palestine, où ils se mêlèrent, dans la suite, avec les Cananéens, pareillement originaires de la Perse. C'est, du moins en partie, la race des Géans dont il est fait mention dans le livre de Josué. Parmi ceux qui échappèrent au massacre qu'en firent les Israélites, plusieurs furent s'établir près du golfe de Sidras, la petite Syrte, dans le royaume de Tripoli. Les noms de Triton Fluvius, de Cercinna Insula et Civitas, et quelques autres, indiqués dans ce canton par Ptolémée, semblent, par leur analogie avec les désignations locales de l'île d'Hespérie de Diodore, nous l'annoncer. Une branche de cette peuplade s'avança plus loin, se fixa à l'extrémité méridionale du royaume de Maroc, et gagna ensuite les îles Fortunées. Ce sont les Syranges de Ptolémée, les Gorilles du périple d'aHnnon, et les Gouanches des modernes. Ils appliquèrent probablement à divers objets de leur colonie, les noms de leur terre natale. De là cette confusion nominale și embarrassante pour le critique, et qu'il est impossible de démêler, si l'on ne suit cette filière d'énigration. Ces peuples ne quittèrent cependant pas tous leurs foyers. Néarque, amiral d'Alexandre, trouva sur la côte occidentale de lạ Gédrosie, dcs hommes sauvages, et qu'il nous dépeint tèls que sont représentés les Gorilles dans le périple d'Hannon. Comme la position qu'Arrien; d'après Nénrque, leur assigne, est plus à l'ouest que celle des 
Saranges, il seroit cependant possible que les premiers différassent des seconds par quelques traits physiques et des mours plus barbares.

Au témoignage de Diodore, on disoit que le lac Trito- nide avoit entièrement disparu par la rupture de toút le terrain qui le séparoit de l'Océan. Faisoit-on allusion aux changemens qui se sont opérés dans cette partie du Mékrân, appelé Nouveau-Continent, ou bien cela doit-il s'entendre de l'inondation de la Perse, produite par le déluge de Noé? C'est ce qu'il est diffcile de décider. Quoi qu'il en soit, les causes qui, suivant le récit de Platon, engagèrent Jupiter à détruire les Atlantes, sont évidemment les mèmes que celles indiquées par la Genèse, relativement à ce déluge.

Quelques auteurs ont pris le stade employé dans la mesure de l'Atlantide, pour le stade ordinaire des Grecs, ou l'olympique ; cette île auroit donc eu r 25 lieues communes de France en longueur, sur 83 et un tiers de large , c'est-à-dire qu'elle auroit été presque aussi grande que la moitié de la France. Mais l'équivoque qui paroît résulter du mot de stade est détruit par la comparaison que fait Platon de l'étendue de l'Atlantide avec celles de la Libye et de l'Asie-Mineure; elle les surpassoit sous ce rapport, et dès İors ce stade devoit être beaucoup plus grand que l'olympique; on a vu en effet que notre estimation s'accordoit parfaitement avec l'évaluation de la surface de la Perse. Comment pourra-t-on maintenant concevoir qu'une contrée aussi vaste ait pu totalement disparoître? Quelle catastrophe épouvantable et inouie ne faut-il pas admettre, pour que les abîmes de l'Océan aient pu recevoir cette contrée, sans qu'il n'en reste de vestige? Comment l'Egypte, qui n'en étoit pas fort éloi- 
gnée, et dont le terrain est bas, auroit-elle échappé à une telle destruction? Il n'est pas surprenant qu'on ait cru qu'une submersion de cette nature avoit exhaussé le fond de la mer: Atlantique, et opposé aux navigateurs un obstacle insurmontable. Il n'a pas effrayé ni arrêté nos marins. Les débris de cette terre antique et malheureuse n'ont été rencontrés nulle part, à moins qu'on ne veuille considérer comme tels des rochers et des îlots sous-marins; on auroit ainsi une grande latitude pour forger des hypothèses, et avec de semblables données, l'on seroit le maître de placer l'Atlantide où l'on voudroit. Je ne m'amuserai point à discuter les diver'ses opinions qu'on a émises à cet égard; la mienne en diffère totalement, et si elle est vraie, ainsi que je pense l'avoir prouvé, les autres sont fausses; cet examen est donc superflu.

Il m'eût été facile, en suivant le passage de Platon dans toute son intégrité, de traiter ce sujet d'une manière plus étendue et plus complète; mais ces recherches minutieuses n'eussent pas éclairé davantage la partie essentielle et fondamentale de cette belle question de géographie historique: Je crois en avoir déterminé les rapports généraux par un ensemble de moyens que personne n'avoit employés avant moi, et c'est tout ce que je me suis proposé. J'oublierai, sans peine, les fatigues de mes voyages, si l'on peut dire que je suis enfin arrivé au port de l'Atlantide et qu'il m'étoit réservé la gloire d'en être le Christophe Colomb. 


\section{CONS IDERATION S}

NOUVELLES ET GÉNÉRALES

\section{SUR LES INSECTES}

VIVANT EN SOCIÉTÉ (I).

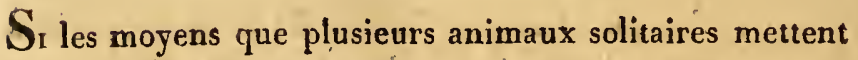
en usage pour leur conservation et celle de leurs races, nous inspirent déjà un sentiment de surprise et souvent d'admiration par leur simplicité, leur variété et surtout par leur appropriation au but qui en est l'objet, combien doivent nous intéresser davantage les animaux qui vivent réunis en corps de société, soumis à une sorte de police et de gouvernement qu'on a qualifié du nom de république. Lorsqu'après avoir étudié les habitudes des premiers nous observons les moeurs des autres, il semble que nous nous soyons transportés du séjour d'une peuplade grossière de sauvages au sein d'un grand empire. Au lieu de quelques buttes éparses, nous trouvons des cités populeuses bâties sur le plan le plus régulièr, divisées avec un ordre merveilleux pour la plus grande commodité des habitans, dans lesquelles la moindre portion de terrain est employée de la manière la plus utile, où tout enfin est prévu avec cette sagesse digr : du Grand Maître qui a dirigé les travaux; c'est, pour me

(1) Discours lu à la séance publique de l'Académie des Sciences, le if mars 1817 . 
servir de la comparaison de Bonnet, la cabane de Robinson mise en parallèle avec les monumens de Rome.

Quel est celui de nous qui, après avoir lu l'histoire de ces animaux singuliers connus sous le nom de castors, dont la nature a fait des ingénieurs laydrauliques et des architectes, n'a désiré de pouvoir jouir par ses propres yeux du spectacle de leur vie sociale. Ce plaisir est refusé à nos pays où l'homme est seul le maître. Soit que notre tyrannie retienne leur instinct captif ou l'ait dégradé, soit plutôt que réduits dans les lienx qu'ils hạbitent, à un petit nombre dindividus persécutés, ils se voient dans l'impuissance d'exécuter des entreprises qui exigent du repos et de la liberté, les castors de nos climats restent dans l'inaction, et bornent toute leur industrie à éviter les regards et les poursuites de l'hómme.

Mais dans nos contrées mêmes, dépouillées de ces grandes peuplades, la nature pour qui sait la connoître, a ménagé des sujets d'observations analogues, dans des familles que nous avons conservées parce qu'elles nous छ́toient utiles, ou qui par. Jeur multiplicité et le nombre des individus qui les composent, se dérobent à notre pouvoir. Partout s'offient à nos regards des sociétés d'animaux dont les ouvrages quoique moins imposans, à raison de la petitesse des ouvriers, n'en sont pas moins propres à piquerınotre curiosité, et dont notre intérêt même nous commande l'observation. Je veux parler des termès, des fourmis, des guêpes, des bourdons et des abeilles. L'étude de ees insectes exerce depuis long temps la patience et la sagacité des naturalistes; elle a e's pour 'Swammerdam, Réaumur, Degéer, Bonnet et lesiHubert, un vaste champ de découvertes, et ce champ est bien loin d'être épuisé. L'observation et la crịitqué 
ont fait connoître les véritables merveilles de l'bistoire de ces insectes, et si elle a perdu les faux ornemens qu'elle avoit reçus de ses romanciers, elle s'est vue enrichie de faits incounus aux anciens, et dont quelques-uns même sont si extraordinaires qu'on seroit tenté de les prendre pour des fictions. Aucune classe du règne animal ne manifeste avec tant d'éclat et de tant de manières la sagesse infinie de l'Auteur de la nature; et comment, en effet, sans des précautions multipliées, auroit-il pu garantir l'existence d'êtres aussi foibles et environnés d'un si grand nombre d'ennemis?

Après avoir long-temps médité sur l'histoire des insectes qui vivent en société, il m'a paru que les faits dont elle se compose dérivoient de quelques lois générales et dont les naturalistes, dans la persuasion peut-être qu'elles se rattachoient à une question trop obscure, celle des causes finales, ont négligé la recherche. Mais sans courir les risques de s'égarer dans un labyrinthe d'hypothèses, ne peut-on pas essayer d'analyser ces faits, de les réduire à quelques vérités principales et d'en déccurrir l'enchaînement et la subordination? J'ai pensé que ce travail ne irouveroit point de contradicteurs, et que dans la supposition même que la philosophie de la science n'en retirât aucun avantage, l'historien de la nature y puiseroit des secours pour donner à sa narration plus de méthode et de clarté.

Quoique les travaux des insectes paroissent annoncer une industrie dont les animaux des classes supérieures nous offrent peu d'exemples, je suis cependant bien éloigné de les comparer à eux, sous le rapport des facultés intellectuelles, et de leur prêter ces combinaisons didées et ces jugemens qu'une organisation beaucoup plus par- 
faite et plus compliquée permet à d'autres animaux. Les insectes ont en naissant toutes les connoissances qu'exige leur destination et qui se composent d'un certain nombre d'idées relatives à leurs besoins et à l'emploi de leurs organes. Le cercle de leurs actions est tracé; ils ne penvent le franchir. Cente disposition naturelle qui les rend propres à exécuter d'une manière déterminée et constante ce qui est nécessaire an maintien de leur vie et à la propagation de leur race, est ce que j'appelle instinct. Ils ne pouvoiert avoir de meilleur guide. Trop passagers sur la scène de la nature, ils n'avoient ni le temps de délibérer ni celưi de profiter des leçons de l'expérience; tout faux calcul eût compromis le sort de leur postérité.

L'abeille vient à peine de naître', qu'elle se met déjà au travail; qu'elle montre les talens de l'artiste le plus expérimenté; qu'elle exécute dans les proportions les plus exactes et les plus régulières, sans avoir aucun modèle, sans la moindre hésitation, un ourrage qui suppose les calculs d'une haute géométrie, et dont un habile mécanicien ne pourroit venir à bout qu'après de longs tâtonnemens et avec des instrumens dont l'abeille est dépourvue. En les accordant mème à cet insecte, il lui scroit impossible de construire d'avance ses alvéoles dans des proportions converables au nombre de la populan tion future qu'elle ne prévoit pas, et de donner aux alvéoles qui doivent renfermer le convain des mâles et des femelles, la grandeur requise pour ces individus qui n'existent pas encore. Mais la nature a été le précepteur de l'abeille ét l'a formée géomètre. Ne voyons-nous pas áussi, parmi les hommes mêmes, des individus qui naissent arec des dispositions heureuses pour les arts 
mécaniques, et y excellent, sans. avoir eu de maître. Les idées les plus justes et les plus ingénieuses qui sont d'ordinaire le fruit de la méditation et de l'enseignement, se présentent, avec vivacité et sans efforts, à leur esprit; l'instinct le plus parfait des insectes n'est que ce don accidentel de la nature, converti en habitude nécessaire, persévérante, et se perpétuant de race en race.

Aux causes habituelles et stimulantes de ce penchant, telles que l'impression qu'excitent sur les sens les objets extérieurs, la faim, le désir de se reproduire, il faut ajouter un sentiment prédominant, celui de la conservation de la postérité. Pourquoi l'abeille neutre, à laquelle la maternité est interdite, étant mise dès l'instant de sa naissance dans une ruche neuve, travaille-t-elle aussitôt à la construction de ses rayons? Si ce n'étoit que pour sa propre nourriture, seroit-il nécessaire qu'elle se livrât à des travaux aussi longs et aussi pénibles? et alors pourquoi se laisseroit-elle mourir de faim lorsqu'elle est privée de cette reine qui doit propager sa race? Qui peut lui inspirer ces soins si détaillés, si attentifs? Pourquoi les femelles des insectes, lors même qu'elles ont vécu isolées et solitaires, déposent-elles leurs oufs avant de terminer leur vie? N'est-ce pas l'effet d'une impulsion intéricure ou d'un sentiment maternel auquel ces animaux sont forcés d'obéir?

Les premiers naturalistes, pénétrés d'une sorte de respect pour l'industrieuse société des abeilles, et envisageant aussi son utilité, lui donnèrent la première place dans leurs classifications méthodiques des insectes; mais, à cet égard, l'organisation intérieure est le caractère essentiel sur lequel nous devons nous régler: le don plus ou moins étendu de l'instinct seroit un indice peu. 
fidèle. Parmi les abeilles elles-mêmes, on trouve plusieurs espèces qui bien qu'extrèmement rapprochées par leur organisation de l'abeille commune; mais vivant so* litaires, lui sont extrêmement inférieures sous le rapport de l'instinct. La perfection de cette qualité est donc en quelque sorte accessoire à l'organisation de l'animal. Ainsi le castor, quoique plus industrieux que les quadrumanes et les mammifères carnassiers, est bien au.dessous, d'eux quant à l'organisation.

On voit souvent des insectes rassemblés en grande quantité dans le même lieu; mais si leur conservation individuelle est le seul motif de leur réunion, s'ils ne sont là que parce qu'ils y ont trouvé avec plus d'abondarce des alimens qui leur sont communs, un abri où ils sont moins exposés, soil aux intempéries des saisons, soit-aux attaques de leurs ennemis, ces réunions accidentelles ne peuvent être considérées comme des sociétés proprement dites. Certaines chenilles, qu'on a désignées sous le nom de communes, de processionnaires, etc. , déjà rapprochées les unes des autres lorsqu'elles étoient sous la forme d'œufs, filent de concert une toile qui, semblable à un hamac ou à une tente, leur sert d'habitation jusqu'à leur dernière métamorphose. Mais ces travaux n'ont trait qu'à leur propre existence ; elles ne s'occupent que d'elles-mêmes; point de famille à élever; point de peines ni de soucis au sujet des générations auxquelles elles donneront un jour naissance. "Il règne par" mi elles, dit Bonuet, la plus parfaite égalité; nulle "distinction de sexe et presque nulle distinction de " grandeur ; toutes se ressemblent; toutes ont la même " part aux travaux; toules ne composent proprement ? qu'une seule famille issue de la même mère. "Cette 
société temporaire est dissoute dès le moment que ces chenilles passent à l'état de chrysalides ; tout rentre alors dans l'inertie, et dans un isolement absolu.

Il n'en est pas ainsi des sociétés dont je vais vous entretenir; elles se distinguent éminemment des précédentes non-seulement à raison des différences très-remarquables que l'on observe dans les formes extérieures des individus qui les composent, mais encore par les institutions qui les gouvernent. Leur fin principale est l'éducátion des petits, et ceux même qui sous la forme de nymphes n'auront plus besoin de nourriture, trouveront dans des sentinelles actives et vigilantes, de prévoyans défenseurs contre les dangers qui menacent leur exisvence.

A l'époque où cette éducation est achevée, ces assoeiations nous offrent trois sortes d"individus parfaits ou jouissant de toutes leurs facultés, des mầles, des femelles, et des individus du même sexe, mais nuls pour la reproduction. On a désigné ces derniers sous les noms de neutres, de mulets, d'ouvriers et mème sous celni de soldats, comme dans les termès: La dénomination d'ouvrier employée le plus souvent est équivoque, puisque les guêpes et les bourdons femelles sont aussi laborieux que ces individus; celle de neutre me semble donc préférable.

Ces sociétés sont temporaires ou continues. Temporaires, elles doivent leur origine à une femelle qui sans aides, ou abandonnée à ses propres moyens, jette les fondémens de la colonie et trouve bientôt deś auxiliaires dans les neutres qu'elle commence par mettre au monde. Telles sont les sociétés des guêpes et des bourdons; mais celles qui sont continues nous offrent en tout temps des 
neutres. Tantôt, ainsi que parmi les fourmis et les abeilles, ils sont chargés exclusivement de tous les travaux et des soins de la famille; tantôt ils n'ont d'autres fonctions que de veiller à la défense de la communauté, et peut-être à la conservation des germes de la race, comme dans les termès.

Les contrées situées entre les tropiques, sont celles, en général, où la nature a le plus d'énergie et où ces réunions d'insectes sont plus multipliées et plus redoutables. L'action qu'exercent sur les substances animales et végétales les insectes qui vivent isolés ou solitaires, est ordinairement lente et ses effets ne sont sensibles qu'au bout d'un temps, quelquefois assez long; mais que ces animaux soient rassemblés dans le même lieu, en grandes corporations, qu'ils forment, comme les termès et les fourmis, des légions innombrables, bientôt, malgré leur petitesse, ils dévoreront et feront disparoître tous les corps organisés qu'ils trouveront privés de la vie. Le but de l'Auteur de la nature, en établissant de telles sociétés d'insectes, paroît donc avoir été d'augmenter l'énergie de cette force active et réactive qui maintient l'équilibre parmi les êtres et qui par des créations et des destructions continuelles rajeunit sans cesse sur notre globe la matière organisée. Si les régions voisines de l'équateur développent des productions plus nombreuses, le nombre des agens destructeurs, par une juste compensation, y est aussi bien plus considérable. Des millions de fourmis, de termès, travaillent sans cesse à purger la surface du sol des cadavres par lesquels l'air seroit bientôt corrompu ; et tels sont leur voracité et leur nombre que souvent en une journée ces armées d'insectes-vautours ont dévoré les chairs d'un quadrupède colossal. 
A leur tour ils deviennent la pâture d'une infinité d'oiseaux, de'reptiles, de quadrupèdes, sans parler des ennemis que leur oppose la classe d'animaux dont its font eux-mêmes partie.

Les femelles des insectes sociaux sont d'une fécondité prodigieuse. Réaumur évalue à douze mille le nombre des oufs que l'abeille domestique pond au printemps dans l'espace de vingt jours. Mais cette fécondité est bien inférieure à celle des termès du nême sexe. Leur vcntre à l'époque de la ponte est tellement distendu, à raison du nombre des oeufs dont il est rempli, que cette partie est alors, suivant Sméathman, quinze cents ou deux mille fois plus grosse que le reste de leur corps; son volume est vingt ou trente mille fois plus grand que celui du ventre du neutre; enfin, le nombre des oufs que la femelle peut pondre dans l'espace d'un jour, s'élève audelà de quatre-vingt mille. Or, cette excessive fécondité des insectes vivant en société et la nature des alimens dont leurs petits se nourrissent, me paroissent établir la nécessité de l'existence d'une troisième sorte d'individus ou des neutres, qui n'aient de la maternité que les affections sans faculté reproductive.

Tous ces insectes, à l'exception des termès, sont du nombre de ceux qui subissent des métamorphoses complètes, et qui dans leur premier âze ont la forme d'un vermisseau, très-mou, sans pieds, dont la bouche est si petite qu'elle est à peine visible, incapable en un mot de pouvoir par lui-même suffire à ses besoins. D'ailleurs vainement chercheroit-il à se procurer sa nourriture, puisqu'elle consiste en matières animales ou végétaies ayant subi une préparation digestive. Il est certain que, dans cet état de choses, des secours presque journaliers. 
leur sont indispensables. Comment les mères, si elles eussent été seules, auroient-elles eu le temps et la force de rassembler des magasins de vivres pour une famille aussi nombreuse? Ces provisions, celles đu moins qui auroient été recueillies les premières, auroient-elles pu se conserver jusqu'au temps où les petits viendroient à éclore? Si nous prolongeons au-delà de ce terme l'existence de ces mères et si nous leur confions l'éducation de leurś enfans, les difficultés croîtront encore; trouveront-elles chaque jour, surtout dans les temps pluvieux, la quantité d'alimens nécessaires ? supposant même qu'elles s'en procurent en abondance, auront-elles le temps de les distribuer à chaque petit? Comment pourmientelles aussi veiller sur eux et les préserver du nombre infini de périls qui les menacent? Il n'en est pas ainsi des insectes solitaires. Leur famille peu nombreuse, isolée, cachée, n'occupant qu'un très-petit espace, peut aisément se soustraire aux recherches de ses ennemis. Mais les insectes réunis en grand nombre dans le même nid, ont plus de chances défavorables à courir. N'avonsnous pas été souvent touchés de la sollicitude des fourmis neutres pour leur famille, lorsque leur habitation éprouve quelque désordre? Observez-les surtout au moment où la pluie pénêtrant la terre en trop grande abondance peut atteindre les galeries où les petits sont déposés; voyez avec quelle vivacité elles les saisissent et les transportent à de plus grandes profondeurs; l'orage a-t-il cessé et le soleil a-t-il séché leur asile, considérez avec quel soin attentif elles les rapportent au faîte de l'édifice, pour les exposer à l'influence d'une bienfaisante chaleur.

La conservation de ces animaus et la prospérité de 
leur famille ne pouvoient lonc ètre assurées que par l'êtablissement d'un ordre particulier et nombreux d'iudividus qui suppléassent aux fonctions des mères et qui n'en eussent même que les sentimens et les affections. La nature, en formant icj des neutres, s'est vue contrainte de s'écarter de ses lois ordinaires, pour que son ouvrage subsistât, et sa prévoyance a modifié ses ressources selon lés circonstances où les êtres devoient être placés. Par exemple, elle a suivi un autre plan à l'égard des termès dontles jeunes individus n'ont point cette foible enfance, et ne diffèrent de ceux qui sont adultes que par une taille plus petite, l'ạbsence ou la briéveté des ailes et quelques autres particularités peu importantes. Alors les neutres, justement appelés soldats, ont une grande tête, de fortes mâchoires (mandibules) agissant en manière de pinces, et ne composent guère que la centièmé partic de la population; ils en sont simplement les vedettes et les. défenseurs. Les autres individus, jusqu'au moment où leurs organes sont entièrement développés, demeurent exclusivement chargés de tous les travaux intérieurs, Encore délicats et sans défense, ils ont seulement besoin d'être garantis de l'impression trop forte de la chaleur, et des attaques des ennemis qui pourroient s'introduire dans leur habitation. En travaillant à couvert et dans des galeries souterraines, ils évitent le prenier de ces dangers; les neutres armés les préviennent contre le second, et la société se maintient par cette réciprocité de sert vices: Une activité commune à tous les membres de la. population distingue ainsi la société des termès, qui sont un des plus terribles agens de destruction des contrées. équatoriales. Comme ils ne travaillent que dans leur enfince, et qu'à cet âge ils sant privés d'ailcs ou n'en aut 


\section{VIVANT EN SOCIËTÉ.}

que les rudimens, ils ressemblent alors beaucoup par leurs habitudes aux fourmis. Cependant leur pullulation étant bien plus grande, ils construisent des habitations plus vastes, plus solides, et comme leurs besoins sont plus grands; leur force destructive est aussi plus puissante. On peut d'autant moins s'opposer à leurs invasions qu'ils agissent dans les ténèbres ct qu'ils échappent ainsi aux regards de l'homme et à sa vengeance.

L'historien de cesinsectes, Smeathman, n'a pas connu leurs nymphes; lè individus qu'il semble considérer comme tels sont des neutres, ce sont ceux qui défendent l'babitation; et les individus qu'il appelle ouvriers ne sout que les termès dans leur premier àge, on en forme de larves. Ces insectes ne subissent point leur dernière mélamorphose à la même époque. Les individus mains avancés recueillent les femclles qui ont étéfécondées, et prennent soin des oufs. Les termès forment donc, sous tous les rapports, une société très-distincte de celles des fourmis, des guêpes, des bourdons et des abeilles, insectes qui subissent tois une métamorphose parfaite. Ces dernières sociétés, d'après la considération des organes du mouvement, sont établies sur trois modèles.

Dans l'une, telle que celle des fourmis, les neutres sont dépourvus d'ailes, et n'ont pour la confection de leurs travaux d'autres instrumens que les parties de la bouche.

Tous les individus des autres sociétés ont des ailes; mais les guêpes ne sont pas mieux partagées que les fourmis à l'égard des moyens directement piopres à l'exécution de leurs ouvrages. Il n'en est pas ainsi des bourdons, et des abeilles: les jambes et les tarses de leurs pattes postérieures ont une forme particulière qui leur permet. 
de récolter le pollen des fleurs. Ces insectes ont en outre des organes destinés uniquement à élaborer et à secréter le miel et la cire. Ainsi que parmi les guêpes, la femelle fait partie intégrante de la socićté, tout le temps qu'elle subsiste; les femelles des guêpes et celles des bourdons commencent même l'établissement, ct sont fondatrices e: 1 même temps que reines.

Ces difiérences organiques ont une grande influence sur l'instinct de ees insectcs; car la perfection de lcurs ouvrages est proportionnée à leurs mojens.

Privées d'ailes, les fourmis neutres vivent à terre ou s'établissent dans les fentes des murs et des arbrcs, à peu d'élévation au-dessus du sol. Cclles qui eonstruisent des habitations emploient un temps considérable à charrier les matériaux qui doivent les composer; aussì se contentent-elles de les rapprocher et $d^{\prime} y$ pratiquer diverses routcs, conduisant au séjour de la famille qu'cllesélèvent. Tous leurs ouvrages sont d'une construction rustique et très-simple. Les guêpes, les bourdons et les abeilles, auxquels les organes du vol donnent la facilité de s'éloigner rapidement et à de grandes distances de leur domicile, et d'y revenir avee autant de célérité, après avoir récolté les matières de lcur choix, sont plus favorisés dans leurs travaux. Leurs produits sont connus et l'objet de notre admiration. Mais l'observation suivante me paroìt avoir échappé anx historiens de ces animaux. De toutes les substances que les guêpes et les abeilles peuvent mettre en œuvre, cclles qu'elles préfèrent sont les plus propres à la construction d'un édifice, qui, suspendu dans les airs, soit, sous un volume donné, le mienx distribué pour le nombre de la population, le moins pesant et le plus solide, relativement à la durée de la société. 


\section{VIVANT EN SOCIETE.}

Ainsi les nids des guêpes sont de carton ou de papier très-épais, dans la construction duquel domine la matière ligncuse. L'abeille sait recucillir et préparer une substance résineuse, susceptible par sa ductilité d'être réduite en lames très-minces, d'ètre façonnée au gré de l'animal, en un mot, la cire, matière pareillement résistante et légère, dont l'abeille est seule le fabricant. L'entrée des pièces qui composent l'édifice est tantôt vcrticale, tantôt horizontale, mais toujours inférieure, ce qui met leurs habitans à l'abri de la pluie, lors même que des murs solides ne les protègent pas.

L'abcille est de tous ces insectes celui dont l'instinct est le plus parfait, le scul qui n'ait point d'habitudes carnassières, et son existence est un bienfait de la nature ; les autres sont nés pour la destruction; elle semble au contraire être faite pour assurer la fécondation des végétaux, en transportant des uns aux autres le pollen de leurs flcurs que les vents sculs n'auroicnt pas aussi certainement propagé. Elle a, seule, une brosse et une corbeille pour recucillir ce pollen, une espèce de siphon pour puiser le miel, et des organes spéciaux et intérieurs où il est reçu, où il s'élabore et se convertit en cire. Les rayons qu'elle construit sont disposés sur un plan vertical et garnis, des deux côtés, d'alréoles, tandis que ceux des guêpes sont toujours horizontaux et n'offrent qu'un seul rang de cellules. La société des guêpes est temporaire; celle des abeilles; dont le régime est d'ailleurs monarchique, est durable et ne cesse que par des circonstances accidentelles. Notre abeille domestique peut s'acclimater partout; elle brave les froids de la Sibérie comme les chaleurs de la zone torride, où les Européens l'ont transportée. 
Quoique l'instinct de ces insectes soit assujéti à une. marche uniforme, il est cependant des cas extraordinaires où, pour le salut de lcur race, ils varient leurs procédés. L'Auteur de la nature a prévu ces circonstances particulières, et a permis à l'instinct de se modifier avec elles autant qu'il le falloit pour la permanence des sociétés qu'il avoit formées. C'est ainsi que pour réparer la perte des abeilles femelles, l'unique espoir de leurs sociétés, il apprend aux abeilles neutres à transformer la larve d'un individu de leur caste, qui n'est pas âgé de plus de trois jours, en une larve de reine ou de femelle; c'est ainsi encore que cette espèce d'abeille solitaire (osmie $d u$ pavot) qui revêt l'intérieur de l'habitation de seś petits d'une tenture formée de morceaux arrondis de pétales de coquelicot, emploie au même usage, lorsqu'elle en est dépourvue, les pétales de fleurs de navette : il est évident que dans cette occasion le sentiment intérieur qui la guide se plie à la nécessité.

Les sociétés dont nous avons parlé jusqu'ici sont toutes composées d'individus de la même espèce; mais deux sortes de fourmis, que l'on désigne par les dénominations de roussâtre et de sanguine, nous présentent à cet égard, un fait bien étrange, dont l'observation est due à M. Hubert fils. Les sociétés de ces insectes sont mixtes; on y trouve, outre les trois sortes d'individus ordinaires, des neutres provenus d'une ou même de deux autres espèces de fourmis, enlevés de leurs foyers sous la forme de larves ou de nymphes. Les neutres de l'espèce roussâtre composent un peuple de guerriers, et de là viennent les noms d'amazones, de légionnairés, sous lesquels M. Hubert les a désignés. Vers le moment où la chaleur du jour commence à décliner, sile temps est 
favorable, et régulièrement à la même heure, du moins pendant plusieurs jours consécutifs, ces fourmis quittent leurs nids, s'avancent sur une colonne serrée et plus ou moins nombreuse suivant la population, se dirigent jusqu'à la fourmilière qu'elles veulent envahir, y pénètrent malgré la résistance des propriétaires, saisissent avec leurs mâchoires les larves ou les nymphes des fourmis neutres de l'habitation et les transportent en suivant le même ordre dans leur propre domicile. D'autres fourmis neutres de l'espèce conquise, nées parmi ces guerriers, et autrefois arrachées aussi dans l'état de larves à leur terre natale, prennent soin des larves nouvellement apportées, ainsi que de la postérité même de leurs ravisseurs. Ces fourmis étrangères que $M$. Hubert compare à des nègres esclaves et à des ilotes, appartiennent aux espèces que j'ai désignées dans mon histoire de ces insectes, sous les noms de noir-cendrée et de mineuse.

Les fourmis amazones s'emparent indistinctement de l'une ou de l'autre. J'avois été témoin en 1802 d'une de leurs excursions militaires. L'armée traversoit une de nos grandes routes, dont elle couvroit la largeur sur un front d'environ deux pieds. J'attribuois ces mouvemens à une émigration forcée. Cependant d'après la forme de cette espèce , j’avois déjà soupçonné, avant que M. Hubert en publiàt l'histoire, qu'elle avoit des habitudes particulières. J'ai depuis trouvé cette fourmi dans les bois des environs de Paris, et tous les faits avances par ce naturaliste ont été vérifiés. J'essaierai ici d'en donner une explication et de prouver qu'ils sont en harmonie avec d'autres lois déjà connues. Les fourmis neutres enlevées par les guerriers de la fourmi amazone ne sont qu'expatriées, et leur condition n'éprouve aucun chan- 
gement. Toujours libres, toujours destinées aux niêrnez services, elles retrouvent dans une autre famille des objets qui les auroient attachées à la leur, et même des petits de leur propre espécef; elles les élèvent ainsi que ceux de leurs conquérans. Ne voyons-nóus pas plusieurs de nos oiseaux domestiques nous donner l'exemple de pareilles adoptions, et se méprendre dans l'objet de leur teudresse maternelle? Les fourmis neutres ne sont done ni des esclaves ni des ilotes. Afin de diminuer certaines races et d'en propager d'autres, la nature, toujours fidèle à son système d'actions et de réactions, a voulu que plusieurs animaux vécussent aux dépens de quelques autres. Les insectes dont les espèces sont si multipliées, nous en fournissent une infinité de preuves. C'est ainsi que dans la famille des abeilles, celles qui forment le genre des nomades, vont déposer leurs oufs dans les nids que d'autres abeilles ont préparés à leurs petits, et les provisions que celles-ci avoient rassemblées deviennent la proie de la postérité des nomades. Ces sortes de larcins eussent été insuffisans à des insectes qui, comme les fourmis amazones, sont réunis en grandes corporations; les vivres auroient bientôt été épuisés. Il n'y avoit de remède sûr que de s'approprier ceux qui les récoltent, et de profiter non-seulement de leurs labeurs d'un jour, mais de ceux de toute leur vie. Au surplus, il étoit physiquement impossible aux fourmis amazones, d'après la forme de leurs mâchoires et des parties accessoires de leur bouche, de préparer des habitations à leur famille, de lui procurer des alimens et de la nourrir. Leurs grandes màrhoires, en forme de crochets, annoncent qu'elles ne sont destinées qu'au combat. Leurs sociétés sont peu répandues, au lieu que celles des fourmis noir-cendrées et mineuses 


\section{VIVANT EN SOCIETTE.}

sont trés-abondantes dans notre climat. Par leurs habitudes parasites, ces fourmis amazones mettent un obstacle à la trop grande propagation des dernières, et l'équilibre est rétabli.

Les fourmis sanguines, assez rares en France, trèsrapprochées, quant aux organes et l'amour du travail, des fourmis communes, sembleroient devoir se passer d'anxiliaires. Aussi ne se livrent-elles à ces déprédations que dans une extrême nécessité. M. Hubert remarque qu'elles n'attaquent que cinq ou six fois dans un été les fourmis noir-cendrées, et qu'elles en emportent beaucoup moins d'individus que les fourmis anazones. Celles-ci sont presque toujours en course dans l'été, lorsque le temps est beau. Les précédentes étant trèscarnassières, presque toujours occupées de chasse, sortant souvent ensemble afin de se prêter des secours dans le danger, seroient obligées de laisser leur famille sans défense; elles chargent de ce soin les fourmis noircendrées, qu'elles ont associées à leurs travaux. Mais les fourmis sanguines se procurent encore, et par des procédés également violens, d'autres auxiliaires, les neutres des fourmis mineuses; leur société offre ainsi trois sortes de neutres, dont deux étrangères.

On a soupçonné, d'après des observations relatives aux abeilles rapportées plus haut, que les individus neutres tiroient leur origine de femelles imparfaites, sous le rapport des facultés génératrices, qui auroient formé, par voie de génération, avec le laps du temps, une race particulière et constante. Mais je crois avoir prouvé que le régime politique des insectes sociaux émanoit d'un plan général, complet, parfaitement ordonné, et que l'existence des neutres étoit liée au maintien de cet état de 
choses. Nous avons vu encore qu'une impérieuse nécessité maîtrisoit toutes leurs actions. Tout changement dans leur manière de vivre est donc impossible, d'autant plus que ces animaux, à l'exception des abeilles, ne sont point du nombre de ceux que l'homme a fait entrer dans son domaine, et dont il peut modifier, jusque dans de certaines limites, les propriétés. $\mathrm{Si}$ on ne veut point ad. mettre un plan primitif, que l'on me dise d'où proviennent ces différences extérieures et si frappantes que l'on remarque entre les neutres et les femelles capables de se reproduire; celles, par exemple, que nous offrent comparativement les pieds et les mâchoires des abeilles, le thorax des fourmis, la tête des termès, etc. Que l'on m'explique l'origine de plusieurs habitudes de ces irusectes et de quelques lois si extraordinaires de leur gouvernement ; par exemple cette proscription générale à laquelle sont voués les mâles des abeilles, devenus inutiles; et les larves et les nymphes des guêpes qui n'ont pu se développer avant l'arrivée des mauvais temps. Comment encore les fourmis amazones ont-elles pu acquérir ce tact si fin, par lequel elles discernent, toujours sans erreur, les larves et les nymphes des fourmis neutres, qu'elles enlèvent pour la prospérité de leur propre race? Quoique les abeilles puissent transformer, dans quelques circonstances, des larves d'abeilles neutres, en celles de reines ou de femelles, il n'en est pas moins vrai que les germes de ces larves neutres existent, et sons un nombre déterminé, dans le ventre de leur mère; qu'elle sait distinguer les alvéoles qui leur sont propres. Entin les insectes qui, dans leur premier âge, n'ont pas été aussi bien nourris qu'ils auroient pu l'être dans un état ordinaire, ne diffèrent absolument que par la petitesse de 


\section{VIVANT EN SOCIETÉ.}

leur taille, de ceux qui, à la même époque de leur vie, n'ont pas éprouvé de semblables privations.

De tout ce que je viens d'exposer, je me plais à déduire cette conséquence : les lois qui régissent les sociétés des insectes, celles même qui nous paroissent les plus anomales, forment un système combiné avec la sagesse la plus profonde, établi primordialement, et ma pensée s'élève avec un respect religieux verś cette raison éternelle qui, en donnant l'existence à tant d'êtres divers, a voulu en perpétuer les générations, par des moyens sûrs et invariables dans leur exécution, cachés à notre foible intelligence, mais toujours admirables. 


\section{REMARQUES}

Sur divers Mémoires contenus dans ce volume.

Sur be Premier Age du Monde.

13

- AGE 4, ligne 4. - Les Parses (Boun-Dehesch, ou Cosmogonie) désignent le paradis terrestre sous le nom de Bérézeseng, et le placent daus le Khoraçan. C'est là aussi qu'est le hom blanc, 'qui donne la santé et qui fait concevoir; il croît dans la source de l'eau Ardouisour. Quiconque boira du jus de cet arbre, ne mourra pas. On l'appelle l'arbre Gokeren (Voyez ci-après), comme il est dit : Le hom (génie présidant aux arbres) qui éloigne la mort, à la résurrection, rendra la vie aux morts; il est le chef des arbres. C'est par le Var (source d'eau) Khâresen, qu'Aschesging (nom d'un Ized, génie du second ordre), donne Ies biens, la puissance, le profit pur, et le bonheur de l'âme. Plusieurs autres passages nous prouvent que les Parses regardent le Khoraçan comme le berceau du genre humain.

Page 6, ligne 19. - "Il est dit dans la loi, au sujet de l'arbre appelé Grogard, queqcet arbre appelé Gogard, et qui dans les premiers temps a crû dans le Zaré Ferakh Kand (la mer Caspienne), dans cette bouche de la montagne (que cet arbre, le hom), à la résurrection fera vivre les bienheureux)." Zend-Avesta. Anquet. du Perr., tome 2, page 384.

7’age 7, ligne 27. - Afrasiab (Zend-Avesta, Anquetil, tome 2 , page 393 ) s'empara des mille sources (ou bras) du Zaré Kéaiànseh (lac Zéreth), de la rivière Hemend ou eu Source-d'Or, et du Rou Véteéné, qui est l'eau Naodak 


\section{SUR LE PREMIER AGE DU.MONDE. 243}

( le Nedha, ou le Mehra, continuation du Véh-Roud, appelé Kasé dans le Sind). Ce Zaré est le lieu du germe des Kéans ou de Kaiomorts, de Meschia, de Siahmak, Férvak et Hoschingh (les premiers patriarches).

Page 7, ligne 28. - Le Boun-Dehesch, ou la Cosmogonie des Parses, donne ainsi la généalogie de Cain. Zohâk, appelé Bévarasp, que Féridoun (Noé) a vaincu et qu'il a lié sur le mont Demavand, ou il doit rester jusqu'au jour de la résurrection générale, étoit fils de Khrotàsp, fils de TcheenéGêve, fils de Veveré, fils deFschengbhé, fils de Tazé, fils de Frevak, fils de Siahmák. Dans le Mlodjmel el Tavarik, Zohâk est fils de Nedasp, appelé aussi Arvandasp, visir de Tchmourets, fils de Devagan, fils d'Iadsaréh, fils de 'Tadj ou Taz. De ce dernier et de Tazé, sa femme, descendent les Arabes qui se sont établis dans les déserts des Tazians. Tadj est probablement l'Irad de la Genèse, fils d'Hénoch, nommé Frẻvak dans la première de ces généalogies. Siahmak représente alors Caïn. Il étoit fils de Meschia et Meschiané, Ladan(1) et Ève. Kaïomorts, ou Graiomard en Pehlvi, le premier tomme, est un être allégorique désignant, sous la forme d'un lommetaureau, le germe de l'espèce liumaine et de tous les corps vivans de la terre. De Meschia et de Meschiane vinrent sept couples. L'un fut Siahmak, nom de l'homme, et Veschak, sa femme. Ils produisirent Frévak et sa femme Frevekein. De ce dernier couple en naquirent quinze autres; ils formèrent ensuite autant d'espèces particulières de peuples, qui se sont multipliés sur la terre. Neuf de ces espèces passèrent sur le dos du taureau (au nord), par le Zaré Ferakh Kand (la mer Caspiennc), dans six keschwars (portions) de la terre, et s'y fixèrent. Les six autres espèces restèrent dans le khounnerets (la partie du milieu). Le premier de ces couples fut Taz et Tazé, d'ou sont sortis les Arabes. Le second fut Hosching et Goujeh, souche des Iranians ou des Persans.

(i) $A d x$, en pehlvi, signifie vie. 
Un autre fut Mazendran, dont les descendans ont habité, l'urr les villages de Sourâ (l'Assyrie); un autre, les villages d'Avir ( au bas de l'Albordj); un troisieme, les villages de Tour ; un quatrieme, le Tchinestan; enfin celui-ci les villages de Dâi, et celui-là les villages de Satad.

Dans les villages de Salem est Aroum (sans chef) ou les Amazones; dans les villages de Sind, est l'homme à une oreille, à un œil, à un pied, et celui qui a des ailes comme le dew; dans le désert est l'homme à queue, qui a du poil sur le corps.

Le keschvar khounerets (ou la partie du milien) est ainsi divisé : Le Hébâvenhâe, où le violent Pétîâréh, qui ne cherche qu'à nuire (Typhon) a été, au commencement des teinps, attaché au céleste, au fort pont; le Kanguedez (le Kouhes$\tan$ ), la terre Sủokâvestâ (le pays où l'on prononce la parole, le Sedjestân), le désert des Tazians (Arabes) le désert Peschiânzé ( celui du Zabulistan), l'Iranvedj ( pays trèsfroid, voisin de la source de l'Indus), le Verdjemgued, qui répond au milieu de la Perse (Miané Pares), sous le mont Damégan et le Kaschmire.

Dans l'Iran-Vedj ( 1 ) est l'arbre qui éloigne le mal (l'excellent hou ), paroles qui paroissent faire allusion à l'arbre de vie du Paradis terrestre. Il est dit que de la mère de Zohâk sont venues dix hontes (Zolhâk), qui est la honte même, pleine de crainte, qui déchire, livré au péché de l'envie, inspiré par Ahriman. On ne peut guère appliquer ces paroles qu'à la race de Caïn. Les Tazians ou les Arabes qui en descendoient, devoient habiter le désert du Moultan, jusqu'à l'embouchure du Sindé ou de l'Indus. Les peuples de cette contrée ont été appelés, à raison de leur couleur noire, Ethiopiens; mais, comme Arrien l'avoit déjà observé, ils n'ont point les traits distinctifs des Negres; c'est une branche de la race caucasique.

(I) Il paroît que cette contrée portoit d'abord le nom d'Asie, car Asiav veut dire, en pehlvi, jardin, vigne; $A$ sia signific via. 


\section{LE PREMIER AGE DU MONDE.}

Suivant la cosmogonie des Parses, Djemchid (confondu probablement avec Hénoch, fils de Cain), déjà marié a Djemé, prit pour autre femme une Dew (mauvais gènie), et donna sa propre sœur a un Dew, frère de la précédente. De là naquirent les hommes des montagnes ou effrayans (les satyres, les faunes, les cyclopes (1), etc.), qui ont une queue, et les autres espèces de pécheurs. La dénomination d'An-Nan, commune aux peuples de la Cochinchine, du Tong.Quin et de quelques autres contrées adjacentes, dérive peut-être du mot pehlvien $A n b a ̂ m$, qui signifie queue, corps, ou de celui d'Andam, indiquant la même chose dans la langue persane pure. Le nom de Daonce, ou des peuples du royaume d'Ava, vient aussi peut-être de Dounia, qui, dans la première de ces langues, veut dire monde. La même cosmogonie nous présente les Éthiopiens ou les Tazians comme le produit de l'union de Djemschid avec une femme infernale, et d'un lomme infernal avec une fille belle conme un Pari. De ces couples vint, suivant la même cosmogonie, l'infernal, l'impie, le noir de pean, l'Arabe du désert. Féridoun recouvra sur les 'Tazians les villes de l'Iran, et les obligea d'habiter les bords du Zaré. Nous avons vu plus haut que ce peuple descendoit de Taz et de Tazé. II semble donc qu'on a voulu ici distinguer plus particulièrement les Indiens noirs.

Les Dews, les Paris, ou mauvais génies, étoient de deux sexes, et pouvoient ainsi avoir commerce les uns avec les autres, en quoi ils différoient des Férouërs ou bons génies, qui étoient tous femelles. Les premiers paroissoient aussi sous a forme d'homme. S'il étoit vrai que les Tibetains fussent e fruit de l'alliance d'hommes de la race caucasique avec des femmes Montgoles, l'on expliqueroit aisément les rapports que présente la langue sacrée de ce peuple ou l'ouchen,

(I) Aioman signifie, en pellvi, oil. 
avec quelques anciennes langues de la Perse. Nous avons dit, page 62, qu'ils devoient probablement 'leur civilisation aux Chinois, et telle est aussi la raison de l'affinité qu'a leur lan. gue ordinaire avec celle des derniers. Toutes les traditions orientales nous montrent les descendans de Seth continuellement en guerre avec les Cainites, et paroissent établir que ceux-ci habitoient les contrées désertes situées sur la rive occidentale de l'Indus, depuis Câboul inclusivenent jusqu'aux bouches de ce fleuve. C'est de temps immémorial le séjour d'Ethiopiens ou d'Indiens noirs, et ce peuple auroit formé, plutôt que les Scythes et les Montgoux, avec lesquels la lignée de Seth ne paroît pas avoir eu de démêlés, celle de Caïn, ou du moins son premier rejeton. L'alliance de ces -leux races auroit-elle produit celle que l'Ecriture désigne sous le nom de géans, et qui semble exister dans le Kafristan? C'est une conjecture qui dérive naturellement, de la précédente, et qui me paroît la plus probable. L'éloignement oì étoient les Montgoux des descendans de Seth, interdit la possibilité de l'alliance des uns avec les autres. Les Guanches, quoique de la race caucasienne, ont néanmoins le nez gros et ap ati, avec un teint très-basané. Tel a dû être, en effet, le résultat de l'union des Indiens noirs, de ceux surtout qui, à cette époquc, habitoient les montagnes du Zabulistan, avec la race précédente. Il est probable au surplus que ces dénominations d'hommes de montagnes, d'hommes à queue, de satyres, affectécs d'abord aux habitans de ces montagnes, s'est ensuite étendue aux Sères, aux Sines, et aux autres peuples des extrémités orientales de l'Asie.

Prge 8 , ligne 16. - Les Afghâns sont bien possesseurs du pays qu'occupoient les Indo-Scythes; mais ils doivent en être. distingués; ceux-ci étoient une branche des $Y_{v e-C h i}$, qui étoient probablement d'origine Montgolique. ( Voyez De Guignes, Hist. des Huns.) 
Page II, ligne 5. - Le nom de Zarispa (Ptolém.), ville de la Bactriane, paroît dériver du Zend et signifier terre à bled et à millet, ou simplement terre à millet.

Il est probable que le mot serere, ensemencer, a aussi une éty mologie orientale et faisant allusion aux Sères, le bled ètant originaire de leur pays.

On a représenté sur une des faces de quelques médailles antiques une tête de gorgone, placée centralement au point de réunion de trois pieds humains, disposés en manière d'étoile, avec trois épis de bled dans les intervalles. Auroit-on voulu iudiquer que cette plante étoit originaire du Caucase?

Page 12, ligne ı0. - (1) Les îles Canaries étoient habitées, lorsque les Espagnols en firent la découverte, par des hommes sauvages qu'ils nommèrent Gouanches, et qui formoient, dans la grande île Canarie, une population de neuf mille âmes; celle de Ténériffe fut estimée à quinze mille; leur race n'est pas entièrement éteinte, et on en trouve encore des restes soit dans ces îles, soit sur la côte de Mogador.

Il est inutile de reproduire ce que différens voyageurs en ont dit; je ne puis cependant me dispenser de donner une esquisse du caractère et des mœurs de ce peuple extraordinaire,

Les Gouanches appartiennent, d'après les observations de M. Cuvier, à la race caucasique. Ils sont de hante taille, robustes, quoique maigres, avec le teint basané et le nez gros et aplati. On prétend que les plus anciens surpassoient ceux d'aujourd'hui par la force et la grandeur. Ils sont vifs, actifs, courageux , rusés, et d'une humeur guerrière. Plusieurs auteurs assurent que leur appétit est si dévorant qu'ils mangent quelquefois, dans un seul repas, vingt lapins et un che-

(1) Cette note est extraite de l'Histoire Universelle, par une société de gens de lettres, traduite de l'anglais. Voyez aussi le Voyage aux Âles Fortunées, de M. Bory de Saint-Vincent. 
vreau. Leur agilité et leur légèreté sont telles qu'ils sautent de rocher en rocher, avec une facilité súrprenante, et que vingt-huit hommes de cette nation, renfermés dans un château d'une prodigieuse hauteur, en franchirent les murailles et s'échappèrent. Ils empioient, pour sauter ainsi que pour briser les coins des rochers, des piques de bois, de neuf a dix pieds de long. Ils se tiennent souvent sur un espace qui n'a pas trois pouces de largeur, et s'appuyant avec leurs orteils, ils paroissent comme suspendus au-dessus des plus affreux précipices. Ils lancent des pierres avec tant de justesse, qu'ils atteignent toujours leur but à une grande distance, et avec tant de force qu'on les a vus briser un bouclier en un petit nombre de coups. Ces pierres et des lances de bois, dont les unes armées de cornes et les autres aiguisées en pointe, au moyen du feu, sont leurs seules armes; l'usage du fer leur étoit inconnu. Dés gâteaux faits d'orge, de lait et de miel, renfermés dans des petits sacs de peau, suspendus à la ceinture, et dans lesquels on les fait cuire au moyen de la fumée, composent leur nourriture habituelle. Quelquesuns s'abstiennent absolument de vin et ne mangent point de chair. Il parlent peu, extrêmement vite, et font entendre un sifflement aigu, dont le son se propage jusqu'à la distance de cinq milles. Mais pour mieux connoître les Guanches, il faut se reporter au temps où les Espagnols en firent la découverte. Une polygamie, n'ayant d'autres bornes que la difficulté de l'entretien, étoit en usage parmi eux; mais la virginité des mariées appartenoit de plein droit au chef de la peuplade dont les époux relevoient. Des chèrres nourrissoient leurs enfans, et tous les biens étoient en commun. Ils cultivoient la terre avec des cornes de bœuf, et se servoient de pierres tranchantes pour se raser la barbe et couper leurs cheveux. Divisés en petites comınunautés, chacune d'elles aroit un chef ou un petit roi. Lorsqu'il venoit à mourir, on laroit son corps avec beaucoup de soin; on le plaçoit debous dans une cayerne, avec un sceptre a la main et deux cruches 
à ses côtés, l'une remplie de lait et l'autre de vin. On embaumoit les corps et on les enfermoit dans des peaux consues, oi ils se conservoient parfaitement. Le soleil, la lune et les autres astres étoient les objets principaux du culte religieux de ce peuple, culte cependant tellement varié, qu'on en a distingué jusqu'à dix. L'idée d'une autre vie ne leur étoit pas étrangère. Au renouvellement de lcur chef, des jeunes gens de l'un et l'autre sexe, après avoir assisté à un grand festin qu'ils donnoient, et après des cérémonies religieuses, se donnoient la mort, en se précipitant $d u$ sommet d'un rocher escarpé. Les familles des victimes de ce dévouement étoient dès lors sous la protection spéciale du chef, et l'objet particulier de sa tendresse. Dans la paix, ils avoient en horreur l'effusion du sang humain; mais si la guerre s'allumoit entre eux, tous les sentimens d'humanité étoient étouffés, et le pays n'étoit plus qu'une scène d'horreur et de carnage. Du jus de certaines herbes, mêlé avec du suif, étoit appliqué sur leur peau, afin de la garantir des ardeurs du soleil et de la rigueur du froid. C'étoit aussi un ornement, mais très-bizarre à raison de la diversité des conleurs que l'on employoit. Les Espagnois ont cherché peu à peu à détruire ces contumes, ainsi que les idées superstitieuses de ce peuple.

Page 14, ligne 1o. - Les hommes (Zend-Avesta, tome 2, p. 383 ), qui se trouvant sur le dos du taureau zareseok, passerent du Khounnerets (partie du milieu) dans les au tres Keschvars (autres parties) allumèrent pendant la nuit, au milieu du Zaré , un feu que le vent fit briller. L'atoun-gâh, dans lequel étoit le feu, ayant par le moyen du dos du taureau, été établi dans trois endroits du Zaré, le vent, avec le feu, répandit la lumière. Ces trois feux, comme trois lumières, furent d'une grande utilité dans les lieux oì l'on mit le feu, porté sur le dos du taureau, jusqu'à ce que la lumière (le jour) parût, tandis que les hommes alloient et revenoient dans te. faré. 
Page 1/4, ligne 27. - Je n'ai pas eu le lemps d'approfondir l'histoire des divers Bacchus, recueillie par Diodore, et mon opinion sur celui que l'on fait naître de Jupiter el de Cérès ou de Proserpine, n'est qu'un simple soupçon. La confusion est d'autant plus grande que le nom d'Ammon a été commun à deux ou trois personnes qui figurent dans cette histoire. Le demi-dieu égyptien, ainsi désigné, et auquel on peut rapporter le patriarche Lamech, père de Noé de l'Ecriture, ou du moins Jabel, de la race de Cain, est l'Athvian, grand-père de Féridoun, de la cosmogonie des Parses; car il est dit qu'il avoit des bnufs noirs, et que ces animaux, mais sous des couleurs plus ou moins différentes, avoient formé la richesse de ses ancêtres. Bacchus l'indien, ou Noé, et le même que Féridoun, a été pareillement nommé Osiris. L'histoire de son ministre Hermès, le plus sage et le plus fidèle de ses amis, et d'Hercule, général de ses troupes, a élé tirée des traditions orientales. Les succes de Féridoun y sont principalement attribués à Gao et à Sam Souvar, autrement Sam Nériman. Celui-ci dompte un animal furieux, de la nature et de la couleur du feu, nommé Soham, et dont il fait son coursier. C'est probablement une allégorie relative à la constellation du grand chien et à l'institution de la période sothiaque. Sam Nériman fait la guerre à Cous, surnommé Fil dendam, dent d'éléphant, et le force à recevoir la loi. II fut père de Zalzer, qui donna le jour au célèbre héros persan, appelé Rostam ou Rustem, qui pourroit bien être le Pemphon-Althotes, surnommé l'Hercule, des rois de Thébes d'Erastothène : car on ne débrouillera jamais les premières dynasties des rois d'Égypte, si l'on ne consulte pas les traditions orientales, sur lesquelles elles sont, en grande partie, fondées.

J'ai cru reconnoître Noé dans l' Uranus des théogonies phéniciennes et atlantiques, et Cham, un de ses fils, m'a paru être le même que Zeus ou le dernier demi-dieu égyptien. Si l'on compare cette dernière théogonie ayec les traditions 
correspondantes des Parses, le Minotcher ou Minougeher de celles-ci (Mesraim, de la Genèse; Ménès, des Egyptiens), petit-fils de Féridoun, et auquel il succéda après avoir tué Salm et tous ses oncles, meurtrier de son aieul, représenteroit le Bacchus des Atlantes. Celui-ci étoit fils d'Amalthée et d'Ammon, roi d'une partie de l'Afrique (partie occidentale et méridionale de la Perse), et qui avoit épousé Rhéa, fille d'Uranus. Jalouse de la réputation de Bacchus, Rhéa quitta Ammon pour se remarier avec Saturne, l'un des Titans. Mais l'Uranus de la théogonie des Atlantes est plutôt Adam que Noé, puisqu'il rassembla, le premier, les hommes, jusqu'alors épars dans les campagnes, qu'il leur enseigna l'usage des fruits, et plusieurs autres inventions utiles, et que son empire s'étendoit presque sur toute la terre, particulièrement surtout au nord et au couchant.

Bacchus, quoique l'on ait mis sur son compte des faits uniquement propres à son petit-fils, seroit toujours Noé, fils de Lamech ou d'Ammon; il auroit établi roi d'Egypte, Jupiter olympien, fils de Saturne, ou Mesraïm, fils de Cham, et après sa mort, celui-ci auroit hérité de son empire, se composant de la Mauritanie, de la Numidie et peut-être d'une portion d'extrémité méridionale de l'Europe. Les Égyptiens, d'après les traditions des Atlantes et celles des Perses, auroient fait à la fois de ce fils de Saturue un demi-dieu, leur Zeus, et leur premier roi mortel ou Ménès.

Page 14, ligne 32. - Le nom d'Amasirgh, que porte une des tribus de la race des Arabes Berbers, paroît dériver dus not Amargan, qui signifie en pehlvi immortel. Il seroit possible que cette nation, ajnsi que les autres de la même race, fussent originaires de l'Hyrcanie ou de quelque autre province voisine. On sait que les Perses désignoient sous le nom d'immortels, un corps d'élite de leur cavalerie.

Page 15, ligne 14.- Je n'ai point parlé des Gomérites, désignés autrement sous les nouns de Titans, Saces, Curètes, 
Celtes, etc. Mais je ne doute point que leur théogonie ne vienne aussi de la même source. Man ou Maneus, leur premier prince, est Adam. Acmon et son frère Dceas représentent l'Hercule et l'Apollon des Egyptiens, ou du moins Mars et Anubis. (Voyez plus bas l'article sur l'Atlantide.) Nous trouverons Noé dans Uranus, Cham dans Saturne, et Mesraïm dans Jupiter. Un passage du Boun-Dehesch (ZendAvesta, tome 2, p. 418) paroît faire allusion à ce qu'on raconte de la défiance de Saturne, de sa cruauté envers ses enfans et du soin que prit Rhéa pour sauver Jupiter. Teuthat est le fils de celui-ci, et peut-être le Thoth égyptien. L'empire de Jupiter devoit être très-étendu, et il est possible qu'il on ait divisé une partie entre deux de ses autres enfans, Atlas et Pluton.

Pagre 16, ligne 27.- Ptolémée place des Saracènes (les Sarrazins de divers auteurs modernes) dans l'Arabie Pétrée.

Page 18, ligne 30. - Dans la cosmogonie des Perses, 'Taschter, qu'Anquetil soupçonne être l'étoile Sirius, mais qui est plutôt celle d'Antarés, réunie à la constellation du Sagittaire, descendit, sous la forme d'un cheval blanc à longue queue, dans le 'Zaré, pour détruire les reptiles, qui étoient en grand nombre sur la terre. Il fut d'abord vaincu par le dew Apevesch; mais il en triompha bientôt, avec le secours d'Ormusd.

Page 20, ligne 17. - "Il est dit dans la loi, a u sujet des Zarés, que le Zaré Férakh Kand ( la mer Caspienne), du côté du midi, lui qui estl'œuvre de l'Albords, arrosoit lui seul cette terre. "Zend-Avesta, Anquet. du Perr., tome 2, page 368.

Page 40, lignes 18 et 19. - Cinq étoiles, dans la cosmogonie des Parses, sont comme les sentinelles et les gardiennes des autres; taschter défend l'est; satéris, l'ouest; venand, le midi; haftorang, le nord; meschgêh, plus grande, est au milieu du ciel. Les Parses comptoient 6/48o petites étoiles. Ce nonbre est remarquable, en ce qu'il représente lo cycle lu- 
naire primitif, de 18 ans, de 360 jours cliaque ; 6480 jours composent en effet 240 lunaisons périndiques de 27 jours chacune. De là aussi la période de 60 lunaisons, avec le cinquieme de laquelle on pouvoit former une autre sorte d'année et un cycle de 20 ans.

On voit par les annales chinoises que l'empereur Hoang$\mathrm{Ti}$ ayant découvert que l'année lunaire ne correspondoit point à l'année solaire, intercala sept lunes dans l'espace de 19 années solaires, en faisant les mois alternativement de 29 et de 30 jours; l'on augmentoit d'un mois chaque troisième année. Tel est encore du moinsl'usage de quelques peuples de l'Asie orientale.

Page 40 , ligne 19. - Sirius se levoit aussi à la même époque, peu de temps après le coucher du soleil. La figure allégorique qui désigne cètte étoile sur les zodiaques égyptiens est remarquable. C'est une vache assise dans une barque, avec une étoile au-dessus de sa tête. Sur le zodiaque du portique du temple, au nord d'Esné, on voit, en outre, dans la barque, une femme ( $I$ sis) portant sur sa tête une couronne, et au-dessus de la vache est un groupe de trois petits corps en forme d'œufs, avec une flèche et une étoile. Le signe de cette constellation est placé à côté de celui du dragon. Auroit-on voulu faire allusion, par cet emblême, au moyen que prit Noé pour sauver du déluge les races d'animaux?

Page 43, ligne 32. - Voyez ci-après un passage qui sembleroit indiquer que ce fut plutôt Sirius. Nous avons vu que l'observation de la constellation de la Lyre est antérieure.

Page 44, ligne 20. - Le Simorg (Zend-Avesta) ou SinMour, l'aigle, se balance avec ses ailes aux deux extrémités ou aux deux portes du monde. De tous les oiseaux qui font la guerre aux dews, le Veragh (d'où vient le nom de Wegha, donné à la première étoile de la lyre ) est celui qui leur fait le plus de mal. 
L'oiseau de l'espèce des kehrkâs (vautours), nommé kargues, a été destiné à manger les corps morts.

Celui qu'on appelle kareschfat sait parler; il a porté la. loi dans le Vardjemguerd et la fait pratiquer; il prononce l'Avesta dans la langue des oiseaux.

On trouvera dans le Boun-Dehesch l'exposition des propriétés qu'on attribuoit aux animaux et aux végétaux. Cette cosmogonie des Parses est la base de plusieurs traditions primitives relatives aux religions, à l'astronomie, à l'histoire et à la géographie. Elle servira surtout a débrouiller les antiquités égyptiennes.

Page 45 , ligne 9. - Pline dit, d'après Manilius, que le phénix est l'emblême de la grande révolution sidérale. Les manuscrits de cet historien offrent à l'égard de la durée de la vie de cet oiseau plusieurs variantes, comme 511,560 , 660 , etc. Isidore de Séville a suivi une de ces premières versions, puisque le phénix vit, selon lui , 500 ans et au-delà, opinion plus rapprochée de celle d'Hérodote, d'après lequel celte durée est de cinq siècles. En admettant celle-ci, il est aisé de voir que la période astronomique dont cet animal est le sujet allégorique, dérive de celle des 7000 ans, ou plutôt de 7000 jours, dont nous avons parlé. Ce nombre de 500 ans, qu'il faut anssi considérer comme des jours, est la quatorzième partie du cycle précédent; ce cycle se compose de 237 révolutions lunaires synodiques, et d'une petite fraction de huit jours et demi. Si nous supposons, en compte rond, 238, 17 lunaisons feront juste la quatorzième partie de ce nombre, ou du cycle de yooo jours.

La période sothiaque est de $147^{\circ}$ années, de 360 jours chaque, et se compose soit de 105 cycles de 14 ans, soit de 30 cycles de 49 ans. La racine de cette dernière quantité est 7. Or 7 ans, de 36 io jours chaque, comprennent 85 lunaisons, 12 jours et demi, et dont le cinquième forme 17 lunaisons, 2 jours et demi; ainsi la période astronomique dont le phénix 
étoit l'emblême, se déduit encore de la période sothiaque; on a pu désigner aussi cette période sous le nom de phénix. 49 ans donnent 597 lunaisons, 28 jours et demi, ou presque 598 . Il est possible qu'on ait porté ce nombre à 600 (I); alors 30 cycles de 49 ans formeroient I8, ooo révolutions lunaires synodiques, ou 2/,000, en ajoutant à cette somme dix cycles de plus.

\section{Page 5o, ligne 22. - De Djedaschter, à la mort de Sa} kant Garhi, commencement d'une ère nouvelle, on compte 3044 , ou plus exactement (Anquetil du Perron) 3037 ans et neuf mois. Cette ère nouvelle fut établie l'an 78 de l'ère clurétienne. L'ère de Djedaschter auroit donc commencé 2960 ans avant J. - C. Nous avons vu ( MIém. sur la Chronologie Egyptienne) qu'il faut rapprocher cette ère d'environ deux siecles.

Page 53, ligne 10.'- Dans mon hypothese, quelques patriarches auroient vécu près de deux siècles, ce qui seroit toujours extraordinaire et conforme au sens de l'Ecriture. J'ai pris pour exemple Malaléel, qui engendra Jared, sixième patriarche, à l'àge de 65 ans. L'intervalle qui s'écoule entre la naissance de l'homme et sa nubilité, fait à peu près le quart de la durée moyenne de sa vie. En supposant que l'époque de la virilité fủt progressivement retardée 'à l'égard dés patriarches, le même laps de temps comprendroit le neuvième ou même une moindre portion de la durée moyenne de leur vie; tous les rapports fondés sur la nature ou le développement de l'organisation du corps humain, seroient dès lors anéantis.

Page 54, ligne 27. - Une demi-révolution lunaire; lisez : Une lunaison, trois quarts, composée en compte rond, de 28 jours, ou bien encore au nombre de ceux d'une semaine, multiplié par lui-même.

(1) C'est peut-être ce qu'on a pris pour larpériode de 600 ans, ou celle de 60 multipliée par io. Voyez aussi page 253 , ligne 3. 
Ce n'est qu'après beaucoup de tâtonnemens et d'observations qu'on a pu déterminer avec exactitude une révolution. lunaire, $\tan t$ périodique que synodique. On a dû, dans les premières estimations se, tromper de plusieurs heures, négliger des fractions, ou du moins y suppléer par des modes d'intercallation qui nous sont inconnus. Ainsi dans la supposition qu'on eût d'abord composé une lunaison synodique de 28 jours, I 7 heures, l'année lunaire auroit été de 344 jours et denii. L'observation ayant depuis fait reconnoître que la lune employoit près de 18 heures de plus pour se retrouver en conjonction avec le soleil, la différence de ces deux estimations doit produire, au bout de 19 ans, la moitié d'une année de 36 o jours. C'est sur ce principe qu'on auroit pu, dans mon opinion, réformer les șares primitifs. Mais il se présente, à l'égard de cette difficulté, une solution bien plus simple et plus naturelle. Suidas nous apprend que le sare se composoit de 222 ( 223 selon Halley, mais à tort, au sentiment de Bailly) mois lunaires. Nous avons vu que, d'après Bérose, la mêrme période étoit de 3600 ans. Si nous prenons ces années pour des jours, ce nombre nous donnera 122 lunaisons ( 125 , en les estimant 28 jours 17 heures) de 29 jours et demi. On aura formé un nouveau sare en ajoutant au précédent 100 lunaisons. Ce changement étoit avantageux; car le nombre 222 est susceptible d'être divisé, sans reste, en 6 parties de 37 lunaisons chacune, et se trouve en harmonie, avec de petites périodes de 3 années solaires. C'est ainsi encore que 18 de ces années répondoient au sare composé de 18 années lunaires et demi.

Nous avons dit, dans une note précédente, que le cycle, dont le phénix étoit l'emblême, comprenoit I7 lunaisons, 2 jours et demi. Or, $\mathbf{3}$ de ces cycles forment juste le même sare de 222 lunaisons. Enfin la période sothiaque embrasse ro5o cycles semblables. Il est probable que l'institution de cette période a un autre fondement que celui indiqué dans ma note de la page 54 ; elle suppose une connois- 
sance plus rigoureuse des lunaisons synodiques. Voyez ce que j'ai dit page 254 , à l'occasion du phénix.

Je suis bien loin de penser que dans ces supputations astronomiques, il ne me soit pas échappé quelques erreurs, et je réclame, à cet égard, l'indulgence des savans versás dans ces connoissances.

Page 56, ligne 4. - Lamech, père de Noé, mourut cinq ans avant le déluge. Dès lors l'ère du „kaliougam n'est antérieure à ce cataclysme que du même nombre d'années. Si elle date de 3156 ans avant l'ère chrétienne, le déluge auroit eu lien en $3 \mathrm{r} 5 \mathrm{r}$, et non en 3 ror. Voyez ce que je dis à cet égard, en trailant de la chronologie égyptienne.

Page 58, ligne 2.-Ajoutez après le mot Genèse : Ce livre ne fut-il considéré que comme un simple monument historique.

Page 58, ligne 9. - Sans vouloir établir une comparaison entre le nègre et le singe, il n'est pas moins remairquable que les babouins, les magots, les macaques et les cynocéphales, singes plus rapprochés des animaux carnassiers, et les plus éloignés physiquement de l'homıe, sont exclusivement propres aux contrées les plus chaudes de l'ancien continent. Les hommes noirs représentés sur les monumens de Thèbes, sont plutôt, peut-être, des Indiens noirs que des nègres proprement dits. Il seroit possible que cette race dérivât de la variété humaine précédente, et que cette altération eût été produite par l'influence du climat et des différences d'habitudes.

Page 59, ligne 24. - Chou-Ki, lisez: Chou-King.

Pags 6o, ligne 6. - Confucius, contemporain du prophète Daniel (le troisième Zoroastre des Perses), d'Anaximandre et presque aussi d'Anacharsis, ne commençoit sa Chronique abrégée des bonnes et mauvaises actions des émpereurs de ja Chine (le livre nommé Tchun-Tsiou), que depuis la quarantième année du règne de Ping-Ouang, le même probable- 
ment que Poan-Keng, l'un des deruiers souverains de la seconde dynastie, et qui mournt 1374 ans avant notre ère (Hist. de la Chine, du P. Mailla, tome 2, page 22 I). Ne peuton pas en conclure que les traditions antérieures lui paroissoient peu dignes de confiance ou incertaines? La civilisation des Tibétains date du mệme siècle, et si ce peuple en est redevable aux Chinois, comment se fait-il que leurs lunaisons ne soient que de 29 jours, ainsi qu'on les estimoit avant la découverte de la période astronomique de 19 ans? Ne pourroilpas soupconner qu'à l'époque de cette civilisation, les Chinois n'étoient guère plus éclairés que les Tibétains, et que les lettrés de ce peuple ont, par jactance, faussement attribuéà leurs premiers empereurs, des observations astronorniques qu'on avoit. reçues avec d'autres connoissances, des Indiens et des Chaldéens, et par le canal, peut-être, de Confucius, le premier maître de ces leltrés? Croiroit-on, par exemple, qu'ou eût déjà remarqué dı temps d'Yao, que la révolution annuelle du soleil est de 365 jours et un quart (1)?

Page 62, ligne r2. - Le basque m'a paru différer du zend et du pelilvi, et se rapprocher des langues du nord de l'Asie; mais cela ne suffit point pour établir son origine, et l'opinion que j'ai émise à cet égard estı trop liasardée. L'étude de l'ancien arménien, de quelques autres langues des pays situés entre la mer Caspienne et la mer Noire, et des recherches sur la langue primitive de l'Asie mineure, uous donneront peut-être un jour le moyen d'éclaircir cette question.

Page 64, ligne 25. - Féridoun est un nom persan, correspondant à celuai de T'hréeteonéhé du zend. Je ne connois point l'étymologie du dernier; mais je remarque qu'il se termine par deux syllabes formant un mot très-analogue a celui de Noé.

(1) On trouve dans la cosmogonie des Parses la même observation; mais je présume qu'ils l'avoient empruntée des Chaldéens ou des Egyptiens, et qu'elle ne dáte que de 13 à 14 siècles avant l'èrs chrétienne. 
LE STSTEME METRIQUE DES ANCRENS. $23 \mathrm{G}$

Page 64, ligne 34. - L'Arc est la constellation du sagittaire. Le zodiaque fut dans l'origine divisé en $2 \$$ signes on khordéhs mâles, correspondans aux 28 jours de la révolution de la lune. On le partagea ensuite en douze constellations, qui étoient camme les mères des autres. Si dans l'énumération que nous en avons faite, celle du sagitlaire se trouve la dernière, c'est probablement parce que le capricorne étoit alors au solstice d'hiver, et formoit un point de départ. J'avois d'abord soupçonné que l'on pouvoit rapporter à la coustellation du sagittaire les versets $13-17$ du chap. 9 de la Genèse. Le soleil étoit dans ce signe lorsque le délugé eut lieu; mais le sens littéral du passage indique plutôt l'arcen-ciel.

\section{Système métrique des Anciens.}

Page 100, ligne 15. - D'après l'estimation du pied primitif des Chinois (page 99), leur li, en le supposant de 300 pas, dut valoir originairement 233 toises 2 pieds, mesure prestque égale à celle de trois stades pythiques ( 238 toises), ou ceux que les Arméniens nomment vétavan.

Page 100, ligne 16. - Lisez 36o, au lieu de 366.

Page 10o, ligne 24. - Je me suis expliqué d'une manière inexacte à l'égard des différences des progressions arithmétiques dont il est question dans cette note. Si au nombre 6 , premier terme de l'une de ces deux progressions, l'on ajoute 2 , ou le tiers de cette quantité, l'on aura le premier terme, 8 , de l'autre progession. Le second terme de chacune d'elles se compose du premier, plus de sa moitié, ou 9 et 12; ce second terme, forme pour les suivans une différence constante : $18,27,36$, etc., pour la première progression ; 24 , 36,48 , etc., pour la seconde.

Page 1oo, ligne 3o. - Les mesures fondées sur ce principe ont dû nécessairement différer un peu entre elles et éprouver. par le laps de temps des altérations. 
Notice sur les peuples désignés anciennement sous le nont. de Sères.

Page I1 3 , ligne 2. - Le nom de Sères, si on le fait dériver de l'hébreu, présentera d'autres significations. J'ai adopté celle qui m’a paru la mieux fondée.

Les anciens, en général, ont désigné sous ce nom, les Mongols et les Tartares. Les matériaux sur lesquels Ptolémée a rédigé sa géographie de la Sérique, avoient été recueillis dans un temps où les Huns du Nord, les ancêtres des Turcs, occupoient une graude portion de la petite Bucharie. Les Hiong-Nou, ou les Huns du nord, qui avoient demeuré longtemps sur les frontières septentrionales de la Chine, et qui connoissoient le ver-à-soie, introduisirent sa culture dans cette contrée et dans celles qui lui sont limitrophes. Après y avoir resté 450 ans, ils en sortirent vers la fin du sixième siècle de l'ère chrétienne, pour regagner la petite Bucharie, et fonderent un nouvel Etat dans cette partie, qu'on nomme le Turquestan. Vingt-deux générations après parut le famèx Genghiskan, arrière-petif-fils de Cabull-Chan, cinquième fils de Tumana-Chan, roi des Turcs. Voilà, du moins, ce que l'on peut déduire de l'histoire des Tartares d'Abulgasi.

Page I16, ligne 4.- Le Ser-Hind est une colonie de Miong-Nou (Huns du Nord), les ancêtres des Turcs, et qui fut établie au commencement du second siecle de l'ère chrétienne, lorsque ce peuple, très-affoibli par les guerres qu'il eut à essuyer, soit des autres peuples Tartares, soit des Chinois, fut obligé de se partager. La contrée où se retirèrent ceux qui furent vers l'occident ou au sud-ouest, reçut d'eux le nom d'Irgana-Kon; c'est ce qu'on nomme le TurkHend, et que plusieurs géographes placent, mais faussement, à ce qu'il me semble, sur les limites méridionales et occidentales de la petite Bucharie. Le passage d'Abulgasi, relatif à cette émigration, paroît indiquer le pays adjacent \& la partic orientale du Kachemire, et composé.des pro- 

binces de Ladak et de Nagari. L'empire des Huns avoit été fondé environ douze siècles avant notre ère; il ne commença à jouer un rôle important que sous Me-Té, qui nous paroît être le même que l'Oguz-Khan de plusieurs auteurs orientaux, mais auquel on attribue des conquêtes faites par les Scythes, dans un temps très-antérieur. Il faut distinguer, parmi celles qui lui sont propres, le royaume du Kitay (Cathce Scythae, Ptol.) ou celui de Kâchegâr, confondu, par erreur, avec la Chine, la ville de Dsurdsut (Drosache? Ptol.), qui doit aussi appartenir à la petite Bucharie, une portion du Tibet, et le Kara-Kitay ou le Cafristân, habité par un peuple aussi noir que les Indiens méridionaux, etc.

\section{Eclaircissemens sur la Chronologie égyptienne.}

Page 124, ligne 25. - Dans le système chronologique de Genébrard, il s'est écoulé 600 ans depuis qu'Abraham alla en Egypte jusqu'à l'Exode.

- Page 128, ligne 17. - J'ai restreint, dans les observations en tête du mémoire, la durẹe que j’avois donnée à l'empire égyptien, et je fais remonter aujourd'hui la première année de Ménès à 2932 ans avant notre ère. Il a été dit, page 127 , que la durée moyenne des règnes des 191 souverains qui avoient gouverné le Kachemire, jusqu'à l'an 1586 , étoit d'un peu moins de 22 ans, on d'environ 21 ans et demi. En partant de cette dernière estimation, les i i 3 générations de Manéthon, avecle nombre d'années qui s'est ensuite écoulé jusqu'à l'ère chrétienne, nous donneroient $277^{5}$ ans, pour le commencement du règne de Ménès. La différence comprise entre cette époque et la précédente ne seroit que de 43 ans et demi.

Page 129, note. - Le passage de Justin, relatif à Vexoris, roi d'Egypte, paroît faire allusion à la guerre que Minotcher ou Ménès eut à soutenir contre Afrasiab, roi du Turquestan, 
*62 REMARQUES SUP LA CHRON. ÉGYPT.

qui l'obligea de se réfugier dans des lieux inaccessibles de l'Hyrcanie ( Voyez d'Herbelot, Bibliot. Orient., article M(cnougeher). Si cette conjecture est fondée, ce passage confirme parfaitement notre opinion au sujet de l'époque du règue de Ménès.

FIN. 


\section{TA B L E \\ DES MEMOIRES}

CONTENUS DANS CE VOLUME.

Du premier age nu Monde, et de l'accord des théogonies plıénicienne, clıaldéenne el égyptienne, avec la Genese...................... Page

Tableau comparatif et accord de la théogonie des Phéniciens, des Chaldéens et des Égyptiens, ainsi que des hiéroglyphes astronomiques relatifs aux demi-dieux égyptiens, avec la Genese....... 26

Eclaircissemens et Additions............. 32

Dissertation sur l'expédition du Consul Suétone Paulin en' Afrique, et sur diverses parties de la Géographie

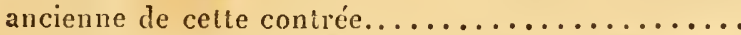

Ire. Partie. De l'expédition du consul Suétone Paulin

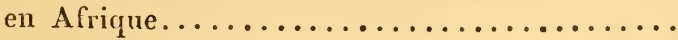

IIe. Partie. Du fleuve Niger de Pline, ou du Nigir

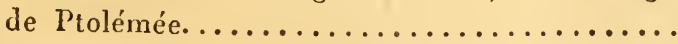

ObServations sur l'origine du Système Métrique des peuples anciens les plus connus, considéré dans son application aux distances itinéraires............. 94

NoтісE sur les peuples désignés anciennement sous le nom de Sères.

Eclaircissemets sur la Chronologie Égyptienne......

Dynastie des Rois d'Egypte, depuis la fondation de cet empire jusqu'au règne d'Alexandre....... $1 / 42$ 
Des Insectes peints ou sculptés sur les Monumens antiques de l'Egypte.................. Page 145

Introduction à la géographie générale des Arachnides el des Insectes, ou des Climats propres à ces animaux.. I66

De l'Atlantide de. Platon. Lu à l'Académie des Sciences, dans sa séance du 5 juillet 18 ig ............ Ig 6

Considérations nouvelles et générales sur les Insectes vivant en société............................ 222

Remarques sur divers Mémoires contenus dans ce volume...........................242 






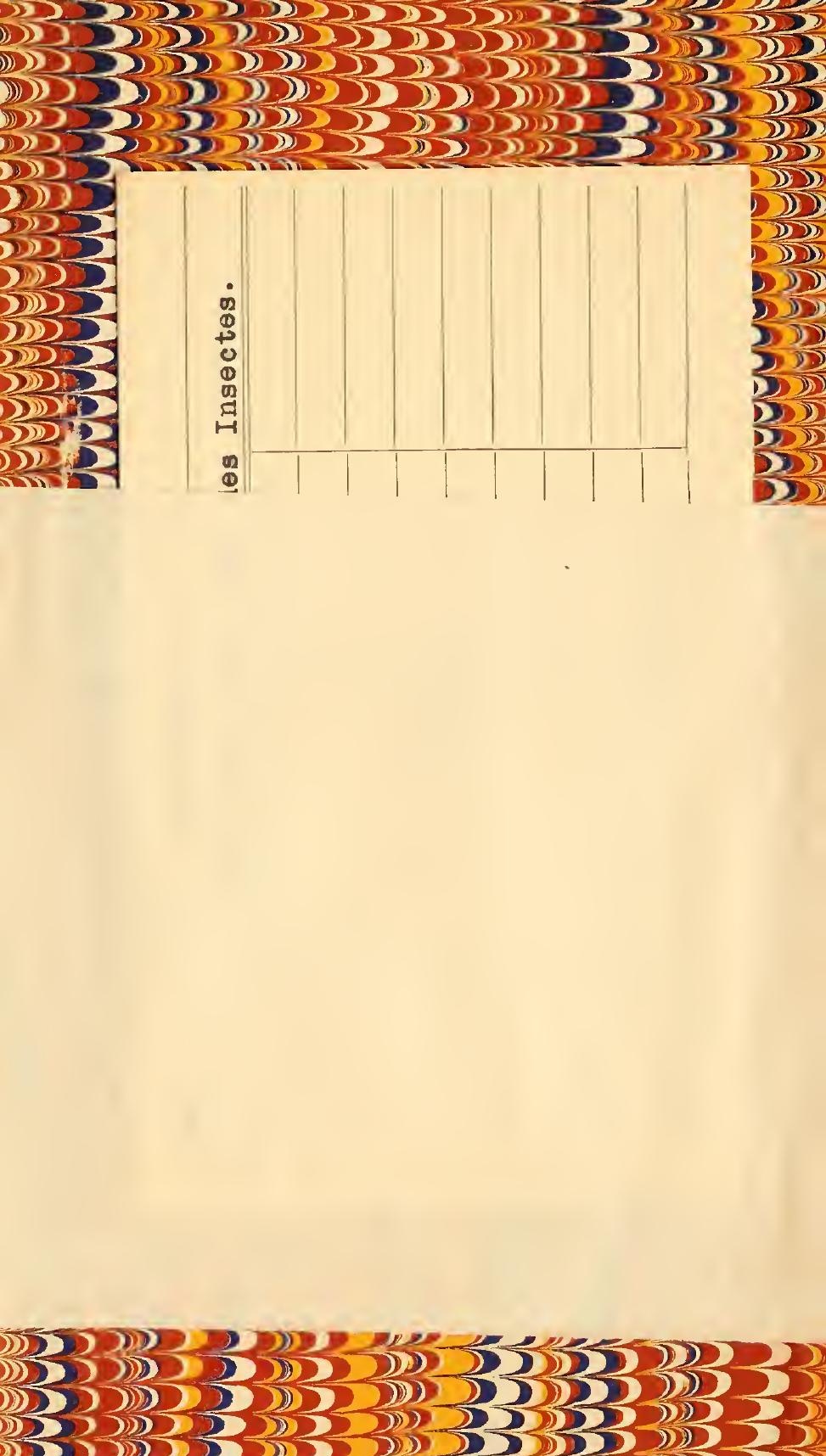
SMITHSONIAN INSTITUTION LIBRARIES 